João Gilberto Zalla Filho

\title{
ANÁLISE DOS ESTOQUES EM PROCESSO DE UM SISTEMA DE PRODUÇÃO DE CABINAS DE CAMINHÕES COM O USO DA SIMULAÇÃO DE EVENTOS DISCRETOS
}

Dissertação apresentada à Escola de Engenharia de São Carlos da Universidade de São Paulo, como parte dos requisitos para obtenção do título de Mestre em Engenharia Mecânica.

Orientador: Prof. Dr. Arthur José Vieira Porto

São Carlos - SP

2006 



\section{Dedicatória}

Aos meus pais João Gilberto e Albina e Ao meu irmão João Ricardo Por tudo que eles significam. 


\section{Agradecimentos}

Ao Professor Titular Arthur José Vieira Porto, pela orientação, ajuda, amizade e apoio profissional desde o início deste trabalho.

Aos meus pais e ao meu irmão pelo incentivo, apoio, disciplina, amizade, educação, exemplo e amor.

À empresa DaimlerChrysler do Brasil pela oportunidade e apoio dados para a realização e sucesso desse trabalho, em especial à Sra. Regina Maria Saporito e ao Sr. Renato Ferreira Junior pelo apoio, confiança e oportunidade.

À Fundação para o Incremento da Pesquisa e do Aperfeiçoamento Industrial (FIPAI) pela bolsa concedida e toda ajuda e suporte dados durante a realização de todo o trabalho, em especial à Rosana, pela ajuda em diversos momentos.

Aos amigos do Laboratório de Simulação e Controle da EESC / USP José Hamilton, Mamoru, Ana Paula, Chin, Denise, Ricardo, Merylin, Daniel Maeda, Silmara, Mariella, Ana Rita, Heleno, Heráclito, Hilano, pela amizade e auxílio na convivência diária. Um agradecimento especial à Beth.

A todos os colegas, professores e funcionários do Departamento de Engenharia Mecânica da EESC/USP, pelas suas colaborações.

Em especial à Escola de Engenharia de São Carlos e à Universidade de São Paulo. 
Sumário

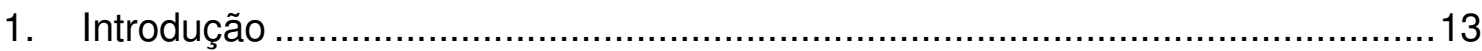

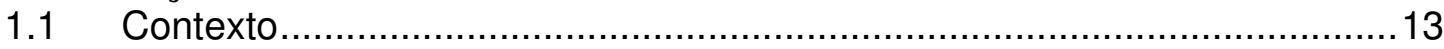

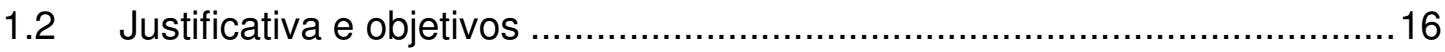

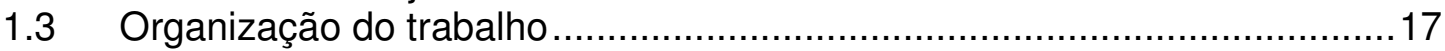

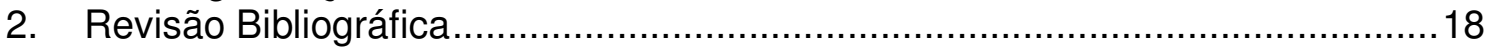

2.1 Controle e Gerenciamento de estoques..................................................

2.1.1 Função e classificação dos estoques ……………………………...19

2.1.2 Razão para controlar os estoques ..................................................20

2.1.3 Controle dos estoques de agregados (FOGARTY et al., 1991) ...........21

2.1.4 Métodos e filosofias para o controle dos estoques ............................22

2.2 O sistema produtivo da Indústria Automobilística e os estoques seletivos .29

2.3 Simulação de Eventos Discretos ..........................................................34

2.3.1 Definições para Simulação encontradas na literatura:.........................35

2.3.2 Conceitos envolvidos na utilização de Simulação................................36

2.3.3 Etapas de um estudo de simulação ......................................................38

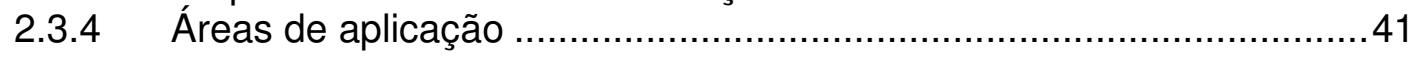

2.3.5 Vantagens e desvantagens da utilização de simulação........................41

2.4 Utilização de Simulação em análises de sistemas de manufatura e na indústria automobilística ........................................................................42

2.4.1 A simulação aplicada à indústria automobilística nacional ..................47

3. O estudo de caso ...............................................................................

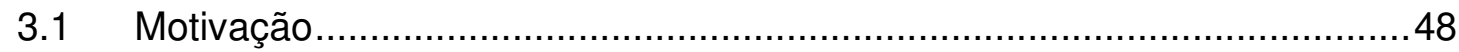

3.2 Objetivo do trabalho .................................................................. 49

3.3 Necessidade da utilização de simulação .................................................49

3.4 Etapas do estudo desenvolvido e cronograma .........................................50

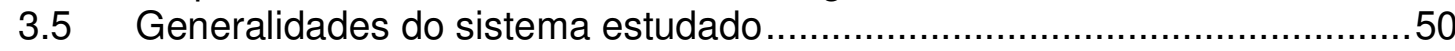

3.6 Descrição do sistema ....................................................................51

3.7 Descrição das etapas produtivas ......................................................53

3.7.1 Produção das cabinas brutas LTC e FSK - Neu Rohbau (A da figura 3.1) 53

3.7.2 Produção das cabinas brutas HPN, L98, HSK e HPN, - Rohbau (B figura 3.1)

3.7.3 Transportador aéreo (T Figura 3.1) ...........................................67

3.7.4 Preparação e Pintura das cabinas (D figura 3.1) ................................69

3.7.5 Estoque de cabinas pintadas - Puffer (S1 figura 3.1) ........................73

3.7.6 Montagem de acabamento das cabinas (E figura 3.1) .......................75

3.7.7 Estoque de cabinas acabadas - Depósito Vertical de Cabinas DEPOVERT (S2 Figura 3.1) ............................................................. 77

3.7.8 Montagem final de caminhões leves e médios e montagem final de

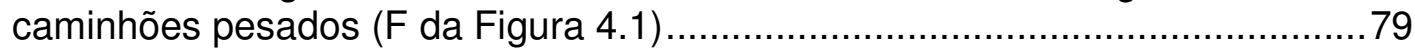

3.8 Programação das cabinas e seqüência dos processos ..............................81

3.9 O problema e os objetivos do estudo..................................................... 85

3.10 O cálculo dos custos de operação dos estoques seletivos ..........................86

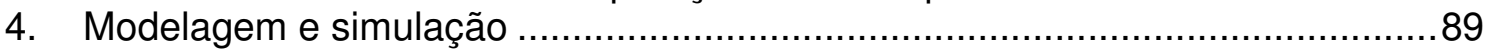

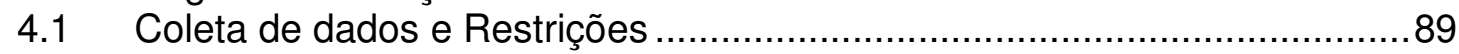

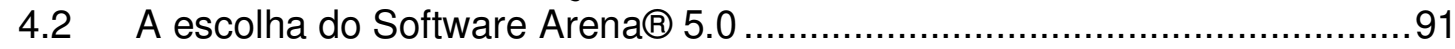

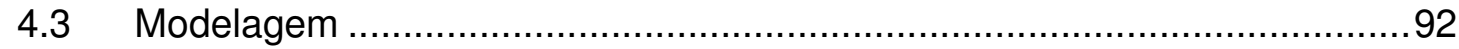


4.3.1 Criação das entidades, Seqüenciamento e programação das ordens de

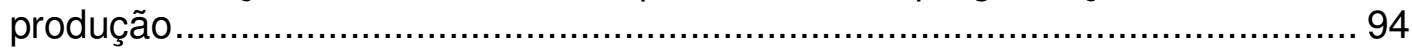

4.3.2 Linhas e processos de produção Rohbau ........................................ 101

4.3.3 Linha e processo de produção nova Rohbau .................................. 106

4.3.4 Saída das Rohbau e o Transportador Aéreo................................... 109

4.3.5 Processos de Pintura ............................................................ 111

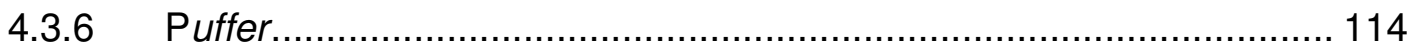

4.3.7 Montagem acabamento das cabinas .......................................... 120

4.3.8 Depósito Vertical de Cabinas Acabadas - DEPOVERT ..................... 122

4.3.9 Montagem Final dos Caminhões ............................................... 124

4.3.10 Lógicas para controle, análise e modificação da seqüência programada ao longo de todo o processo .................................................................... 125

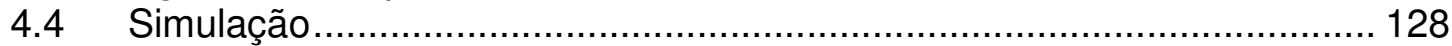

4.5 Verificação e Validação do modelo .................................................... 130

4.6 Resultados e conclusões............................................................... 134

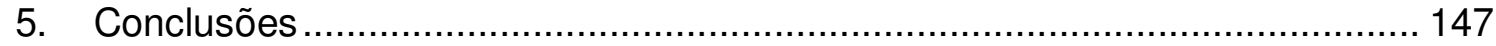

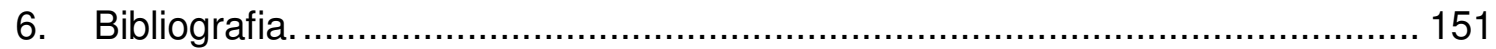

APENDICE I - A comparação com o sistema de produção de caminhões da

DaimlerChrysler da Alemanha, fábrica de Wörth ................................................. 158

APENDICE II - Relatório “Category Overview": ................................................... 162 
Sumário de figuras e tabelas

Figura 2.1: Relações e informações utilizadas em um sistema MRP ......................24

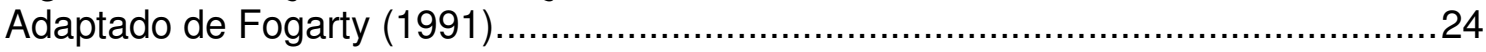

Figura 2.2: Diferenças na abrangência do MRP e do MRP II...............................25

Adaptado de Correa et al. (2001) ............................................................25

Figura 2.3: Organização típica dos processos produtivos em uma indústria

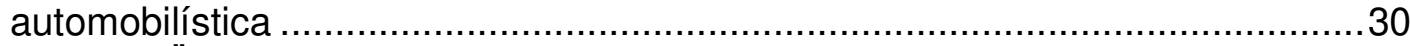

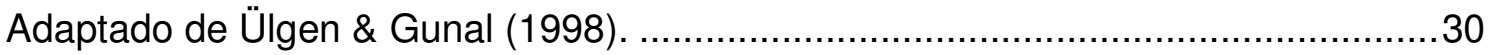

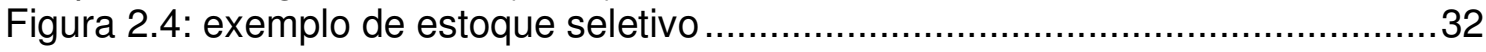

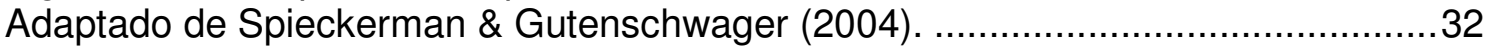

Figura 2.5: Sistema influenciado pelo meio externo ............................................. 36

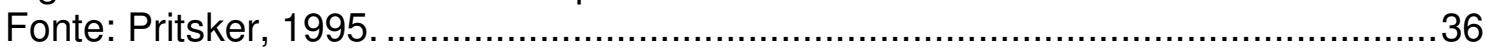

Figura 2.6. Etapas de um estudo de Simulação ................................................ 39

Adaptado de Banks (1998)................................................................... 39

Tabela 2.1 Classificação das aplicações de Simulação na Indústria Automotiva......45

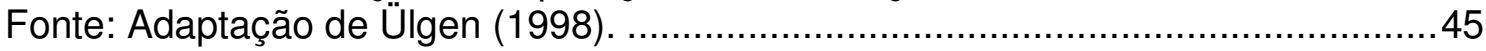

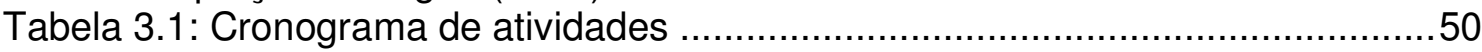

Figura 3.1: Diagrama descritivo do sistema estudado........................................52

Tabela 3.2: Descrição dos modelos e variantes de produtos estudados ..................53

Figura 3.2: Diagrama de blocos da produção das cabinas LTC e FSK ....................54

Figura 3.3: Montagem das paredes frontal e traseira das cabinas FSK ...................56

Figura 3.4: Montagem da cabina bruta LTC ...................................................... 57

Figuras 3.5: Montagem das portas das cabinas LTC e FSK. ...............................57

Figuras 4.6: Estações de funilaria das cabinas LTC e FSK. .................................58

Figura 3.7: Diagrama das etapas da produção da Rohbau..................................59

Figura 3.8: Fluxo de Processo das Cabinas HPN, HSK e LN. ...............................59

Figura 3.9: Fluxo de Processo das Cabinas FPN e L98....................................60

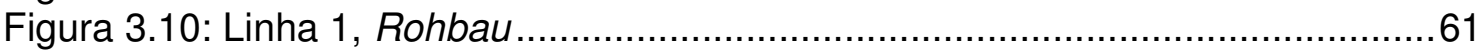

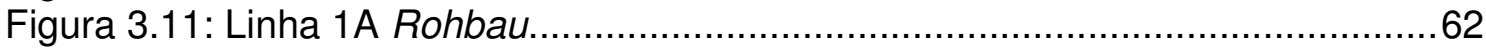

Figura 3.12: Linha 2/3 Rohbau ............................................................ 63

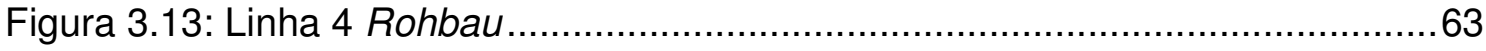

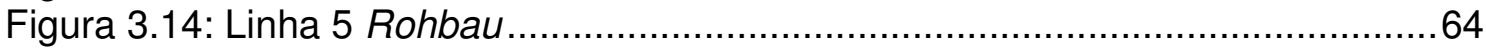

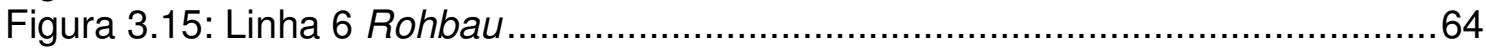

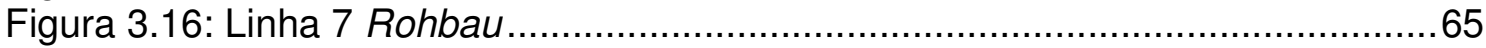

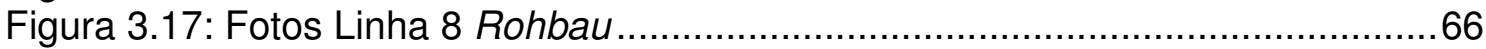

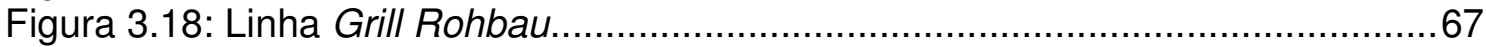

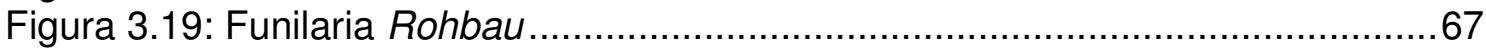

Figura 3.20. Diagrama dos processos do Transportador Aéreo..............................68

Figura 3.21: Fotos do Transportador Aéreo .....................................................69

Figura 3.22: Diagrama dos processos de preparação e pintura ...........................69

Figura 3.23: Fotos ilustrativas dos processos de Pintura: a) aplicação KTL; b) área de transferência; c) Primer; d) cabines de retrabalho; e) retrabalho nas cabinas

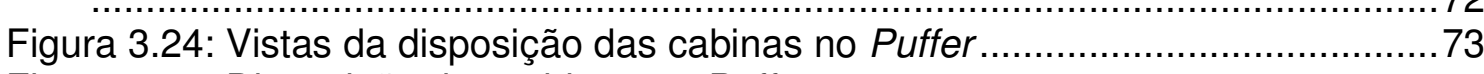

Figura 3.25: Disposição das cabinas no Puffer .................................................. 75

Figura 3.26: Diagrama dos processos do acabamento das cabinas ....................... 76

Figura 3.27: Vistas da montagem acabamento de cabinas.................................77

Figura 3.28: Fotos do interior do DEPOVERT ................................................... 78 
Figura 3.29: Montagem Final dos Caminhões, linha leves e médios: a) foto da chegada das cabinas para montagem; b) mostra o transporte da longarina com os eixos; c) foto da montagem do motor; d) foto da montagem da cabina na longarina.

Figura 3.30: Montagem final de Caminhões, linha extrapesados: a) Montagem do Motor; b) Montagem da cabina.

Figura 3.31: Diagrama das etapas produtivas e suas ligações............................ 81

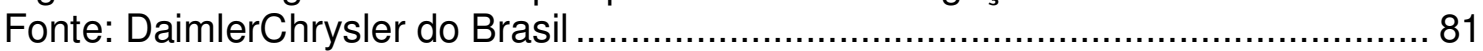

Tabela 3.3: Cálculo dos custos operacionais do Puffer. .................................... 87

Tabela 3.4: Cálculo dos custos operacionais do DEPOVERT ............................. 88

Tabela 4.1: Parte da tabela fornecida pela montadora sobre os veículos produzidos em um ano

Tabela 4.2: Proporções dos tipos de veículos produzidos no ano de 2003

Tabela 4.3: Proporções acumuladas dos tipos de veículos produzidos no ano de

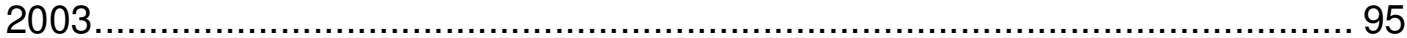

Tabela 4.4: Proporções das Variantes Brutas .................................................... 96

Tabela 4.5: Correlações entre tipos de veículo e variantes brutas com o tipo de entidade e 0 atributo de variante exata....................................................... 98

Figura 4.1: Modelo da programação da seqüência de produção dos veículos ......... 99

Figura 4.2: Dois dos blocos Assign de definição dos atributos das entidades........ 100

Figura 4.3: Modelo para modificar a seqüência devido à restrição de cabinas

pesadas .................................................................................................. 101

Tabela 4.6: Cálculo do takt time de cada etapa do sistema................................. 102

Figura 4.4: Implementação no Arena® da linha 2/3 ........................................... 102

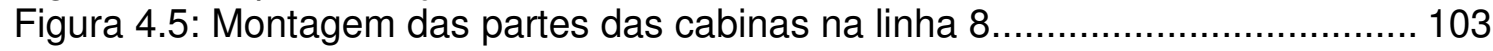

Tabela 4.7: Estatística de falhas de processo - Rohbau ..................................... 104

Figura 4.6: Resource Linha 1 e a sua respectiva estatística de falha ...................... 105

Figura 4.7: Modelo no Arena ${ }^{\circledR}$ da Rohbau .......................................................... 105

Figura 4.8: Exemplo da configuração do processo da área 11, através dos blocos

Process, Resource e Schedule para 1 único turno....................................... 107

Tabela 4.8: Estatística de falhas de processo Nova Rohbau............................... 108

Figura 4.9: Implementação no Arena ${ }^{\circledR}$ do modelo da Nova Rohbau...................... 108

Figura 4.10: Modelo do Transportador Aéreo ................................................. 110

Figura 4.11: Verificação da seqüência na saída da Rohbau............................... 110

Figura 4.12: Demonstração do arranjo dos blocos Seize e Release ....................... 111

Figura 4.13: Modelo dos processos de pintura ..................................................... 112

Figura 4.14: Determinação das cores das cabinas ........................................... 113

Tabela 4.9: Estatísticas de paradas na Pintura de acordo com o posto de trabalho

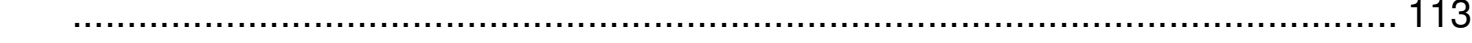

Figura 4.15: Blocos Hold e Signal para modelagem do Puffer ............................. 115

Figura 4.16: Modelo do Puffer com a utilização de blocos Match........................... 116

Figura 4.17: Bloco Delay que determina o número de cabinas no Puffer............... 116

Figura 4.18: Controle das entidades da seqüência final para operação do Puffer.. 117

Figura 4.19: Submodelo Puffer Virtual .............................................................. 119

Figura 4.20: Modelo das linhas de montagem acabamento ................................ 120

Figura 4.21: Configuração dos transportadores: a) Transportador da linha de leves e

médios com 22 postos e velocidade de 1,8 m / min; b) Transportador da linha de

pesados com 8 postos e 1,5 m / min ...................................................... 121

Figura 4.22: Lógica de modelagem das falhas de processos em transportadores. 122

Figura 4.23: modelo do DEPOVERT e do filtro para controle da seqüência........... 123 
Figura 4.24: Modelo da montagem final Prédio de leves e médios .........................125

Figura 4.25: Modelo da montagem final do prédio de pesados.............................125

Figura 4.26: Modelo dos bloqueios e mudanças na seqüência final. ......................127

Figura 4.27: Animação para verificação do modelo .............................................131

Tabela 4.10: Dados de verificação da Rohbau.................................................... 132

Tabela 4.11: Dados de verificação da nova Rohbau............................................132

Tabela 4.12: Dados de verificação da Montagem Acabamento ..............................133

Tabela 4.13: Dados de Verificação da Montagem final de Caminhões ....................133

Tabela 4.14: Dados gerais de validação do modelo.............................................134

Tabela 4.15: Análise do cenário do sistema com bloqueios, Puffer aumentado e sem

DEPOVERT

Tabela 4.16: Análise da influência das características do sistema no atraso de

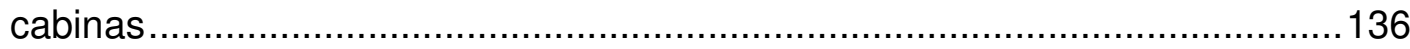

Gráfico 4.1: Influência das características do sistema no atraso das cabinas ........136

Tabela 4.17: Influência das mudanças arbitrárias da seqüência no sistema ..........137

Gráfico 4.2: Influência das mudanças arbitrárias da seqüência no atraso do DEPOVERT

Gráfico 4.3. Gráficos do comportamento das cabinas na saída da Rohbau e nova Rohbau...

Gráfico 4.4. Gráficos dos veículos e cores atrasados na Pintura ............................140

Gráfico 4.5. Gráfico do número de posições perdidas ....................................... 140

Gráfico 4.6. Comportamento da seqüência na saída do Puffer..............................142

Gráfico 4.7: Histograma das cabinas que irão bloquear veículos na montagem final

Gráfico 4.8: Atraso de cabinas na saída do DEPOVERT

Tabela 4.18: Atratividade da modificação do Puffer e eliminação do DEPOVERT .147

Figura 5.1: Teoria JIT aplicada à redução de estoques.

Figura A. Puffer de cabinas pintadas de Wörth

Figura B. Estoque de cabinas Acabadas de Wörth 


\section{Lista de Abreviaturas}

MRP - Material Requirements Planning (Planejamento da Requisição de Materiais)

MRP II - Manufacturing Resources Planning (Planejamento dos Recursos de Manufatura)

ERP - Enterprise Resources Planning (Planejamento dos Recursos da Empresa)

JIT - Just In Time

BOM - Bill of Material (Lista de Materiais)

TOC - Theory of Constraints (Teoria das Restrições)

CEP - Controle Estatístico do Processo.

AS/RS - Automated Storage / Retrieval System (Sistema Automático de estocagem e seleção.

CDP - Centro de Distribuição de Peças

CKD - Completely Knocked Down (Completamente Desmontado)

HPN - Haube Projekt Neu (Novo Projeto com Capô)

LN - Lastwagen Neu (Caminhão Novo)

FSK - Front Schwere Klasse (Veículo Pesado de Cabine Frontal)

FPN - Front Projekt Neu (Novo Projeto de Cabine Frontal)

HSK - Haube Schwere Klasse (Veículo Pesado com Capô)

LTC - Light Truck Concept (Caminhão Leve Conceito)

L98 - Lastwagen 98 (Caminhão Modelo 98)

OF - Omnibus Front (Ônibus de Motor Frontal)

Rohbau - em alemão: Construção, Montagem.

AGV - Automated Guided Vehicle (Veículo Guiado Automatizado)

KTL - kataphoretische Tauchlackierung (pintura catódica de imersão)

Puffer - em alemão: Pulmão

DEPOVERT - Depósito Vertical

SELIC - Sistema Especial de Liquidação e de Custódia (taxa de juros).

VBA - Visual Basic Application (Aplicação em Visual Basic)

FIFO - First In / First Out (Primeiro que entra / Primeiro que sai) 
Resumo

ZALLA FILHO, J. G. Análise dos Estoques em Processo de um Sistema de Produção de Cabinas de Caminhões com o uso da Simulação de Eventos Discretos. 2006. Dissertação (Mestrado em Engenharia) - Escola de Engenharia de São Carlos, Universidade de São Paulo, 2006, p. 180.

Essa dissertação tem como objetivo utilizar a simulação de eventos discretos na análise dos estoques seletivos em processo de cabinas, em uma montadora de veículos comerciais de grande porte instalada no Brasil. A análise e a redução desses estoques seletivos são desejadas, pois o armazenamento de cabinas de caminhões, além de representar um alto custo para a produção, é de difícil controle e de alto risco. O desenvolvimento deste trabalho contribuirá para o conhecimento das dificuldades e benefícios da aplicação da simulação de sistemas discretos em sistemas produtivos de alta complexidade, como são os sistemas de manufatura da indústria automobilística. A análise desse sistema é de significativa dificuldade, devido ao tamanho dos produtos, ao mix de produção, à variabilidade do fluxo das etapas de produção $e$ às diversas variáveis que influem no sistema simultaneamente. A técnica de simulação de eventos discretos foi escolhida por ser a mais indicada para analisar todo o sistema e auxiliar na tomada de decisão. Todo o estudo do sistema, modelagem, verificação, validação, simulação e resultados foram feitos de acordo com procedimentos já sedimentados para o uso da simulação de eventos discretos, de acordo com a bibliografia apresentada. Os resultados mostram a eficiência do método utilizado e propõem um cenário otimizado para o sistema estudado. $O$ estudo foi realizado com a utilização do software de simulação de eventos discretos, Arena® 5.0 .

Palavras-chave: Simulação de eventos discretos, controle de estoques seletivos, indústria automobilística. 
Abstract

ZALLA FILHO, J. G. The Cabins Storage System analysis from a Commercial Vehicle Production System by the use of Discrete Event Simulation. 2006. Dissertação (Mestrado em Engenharia) - Escola de Engenharia de São Carlos, Universidade de São Paulo, 2006, p. 180.

This work has the main objective to use the Discrete Event Simulation to analyze the in process cabins selective banks of a commercial vehicle assembler. The analysis and reduction of the selective banks are useful because the storage of cabins represents some production risks, is hard to control and implies in high costs. The developing of this work will contribute to the knowledge of the difficulties and benefits of the use of Discrete Event Simulation applied to high complexity production systems like the automotive industry. The size of the products, the production mix, the throughput variability and the other simultaneous variables turn the storage analysis to a hard level. In this way, the Discrete Event Simulation is the most indicated technique to help the analysis and the decision making. The whole study of the system, the modeling, the validation and verification, the simulation runs and the results were done according to known procedures of using the Discrete Event Simulation, which are mentioned in the references. The presented results show the efficiency of the utilized method and propose optimized scenery of the studied system. The simulation software Arena ${ }^{\circledR} 5.0$ was used in this study.

Key words: Discrete Event Simulation, Selective Banks Analysis, Automotive Industry. 


\section{Introdução}

\section{1 $\underline{\text { Contexto }}$}

Desde a década de 80 , as empresas produtivas e as prestadoras de serviço vêm modificando sua estrutura, seus conceitos e filosofia. Buscam, assim, sobreviver frente à competitividade proveniente da difusão mundial da cultura e da tecnologia, à fragmentação contínua dos mercados de massa, a clientes mais exigentes, à segmentação da cadeia produtiva e ao impacto crescente de valores sociais em constante alteração (GOULART, 2000 apud PREISS et al., 1998). No mesmo sentido, Corrêa et al. (2001) citam que, como não há mercados demandantes suficientes para todos os ofertantes venderem seus produtos, alguns conseguirão, e outros não. O que fará a diferença entre os que conseguirão ou não tal objetivo é a capacidade de cada um deles, ao oferecer o que mais interessa aos nichos de mercado. Dentre os aspectos de desempenho que podem influenciar a escolha dos clientes por essa ou aquela empresa podem-se citar:

- Custo percebido pelo cliente;

- Velocidade de entrega;

- Confiabilidade de entrega;

- Flexibilidade da produção;

- Qualidade dos produtos;

- Serviços diferenciados prestados aos clientes.

Esse cenário expõe as empresas a um ambiente altamente dinâmico, forçando-as a se tornarem mais ágeis. Colmanetti (2001) apud Gonçalves Filho (2001) relata que a manufatura é uma das funções que possui influência determinante no desempenho da empresa, pois, para que venha a ter sucesso no mercado, deve possuir um sistema de manufatura enxuto e eficiente. Em Goulart (2000), tem-se que agilidade, no contexto de manufatura, requer a integração de tecnologias flexíveis de produção com a habilidade baseada no conhecimento dos trabalhadores e estruturas flexíveis de gerenciamento.

No âmbito das empresas manufatureiras, Suri et al. (1993) comentam que a maioria das corporações tem aplicado muitos recursos na melhoria contínua dos métodos e processos dos seus sistemas de manufatura. A análise e as melhorias dos sistemas de manufatura são essenciais para a sobrevivência das empresas modernas. 
Corrêa et al. (2001) descrevem como os sistemas de administração da produção influem na competitividade do sistema manufatureiro. Os sistemas de administração da produção devem dar suporte a alguns objetivos estratégicos das companhias, sendo capazes de apoiar decisões. São eles:

- Planejar as necessidades futuras de capacidade produtiva da empresa;

- Planejar os materiais comprados;

- Planejar os níveis adequados de estoques de matérias-primas, produtos semi-acabados e o produto final;

- Programar as atividades de produção para garantir que os recursos produtivos envolvidos sejam bem utilizados;

- Ser capaz de saber e de informar corretamente a respeito da situação corrente dos recursos e das ordens programadas;

- Ser capaz de prometer os menores prazos possíveis aos clientes e fazer com que sejam cumpridos;

- Ter reações rápidas e eficazes.

Dentre os objetivos estratégicos da administração da produção, o controle e o planejamento dos estoques é um dos mais importantes. Os estoques representam grande parte dos custos de produção, mas também são necessários para amenizar incoerências nos sistemas produtivos, evitando custos ainda maiores. Ao mesmo tempo, eles também escondem imperfeições no sistema produtivo e, quando analisados, mostram diversas oportunidades de melhorias na fábrica. $O$ ideal é que as empresas possuam um controle de estoques adequado, para que não tenham nada mais do que o estritamente necessário nos estoques (CORRÊA et al., 2001; MONDEN, Y. 1998; FOGARTY et al., 1991).

As formas mais comuns de administrar os estoques são: lotes econômicos, modelos matemáticos ou sistemas computacionais, como o MRP. As filosofias, como o Just in Time, e teorias, como a Teoria das Restrições, alimentam esses sistemas de controle como filosofias para administrar a produção.

Os meios de controle descritos acima auxiliam a tomada de decisão, mostrando qual a melhor estratégia para controlar os estoques. Diversas técnicas são utilizadas para apoiar a análise dos sistemas produtivos. Dentre elas, uma que se destaca é a Simulação de Eventos Discretos. 
Desde a década de 70, a Simulação de Eventos Discretos é utilizada com sucesso no auxílio à tomada de decisão em estudos de projetos e de melhorias dos sistemas de manufatura (LAW \& MCCOMAS, 1997; WILLIANS \& ÇELIK, 1998). A necessidade da utilização dessa ferramenta é ainda maior, quando se deseja realizar uma análise com grande quantidade de detalhes de sistemas de manufatura complexos. Os sistemas manufatureiros modernos consistem de diversas operações discretas que ocorrem randomicamente e não linearmente e que inviabilizam a utilização com segurança de alguns modelos matemáticos ou de outros métodos (O'KANE et al., 2000).

A simulação utiliza-se de modelos de um sistema real ou imaginário, com o propósito de avaliar o comportamento randômico desse sistema sob várias condições. É realizada segundo um experimento planejado que permite que os analistas visualizem e concluam sobre novos sistemas sem precisar construí-los, ou fazer alterações em sistemas existentes sem perturbá-los (LAW, 1986). Reduzemse, assim, o tempo e os custos da implementação de novas soluções, além de se obterem diversas informações sobre os sistemas.

A indústria automobilística, uma das mais importantes da indústria mundial, apresenta sistemas de manufatura de alta complexidade, envolvendo muitas etapas de fabricação e montagem. Normalmente, diversos componentes, como carroçaria, chassis, motores e agregados, são montados em diferentes subsistemas e são movimentados entre eles por meio de complexos sistemas transportadores, em um sistema flexível em que vários produtos diferentes são produzidos. Os itens são programados e essa programação deve ser mantida nas diversas etapas, para que a montagem final trabalhe sem problemas. Para manter a seqüência programada e amenizar as variações do fluxo que ocorrem entre as etapas, são utilizados estoques seletivos entre os subsistemas e a montagem final dos veículos (JARAYARAMAN et al., 1997).

A análise dos estoques seletivos é dificultada pela quantidade de subsistemas com muitas atividades paralelas e diversas variáveis de natureza estocástica que influem simultaneamente. Devido à grande quantidade de variáveis estocásticas, a Simulação de Eventos Discretos apresenta-se como a técnica mais indicada na análise de diversas questões relativas aos sistemas produtivos da indústria automobilística, principalmente na análise de viabilidade, necessidade e dimensionamento dos estoques existentes. 
Ülgen e Gunal (1998) citam que, na indústria automotiva mundial, as ferramentas de simulação já vêm sendo largamente utilizadas. Também citam que, nas grandes montadoras dos Estados Unidos (General Motors, Ford Motors e DaimlerChrysler), antes de ser executada qualquer nova modificação nos sistemas de produção, no layout, ou antes de serem compradas novas máquinas e dispositivos nos quais possam ser gastos algumas dezenas de milhares de dólares, estudos de simulação são invariavelmente utilizados, para aprovação dessas modificações.

Já na indústria nacional, apesar de ser uma técnica conhecida e com recursos computacionais disponíveis, existem apenas algumas aplicações de simulação. A indústria nacional, para continuar competitiva, também necessita de ferramentas que auxiliem a tomada de decisão no que se refere à análise de melhorias do seu processo produtivo. Tem-se, então, um grande campo de trabalho a ser realizado, utilizando-se a simulação discreta como técnica de auxílio.

\subsection{Justificativa e objetivos}

De acordo com a introdução, melhorias nos sistemas produtivos são desejadas, pois têm forte influência nos fatores de competitividade de uma indústria. Dentre essas melhorias, a redução e controle dos estoques são importantes para evitar desperdícios, reduzir os custos produtivos e corrigir diversos problemas dos sistemas de produção. Além das técnicas tradicionais, a simulação de eventos discretos também se mostrou muito útil no auxílio à tomada de decisão e em análises e solução de problemas nos sistemas produtivos (LAW \& MCCOMAS, 1999).

No caso da indústria automobilística, a existência de diversos subsistemas produtivos, nos quais influem diversas variáveis aleatórias, torna ainda maior a dificuldade de análise, e a utilização de simulação configura-se mais atrativa.

Durante a análise dos sistemas de montagem de uma fabricante típica de automóveis, a análise da necessidade e do dimensionamento dos estoques seletivos entre os processos caracteriza-se como de grande dificuldade. Isso porque a existência desse estoque resulta da necessidade de corrigir ou reprogramar a seqüência dos diversos componentes dos automóveis e amenizar a influência das diversas variáveis aleatórias que atuam no fluxo das diversas etapas do sistema. Freqüentemente, o dimensionamento desses estoques depende da política de 
administração e controle do sistema e das utilizações a eles atribuídas. Existem diversas maneiras de abordar esse problema, mas, devido à complexidade das variáveis envolvidas, os modelos matemáticos e as análises analíticas podem não ser suficientes para resolvê-lo. A simulação tem-se mostrado bastante adequada para análise de problemas relativos aos sistemas de manufatura, principalmente os da indústria automobilística.

A simulação de eventos discretos traz maior segurança e se mostra bastante adequada na análise da necessidade e dimensionamento desses estoques seletivos, pois não é possível testar novos cenários sem prévia análise, e é muito difícil verificar quais variáveis do sistema têm maior influência nos estoques.

Esta dissertação tem como objetivo utilizar a simulação de eventos discretos na análise dos estoques seletivos de cabinas em uma montadora de veículos comerciais de grande porte instalada no Brasil. É objetivo deste estudo de simulação, também, a redução desses estoques, pois o armazenamento de cabinas de caminhões representa um risco para a produção, é de difícil controle e onera a produção. $O$ desenvolvimento deste trabalho poderá contribuir para o conhecimento das dificuldades e benefícios da aplicação da simulação de sistemas discretos em sistemas produtivos de alta complexidade, como são os sistemas de manufatura da indústria automobilística. Outro aspecto do estudo de simulação, que será verificado, é a precisão que se pode alcançar, pois, para tomar qualquer atitude, é necessário ter certeza de que a modificação proposta funcionará como previsto. Como os níveis de produção estão altos, não é admitido qualquer erro que prejudique esses níveis, por isso um estudo de simulação é indicado.

Para desenvolver um projeto desse tipo, é necessário o aprendizado de diversos conceitos do controle e planejamento de estoques, principalmente os seletivos. É necessário, também, conhecer a teoria que embasa o uso da simulação de eventos discretos e o desenvolvimento de projetos de simulação, para aplicação no desenvolvimento do estudo de caso a ser feito na planta da empresa em questão, de acordo com os objetivos.

\subsection{Organização do trabalho}

No Capítulo 2, faz-se uma síntese de toda a bibliografia pesquisada e incluise um primeiro tópico sobre o Controle e Gerenciamento de estoques, explicando-se a função dos estoques e os diversos métodos, filosofias e processos de controle e 
gerenciamento. No segundo tópico está resumida toda a teoria de simulação de eventos discretos e os passos necessários para o desenvolvimento de um estudo de simulação. Já no terceiro tópico apresenta-se um resumo de alguns estudos de caso utilizando a simulação na análise de sistemas de manufatura e na indústria automobilística, inclusive na análise dos estoques seletivos em processo, tema deste trabalho.

No terceiro capítulo estão os objetivos e algumas considerações do estudo de caso, a descrição de todas as características do sistema, os dados coletados e as restrições assumidas.

O quarto capítulo apresenta detalhes sobre a modelagem, a verificação do modelo de acordo com o modelo conceitual, a validação de acordo com o sistema real e as corridas de simulação.

Os resultados obtidos e as conclusões do projeto formam o quinto capítulo.

Ao final, tem-se a bibliografia utilizada e os apêndices, I e II, que mostram uma comparação com o sistema de produção de caminhões da matriz alemã e um relatório do Arena ${ }^{\circledR}$, respectivamente.

\section{Revisão Bibliográfica}

\subsection{Controle e Gerenciamento de estoques}

Os estoques constituem um elemento gerencial essencial na administração da produção. Os estoques podem ser descritos como acúmulos de recursos materiais entre fases específicas de processos de transformação e distribuição. Esses acúmulos proporcionam independência entre as fases dos processos do sistema (CORRÊA et al., 2001). Isso significa que uma interrupção de uma das etapas pode não acarretar na interrupção da outra etapa. Recursos materiais, como matéria-prima, material semi-acabado, componentes, pré-montagens e produtos acabados podem ser estocados para serem requisitados nos processos de transformação e distribuição (FOGARTY et al., 1991).

Hoje, sabe-se que os estoques são necessários devido às diferenças de fluxo entre as diversas etapas dos sistemas produtivos e de distribuição. Busca-se, então, o controle sobre os sistemas produtivos e de armazenagem, para que não se tenha nada estocado além do estritamente necessário estrategicamente (CORRÊA et al., 2001). 


\subsubsection{Função e classificação dos estoques}

De acordo com Fogarty et al. (1991), a função primária de um estoque é amortecer as variações entre a quantidade de demanda e a quantidade de oferta nas diversas etapas da cadeia produtiva. Por exemplo, as variações de demanda do consumidor em relação a uma oferta constante do produtor, ou a formação de lotes econômicos de matéria-prima em relação a uma demanda constante etc.

Sugerem-se, então, algumas classificações funcionais para os tipos de estoques utilizados (FOGARTY et al., 1991):

- Estoques de previsão: férias produtivas, picos nas vendas, vendas promocionais, escassez de produtos etc. fazem com que as organizações produzam ou comprem recursos materiais adicionais para suprir essas variações de demanda ou de oferta. Esses recursos ficam armazenados e têm previsão de utilização nessas situações.

Apesar de também serem baseados em previsões, os estoques especulativos, muito comuns em países com significativa inflação, são diferentes. No caso dos estoques especulativos, cada estoque é montado de acordo com decisões financeiras de algum risco e se tornam investimentos. Os estoques especulativos baseiam-se na previsão de que algum recurso material terá algum aumento de preço no futuro; assim, é feito um estoque desse recurso para que esse aumento de preço possa ser incorporado ao lucro sem afetar os custos dos produtos.

- Estoques cíclicos devido a lotes de produção (lotes de produção): em alguns casos, não compensa produzir ou comprar algum produto em pequenas quantidades, de acordo com a demanda ou necessidade. Nesses casos, é necessário produzir lotes econômicos dos produtos, que ficam em estoque até que se atinja uma quantidade mínima estocada, para que seja produzido ou adquirido mais um lote.

- Estoques flutuantes devido às incertezas: é comum a variação da demanda ou da oferta fora das previsões em razão de ocorrências alheias ao planejamento. Diante disso, é necessário estocar os recursos materiais para que esses não faltem e para que as variações de oferta sejam absorvidas. O ideal é que os estoques se mantenham no mesmo nível, absorvendo a falta dos recursos e suprindo a demanda. 
- Estoques para transporte: é muito comum que os recursos materiais tenham que ser transportados entre as etapas produtivas e até o consumidor final. Para utilização dos veículos comuns de transporte, normalmente é necessário acumular produtos até completar o volume necessário para que o transporte seja economicamente viável. Muitas vezes não é utilizado só um meio de transporte, e isso torna necessários vários estoques entre os sistemas de transporte.

- Estoques para reposição: são estoques compostos de partes utilizadas para reposição ou manutenção. Esses estoques, apesar de pequenos, são importantes, pois, apesar dos esforços em manutenção preventiva, a demanda por essas partes tem difícil previsão e a falta delas representa muitos prejuízos.

- Estoques gerados pela desinformação entre as etapas: muitas das causas apresentadas até agora são agravadas pela falta de coerência das informações entre as etapas. Muitas vezes, a falta de previsão, tanto da oferta, como da demanda, ocorre porque as informações não foram passadas corretamente entre compradores e vendedores. Isso gera erros de planejamento que, por sua vez, geram a necessidade de estocar recursos materiais para suprir uma eventual falha.

\subsubsection{Razão para controlar os estoques}

Os estoques imobilizam capital, ocupam espaço, necessitam de movimentação, podem estragar-se, tornar-se obsoletos, serem taxados, necessitar de seguro, ou podem ser roubados e até perdidos. Por outro lado, os estoques freqüentemente amenizam problemas gerenciais, como previsões ruins, erros na programação e erros no cálculo do tempo de preparação ou no tempo de processo. Também amenizam paradas de produção e outras ocorrências imprevisíveis. Dessa forma, os estoques podem amenizar e esconder diversos problemas na gerência dos setores produtivos, fazendo com que sejam ignorados. Nesses casos, os estoques representam custos desnecessários, que reduzem os lucros e que prejudicam o desempenho da empresa. Por isso, as empresas devem avaliar se estão estocando corretamente e sem prejuízos.

Já os benefícios de se manter os estoques necessários são maiores que os custos envolvidos na sua manutenção, pois a falta de alguns itens críticos pode 
parar todas as etapas da cadeia produtiva e gerar diversos prejuízos. Os objetivos das empresas de atender aos consumidores, de obter produtividade, lucro e retorno dos investimentos exigem que os produtos ou recursos materiais sejam entregues no momento certo e no lugar certo. Isso é válido, tanto para manufatura, quanto para vendas, transporte, saúde, ensino, alimentação etc.

Os estoques podem ser considerados como desperdício, mas são extremamente necessários em alguns momentos. O que não pode acontecer é que sejam utilizados desnecessariamente. Cada tipo de organização pode ter diferentes níveis de performance e produtividade, e necessita, assim, de um adequado controle dos seus estoques.

\subsubsection{Controle dos estoques de agregados (FOGARTY et al., 1991)}

Para este trabalho, os estoques mais importantes são os utilizados entre as etapas produtivas do processo, ou seja, os que são utilizados para armazenar matérias-primas, peças compradas e, principalmente os que armazenam as partes em processo e as partes em transformação, entre as diversas etapas produtivas. Nesses casos, os estoques são considerados como patrimônio e são controlados de acordo com os objetivos de atender aos clientes, ou de acordo com determinados volumes de estoque ou com a taxa de realocação nos estoques.

O controle dos estoques de agregados constantemente enfrenta conflito entre os benefícios dos estoques e o custo neles investido.

Para o controle dos estoques de agregados, são necessárias algumas informações do sistema em questão:

- Previsão de vendas e programa mestre de produção;

- Tempos de processo (lead times) da produção e da distribuição;

- Lista de materiais (BOM);

- Descrição detalhada e objetiva dos processos de fabricação;

- Detalhes dos processos que agregam valor;

- Estoques de segurança;

- Sistemas transportadores entre as plantas e os estoques.

Fogarty et al. (1991) mostram como fazer uma aproximação dos estoques de agregados, a partir dessas informações, em ambientes make to order (produção por encomenda) e job shop (produção por processo). 


\subsubsection{Métodos e filosofias para o controle dos estoques}

Os objetivos, políticas e decisões do controle dos estoques devem estar de acordo com os objetivos gerais da empresa e serem consistentes com os objetivos das áreas de marketing, financeira e de manufatura.

As decisões do controle dos estoques devem estar interligadas com diversas características da organização, como: planejamento da capacidade, estratégias de curto, médio e longo prazo, tipo de produto e sazonalidade. $O$ volume produzido também determina o tamanho dos estoques. $O$ tipo de processo (linhas, células, job shop, flow shop etc.) afeta diretamente os estoques em processo. A organização do sistema de distribuição também determina a organização dos armazéns e centros de distribuição. Decisões como "comprar ou fazer" influem no tamanho e tipo dos estoques utilizados.

A forma como é feito o controle dos estoques deve ser consistente, atendendo a todas essas características da organização, e deve suportar os objetivos principais de satisfação do cliente e o investimento necessário para manutenção dos estoques. (FOGARTY et al., 1991).

São diversos os sistemas, métodos e filosofias adotados para o planejamento da produção e o controle dos estoques. No decorrer deste tópico, é feita uma introdução desses principais métodos e filosofias.

O modelo básico de gestão de estoques, denominado lote econômico, consiste no cálculo matemático do momento e da quantidade que deve ser suprida dos recursos materiais. A esse modelo são adicionadas diversas considerações, como estoques de segurança, falhas de processo ou falta probabilística de itens, questões sobre o reabastecimento, curvas $A B C$ (classificam os itens por prioridade), itens de demanda dependente e independente. Esse modelo serve bem no cálculo de estoques de poucos produtos, com fácil controle e fluxo praticamente constante, em que os estoques são utilizados para suprir diferenças entre a demanda e a oferta.

Os modelos matemáticos são desenvolvidos desde o início do século passado (MUCKSTADT \& ROUNDY, 1993), e diversos trabalhos mostram diferentes métodos, modelos e algoritmos para o controle dos estoques. Harris (1915) apresentou a primeira derivação do método básico de controle de estoques, o Método do Lote Econômico. 
O aumento do número de trabalhos para controle de estoques, utilizando métodos e modelos matemáticos, ocorreu a partir da década de 50 . Esses modelos se tornaram mais complexos, com a utilização de recursos computacionais, para que pudessem descrever mais características e restrições dos sistemas. Alguns exemplos de modelos matemáticos para a análise dos estoques são:

- Lee e Nahmias (1993) mostram diversos modelos para analisar os estoques de um sistema simples, com um tipo de produto e um único estágio.

- Muckstadt e Roundy (1993) apresentam modelos matemáticos para análise de sistemas mais evoluídos, como: diversos produtos e vários estágios de produção, sistemas de montagem, sistemas de distribuição e outros sistemas com estruturas genéricas e demanda constante.

- Federgruen (1993) apresenta modelos que consideram a demanda e os tempos de processo variáveis aleatórias, em sistemas de diversos produtos e diversos estágios, mas somente com um centro de decisão (produção empurrada).

- Já Axsäter (1993) apresenta uma evolução do modelo anterior para sistemas com diversos centros de decisão (produção puxada), mas somente quando o sistema é uma seqüência de etapas.

- Tempelmeier \& Bürger (2001) mostram um estudo mais recente, em que modelos matemáticos são utilizados para descrever um sistema de produção em fluxo, com estoques de tamanhos finitos e equações discretas, baseado nos algoritmos de pesquisa operacional.

No entanto, os modelos matemáticos apresentam limitações quanto à descrição estatística dos fenômenos e à abrangência geral dos sistemas, além de serem complicados para utilização no dia-a-dia das empresas.

Como a geração de estoques também está ligada à qualidade das informações que tramitam entre as diversas etapas da cadeia produtiva, foram desenvolvidos métodos e sistemas computacionais que utilizam diversas informações sobre as diversas etapas da produção. Isso para que os recursos materiais possam ser produzidos, comprados e programados na hora e quantidade exatas, administrando-se, assim, o sistema produtivo e os estoques. Dentre esses sistemas, tem-se o MRP, o MRP II e o ERP, que são baseados em modelos 
matemáticos das características do sistema. Esses sistemas são considerados como a filosofia tradicional de administração da produção e controle de estoques. Esses sistemas, no entanto, necessitam de informações precisas e constantes sobre o sistema e de um forte planejamento de demanda, além de não tratarem a aleatoriedade dos fenômenos envolvidos.

O planejamento de necessidade de materiais (Material Requirements Planning - MRP) tem um conceito básico bastante simples: se todos os componentes de determinado produto e os tempos de obtenção de cada um deles são conhecidos, pode-se (com base na visão de futuro das necessidades de disponibilidade do produto em questão) calcular os momentos e as quantidades que devem ser obtidas de cada um dos componentes. Portanto, o MRP calcula a quantidade exata, o momento de início e fim de produção de cada item, componente ou matéria-prima necessários para a produção dos produtos descritos no programa mestre de produção. A figura 2.1 mostra as relações envolvidas no MRP. A literatura (FOGARTY et al., 1991; CORRÊA et al., 2001) mostra, detalhadamente, como funciona o MRP.

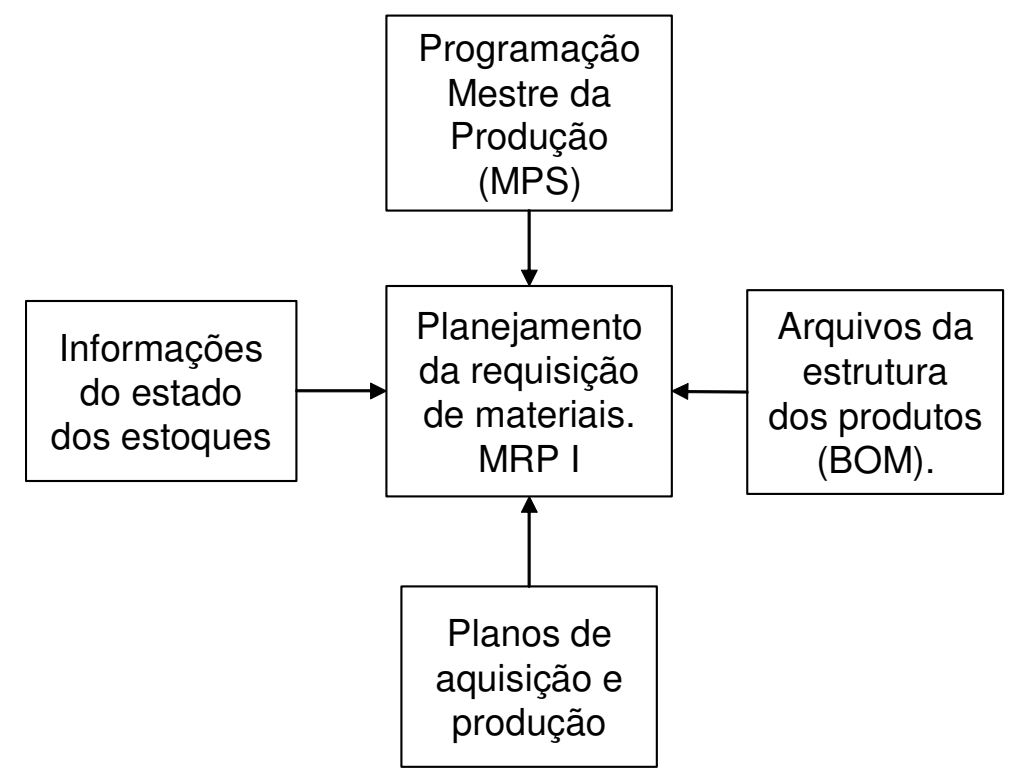

Figura 2.1: Relações e informações utilizadas em um sistema MRP Adaptado de Fogarty (1991).

Muitas vezes, no entanto, máquinas quebram, funcionários têm variação de produtividade, peças são retrabalhadas ou falta matéria-prima. Como o MRP não sabe como está o sistema e a sua capacidade, as previsões feitas por ele podem 
fugir da realidade. Partindo da necessidade de planejar também os recursos do sistema, para que se possa balancear a mão-de-obra ou a carga de máquina e determinar o planejamento de materiais, surgiu o MRP II, ou Manufacturing Resources Planning. O MRP II utiliza uma seqüência hierárquica de cálculos, verificações e decisões que visam chegar a um plano de produção viável, tanto em termos de disponibilidade de materiais, como de capacidade produtiva. A figura 2.2 mostra a diferença entre a abrangência do MRP e a do MRP II. Na literatura (CORREA, 2001; FOGARTY, 1993), é possível obter mais informações sobre o funcionamento do MRP II.

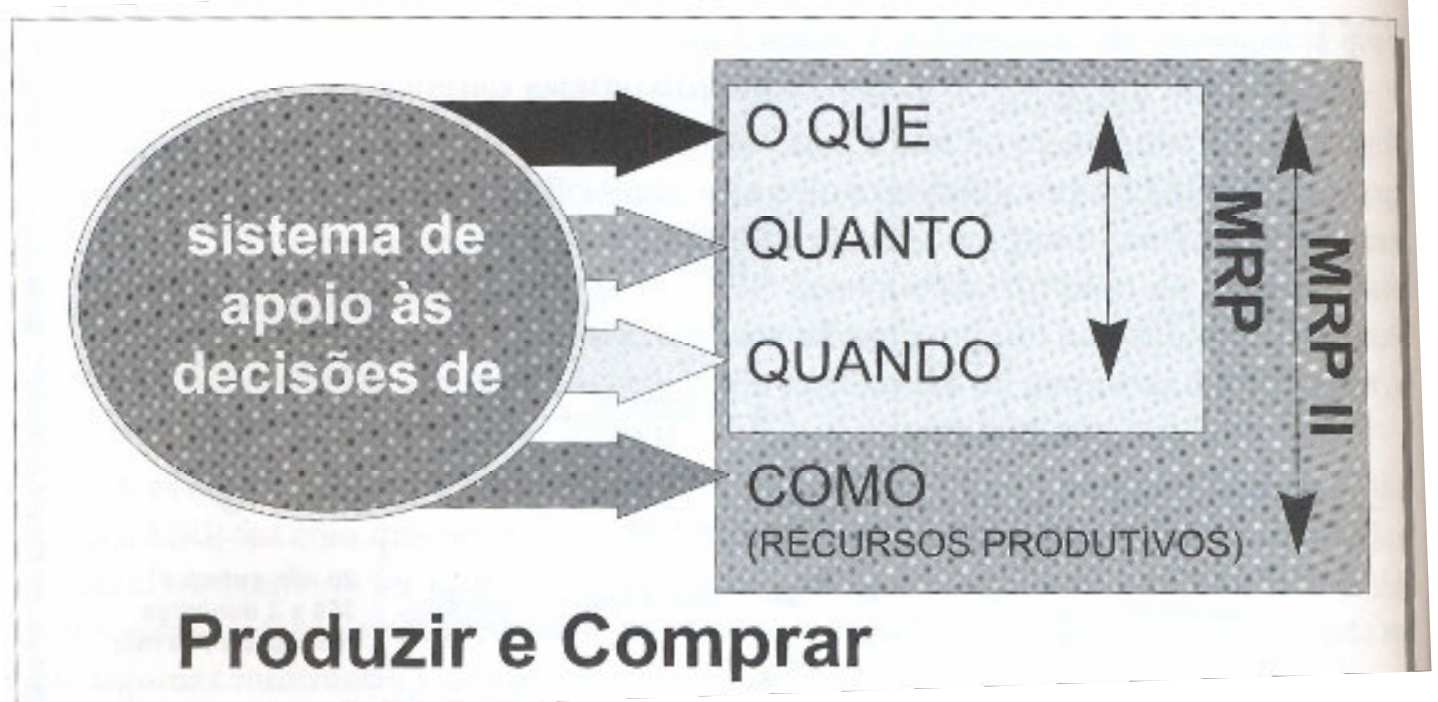

Figura 2.2: Diferenças na abrangência do MRP e do MRP II Adaptado de Correa et al. (2001).

Esses sistemas fornecem bons resultados no controle e gerenciamento da produção, quando utilizados corretamente. Parte-se da idéia de que devem ser adicionados estoques em todas as áreas em que existam diferenças entre demanda e oferta. Nenhum dos sistemas anteriores sugere a redução de estoques pela execução de melhorias, pois só administram corretamente o volume estocado. Essa é a filosofia tradicional de administração da produção. Novas filosofias que mudaram o ponto de vista da administração da produção e do controle dos estoques são o Just in Time (JIT) e a Teoria das Restrições (Theory of Constrains - TOC).

A filosofia do Just in time, muitas vezes denominada produção enxuta, nasceu no Japão na década de 70 . Tem como característica a coordenação da produção por meio da produção "puxada", utilizando o Kanban, a eliminação dos desperdícios, 
além do conceito da melhoria contínua (Kaizen). Os conceitos básicos do Just in Time podem ser encontrados em (FOGARTY et al., 1993):

- Todo desperdício, ou seja, tudo que não agrega valor ao produto ou serviço, deve ser eliminado.

- As melhorias dentro do JIT devem ser contínuas, e nunca cessam.

- O estoque é um desperdício e esconde os problemas que deveriam ser eliminados. O desperdício pode ser gradualmente eliminado, por meio da redução gradual nos níveis dos estoques.

- A qualidade desejada pelos consumidores deve direcionar o desenvolvimento e a fabricação dos produtos. Isso implica diferenciação dos produtos e flexibilização da produção.

- A flexibilidade de produção, incluindo as respostas rápidas às mudanças de demanda e de quantidade, é essencial para manter a qualidade e o custo baixo na fabricação de produtos diferenciados.

- Diante da competição global, é necessário que todos os funcionários da empresa participem. Isso implica aumento da flexibilidade, responsabilidade e autoridade de todos os empregados. $O$ empregado que desenvolve uma tarefa deve ser ouvido, para sugestão de melhorias na respectiva tarefa.

Tradicionalmente, os estoques são vistos como um investimento que está parado aguardando utilização, e servem para reparar a diferença no fluxo de produção entre a demanda e a oferta. No JIT, os estoques são vistos como um desperdício e escondem muitos problemas de administração da produção, como: longos e custosos tempos de preparação, refugos, variação dos lead times da manufatura, longas filas em processo, capacidade inadequada, quebras de máquina, falta de flexibilidade do operário e das máquinas, longos tempos de re-suprimento e quantidades fora do necessário. O JIT enfatiza que, atuando sobre esses problemas, é possível reduzir os estoques gradativamente e melhorar a produtividade. O lema principal do JIT é: "Ter o material certo, no tempo certo, no lugar certo e na quantidade exata". Muitas vezes o custo de manter os estoques são menores que os necessários para implementar as melhorias do sistema produtivo, mas os resultados de aumento de produtividade e controle do sistema compensam a busca pelas melhorias. 
As melhorias buscadas com a utilização do JIT são:

- Redução do tempo de preparação, para diminuir os lotes a serem produzidos;

- Utilização de produção seqüenciada, em vez de linhas dedicadas;

- Aumento do número de operários multifuncionais;

- Aumento da flexibilidade e capacidade dos equipamentos

- Manutenção preventiva total;

- Aumento da estabilidade, consistência e controle da programação;

- Desenvolvimento dos fornecedores;

- Maior freqüência de entrega de suprimentos;

- Envolvimento dos funcionários no processo de decisão e aumento da qualidade;

- Controle estatístico dos processos (CEP);

- A parada da produção ante os problemas;

- Análises de causa e efeito;

A filosofia do JIT altera todas as áreas do negócio, principalmente a gerência da produção, a gerência dos recursos humanos, compras e gerência da qualidade.

A implementação dessas melhorias resulta em diversos custos, que são, normalmente, temidos pelas organizações. Mas a redução do capital imobilizado em estoques e os ganhos em qualidade, produtividade e gerenciamento da produção geram economias que, se corretamente mensuradas, superam os custos da implementação das melhorias. Por isso, o JIT deve ser implementado gradual e continuamente.

Como se sabe, ocorrem diversos fatores aleatórios nos sistemas produtivos, como: paradas de máquina, faltas dos trabalhadores, refugos, retrabalhos, mudanças na demanda. Normalmente, existe também a correlação entre as diversas etapas do sistema, em que uma etapa B depende de uma etapa A. Dessa forma, os eventos aleatórios afetam todo o sistema. A filosofia tradicional de administração da produção diz que devem ser utilizados estoques bem controlados entre as etapas, para que se elimine essa correlação. Já o JIT diz que devem ser trabalhados esses problemas variáveis para que sejam eliminados esses problemas e, respectivamente, os estoques. 
Como se sabe, estoques geram custos que reduzem a competitividade das empresas, mas muitas vezes trazem melhorias em pontos dos sistemas em que é muito dispendioso eliminar os estoques e os resultados não compensam.

É nesse ponto que está introduzida a TOC (Teoria das Restrições). Essa filosofia aceita a existência de problemas e desbalanceamentos no sistema, quando alguns recursos têm capacidade de produção menor que a dos outros. O recurso mais limitado é chamado de restrição e é o enfoque da TOC. Nesse recurso, e somente nesse, é construído um estoque ou pulmão, para que o recurso restrição seja totalmente aproveitado e nunca pare. Os outros recursos têm o chamado estoque de capacidade. A TOC também considera qualquer outro estoque como nocivo e tende a eliminá-lo.

Dessa forma, a TOC não tenta eliminar todos os problemas, pois às vezes isso é mais dispendioso que manter pequenos pulmões, devido às restrições do sistema.

As restrições de um sistema podem ser, não só dos recursos, mas também de vendas e das políticas da empresa. Uma restrição de venda é quando a demanda é menor que a capacidade de oferta. Já a restrição política é quando, por exemplo, se utiliza a quantidade de peças por minuto como desempenho e muitas vezes a demanda é menor do que a capacidade máxima de produção.

A TOC faz uma abordagem mais realista que o JIT, pois não tenta eliminar todos os problemas, mas sim tratá-los e analisá-los diante das restrições do sistema e dos custos envolvidos. Mais informações sobre a TOC podem ser encontradas em Fogarty et al. (1993).

A revisão, até o momento, mostra alguns conceitos de administração da produção que serão utilizados no decorrer do trabalho realizado e descrito nesta dissertação.

Como se pode analisar, a administração da produção é de grande dificuldade e envolve muitos métodos, conceitos, ferramentas e filosofias. Hoje, além de controlar bem os estoques, é necessário implementar melhorias no sistema produtivo, para reduzir as falhas e os estoques, reduzindo assim os custos.

Essas melhorias, no entanto, têm um custo de implementação e, hoje, devido à quantidade de variáveis existentes nos sistemas produtivos e à complexidade de realização de estudos puramente analíticos, existem ferramentas que auxiliam os estudos das melhorias. 
Dentre as ferramentas utilizadas, Suri et al. (1993) apud Law e Haider (1989) citam a simulação de eventos discretos como o método mais utilizado pela indústria para avaliar os sistemas de produção e fornecer informações sobre eles. Com a simulação é possível analisar diversas características dos sistemas, observando os fenômenos aleatórios que ocorrem. Pode ser facilmente implementada e fornece resultados rápidos e precisos. A revisão da literatura sobre simulação discreta está mais adiante, neste capítulo.

O próximo tópico demonstra como é feito o estudo dos sistemas produtivos na Indústria Automobilística.

\subsection{O sistema produtivo da Indústria Automobilística e os estoques seletivos}

A montagem e a produção de automóveis envolve complexa cadeia de processos automatizados e manuais, que são divididos em diversas etapas, formando todo o sistema de montagem. O sistema de produção e montagem de automóveis pode ser dividido em três etapas básicas (ÜLGEN \& GUNAL, 1998): montagem da carroçaria, pintura e montagem final dos veículos. A figura 2.3 mostra um sistema típico de produção de uma montadora de veículos.
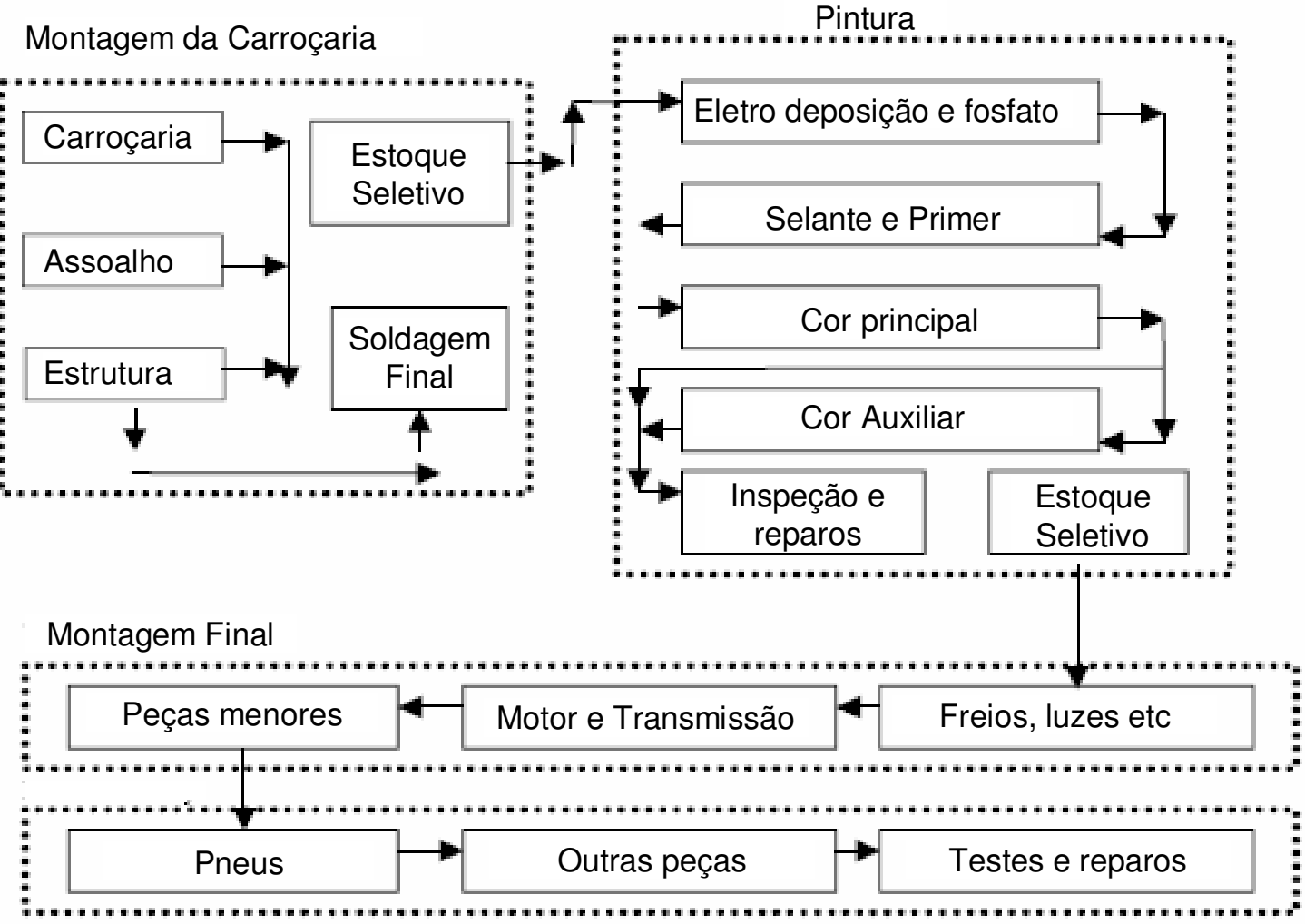
Figura 2.3: Organização típica dos processos produtivos em uma indústria automobilística Adaptado de Ülgen \& Gunal (1998).

A montagem da carroçaria corresponde às etapas em que são montadas a estrutura e as diversas chapas estampadas que formam a carroçaria. Dentre elas, capô, portas, teto e laterais. A maioria dos processos envolvidos corresponde a processos de solda e funilaria em que podem ser utilizados robôs. Dependendo da quantidade de variações de modelos de automóveis, essas etapas podem estar organizadas em células ou em linhas de montagem paralelas e, muitas vezes, com diferentes tempos de processo.

Depois de montadas, as carroçarias são pintadas. Essa etapa compreende diversos processos diferentes, como pré-tratamento, deposição eletrolítica da camada de fundo, Primer e Esmalte e estufas para secagem. Muitos desses processos são contínuos e sem necessidade de parada em postos, pois são utilizados transportadores durante todo o processo (WILLIANS \& SADAKANE, 1997). Um dos problemas típicos da pintura é relativo ao número de diferentes cores a serem pintadas, pois a pintura esmalte utiliza normalmente robôs e, a cada troca de cor, existe um tempo de preparação (set-up) e alguma quantidade de tinta é jogada fora, para limpeza dos tubos do equipamento. Isso obriga que as carroçarias sejam pintadas em pequenos lotes de cores iguais, o que muitas vezes não está previsto na programação inicial de venda e montagem dos automóveis.

Outro problema é o número de retrabalhos que ocorrem nas diversas etapas da pintura devido ao número de processos envolvidos e aos diversos problemas nesses processos. Isso faz com que muitas carroçarias passem por etapas de correção ou pelos diversos processos de pintura novamente.

Depois de liberadas da pintura, as carroçarias vão para a montagem final e recebem os outros componentes do veículo, como motor e transmissão, eixos, interior e acabamento. A montagem final é normalmente disposta em linhas, e os diversos componentes chegam de acordo com a seqüência de montagem predefinida.

Normalmente, as montadoras de veículos produzem diversos modelos de veículos. Essa produção é diversificada, porque reduz os investimentos e os custos dos estoques e porque se consegue um melhor balanço na utilização dos recursos produtivos, além de ser o principal desejo do cliente (MONDEN, 1998). Dessa forma, 
é designada uma seqüência de montagem para esse mix de automóveis, e todo o sistema deve seguir essa mesma seqüência de montagem. Em outras palavras, a produção ou o suprimento dos diversos componentes e agregados que compõem os automóveis devem utilizar essa mesma seqüência, para que o sistema tenha um fluxo constante. Alguns autores chamam esse tipo de produção de Just in Time in Sequence (RIETH \& GERLACH, 1996), ou Entrega em Seqüência (Sequenced Delivery) (DING \& SUN, 2004).

A seqüência da montagem final deve ser mantida sempre; entretanto, a seqüência de produção e montagem dos equipamentos e de suprimento de agregados pode ser modificada muitas vezes dentro dos processos, o que pode acarretar algumas mudanças na seqüência da montagem final. As modificações podem ocorrer intencionalmente ou não intencionalmente, e essas mudanças ocorrem principalmente na pintura, na montagem da carroçaria e na entrega dos principais agregados (motores e eixos).

As mudanças podem ser intencionais, como no caso da pintura (SPIECKERMANN, GUTENSCHWAGER, 2004; LAHMAR et al., 2003), em que é necessário agrupar as carroçarias de mesma cor em pequenos lotes, muitas vezes fora da seqüência original, para diminuir o tempo de preparação e o desperdício de tinta. Ou no caso dos processos de montagem em que alguns modelos de automóveis têm maior tempo de processo e não podem ser montados na seqüência em alguma etapa do sistema, apesar de terem sido programados dessa forma.

Já as mudanças não intencionais ocorrem, na sua maioria, por causa de falhas de processo, faltas de componentes ou até mesmo devido a falhas organizacionais e físicas, no caso de linhas paralelas e com tempos de processo diferentes (DING \& SUN, 2004).

Para sanar os problemas de alterações ou falhas na seqüência, podem-se desenvolver algoritmos que determinem a seqüência a ser utilizada, em que são consideradas todas as restrições, ou utilizar os "Estoques Seletivos".

Monden \& Aigbedo (1997) e Zeramdini et al. (2000) mostram alguns algoritmos para desenvolver a seqüência da montagem final observando diversas características do sistema, como balanceamento da utilização dos recursos, manutenção do fluxo de componentes, variação dos produtos etc. Os autores fazem, também, uma revisão nos trabalhos feitos nessa área de programação. Conseguem determinar uma boa seqüência, mas é difícil que essa seqüência seja adequada a 
todas as etapas da produção. Dessa forma, ainda é necessária a utilização dos "Estoques Seletivos".

Narayanaswamy et al. (1997) definem os Estoques Seletivos (Seletivity Banks) como parte dos sistemas transportadores que, por meio de diversos transportadores paralelos, conseguem armazenar os produtos de cada submontagem ou etapa da produção. Com base em regras predefinidas, os Estoques Seletivos têm flexibilidade suficiente para remanejar os produtos armazenados, para que estes possam sair do estoque na seqüência desejada. Esse tipo de estoque é muito utilizado em sistemas de produção de diferentes produtos e com uma seqüência predefinida, assim como a indústria automobilística. A figura 2.4 mostra um exemplo de estoque seletivo.

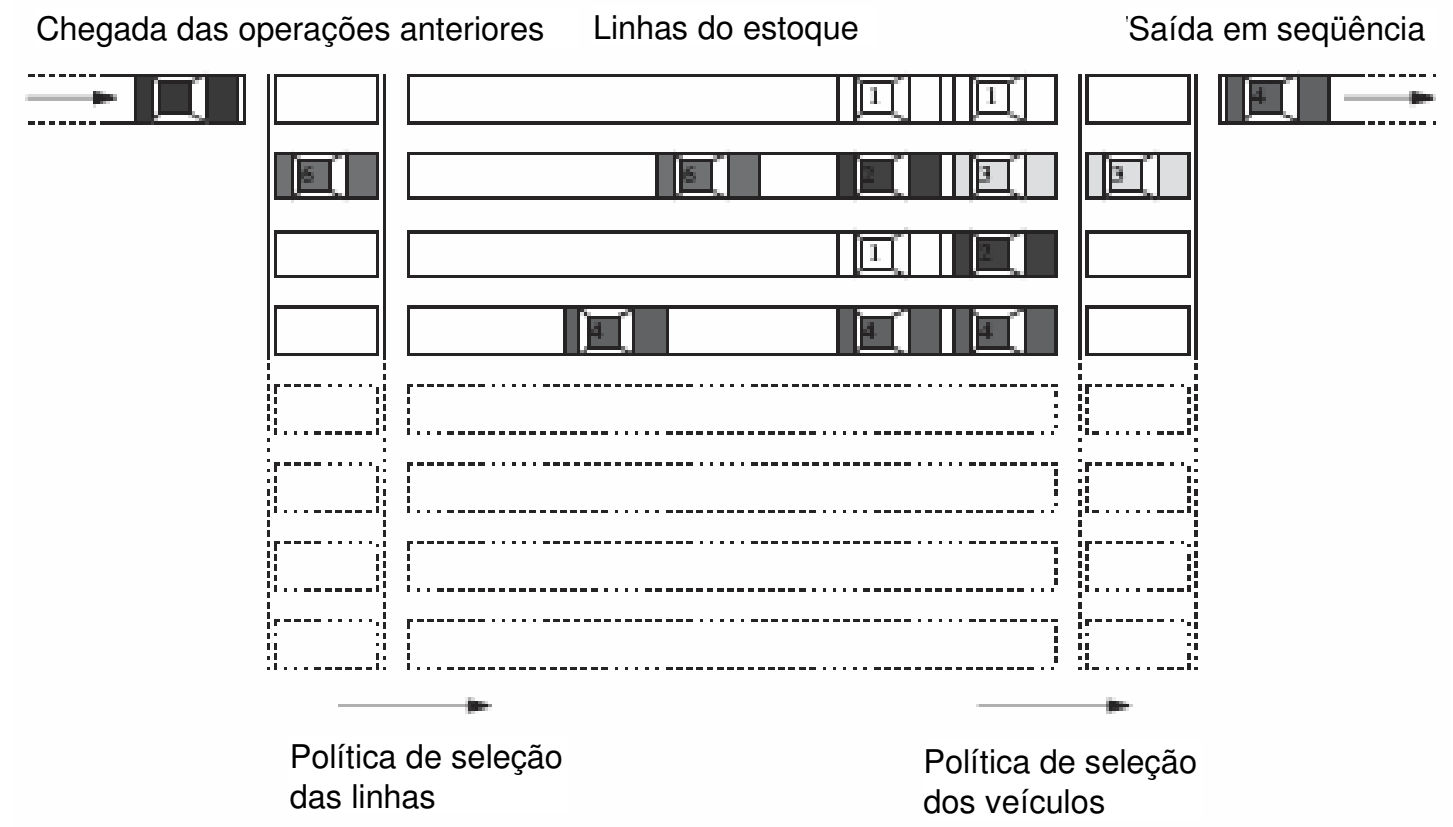

Figura 2.4: exemplo de estoque seletivo Adaptado de Spieckerman \& Gutenschwager (2004).

Um estudo detalhado sobre a utilização de estoques seletivos está em Ding \& Sun (2004). Nesse estudo é apresentada uma descrição detalhada do dimensionamento e utilização dos estoques seletivos em diversas situações específicas. Apresenta-se um algoritmo de utilização e programação do estoque seletivo para que os produtos advindos de um processo produtivo sejam reprogramados para o processo seguinte, podendo ou não voltar à seqüência anterior. Também é descrita a utilização de sistemas que corrijam defasagens não intencionais nas seqüências, para que retornem ao que foram programadas. Um 
exemplo de sistema da literatura útil para o trabalho são os estoques $A S / R S$ (automated storage / retrieval system), que são mais flexíveis que os estoques seletivos baseados em transportadores. Diversos exemplos e algoritmos sobre a utilização desses sistemas são apresentados.

Narayanaswamy et al. (1997) mostram um estudo em uma fábrica de automóveis referente à análise de um Estoque Seletivo entre a Pintura e a Montagem final dos automóveis. Os veículos saem da pintura em uma seqüência diferente da necessária, pois, muitas vezes, os veículos pintados necessitam de algum retrabalho na tinta e perdem a seqüência. $O$ estudo utiliza a Simulação de Eventos Discretos para analisar a influência de diversos cenários de modificações, inclusive diferenças na configuração do Estoque Seletivo, na capacidade de correção da seqüência, ou se são necessárias alterações físicas ou nos algoritmos de seleção do Estoque Seletivo.

Spieckermann \& Gutenschwager (2004) também mostram um estudo em uma fábrica de automóveis; mas, nesse caso, o Estoque Seletivo encontra-se antes da etapa de Pintura, e serve para agrupar os veículos em pequenos lotes de mesma cor para reduzir o número de trocas de cor, o desperdício de tinta e os custos do processo. Nesse estudo, todas as lógicas de decisão e restrições são utilizadas para desenvolver um procedimento branch\&bound para a determinação dos lotes de cores na seqüência que os veículos devem seguir para a pintura. $E$, como a simulação discreta tem sido muito utilizada pela indústria, os resultados gerados pelo procedimento são verificados por meio de simulação em um modelo e sob diversas condições específicas.

Lahmar et al. (2003) apresentam um estudo em uma fábrica norte-americana de caminhões da Ford para determinar lotes de pintura e reduzir os custos de preparação e o desperdício de tinta. Nesse estudo, o Estoque Seletivo utilizado também é baseado em transportadores, mas é um pouco diferente, pois as cabinas dos caminhões são retiradas da fila para uma estação paralela de reparo, onde aguardam para serem re-programadas de acordo com a similaridade de cor (pull-off tables). Esse sistema não é tão flexível quanto um Estoque Seletivo comum, mas também possibilita mudanças na seqüência. $O$ estudo apresenta um algoritmo para determinar a melhor seqüência para reprogramar os automóveis e reduzir o número de trocas de cores de acordo com o número de linhas (pull-off table) para 
reprogramação. Também está designado o número mínimo de linhas (pull-off table) que seja capaz de garantir o mínimo de mudança de cores.

Gunal et al. (1997) apresentam um outro estudo referente ao comportamento da seqüência de produtos em uma fábrica de tratores. Nesse caso, a simulação é utilizada, pois o estudo engloba todo o sistema, e não só os estoques seletivos ou alguma etapa em questão. O sistema estudado produz três tipos de tratores em uma seqüência predeterminada de acordo com as vendas, mas na montagem bruta da cabina existem tempos de preparação entre a produção de veículos diferentes. Para reduzir esses tempos, as cabinas são separadas em lotes, saindo da seqüência. Após cada etapa existem estoques seletivos para que a seqüência seja restaurada. Em paralelo à linha de montagem de cabinas dos tratores, existe a linha de montagem dos chassis. Nessa linha, a seqüência também pode ser modificada devido à falta de peças.

O estudo analisado utiliza simulação para analisar o efeito do tamanho dos lotes, da falta de peças e do tamanho dos estoques seletivos, para que a seqüência e o fluxo sejam mantidos sem perdas de produção. Os resultados auxiliaram o gerenciamento da produção a dimensionar o sistema da melhor forma. Além dos resultados numéricos, foi desenvolvida uma interface para que os planejadores possam usar o modelo de simulação facilmente e analisar novos cenários.

Muitos outros projetos utilizam a simulação na análise de sistemas de produção e dos estoques seletivos existentes na indústria automobilística. Dessa forma, a técnica escolhida para este trabalho é a simulação discreta, e o resumo da teoria envolvida está no tópico que segue.

\subsection{Simulação de Eventos Discretos}

A simulação tornou-se uma das técnicas mais populares na análise de sistemas complexos de manufatura. Um estudo de simulação utiliza um modelo do sistema real e descreve o comportamento de um sistema randômico durante o tempo. A capacidade da simulação de analisar o comportamento aleatório de um sistema é a principal vantagem dessa ferramenta frente às outras ferramentas matemáticas ou analíticas (O'KANE et al., 2000).

Um estudo de simulação é feito antes da construção ou da alteração de um sistema para: reduzir as chances de alguma falha nas especificações, prever algum 
gargalo, prevenir a ociosidade ou a saturação dos recursos e responder a várias outras perguntas do tipo "e se?" (what if?) (MARIA, 1997).

2.3.1 Definições para Simulação encontradas na literatura:

- "Simulação é uma técnica de resolução de problemas, pela observação do comportamento sobre o tempo, de um modelo dinâmico do sistema" (GORDON 1978).

- "Simulação é um método de modelar a essência de uma atividade ou sistema, de modo que possam ser feitas experiências para avaliar o comportamento do sistema ou o seu efeito ao longo do tempo" (MONKS, 1987).

- "Simulação é o processo de projetar um modelo lógico matemático de um sistema real e fazer experimentos deste sistema no computador" (PRITSKER, 1995).

- "Simulação é um método de experimentação que faz uso de um modelo detalhado do sistema real para determinar como este sistema irá responder a mudanças em sua estrutura, no ambiente ou em considerações colocadas a respeito do mesmo" (HARREL et al. 1992).

- "Simulação é uma técnica que utiliza computadores para imitar ou simular as operações ou processos de várias espécies do mundo real” (LAW \& KELTON, 1991).

- "Simulação é a imitação da operação de um processo real sobre o tempo" (BANKS, 1998).

Pode-se resumir Simulação como uma técnica de resolução de problemas por meio da observação, descrição e análise do comportamento do sistema durante o tempo.

Com a utilização de Simulação, pode-se analisar o comportamento de sistemas existentes ou imaginários sob diversas condições a serem experimentadas. Essas análises são feitas de forma rápida, precisa e com baixo custo. Também são muito mais seguras e menos dispendiosas do que fazer alterações reais no sistema. Dessa forma, a Simulação torna-se uma metodologia e uma ferramenta essenciais na solução de problemas e na análise de situações específicas em sistemas reais (BANKS, 1998). 


\subsubsection{Conceitos envolvidos na utilização de Simulação}

No desenvolvimento de um estudo de simulação, são utilizados diversos conceitos. De acordo com Banks et al. (1996), Law \& Kelton (1991) e Banks (1998), esses conceitos são relativos a: sistemas, modelos, eventos, variáveis do sistema, entidades, atributos, recursos, atividades e processos.

- No mundo existem constantes interações de materiais, pessoas, meio ambiente, dentre outras. Essas interações podem resultar em diversos comportamentos. Uma fábrica, por exemplo, devido às constantes interações entre recursos disponíveis e pessoas, gera peças. Esse conjunto de interações constitui o que se chama de sistema. A figura 2.5 ilustra um diagrama de sistema, de acordo com Pritsker (1995).

- A definição de sistema é uma parte ou o todo de um conjunto de objetos que podem ter relações de interação, propositais ou não. Essas relações e esse propósito é o que desejamos estudar.

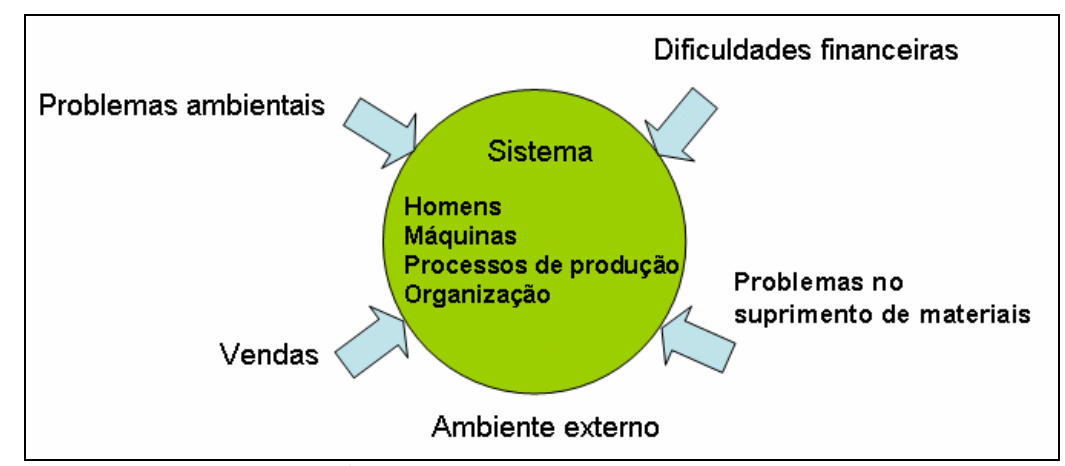

Figura 2.5: Sistema influenciado pelo meio externo

Fonte: Pritsker, 1995.

- Os objetos relacionados em um sistema são as entidades, que representam um objeto que possui uma definição única, a qual pode ser estática como uma máquina ou dinâmica como uma pessoa. Os atributos são condições e características que modificam uma entidade, como cor, tempo de processo, modelo etc.

- Os recursos constituem um tipo de entidade. Executam uma tarefa em uma entidade dinâmica do sistema. Cada recurso pode executar tarefas em uma ou mais entidades e em pontos diferentes do sistema, por 
exemplo, uma empilhadeira (recurso) que movimenta as caixas (entidade dinâmica) entre os processos, ou uma fila (recurso) de peças (entidades) esperando um processo. Os recursos têm estados definidos: ocioso, ocupado, parado, bloqueado etc.

- As atividades e processos são os períodos de tempo específicos que podem ter alguma variação em que as entidades são modificadas por um recurso ou são programadas para esperar. Exemplo desse período pode ser a usinagem (período) de uma peça (entidade) por um torno (recurso).

- Um acontecimento que acarreta uma mudança no sistema é um evento, como a chegada de uma nova entidade.

- As variáveis do sistema constituem uma coleção de todas as informações que definem o que acontece em um sistema, num dado instante. Um exemplo de variável pode ser a freqüência de chegada de entidades, ou o período de atuação dos recursos etc.

Como já mencionado, a simulação utiliza-se de modelos do sistema real. Um modelo é uma representação da construção e dos processos do sistema real de interesse. Esses modelos devem ser uma aproximação do sistema e incorporar suas principais características. Deve-se observar, no entanto, o grau de detalhamento dos modelos, pois estes não devem ser complexos demais a ponto de não serem entendidos ou experimentados. Pesquisadores costumam salientar que os modelos devem ser aperfeiçoados iterativamente, para que atinjam a complexidade necessária para a resolução das situações propostas (MARIA, 1997) Muitas vezes, é necessário mais de um modelo para investigar as mudanças no sistema.

Os modelos podem ser de diferentes tipos (COLMANETTI, 2001):

- Modelos físicos: são representações reais do sistema, muitas vezes em menor escala, mas repetindo suas características físicas e estruturais.

- Os modelos matemáticos descrevem os sistemas por meio de relações lógicas e equações matemáticas, podendo ser, ou não, desenvolvidos com ajuda de softwares.

- Um modelo estático é um modelo do sistema em um instante particular, ou seja, sem alterações no tempo.

- Um modelo dinâmico leva em consideração as mudanças que ocorrem na variação do tempo. 
- Os modelos podem ser determinísticos, e neles as variáveis são constantes e fixas no tempo, ou seja, os eventos ocorrem com a mesma freqüência.

- E também podem ser estocásticos e, nesse caso, as variáveis possuem variação estatística no tempo, ou seja, a freqüência dos eventos é função de eventos aleatórios ou equações estatísticas.

- Os modelos são contínuos quando o estado do sistema é representado por variáveis dependentes das mudanças contínuas do tempo. Nesse caso, são modeladas as mudanças suaves do sistema por meio do uso de equações diferenciais (Pritsker, 1995).

- E são discretos quando o estado do sistema muda de acordo com a ocorrência dos eventos, sem mudanças entre dois eventos consecutivos. Nesse caso, as mudanças ocorrem de acordo com a probabilidade de um evento ocorrer.

No caso da Simulação de Eventos Discretos, como o próprio nome diz, são utilizados modelos dinâmicos, estocásticos e discretos. Os modelos são simulados com variação de tempo, e a ocorrência dos eventos transforma, por meio de descrições estatísticas dos eventos, o estado do sistema. As mudanças que ocorrem entre um evento e outro não são descritas.

\subsubsection{Etapas de um estudo de simulação}

Para o desenvolvimento de estudos de simulação, a literatura sugere alguns passos principais, para obtenção de melhores resultados. Esses passos, no entanto, nem sempre são executados separada e seqüencialmente. $O$ desenvolvimento dos estudos de simulação deve ser um processo iterativo e, muitas vezes, torna-se necessário retornar às fases iniciais, para modificação dos objetivos de acordo com as novas necessidades. A figura 2.6 mostra os principais passos de um estudo de simulação, os quais estão descritos na seqüência deste texto: 


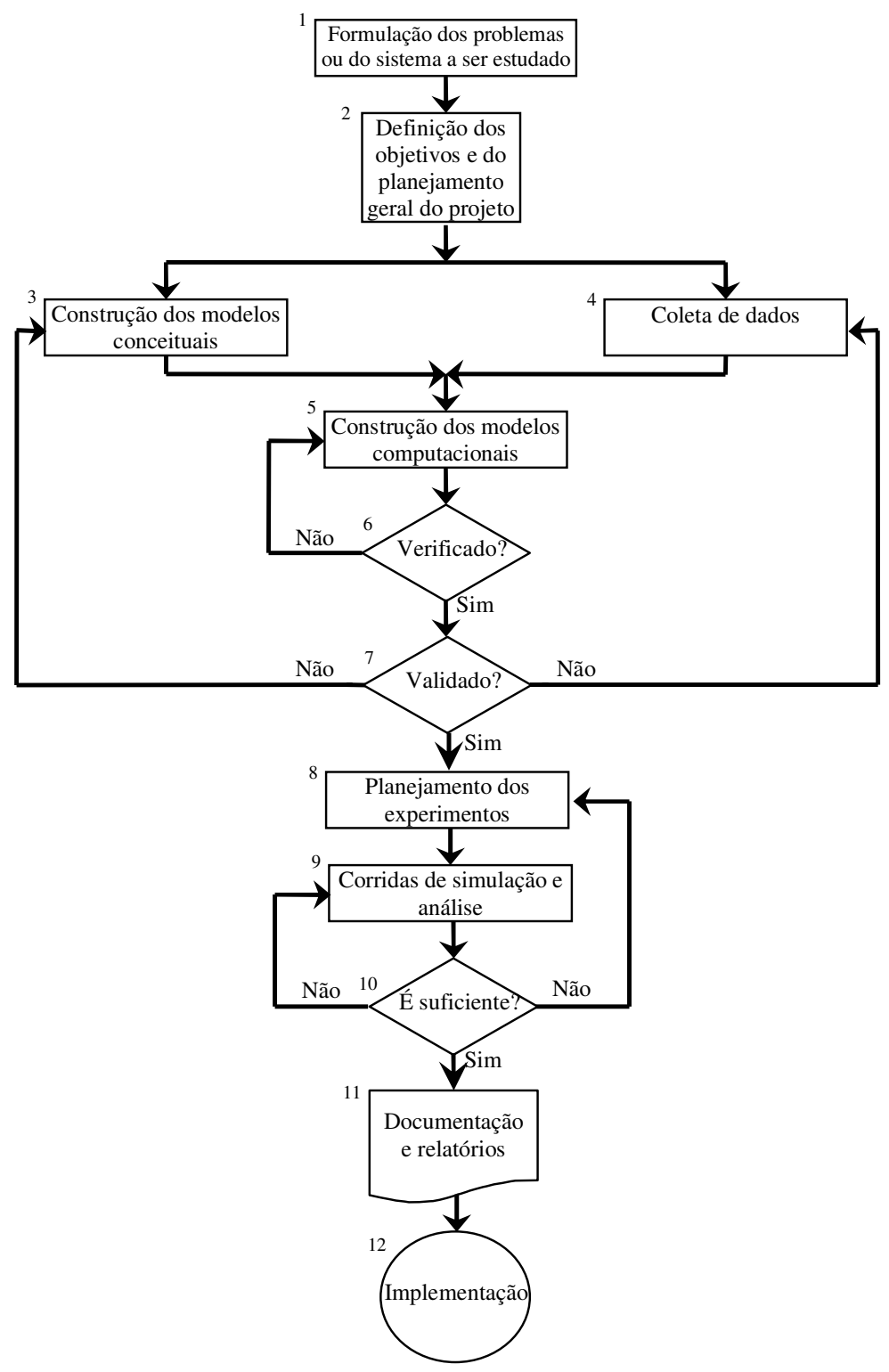

Figura 2.6. Etapas de um estudo de Simulação

Adaptado de Banks (1998).

1. Formulação dos problemas e definição do sistema: todo estudo de simulação começa pela identificação ou formulação da questão ou problema a ser analisado e pela definição do sistema a ser estudado.

2. Definição dos objetivos e planejamento geral do estudo: os objetivos indicam quais perguntas serão analisadas pelo estudo de simulação. É fundamental que os objetivos estejam bem definidos, para que o modelo seja corretamente construído e para que não se tenha de regressar ao início de todo o estudo (MUSSELMAN, 1998). O planejamento do estudo envolve os cenários que serão 
investigados, o tempo necessário, o pessoal e os equipamentos necessários, além de treinamento etc.

3. Modelo conceitual: a primeira abstração do sistema real é feita por meio do modelo conceitual. Esse modelo contém as principais relações e descrições do sistema e deve servir de base para o estudo e para a coleta dos dados necessários. O processo de modelagem deve ser iterativo, e o nível de detalhamento deve ser aumentado gradualmente.

4. Coleta de Dados: essa é uma das fases mais trabalhosas, pois conseguir os dados necessários com qualidade, quantidade e com alguma variabilidade é uma tarefa de grande dificuldade. É comum que os dados do sistema estejam indisponíveis, ou que não estejam no formato desejado para o desenvolvimento do estudo e necessitem de tratamento. Os dados devem ser coletados de acordo com as necessidades do modelo e dos objetivos previamente determinados. É necessário também que os dados coletados sejam tratados e representados por meio de equações e modelos matemáticos. Os autores Vincent (1998), Freimer \& Schruben (2002) e Leemis (2001) mostram alguns métodos de descrever e aproximar os dados de um sistema com utilização de equações matemáticas, estatísticas e outros modelos.

5. Construção do modelo computacional: essa fase se mistura um pouco com a modelagem computacional, pois normalmente a modelagem computacional ocorre após a coleta dos dados necessários, mas antes de uma nova iteração do modelo conceitual.

6. Verificação: constitui em verificar se o modelo foi construído de forma correta, de acordo com os objetivos previstos e com o modelo conceitual. O processo de verificação faz parte das iterações do modelo. Se o modelo não estiver verificado como o conceitual, alterações devem ser feitas para que se aproxime o modelo do conceitual (BALCl, 1998).

7. Validação: essa etapa constitui em determinar se o modelo desenvolvido é uma representação coerente do sistema real, de acordo com os objetivos. Diversos dados obtidos pelo modelo são comparados com o sistema real, de forma a aprovar a utilização do modelo em substituição ao sistema real. A validação também é um procedimento iterativo. Caso o modelo não esteja corretamente validado, deve ser modificado, e o processo deve ser repetido. 
8. Planejamento dos experimentos: essa fase consiste em determinar como os cenários serão simulados, para que se consigam as respostas pretendidas.

9. Corridas de simulação e análise do estudo: essa fase constitui a simulação propriamente dita. Aqui ocorrem as corridas de simulação e o levantamento dos resultados que a simulação proporciona dos vários cenários simulados. Nessa fase também ocorre a documentação e a análise dos resultados.

10. Novas corridas: caso os resultados sejam insuficientes, novas corridas podem ser feitas, para análise de novos cenários e com mais resultados.

11. Documentação e relatórios: como todo estudo ou projeto, a documentação é de grande importância. É necessário que toda a modelagem esteja corretamente documentada, para facilitar o uso futuro em novos projetos ou em modificações do atual, para que não se perca tempo refazendo o estudo e para entender o que já foi feito. Os relatórios de resultados também devem ser preparados de acordo com quem irá recebê-los (gerentes, diretores, analistas), contendo as explicações adequadas para cada tipo de leitor.

12. Implementação: após a divulgação dos resultados, deve-se dar suporte à implementação dos resultados, de acordo com a política de implantação de cada empresa.

\subsection{4 Áreas de aplicação}

As ferramentas de simulação podem ser úteis em áreas como: governo, defesa, manufatura, transportes e movimentação, sistemas computacionais, sistemas de telecomunicação, saúde, ecologia e ambiente, estudos sociais e de comportamento, ensino e ensinamento, serviços econômicos e análises de negócios etc.

2.3.5 Vantagens e desvantagens da utilização de simulação

Segundo Law \& Kelton (1991), Banks (1998) e Berge (1991), a utilização de simulação é útil para:

- Diagnosticar problemas;

- Identificar restrições;

- Entender o comportamento dos sistemas e sugerir mudanças;

- Visualizar o plano de mudanças previsto antes da implementação; 
- Amenizar as diferenças de idéias e produzir o consenso entre os analistas;

- Preparar o sistema e os operadores para as mudanças;

- Treinar os trabalhadores envolvidos no processo;

- Especificar características do sistema.

Dessa forma, pode se identificar as seguintes vantagens em utilizar a simulação:

- Facilidade no estudo de sistemas complexos e com variáveis estocásticas, em que as soluções analíticas comuns não conseguem ser utilizadas;

- Maior viabilidade, em comparação ao estudo das modificações no sistema real;

- Permite o teste de diversos cenários no sistema;

- Fornece melhor controle das condições experimentais do que um teste no sistema real;

- Podem-se simular grandes períodos em pouco tempo;

- Normalmente é bem mais econômico do que testar diretamente no sistema real.

Mas a simulação, como toda técnica especializada, também necessita de condições especiais e apresenta algumas desvantagens, como:

- É necessário um treinamento especial para se desenvolver um estudo de simulação e para a modelagem do sistema;

- Os resultados da simulação podem ser dificilmente interpretados;

- As técnicas de simulação podem ser utilizadas inadequadamente, quando a simulação não for a ferramenta mais adequada ou o estudo não for corretamente planejado e desenvolvido;

- A técnica de simulação não otimiza, ela apenas testa os cenários propostos pelo usuário, que deve escolher qual a melhor alternativa;

- Um estudo de simulação pode se tornar demorado e consumir muitos recursos, se não for corretamente desenvolvido.

2.4 Utilização de Simulação em análises de sistemas de manufatura e na indústria automobilística 
A simulação de sistemas discretos tem obtido bons resultados no auxílio à otimização dos sistemas de produção (WILLIANS \& ÇELIK, 1998). De formas diferentes, a indústria automobilística sempre liderou a aplicação da simulação de sistemas discretos. Faz aproximadamente quarenta anos que a simulação tem sido utilizada na indústria norte-americana, principalmente em sistemas complexos em que variáveis estocásticas tornam as soluções analíticas dispendiosas e complexas. Isso é possível, pois a simulação consegue prever o desempenho do sistema, identificar gargalos, avaliar alternativas propostas para a redução desses gargalos, identificar possíveis pontos negativos nos sistemas, como sobrecarga de recursos, estoques inapropriados ou dispostos erroneamente, ou tempos de processo longos e inadequados.

Diversas empresas norte-americanas e européias solicitam a simulação como análise indispensável, antes de comprar novos equipamentos ou fazer modificações nos sistemas de produção que ultrapassem algumas dezenas de milhares de dólares. Estudos realizados no passado são indicadores do quão útil a simulação pode ser no projeto e operação dos sistemas de produção de veículos.

Assim, com a utilização de simulação é possível responder a algumas questões para que as empresas continuem buscando competitividade. Exemplos de questões (ROHRER, 1998):

- Quando novos equipamentos devem ser comprados?

- Quantos funcionários serão necessários para atender aos pedidos?

- É possível atender a novos pedidos sem que sejam prejudicados os prazos?

- Como estará a fábrica, daqui a cinco anos?

As atividades de produção mais comuns encontradas na indústria automobilística incluem a manufatura, a fabricação de diversos componentes nos fornecedores, a produção e montagem de motores, a montagem de estruturas, carroçarias e cabinas, cabines de pintura, a montagem final dos componentes e a área de testes e inspeção final. Para todas essas áreas, a simulação pode ser aplicada auxiliando a gerência, o planejamento da produção, a área de processos, o controle de qualidade e a área de custos e orçamentos.

Para todas as atividades e setores listados acima, de acordo com Ülgen \& Gunal (1998), as aplicações de simulação de eventos discretos nos sistemas de produção de veículos podem ser divididas em duas categorias. A primeira 
classificação é baseada na etapa de desenvolvimento dos sistemas. A segunda é baseada na natureza dos problemas a serem investigados.

$\mathrm{Na}$ primeira classificação, quatro fases podem observadas: conceitual, de detalhamento, de operação piloto e de produção. A fase conceitual refere-se aos estágios iniciais, quando novos processos de manufatura, movimentação de material e montagem são projetados e testados. Pacotes de simulação de sistemas discretos de três dimensões são populares, nessa fase. $\mathrm{Na}$ fase de detalhamento, são especificados equipamentos e é detalhado o layout da fábrica. Nessa fase, são feitas as justificativas dos equipamentos e são testados os ciclos de operação, processos e seqüenciamento. Pacotes de simulação de sistemas discretos, com modelos de equipamentos e animação tridimensional, são os mais utilizados, nessa fase. A fase de operação piloto refere-se ao estágio em que a fábrica opera abaixo da capacidade de produção, para teste dos sistemas. Nessa fase também são simulados os processos e os ciclos de operação, e estes são simulados em conjunto, para verificação da fábrica como um todo. Os pacotes de simulação de sistemas discretos utilizados nessa fase não necessitam de detalhes dos equipamentos ou de simulação tridimensional, mas são melhores para o trabalho com o todo, em vez da utilização de modelos específicos. Na fase de produção, a planta trabalha na capacidade nominal, e são analisadas decisões sobre o mix de produtos, introdução de novos produtos, novas operações e modificações dos processos. Os pacotes de simulação utilizados nessa fase são similares aos da fase piloto.

$\mathrm{Na}$ segunda classificação também podem ser observadas quatro categorias: equipamentos e layout, mudanças de estratégias de gerenciamento, seqüenciamento do mix de produtos e outras modificações operacionais. Em equipamentos e layout são analisados problemas típicos, como número de máquinas necessárias, verificação de tempos de processo, identificação de locais para pulmões e "buffers", tamanho desses pulmões e "buffers", tamanho e velocidade dos carros transportadores. Já as mudanças de estratégias de gerenciamento envolvem problemas como: políticas de reparos e refugos, variação do volume de pedidos e seqüência nas cabines de pintura. O seqüenciamento do mix de produtos tipicamente envolve a linha de montagem final, as linhas de submontagem, o balanceamento dessas linhas e o cronograma de mudança de produtos. As outras modificações operacionais são, tipicamente, aplicações envolvendo as prioridades 
de algumas tarefas sobre outras, mudanças e paradas de turno e programa de produção da fábrica.

A tabela abaixo exemplifica a utilização das classificações.

\begin{tabular}{|c|c|c|c|c|c|}
\hline \multirow[b]{2}{*}{$\begin{array}{l}\text { Categoria de } \\
\text { aplicação }\end{array}$} & \multirow[b]{2}{*}{ Exemplo de aplicação } & \multicolumn{4}{|c|}{ Fases } \\
\hline & & $\begin{array}{c}\text { Fase } \\
\text { conceitual }\end{array}$ & $\begin{array}{c}\text { Fase de } \\
\text { detalhamento }\end{array}$ & $\begin{array}{l}\text { Fase } \\
\text { piloto }\end{array}$ & $\begin{array}{l}\text { Fase de } \\
\text { produção }\end{array}$ \\
\hline \multirow{3}{*}{$\begin{array}{l}\text { Equipamentos e } \\
\text { layout }\end{array}$} & Análise do tamanho dos pulmões & $x$ & $x$ & $x$ & \multirow{3}{*}{$x$} \\
\hline & Verificação dos tempos de processo & $x$ & $x$ & $x$ & \\
\hline & Velocidade e tamanho dos transportadores & $\mathrm{x}$ & $\mathrm{x}$ & $\mathrm{x}$ & \\
\hline \multirow{3}{*}{$\begin{array}{l}\text { Mudanças de } \\
\text { Gerenciamento }\end{array}$} & Análise de ciclos de testes e inspeção & & $\mathrm{x}$ & $x$ & $\mathrm{x}$ \\
\hline & Análise de refugos & & $x$ & $x$ & $x$ \\
\hline & Cronograma de limpeza dos revólveres de pintura & & $\mathrm{x}$ & $\mathrm{x}$ & $\mathrm{x}$ \\
\hline \multirow{2}{*}{$\begin{array}{l}\text { Seqüenciamento do } \\
\text { mix de pordutos }\end{array}$} & Seqüenciamento da montagem final & & $\mathrm{x}$ & $x$ & $\mathrm{x}$ \\
\hline & Seqüenciamento da montagem da carroçaria & $x$ & $x$ & $x$ & $\mathrm{x}$ \\
\hline \multirow{3}{*}{$\begin{array}{l}\text { Outras modificações } \\
\text { operacionais }\end{array}$} & Seqüencias de montagem & & $x$ & $\mathrm{x}$ & $\mathrm{x}$ \\
\hline & Cronogramas de paradas e mudanças de turno & & $x$ & $x$ & $x$ \\
\hline & Gerenciamento de prioridades & & $x$ & $x$ & $x$ \\
\hline
\end{tabular}

Tabela 2.1 Classificação das aplicações de Simulação na Indústria Automotiva

Fonte: Adaptação de Ülgen (1998).

Na bibliografia, são encontrados muitos exemplos de estudos de simulação para diferentes áreas da indústria automobilística. Dentre eles é possível citar alguns mais significativos, como:

- Estudos de tempos e processos em células de manufatura (ROHRER, 1998; LAW \& MCCOMAS, 1999);

- Processos, tempos e seqüência de produção nas linhas de submontagem e montagem de componentes (ÜLGEN \& GUNAL, 1998);

- Gerenciamento da cadeia de distribuição dos fornecedores (MANIVANNAM, 1998; ÜLGEN \& GUNAL, 1998);

- Estudo de armazéns e estoques (MANIVANNAM, 1998; CHIN, 2005);

- Estudos de movimentação de materiais (ROHRER, 1998; WILLIANS \& NARAYANASWAMY, 1997);

- Tempos de produção, gargalos, cronogramas, ordenação, utilização dos recursos, movimentação de material, processos e linhas de submontagem e montagem nas fábricas de motores e transmissões (JAYARAMAN \& GUNAL, 1997; CHOI \& HOUSHYAR, 2002);

- Movimentação e processos nas estamparias (ÜLGEN \& GUNAL, 1998);

- Seqüência de produção, processos de soldagem, movimentação de material, automação, tempos de produção e processos de montagem nas 
linhas de produção de estruturas, carroçarias e cabinas (SLY, 1997; ÜLGEN \& GUNAL, 1998);

- Seqüência de produção, programação, nível de reparos, tempos de produção, existência e tamanho dos pulmões nas áreas de pintura (ÜLGEN et al., 1994);

- Determinação da melhor seqüência de produção e dos tamanhos de lote através de um algoritmo criado pelo usuário em uma empresa de componentes automotivos (MANE et al., 2002);

- Redução da quantidade de trocas de cor e aumento dos lotes na pintura (HAN et al., 2003);

- Processos, tempos de produção, nível de automação, nível de utilização de recursos, leque de produtos e seqüência de produção nas linhas de montagem final (ÜLGEN, 1998);

- Procedimentos e tempos nas áreas de teste e revisão final (PATEL et al., 2002);

- Número de equipamentos e máquinas necessários, compra de novos equipamentos, mudanças de layout, projeto de novas áreas fabris e orientação em custos (COLMANETTI, 2001).

Rohrer \& Strong (1997) e Smith (2003) apresentam dois levantamentos gerais de diversas aplicações de simulação na indústria automobilística. Muitas das referências utilizadas neste trabalho estão apresentadas nesse levantamento.

Nessas diferentes áreas de atuação, a utilização de ferramentas de simulação tem trazido resultados muito expressivos. Dentre eles, pode-se mencionar maior probabilidade de acerto no projeto de novas linhas e na modificação de linhas atuais de produção, maior confiabilidade dos processos, reduzindo o tamanho dos estoques e pulmões, e melhoria nos tempos de produção. Com a diversificação dos produtos que compartilham linhas de produção, mantendo-se os tempos ou a melhor programação do mix de produtos, no caso de um aumento do nível de produção, consegue-se melhor planejamento das capacidades de produção.

Pode-se citar, também: otimização da distribuição de material diminuindo os tempos de distribuição, configuração da carga dos transportadores, melhoria dos processos de fabricação com redução dos tempos de fabricação devido à 
organização das células e do transporte do material e melhor utilização dos recursos humanos.

Todas essas melhorias resultam no aumento da competitividade da indústria automobilística, pois reduzem os custos operacionais, aumentam a eficiência da produção e a qualidade dos produtos, e diminuem os prazos de entrega.

\subsubsection{A simulação aplicada à indústria automobilística nacional}

Atualmente, e de acordo com o tópico anterior, a simulação de sistemas discretos pode ser utilizada em muitas das áreas de trabalho da indústria automobilística, no auxílio à tomada de decisão, com resultados e soluções para escolha do melhor entre os cenários propostos, com redução de tempo e custos para a implementação de soluções e com alta segurança. Mesmo existindo algum volume de pesquisas e trabalhos na área de simulação, há um grande campo para pesquisas e trabalhos ainda a serem feitos, principalmente na indústria automobilística nacional, em que a utilização dessas ferramentas ainda não é difundida.

Essa restrição se deve a alguns problemas históricos e de custeio. Históricos, porque é recente a busca por estratégias e ferramentas que auxiliem o planejamento e a otimização dos processos, já que é recente a busca por competitividade nos mercados interno e externo. Já os problemas de custeio se referem ao alto custo que envolvia a utilização de sistemas e ferramentas computacionais. No Brasil, até pouco tempo, os estudos de simulação eram de alto custo, pois necessitavam de sistemas computacionais dedicados, sendo essa estrutura dificilmente justificada para o desenvolvimento de estudos. Atualmente, as ferramentas de simulação estão mais acessíveis e são utilizados computadores pessoais, que hoje têm grande capacidade de processamento, para as aplicações, reduzindo de forma considerável os custos dos estudos e tornando-se uma ferramenta extremamente atrativa.

Atualmente, é possível encontrar aplicações recentes desenvolvidas na indústria nacional. Podem ser citados estudos como a análise da submontagem de motores (YAMADA et al., 2002) e estudos de simulação baseada pelo custeio das atividades nas áreas de manufatura (COLMANETTI, 2001). Podem-se citar, também, um projeto envolvendo áreas de movimentação de materiais e logística (JUNQUEIRA, 2001) e um trabalho de análise de Centros de Distribuições de Peças 
(CDP) de uma fabricante de componentes automotivos (CHIN, 2005), além de outros estudos em áreas como montagem final de motores e de veículos.

É possível, ainda, encontrar alguns casos e artigos publicados junto a distribuidores de softwares de simulação e alguns congressos nacionais de simulação. Há alguns artigos, como o publicado por Fioroni et al. (2002), que citam a utilização de Templates em busca da agilidade na simulação de transportadores aéreos. Um outro projeto de destaque ocorreu na Fábrica de Motores da Volkswagen, de São Carlos, onde foram combinadas simulação e Teoria das Restrições (TOC) para análise de problemas de fluxo de materiais, em termos de produtos acabados e matéria-prima (PAOLLILO et al., 2003).

Porto et al. (2001) realizaram um outro tipo de estudo, em que avaliaram a produtividade da utilização de tratores de esteiras no campo. Esse estudo mostra uma outra etapa da aplicação da simulação, o pós-venda, quando o fabricante pode verificar o comportamento do seu produto no campo de atuação e melhorar seu projeto de acordo com índices de competitividade.

Com esses exemplos, pode-se concluir que o desenvolvimento de estudos de simulação ainda é bastante recente, e que existe um vasto campo de aplicação, dentro das atividades da indústria automobilística nacional. Há muitos projetos a serem desenvolvidos, para que essa ferramenta possa ter o mesmo nível de utilização que existe, por exemplo, na indústria automobilística norte-americana, e para que possam ser obtidos os mesmos níveis de resultados.

\section{O estudo de caso}

\subsection{Motivação}

O uso de simulação de eventos discretos como uma técnica de auxílio à tomada de decisão tem mostrado resultados comprovados de sucesso, e diversas melhorias foram alcançadas em menores prazos e com maior potencial de economia.

Apesar das pesquisas e dos projetos que envolvem simulação ainda serem restritos na indústria nacional, os resultados obtidos fizeram com que o interesse pela utilização dessa ferramenta aumentasse, nos últimos tempos. 
Dessa forma, a montadora de veículos comerciais onde foi realizado este estudo já realizou alguns estudos de simulação. Concluiu que seria interessante obter mais conhecimento sobre essa técnica e, ao mesmo tempo, analisar um antigo problema que divide as opiniões de vários setores da fábrica, devido à falta de uma análise mais detalhada.

Foi proposto, portanto, um estudo de simulação que pareceu interessante e desafiador, por mostrar mais uma aplicação da simulação de eventos discretos em uma situação real e com um objetivo a ser atingido. Com isso, surgiu a idéia do estudo de caso para este trabalho.

\subsection{Objetivo do trabalho}

O objetivo do trabalho foi aprender como a simulação de eventos discretos pode ser utilizada para analisar um sistema de produção de automóveis e, por meio da bibliografia estudada, utilizar a técnica de modelagem e simulação no sistema de produção da montadora de veículos comerciais. O sistema escolhido é de grande proporção, e envolve variáveis aleatórias e questões específicas. O objetivo principal do projeto foi analisar, por meio da observação e dos resultados da simulação, a necessidade dos estoques seletivos em processo do sistema e, caso fosse possível, redimensionar esses estoques, que são a principal questão carente de análise no sistema produtivo da montadora. Além disso, foram analisadas as dificuldades e benefícios de um estudo de simulação e a proximidade do modelo gerado em relação ao sistema real.

\subsection{Necessidade da utilização de simulação}

No próximo tópico está descrito detalhadamente todo o sistema produtivo estudado. A razão da utilização da simulação é que, para analisar o sistema em questão, é necessário conhecer o comportamento de quase todo o sistema de produção, pois diversas variáveis ao longo de todo o sistema produtivo causam situações que provocam a necessidade dos estoques seletivos. O difícil é saber quais variáveis influem diretamente e com qual intensidade.

Como não é possível analisar todas essas variáveis, que ocorrem aleatoriamente e simultaneamente com métodos analíticos comuns, a simulação torna-se necessária. Outros métodos complexos também poderiam ser úteis para analisar o sistema, mas demandariam muito tempo e esforços. 
Outra questão decisiva na escolha da simulação é a facilidade de verificar e validar os modelos, além da facilidade de apresentação do estudo e dos resultados.

Outro ponto importante é a não permissibilidade de ocorrerem testes ou modificações no sistema real sem forte embasamento, pois qualquer modificação resultaria na parada e perda de produção, o que não é permitido.

\subsection{Etapas do estudo desenvolvido e cronograma}

$\mathrm{O}$ estudo foi feito junto às atividades normais para o desenvolvimento do mestrado. Abaixo, o cronograma inicial apresentado para o estudo.

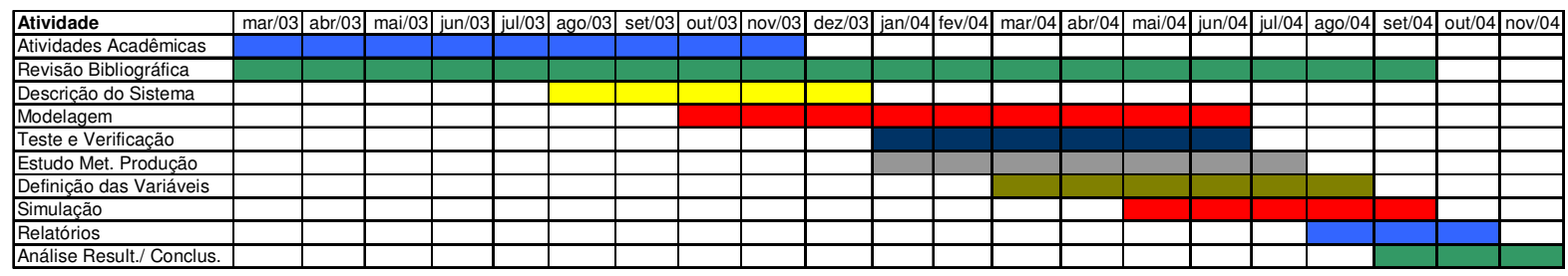

Tabela 3.1: Cronograma de atividades

Foram desenvolvidas atividades acadêmicas, como as matérias do mestrado e a revisão bibliográfica que se deu ao longo de todo o estudo.

Quanto às atividades referentes ao projeto, as etapas foram divididas de acordo com Banks (1998), já apresentadas na revisão bibliográfica, e todos os dados e etapas do estudo do sistema estão descritos nos capítulos que seguem.

O tempo total para realização do estudo foi de pouco mais de dois anos, e a parte prática levou um ano e meio.

\subsection{Generalidades do sistema estudado}

O sistema estudado compreende a parte do sistema produtivo da montadora que tem influência na análise do problema ou questão proposta. Para isso, foi necessário definir previamente quais os objetivos do estudo a ser feito. O tema inicial baseou-se nos problemas que a montadora tinha em analisar e dimensionar os estoques seletivos do sistema produtivo.

O sistema produtivo é um sistema padrão de produção de veículos em que não existem muitas diferenças, pelo fato de serem veículos comerciais. Existem 
etapas de montagem da carroçaria, pintura, montagem do interior, montagem do chassi e montagem final.

Foi importante analisar, dentro desse sistema complexo, quais etapas têm influência na necessidade dos estoques seletivos em questão. Essa análise definiu o sistema a ser estudado, mas somente ao longo do estudo foi plenamente definido, já que um estudo de simulação é iterativo.

É importante salientar que o problema dos estoques seletivos na montadora é uma questão de política interna que envolve pontos de vista diferenciados, o que tornou ainda mais difícil uma análise neutra e real do sistema.

Os capítulos que seguem apresentam o sistema e as suas características mais importantes na realização do estudo de simulação. Apesar da descrição direta, os objetivos finais do projeto só serão mencionados após a descrição do sistema, pois sua análise influiu na definição desses objetivos.

As nomenclaturas utilizadas na descrição são as mesmas utilizadas pela empresa, para facilitar o trabalho e a comunicação. Todas as abreviações podem ser consultadas no início do trabalho.

\subsection{Descrição do sistema}

O sistema é similar a muitos outros sistemas de produção de carroçarias e cabinas de autoveículos. É constituído por 3 prédios de processos, desde a montagem bruta das cabinas, até a montagem final dos caminhões. Pode ser subdividido em 11 etapas básicas, de acordo com a figura 3.1: 


\begin{tabular}{|l|l|l|l|}
\hline A - Produção Cabina Bruta - Linha Nova & & T - Transportador aéreo \\
B - Produção Cabina Bruta - Linha Antiga & \\
C - Montagem portas & S1 - Buffer de cabinas pintadas \\
D - Processos de Pintura & $\mathbf{S 2}$ - Depósito vertical (Cabinas acabadas) \\
E - Montagem Cabina, acabamento & $\mathbf{F}$ - Montagem Final de Caminhões \\
\cline { 2 - 3 } & $\mathbf{M}$ - Supermercado. \\
\hline
\end{tabular}

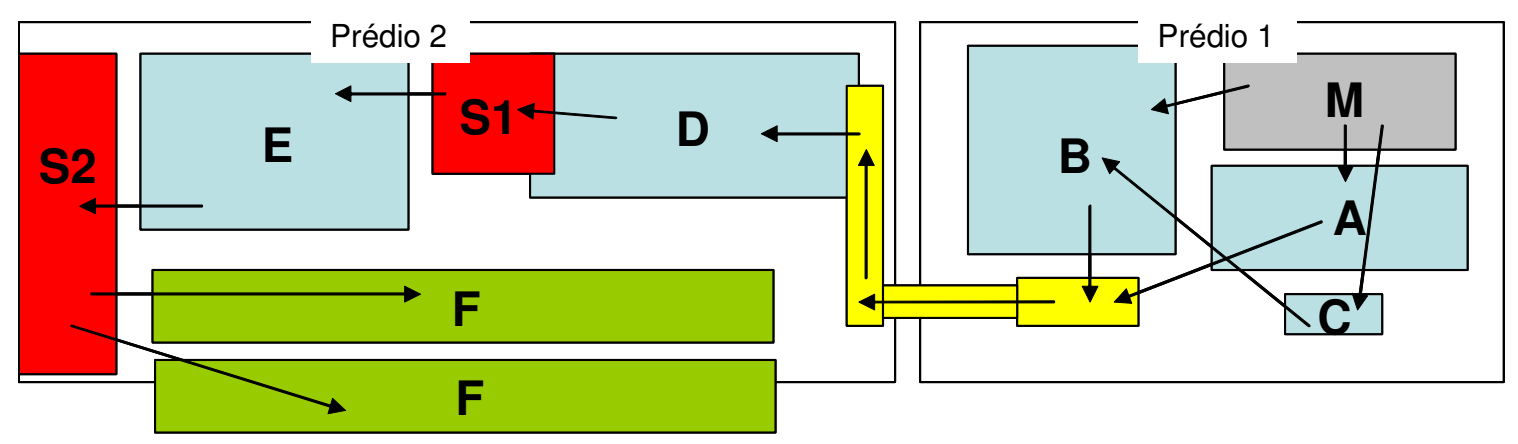

Figura 3.1: Diagrama descritivo do sistema estudado

- Produção de cabinas brutas - sistema novo (A);

- Produção de cabinas brutas - sistema antigo (B);

- Montagem das portas (C);

- Transportador aéreo de cabinas brutas (T);

- Preparação e pintura das cabinas (D);

- Estoque seletivo de cabinas pintadas, Buffer (S1);

- Montagem de acabamento das cabinas (E);

- Estoque seletivo vertical de cabinas acabadas, Depósito Vertical (S2);

- Montagem final de caminhões leves e médios (F1);

- Montagem final de caminhões pesados (F2);

- Supermercados de peças e pré-montagens (M).

Nesse sistema são produzidos 6 tipos básicos de caminhões, além de chassis de ônibus de motor frontal, cabinas para serem vendidas como reposição e cabinas para serem exportadas como CKD (Completely Knocked Down).

A produção trabalha em 2 turnos de 480 minutos, com uma parada de 20 minutos em cada turno. Foi disponibilizado o acesso a diferentes tipos de informações armazenadas em bancos de dados de tempos de processo, paradas de linha, layout, lógicas e procedimentos.

Os 6 tipos básicos de caminhões produzidos necessitam de 6 tipos básicos de cabinas e, como existem diversos níveis de customização, cada tipo básico de 
cabina possui variações para as cabinas brutas, chamadas variantes brutas. Cada uma dessas variações possui mais customizações, em relação às cabinas acabadas, chamadas de variantes exatas, além das diferenciações de cores. A Tabela 3.2 mostra os tipos básicos e as suas respectivas variações. Outras considerações sobre essas variações serão feitas no decorrer do capítulo.

\begin{tabular}{|c|c|c|c|c|c|}
\hline $\begin{array}{c}\text { Código } \\
\text { Entidade }\end{array}$ & Figura & Modelo & $\begin{array}{c}\% \text { do } \\
\text { Volume }\end{array}$ & Var Brutas & Var Exatas \\
\hline 1 & 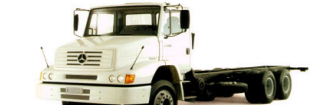 & HPN & $22,1 \%$ & 7 & 63 \\
\hline 2 & & LN & $14,36 \%$ & 5 & 26 \\
\hline 3 & & FSK & $10,27 \%$ & 8 & 81 \\
\hline 4 & & FPN e L98 & $14,27 \%$ & 10 & 104 \\
\hline 5 & & FSK & $5,41 \%$ & 2 & 65 \\
\hline 6 & & LTC & $3,44 \%$ & 4 & 25 \\
\hline 7 & & OF & $27,03 \%$ & - & - \\
\hline 8 & Todos os modelos & CKD/Vendas & $3,12 \%$ & 11 & - \\
\hline
\end{tabular}

\subsection{Descrição das etapas produtivas}

Todas as etapas analisadas no estudo serão descritas nos tópicos que seguem. Como já foi mencionado, a análise e as características descritas estão de acordo com os objetivos do estudo.

3.7.1 Produção das cabinas brutas LTC e FSK - Neu Rohbau (A da figura 3.1) 


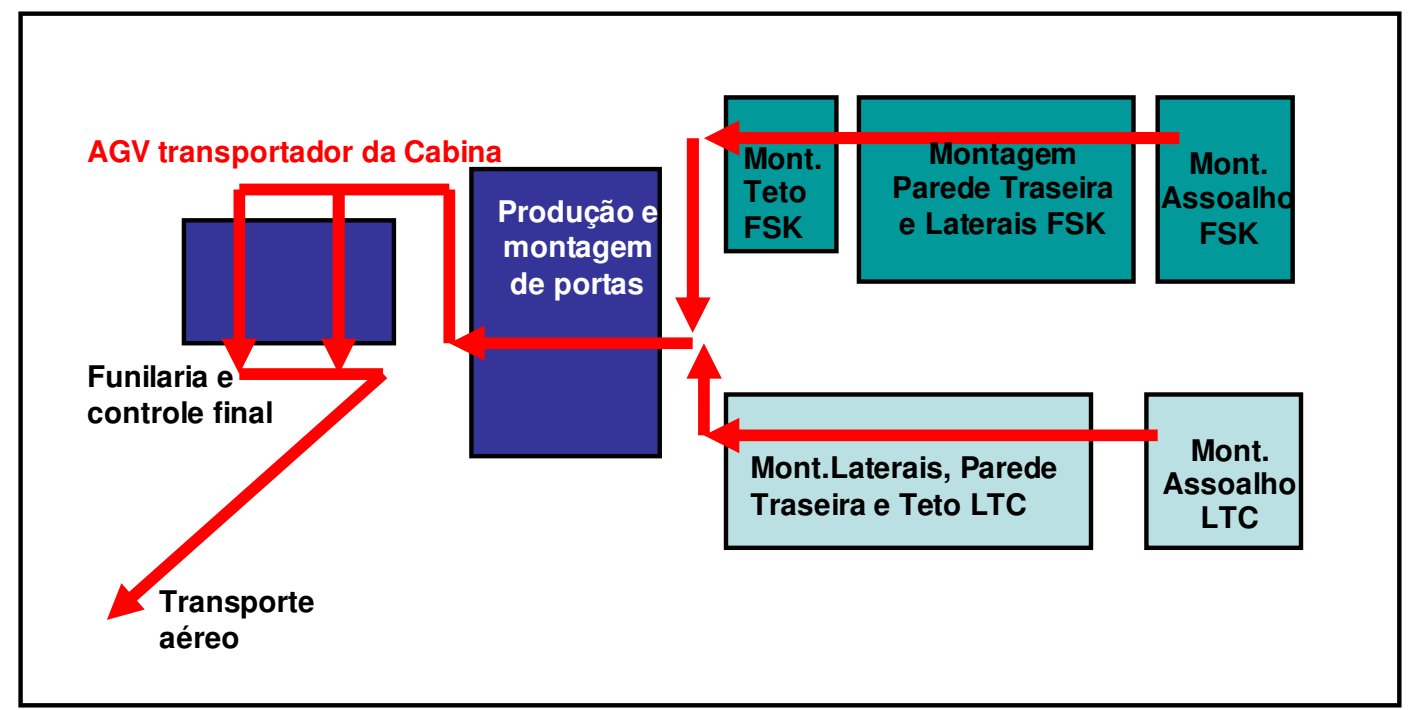

Figura 3.2: Diagrama de blocos da produção das cabinas LTC e FSK

A figura 3.2 mostra um diagrama de blocos do sistema novo de produção de cabinas brutas dos veículos FSK e LTC, denominada Neu Rohbau (Nova Montagem). Nessa área, a linha de produção é altamente automatizada e com poucos operadores. Cada tipo de cabina é montada em dois conjuntos de células de montagem, dispostas em paralelo, que se agrupam antes da célula de montagem das portas. Não existem estoques intermediários de cabinas entre os postos de trabalho da linha Nova Rohbau, e toda a movimentação das cabinas no processo é realizada via AGV (Automated Guided Vehicles).

Os dados de processo para essa linha são menos acessíveis, pois ela opera de forma intermitente durante o turno de trabalho e muitas etapas estão em fase de projeto ou try-out. As informações abaixo mostram as características gerais dessa etapa:

\section{Características gerais:}

- Alto nível de automação, pois é uma linha nova baseada em um novo conceito.

- Devido à baixa demanda dos produtos montados, a linha opera em apenas um turno de produção.

- Tempos de lead e takt dos processos de cada modelo de cabina determinados de acordo com a quantidade de cabinas a serem produzidas diariamente. 
- Difícil aquisição de dados, devido à falta de rotina nos processos; mesmo assim, foi possível obter informações sobre paradas e falhas nas linhas.

- Não existem restrições quanto à ordem de produção das diferentes cabinas.

- A análise dos processos foi dividida apenas nas células macro, ou seja, não foram analisados os processos internos e as submontagens das células.

- O ritmo de produção é empurrado, pois não ocorre a verificação do estado das etapas seguintes de todo o processo, e o volume produzido é determinado por um cálculo diário.

\section{Linha montagem cabina bruta modelo FSK:}

- Três células de produção: uma para montagem do assoalho, outra para a parede traseira e uma última para parede frontal em conjunto e, por último, do teto.

- Para cada célula, existem processos de produção de cada componente maior, ou seja, na célula assoalho, por exemplo, ocorrem subprocessos para a montagem de todo o assoalho e da mesma forma para as outras células.

- Utilização de robôs de alta performance, com alto nível de flexibilização e trocas automáticas de ferramentas.

- O assoalho é colocado sobre um AGV, que avança sobre as células seguintes, onde serão montadas as outras partes da cabina até a liberação, no transportador aéreo.

- A figura 3.3 ilustra algumas das etapas. 


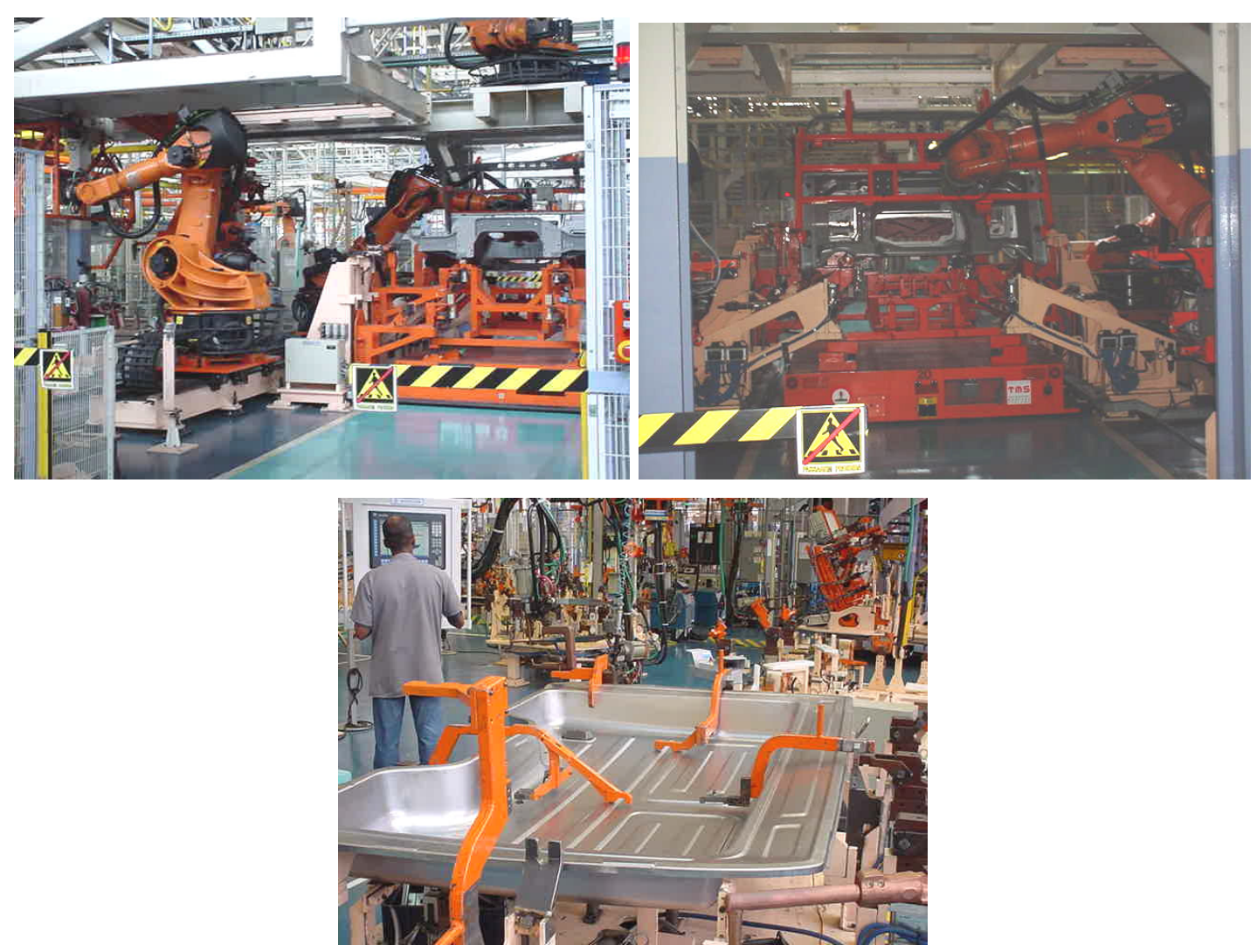

Figura 3.3: Montagem das paredes frontal e traseira das cabinas FSK.

\section{Linha montagem cabina bruta modelo LTC:}

- Duas etapas básicas de produção: Assoalho e linha de montagem das demais partes.

- A etapa assoalho também contém os subprocessos para montagem dos componentes do assoalho.

- A montagem das demais partes ocorre em uma linha de seis postos de trabalho, e nela são montadas as partes restantes (parede traseira, frontal e teto), no assoalho sobre o AGV. Em cada etapa dessa linha de montagem existem postos de trabalho paralelos para fabricação dos subcomponentes e das submontagens.

- O assoalho é colocado no AGV, que transporta a cabina durante todos os processos até a liberação no transportador aéreo.

- A Figura 3.4 apresenta a etapa de montagem do assoalho e das outras partes da cabina. 

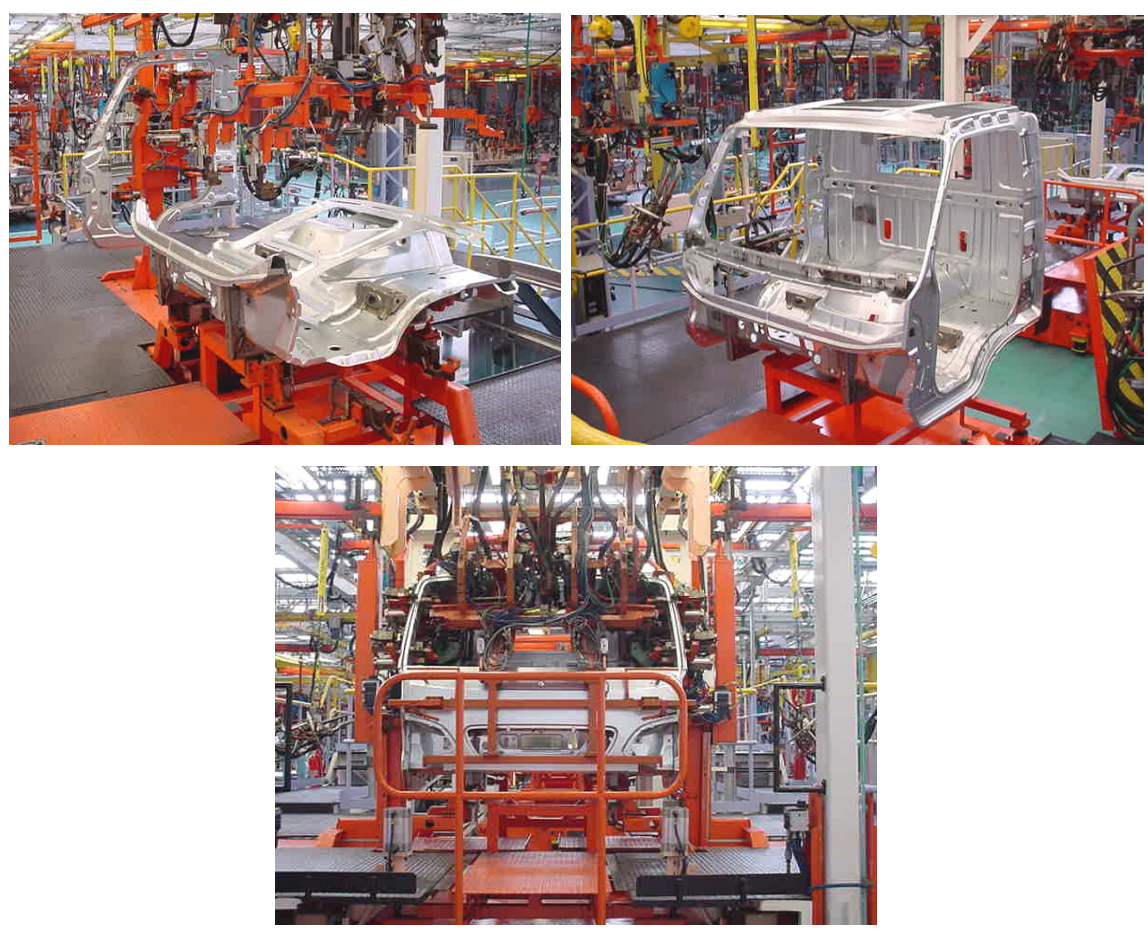

Figura 3.4: Montagem da cabina bruta LTC.

\section{Linha de montagem de portas das cabinas modelo LTC e FSK:}

- As cabinas provenientes das duas linhas anteriores (FSK e LTC) juntamse, nessa etapa.

- Três estações de trabalho.

- Pequena área de acumulação de cabinas na entrada da linha.

- Conjunto porta é montado em células paralelas e depois montado nas cabinas.

- A Figura 3.5 ilustra a etapa da montagem das portas.
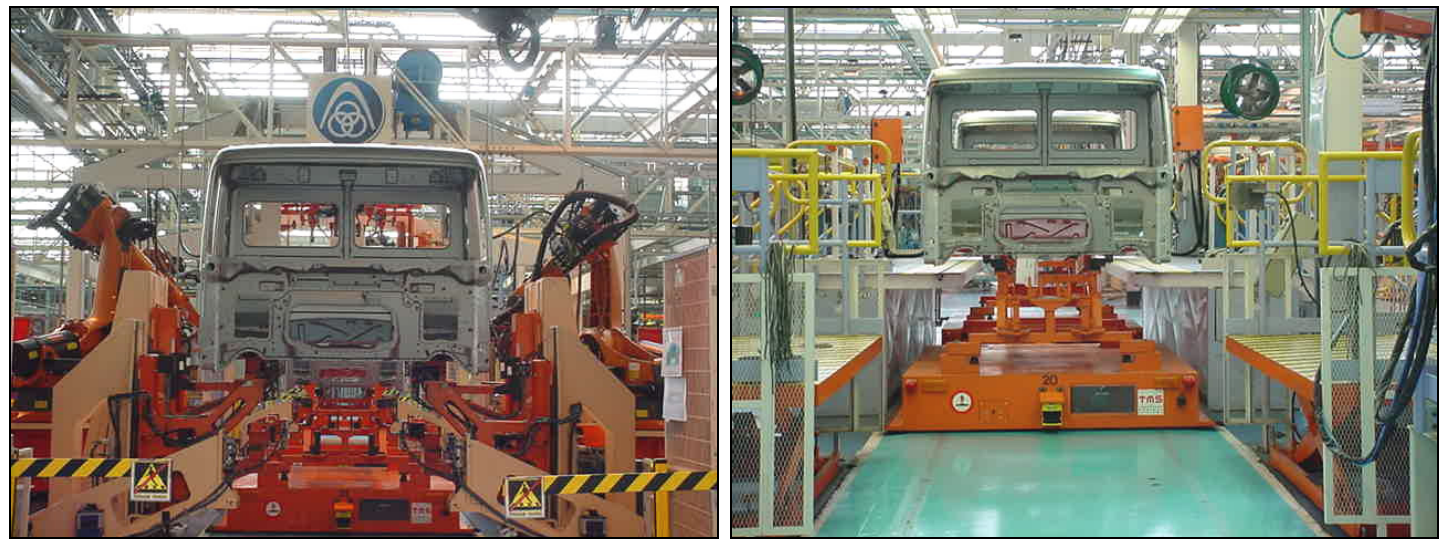

Figuras 3.5: Montagem das portas das cabinas LTC e FSK. 
Postos de inspeção final e funilaria:

- Dois postos de trabalho paralelos.

- Pequena área de acumulação de AGV na entrada dos postos.

- Gargalo da etapa Nova Rohbau de produção, devido às falhas nas cabinas advindas das irregularidades do processo.

- Foi realizado recentemente um estudo do tempo de processo na funilaria, e os dados obtidos geraram tabelas estatísticas que foram disponibilizadas para este estudo.

- A Figura 3.6 mostra os dois postos da Funilaria da Nova Rohbau.
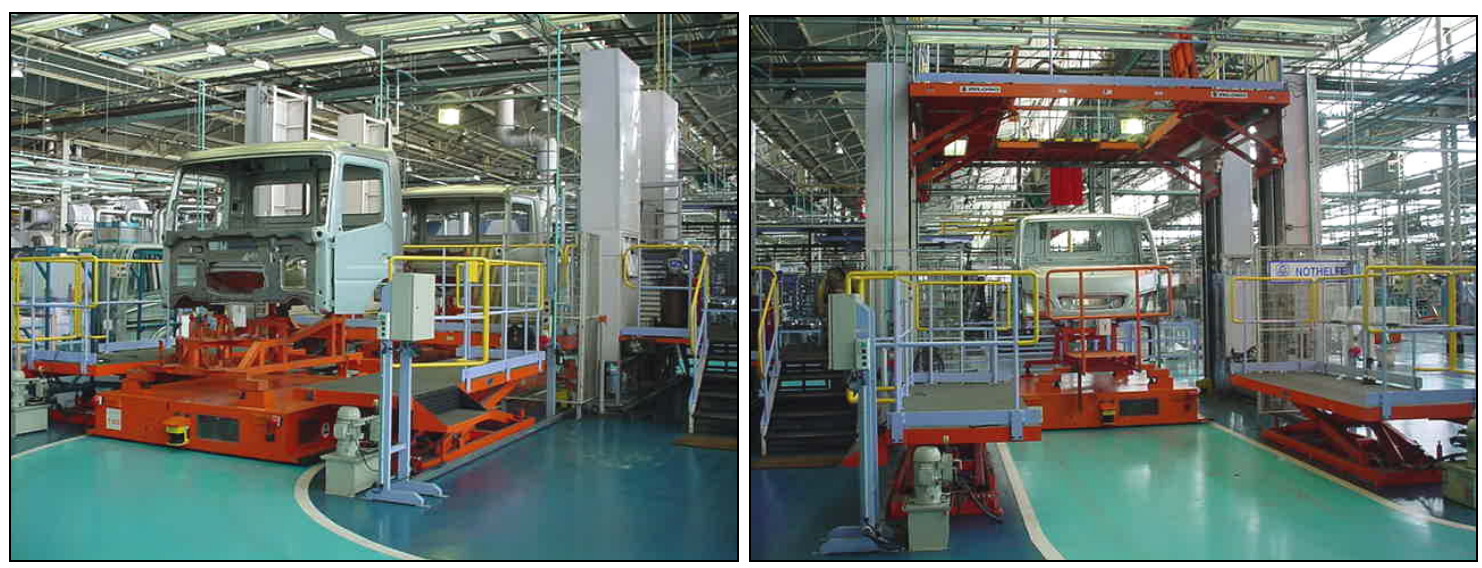

Figuras 4.6: Estações de funilaria das cabinas LTC e FSK.

3.7.2 Produção das cabinas brutas HPN, L98, HSK e HPN, - Rohbau (B - figura 3.1) 


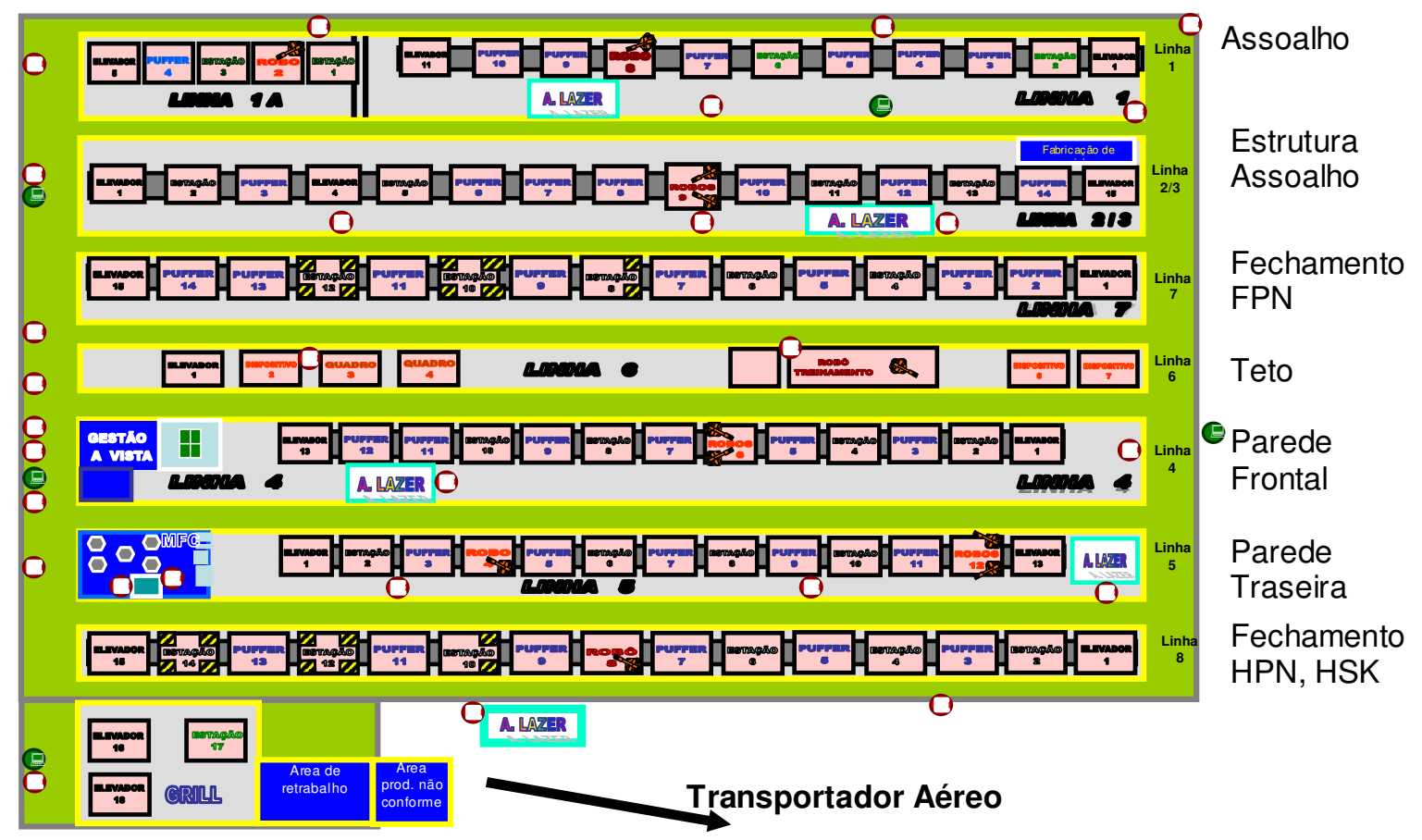

Figura 3.7: Diagrama das etapas da produção da Rohbau.

A área $\mathrm{B}$ da figura 3.1 refere-se à produção das cabinas brutas dos modelos HPN, HSK, LN, FPN e L98, que está detalhada na figura 4.6 e que é denominada Rohbau. Nessa área, as linhas de produção são mais antigas, com diversas estações, muitos operadores e um baixo nível de automatização. Da mesma forma que na Nova Rohbau, não existem filas intermediárias entre os postos de trabalho na linha. Essa área possui duas seqüências diferentes para os processos de montagem, em que o primeiro se refere à produção das cabinas HPN, HSK e LN (Figura 3.8), e o segundo, à produção das cabinas FPN e L98 (Figura 3.9).

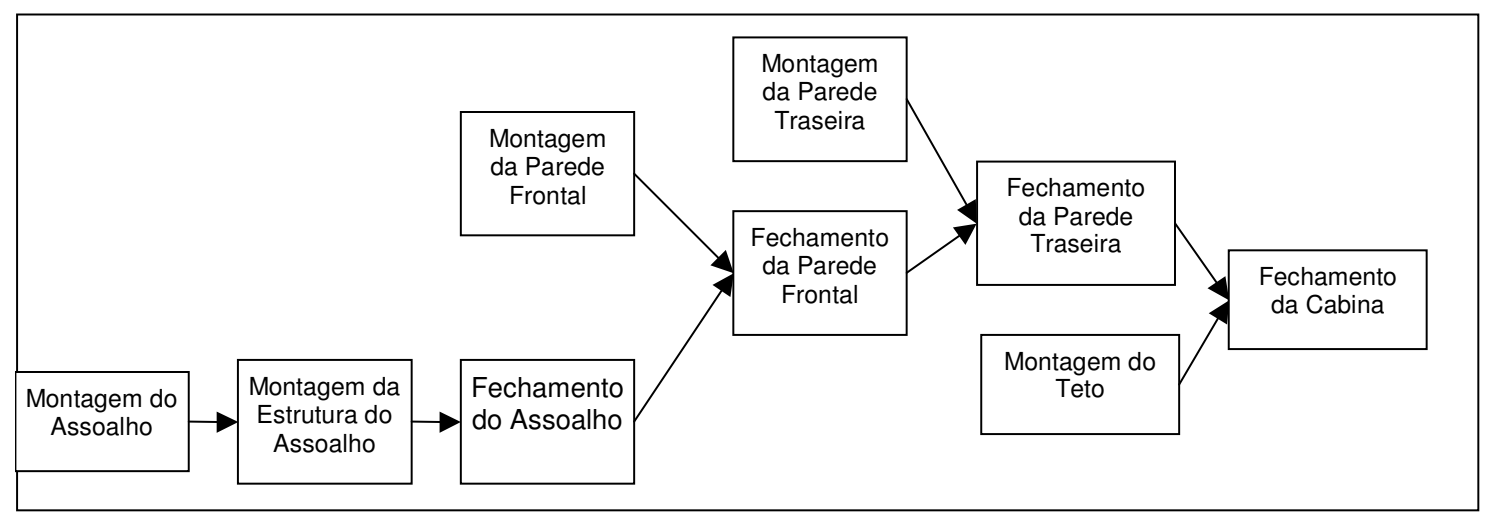

Figura 3.8: Fluxo de Processo das Cabinas HPN, HSK e LN. 


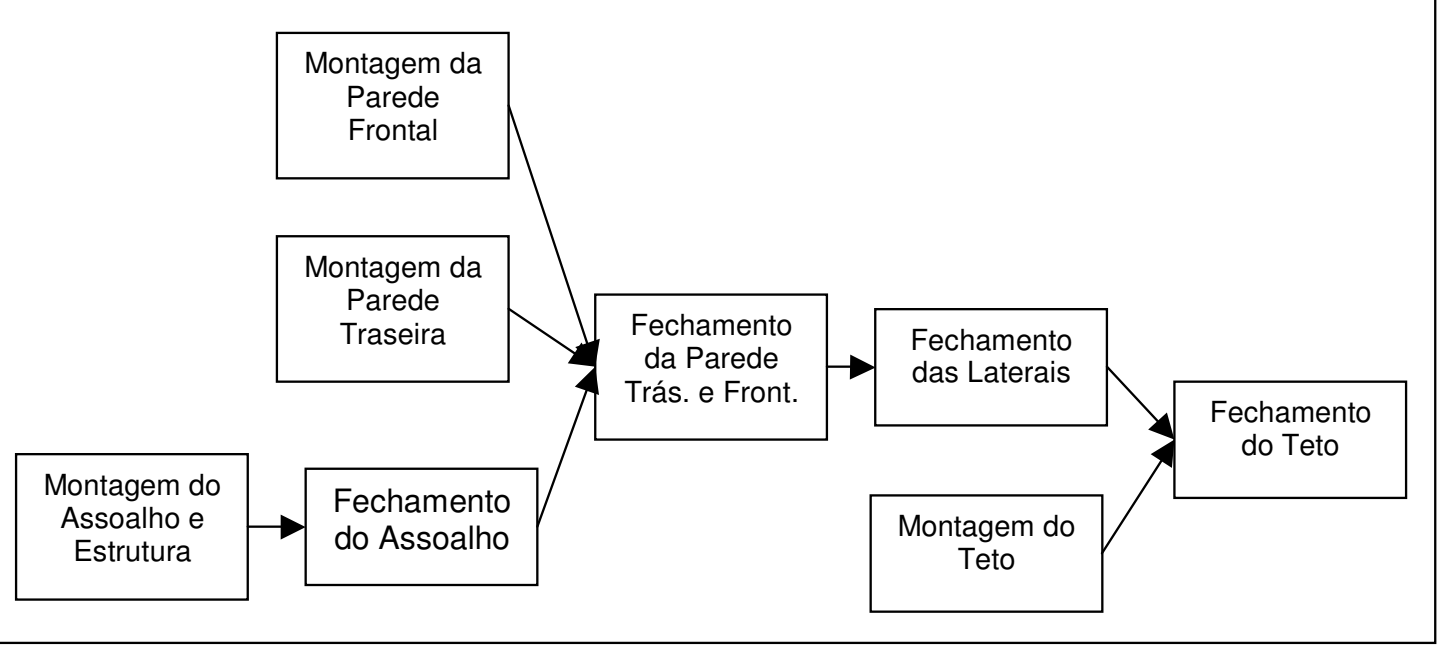

Figura 3.9: Fluxo de Processo das Cabinas FPN e L98

Para cada um desses blocos existe uma linha de montagem com diversos postos de trabalho e diversos operadores. As principais características dessas linhas são:

Características gerais:

- O takt time da linha é determinado pelo número de cabinas a serem produzidas no dia. No entanto, existe um limite máximo de cabinas, e alguns postos trabalham perto desse limite de capacidade.

- O transporte entre as linhas das partes das cabinas é realizado por linhas de transportadores aéreos sobre as linhas de montagem.

- A distribuição de materiais e peças a serem usadas nas montagens é realizada por AGV de distribuição.

- As cabinas são transportadas ao longo das linhas através de Skids, que ficam solidários à cabina por quase todo o processo de montagem.

- Existe uma separação entre as linhas, para montagem de cabinas do modelo FPN e L98 e para os demais modelos.

- É feita uma reprogramação na seqüência das cabinas a serem produzidas, quando muitas cabinas grandes são seqüenciadas em seguida, pois existem restrições na capacidade de produção de alguns postos de trabalho. 
- A produção é da mesma forma que na Nova Rohbau, empurrada de acordo com quantidades predeterminadas, e não se verifica a necessidade das cabinas ao fim do processo, o que pode resultar no bloqueio do sistema.

- Os operários alimentam um banco de dados com a ocorrência e a duração das paradas das linhas por manutenção, falta de peça ou retrabalho, e são geradas tabelas mensais com esses dados. No entanto, a alimentação não é muito confiável.

- Nos tópicos que seguem serão descritas as linhas que compõem a Rohbau.

\section{Linha 1 (Figura 3.7):}

- Montagem do assoalho para os modelos HPN, LN1 e HSK.

- Linha constituída por quatro postos de trabalho, dois elevadores e seis postos pulmão, ou para algum trabalho extra.

- Não é possível fazer o seqüenciamento de 3 cabinas grandes seguidas, pois a linha não tem capacidade de produção, e o tempo máximo de processo seria ultrapassado.

- Seis operadores para todos os postos.

- As peças são movimentadas ao longo do processo em cima de Skids (bases para transporte), retornáveis após a última operação.

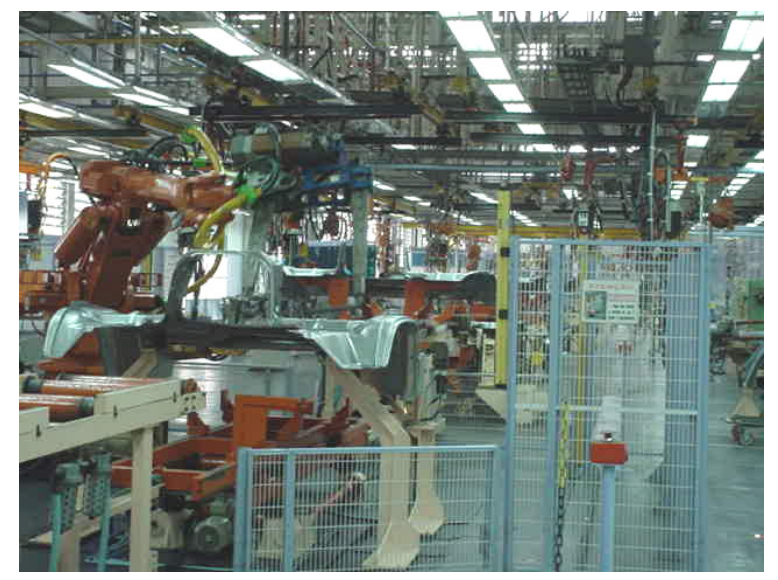

Figura 3.10: Linha 1, Rohbau

Linha 1A (Figura 3.7): 
- Montagem da estrutura do assoalho e do assoalho para os modelos FPN e L98.

- Célula constituída por 4 postos de trabalho e um elevador.

- Quantidade de operadores: 7 (para todos os postos). Esses operadores também trabalham na linha 2/3.

- O skid utilizado na última estação acompanha o assoalho até o final da montagem da cabina.

- Devido à menor quantidade de cabinas desse modelo a serem montadas, são necessários menos postos de trabalho para a montagem do assoalho em conjunto com a estrutura, mas o tempo de cada etapa é maior.

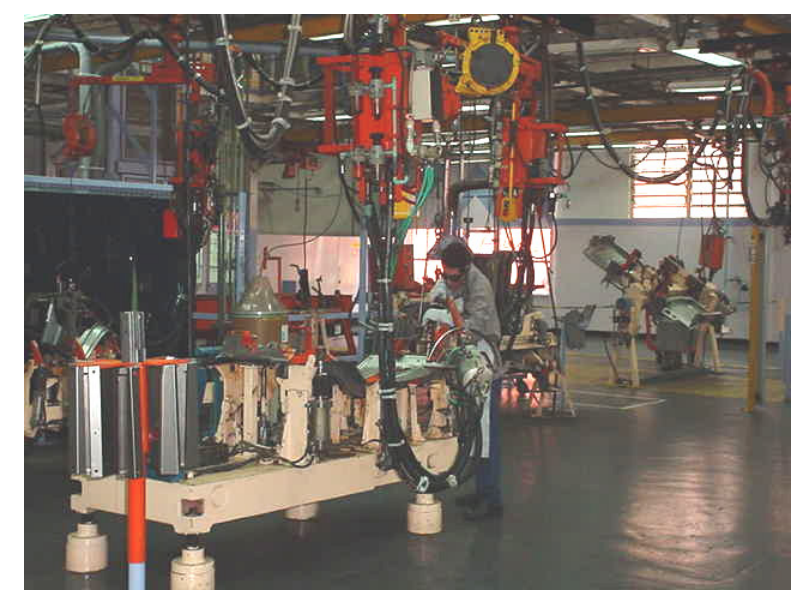

Figura 3.11: Linha 1A Rohbau

\section{Linha 2/3 (Figura 3.7):}

- Montagem da estrutura inferior do assoalho dos modelos HPN, LN1 e HSK.

- As operações principais são: a montagem das longarinas e travessas da estrutura inferior do assoalho e a soldagem da estrutura inferior ao assoalho.

- A linha é composta por cinco postos de trabalho, três elevadores e sete postos para pulmão ou trabalho extra.

- Ao início da linha, as longarinas da estrutura são colocadas sobre um Skid, que acompanha o assoalho até o final da montagem da cabina, ou seja, ao longo de todo o processo. 


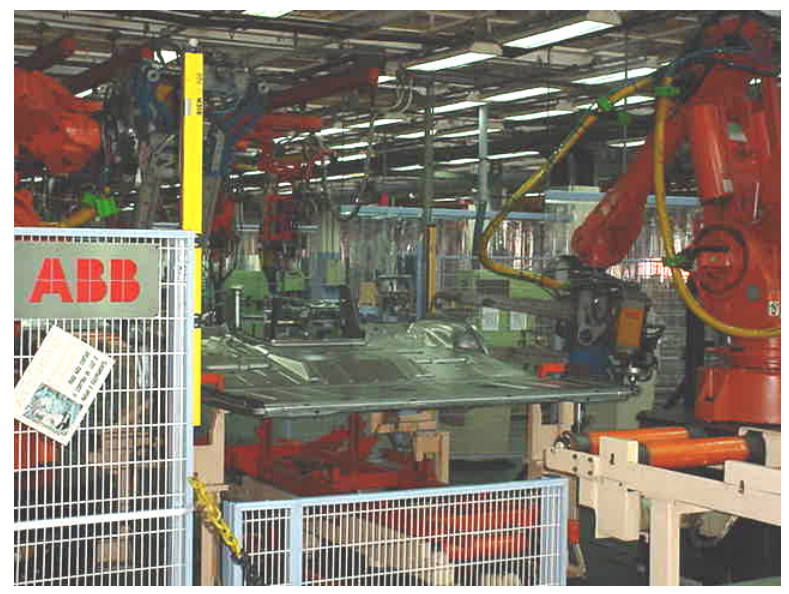

Figura 3.12: Linha 2/3 Rohbau

\section{Linha 4 (Figura 3.7):}

- Montagem da parede frontal de todos os modelos de cabina.

- Essa linha é composta por cinco postos de trabalho, dois elevadores e oito postos pulmão ou trabalho extra.

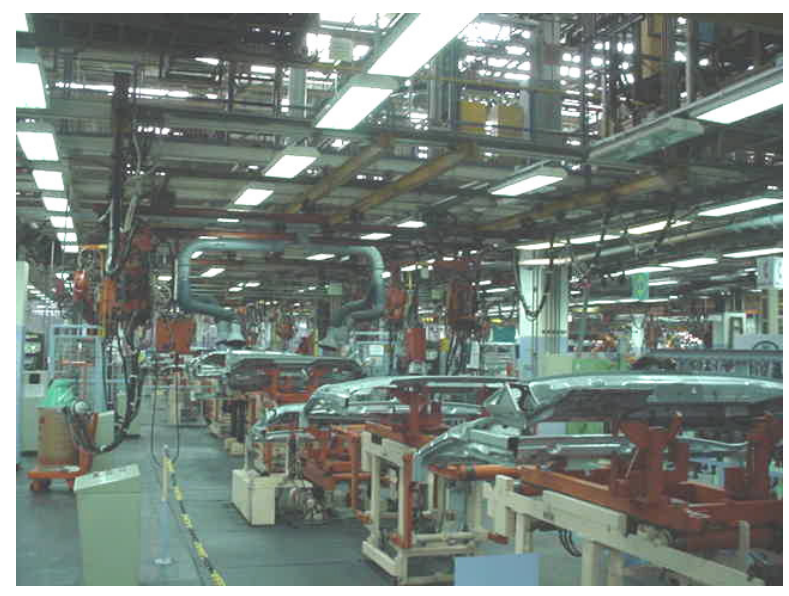

Figura 3.13: Linha 4 Rohbau

\section{Linha 5 (Figura 3.7):}

- Montagem da parede traseira de todos os modelos de cabina.

- Linha composta por seis postos de trabalho, dois elevadores e sete postos pulmão ou trabalho extra.

- As linhas 4 e 5 são as linhas gargalo da Rohbau, pois trabalham no ritmo de produção de todas as cabinas e têm a maior quantidade de postos de trabalho. 


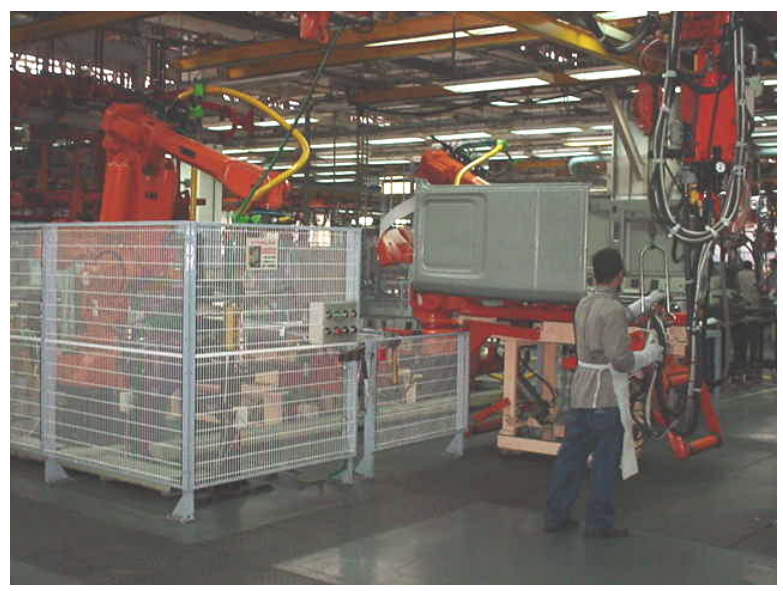

Figura 3.14: Linha 5 Rohbau

Linha 6 (Figura 3.7):

- Montagem do teto de todos os modelos de cabina.

- Quatro estações de trabalho e um elevador.

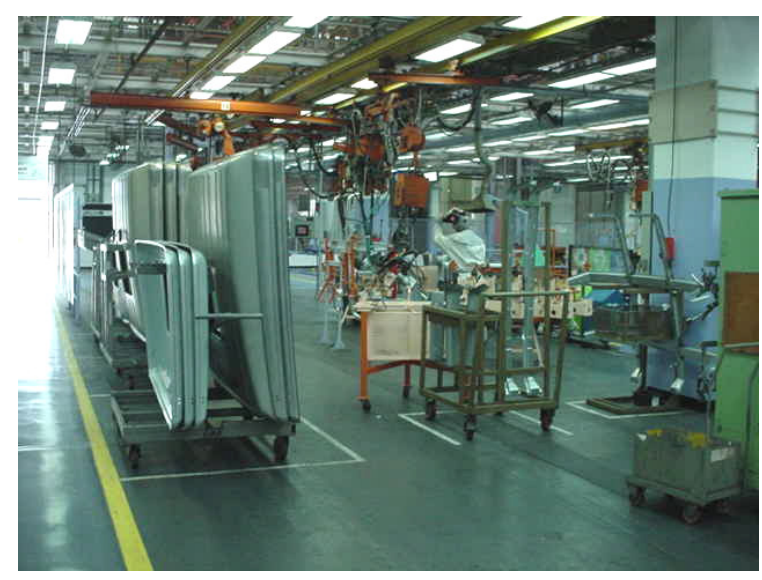

Figura 3.15: Linha 6 Rohbau

\section{Linha 7 (Figura 3.7):}

- Essa linha recebe o assoalho, a parede traseira, a parede frontal e o teto das cabinas dos modelos L98 e FPN, para que a cabina possa ser fechada, de acordo com o fluxograma da Figura 3.9.

- Esta é a linha de fechamento mais antiga e lenta, se comparada à linha 8, e, por isso, produz um único modelo.

- Dividida em 3 trechos: 
Trecho 1: Fechamento do assoalho.

- Um elevador, um posto de trabalho e um pulmão.

Trecho 2: Fechamento da parede traseira e frontal.

- Um posto de trabalho com elevador para a descida da parede traseira e frontal e mais um posto de trabalho com dois postos de trabalho extra.

Trecho 3: Fechamento do teto e da cabina.

- Três postos de trabalho para a descida do teto e o fechamento da cabina, quatro postos de trabalho extra e um elevador para a subida da cabina fechada.

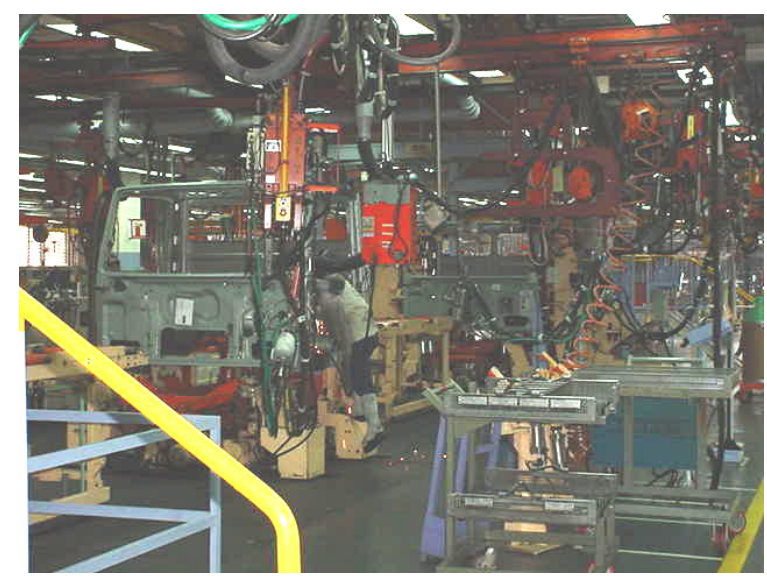

Figura 3.16: Linha 7 Rohbau

\section{Linha 8 (Figura 3.7):}

- Essa linha recebe o assoalho, a parede frontal, a parede traseira e o teto das cabinas dos modelos HPN, HSK e LN, para que a cabina possa ser fechada, de acordo com o fluxograma da Figura 3.8.

- Essa é a linha de fechamento mais moderna e, portanto, mais rápida; por isso fecha tantos veículos.

- Dividida em 4 trechos:

Trecho 1: Fechamento do Assoalho

- Um elevador, um posto de trabalho e um posto de trabalho extra.

Trecho 2: Fechamento da Parede Frontal

- Um posto de trabalho com elevador para descida da parede frontal e um posto de trabalho extra.

Trecho 3: Fechamento da Parede Traseira 
- Um posto com elevador para descida da parede traseira e montagem, um outro posto de trabalho e dois postos para trabalho extra.

Trecho 4: Fechamento da Cabina

- Três postos de trabalho para descida do teto e fechamento total da cabina, dois postos de trabalho extra e um elevador para subida da cabina.
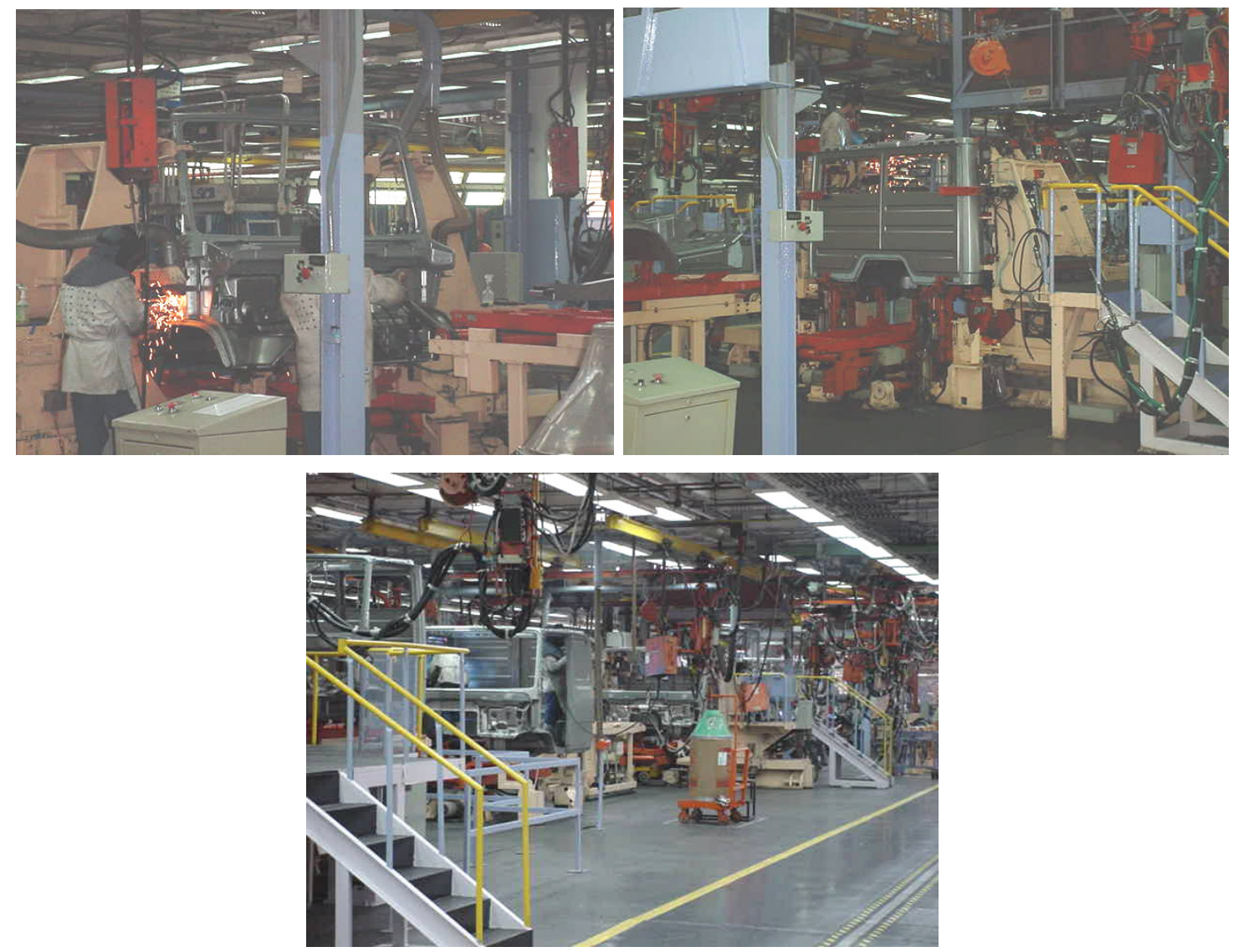

Figura 3.17: Fotos Linha 8 Rohbau

Linha Grill (Figura 3.7):

- Depois de fechadas, todas as cabinas são intercaladas em um transportador aéreo e descem para a linha Grill.

- Nessa etapa são feitos os controles visuais da cabina e a marcação do número de série, além de ocorrer um processo de solda especial por baixo da cabina.

- São três estações de trabalho e, nessa etapa, a cabina pode ser retirada, para algum retrabalho maior. 


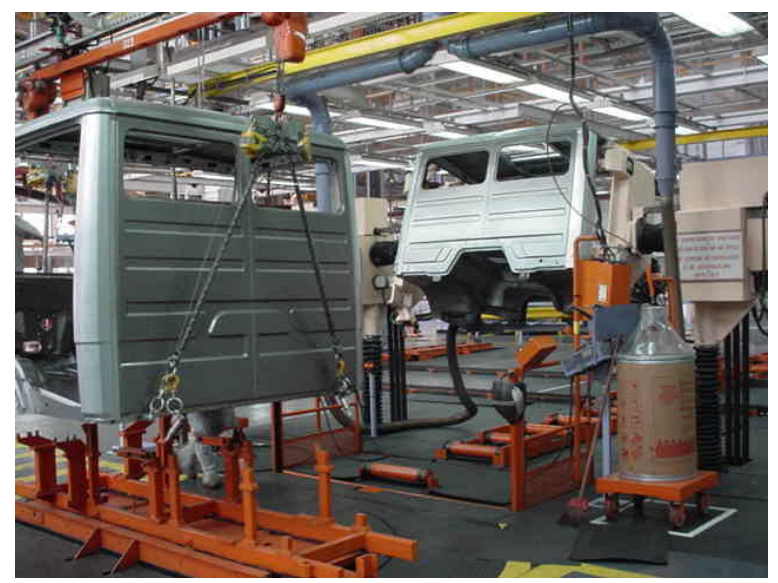

Figura 3.18: Linha Grill Rohbau

\section{Linha Funilaria e Montagem de portas:}

- 5 postos de trabalho: lixamento, montagem de portas, funilaria, controle, retirada para transportador aéreo.

- Existem tabelas estatísticas com os tempos dessa etapa, já que não dependem da quantidade de cabinas, e sim da qualidade do processo.
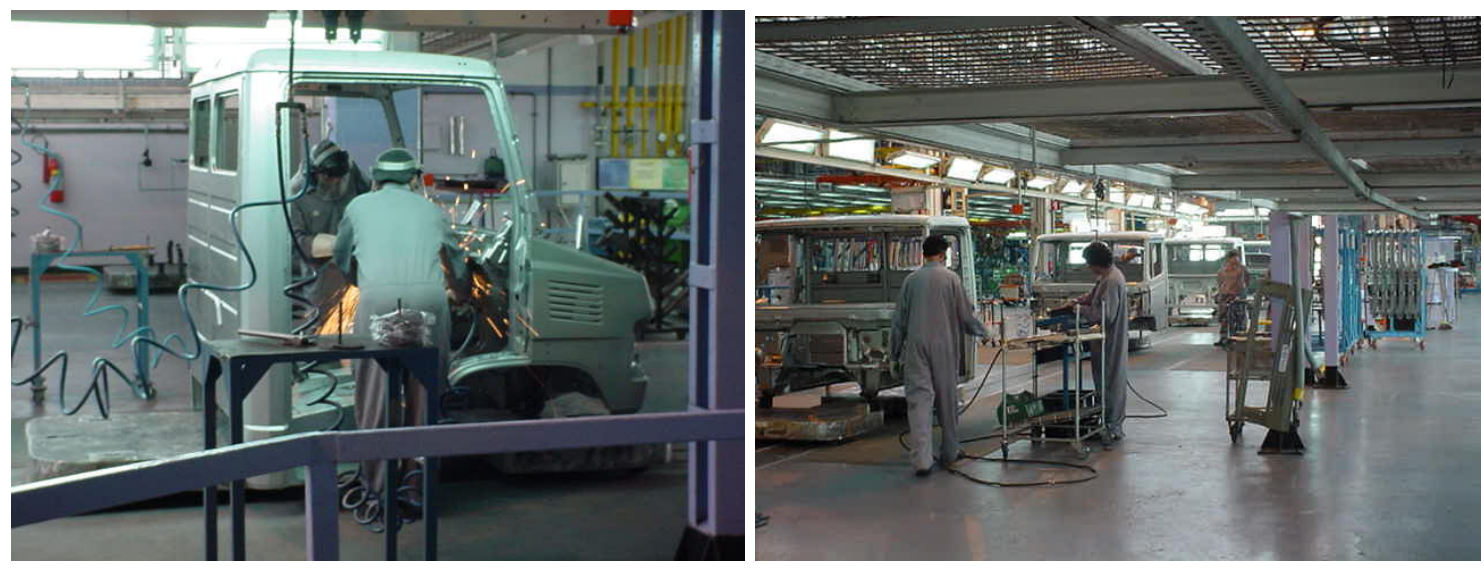

Figura 3.19: Funilaria Rohbau

\subsubsection{Transportador aéreo (T Figura 3.1)}




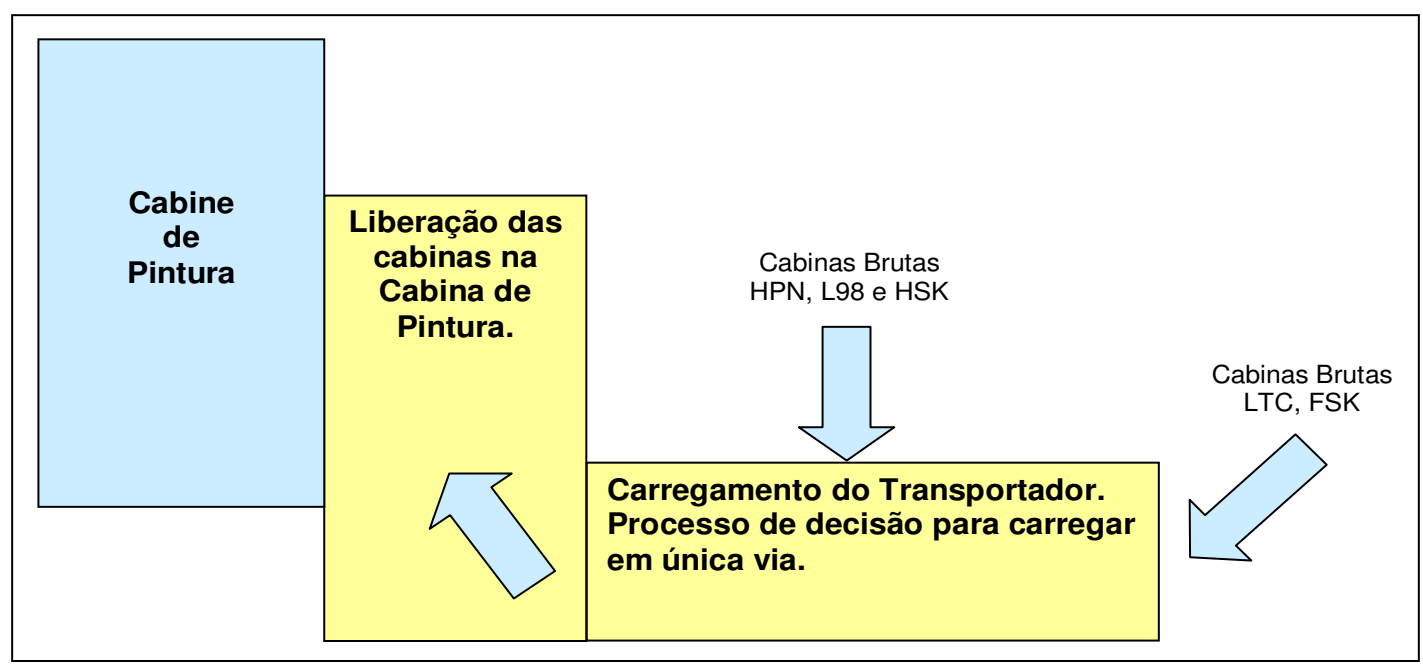

Figura 3.20. Diagrama dos processos do Transportador Aéreo

O Transportador Aéreo interliga as etapas da montagem bruta das cabinas e a pintura das cabinas. Dessa forma, ele interliga dois prédios de processos.

Essa etapa é importante, porque todos os tipos de cabinas advindas da montagem bruta são transportados para a pintura por uma via única. A ordem de transporte das cabinas é de acordo com a chegada, sem preocupação com a seqüência em que elas foram produzidas ou com a seqüência em que serão montadas nos caminhões.

O Transportador aéreo é um transportador acumulativo, e podem ser retiradas algumas cabinas para auditoria, na entrada dessa etapa. A Figura 3.21 mostra detalhes do transportador aéreo. 

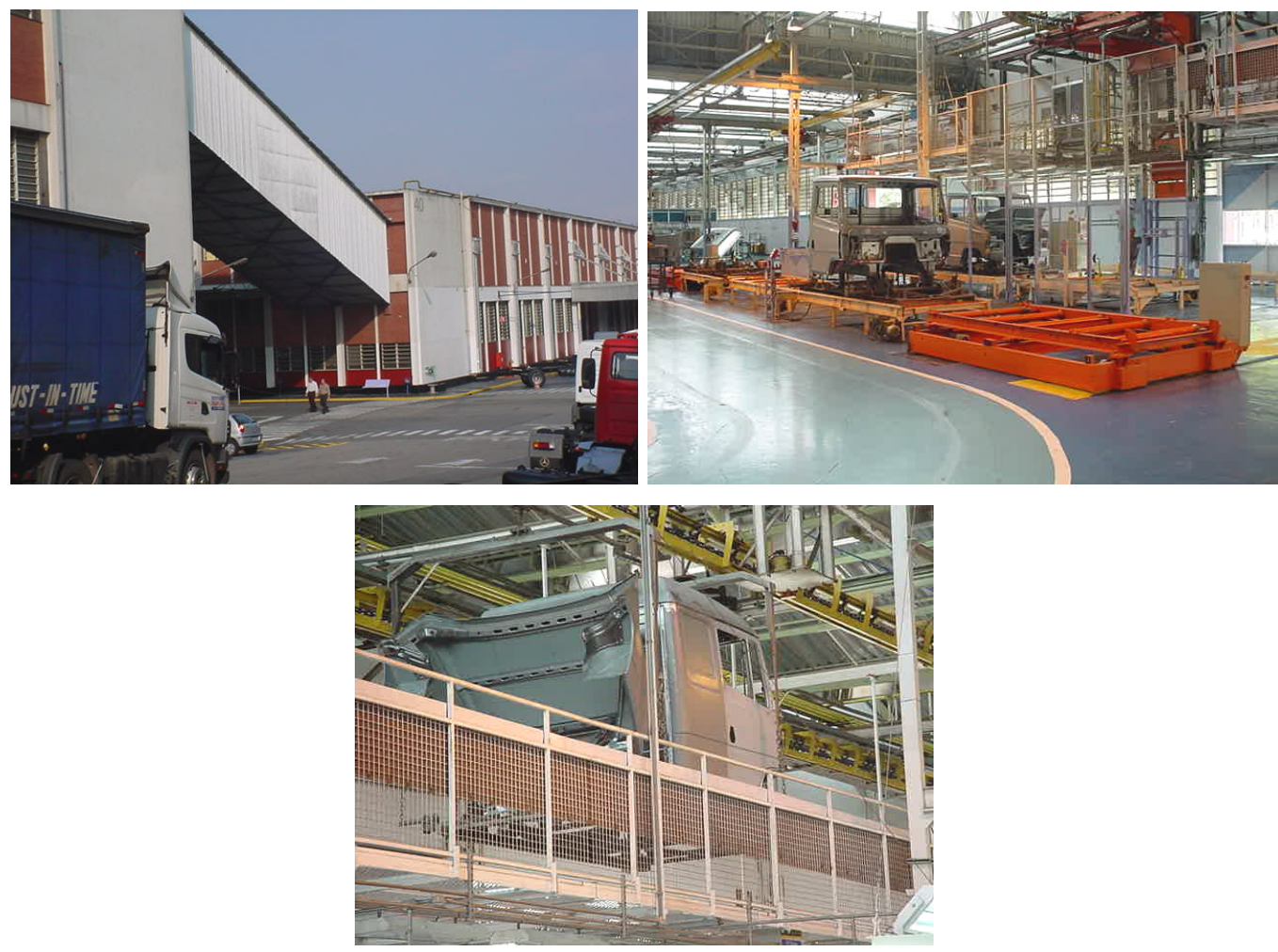

Figura 3.21: Fotos do Transportador Aéreo

\subsubsection{Preparação e Pintura das cabinas (D figura 3.1)}

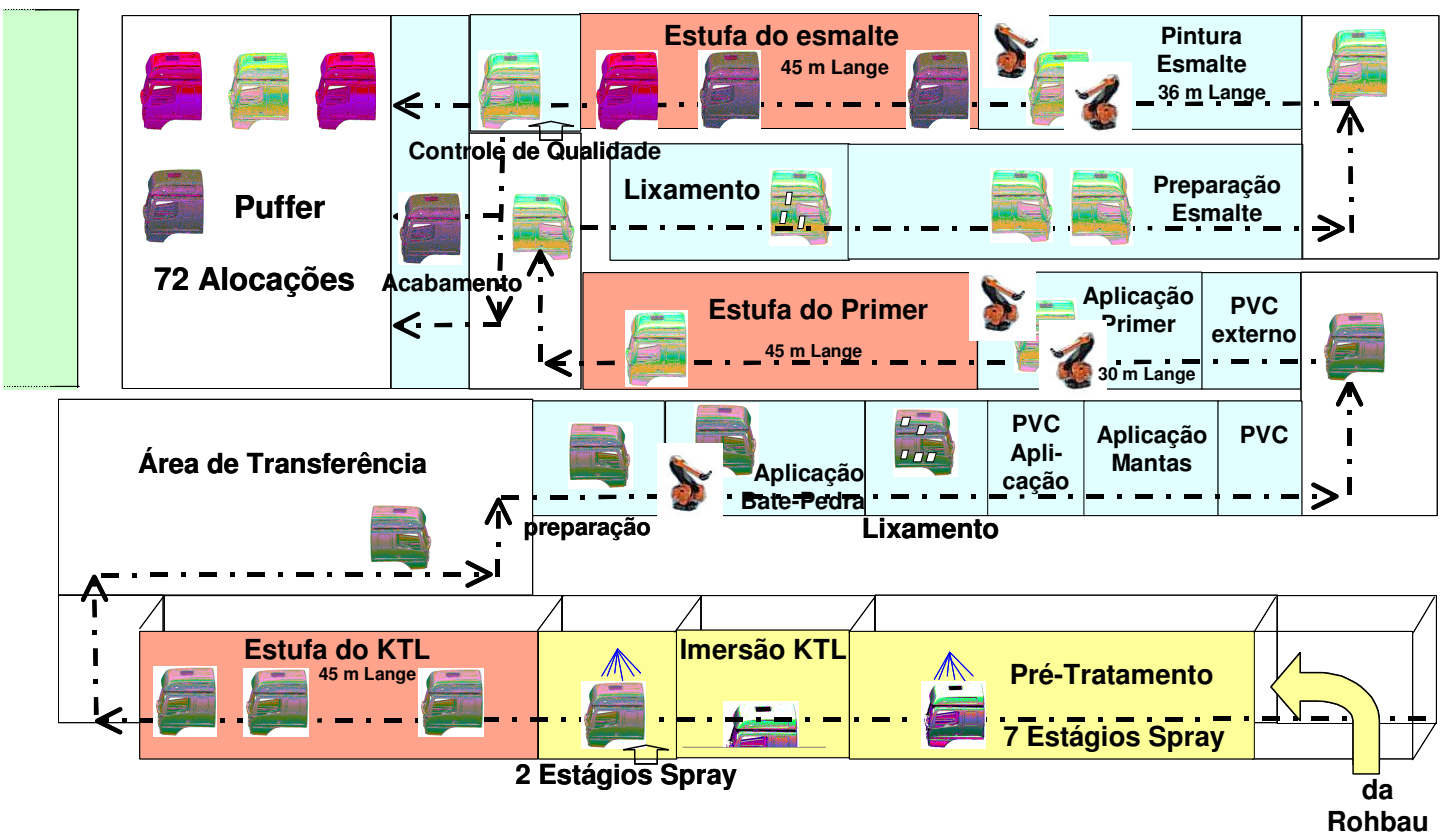

Figura 3.22: Diagrama dos processos de preparação e pintura 
A pintura segue os processos encontrados na maioria das indústrias automotivas de pintura de carroçarias e cabinas. As cabinas advindas da montagem bruta, pelo transportador aéreo, passam em uma única seqüência pelos processos de pintura. Os diversos processos consecutivos necessários para a pintura da cabine são divididos da seguinte forma:

Tipos de processos e características gerais:

- Limpeza e lavagem das cabinas com sete postos de trabalho.

- Aplicação de KTL (kataphoretische Tauchlackierung) ou pintura catódica de imersão, com três postos de trabalho.

- Estufa do KTL com capacidade para 6 cabinas simultaneamente.

- Área de transferência para movimentação das cabinas e com espaço para acumulação de 15 cabinas. Serve como pulmão.

- Aplicação de mantas e preparação para Bate-Pedra, com sete postos de trabalho.

- Aplicação da proteção "Bate-Pedra" por Robô, com linha de retorno para retrabalho e com três postos de trabalho.

- Lixamento, aplicação de mantas da vedação de PVC e preparação para Primer, com oito postos de trabalho.

- Aplicação de Primer, com utilização de robô ou manual, com nove postos de trabalho.

- Estufa do Primer, com capacidade para 5 cabinas.

- Processo de Pintura do Esmalte:

- Manual ou automatizada, dependendo da cor e do acabamento;

- $85 \%$ da produção em três cores básicas (branca - 60\%, azul - 20\% e vermelha $-20 \%$ do subtotal).

- $15 \%$ da produção em diversas cores especiais.

- Diversas trocas de cor durante o dia, com perda de tinta e maior tempo de processo;

- Maior incidência de retrabalho, principalmente nas cores especiais (média de 10\%).

- 11 postos de trabalho, entre preparação e pintura manual.

- Estufa da pintura esmalte, com capacidade para 5 cabinas. 
- Posto de inspeção da qualidade da pintura. A inspeção é visual.

- Caso as cabinas apresentem pequenos problemas na pintura, existem 3 cabines em paralelo, para polimento, retoque e pequenos serviços. $O$ tempo de reparo varia de acordo com o tipo do problema.

- Caso as cabinas apresentem sérios problemas de pintura, o que não é incomum em cores especiais ou pintadas a mão, as cabinas vão para áreas de grande retrabalho, onde são lixadas e repintadas na Pintura Esmalte, ou podem até passar novamente pela aplicação do Primer.

- Após as cabines de retrabalho, as cabinas são liberadas para o estoque seletivo de cabinas pintadas, o Puffer.

$\mathrm{Na}$ Figura 3.23, é possível visualizar alguns dos processos da pintura. 
a)
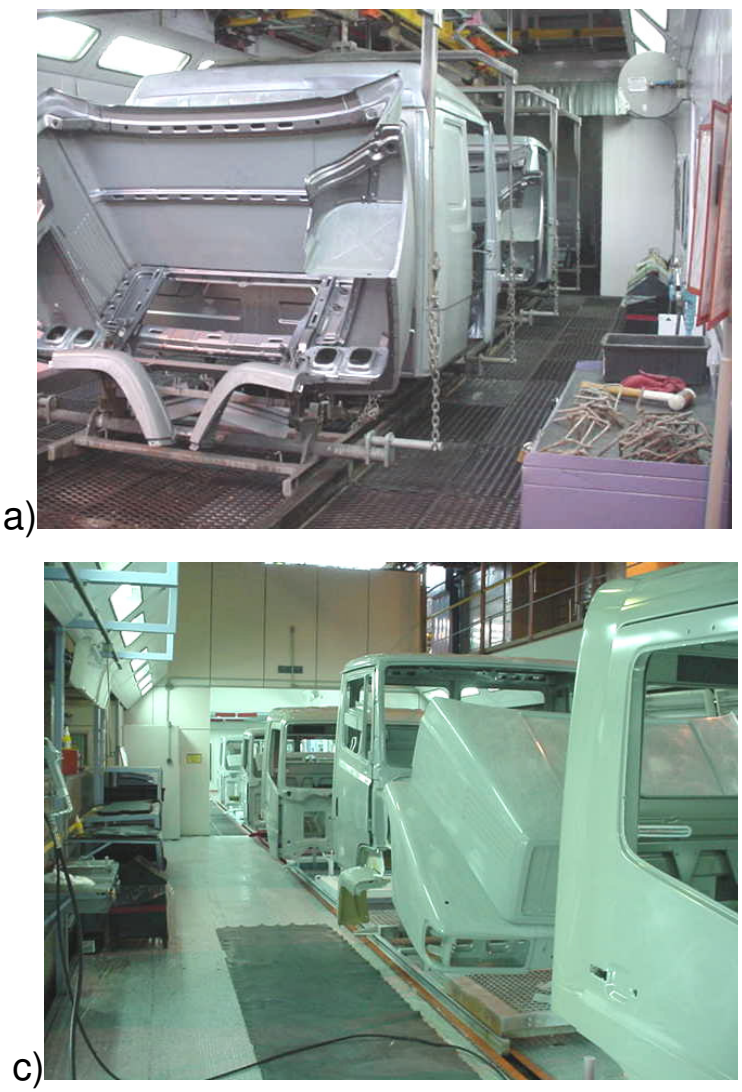

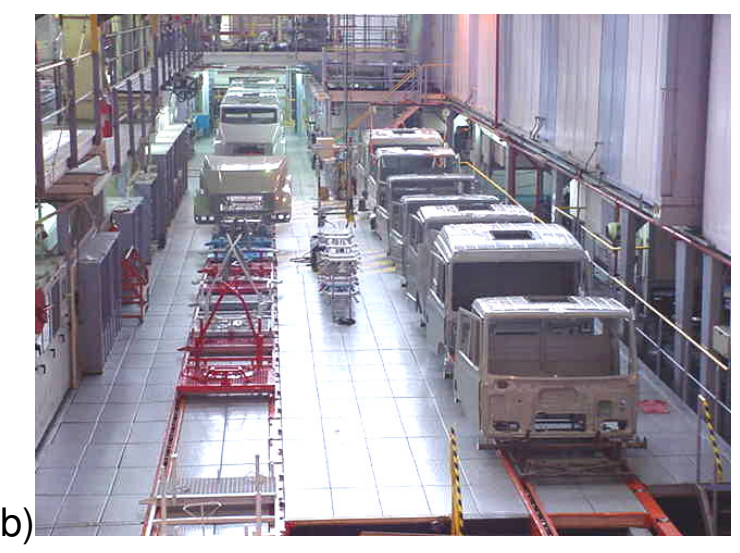

d)

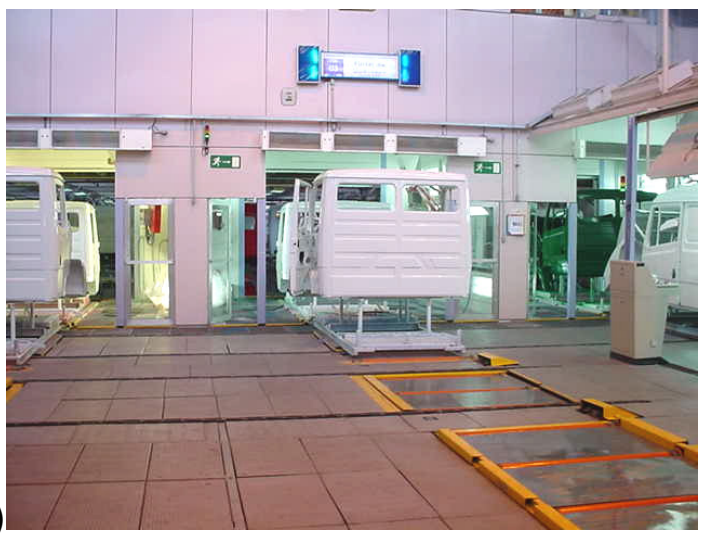

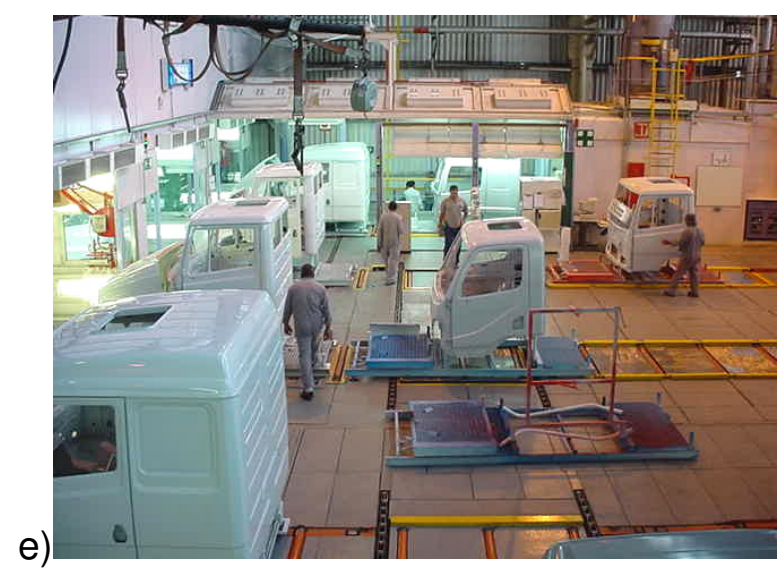

Figura 3.23: Fotos ilustrativas dos processos de Pintura: a) aplicação KTL; b) área de transferência; c) Primer, d) cabines de retrabalho; e) retrabalho nas cabinas

No caso da etapa pintura, os tempos do processo não são determinados de acordo com o nível a ser produzido, e sim de acordo com o tempo real do processo. Como são processos em seqüência, o processo gargalo determina o ritmo de toda a etapa pintura. Hoje, todo o conjunto de processos de pintura é a etapa gargalo de todo o sistema, devido à repintura de várias cabinas e aos processos lentos. 
Também ocorrem falhas e paradas dos processos, as quais são cadastradas em bancos de dados que foram utilizados durante o trabalho.

\subsubsection{Estoque de cabinas pintadas - Puffer (S1 figura 3.1)}

Após saírem da pintura, as cabinas são acumuladas, de acordo com a chegada, no estoque seletivo de cabinas pintadas, chamado de Puffer. Além de servir como pulmão para o processo, esse estoque tem como característica especial identificar qual cabina está em qual posição predeterminada do estoque. O estoque também tem a flexibilidade de movimentar as cabinas internamente e de retirar qualquer cabina armazenada em qualquer ordem. A principal função desse estoque é novamente corrigir a seqüência das cabinas advindas da pintura, em relação à seqüência predeterminada para a montagem final. Considerações sobre a formação e o comportamento da seqüência de montagem final no sistema serão feitas em um tópico no final deste capítulo.

Na Figura 3.24, algumas vistas do Puffer:
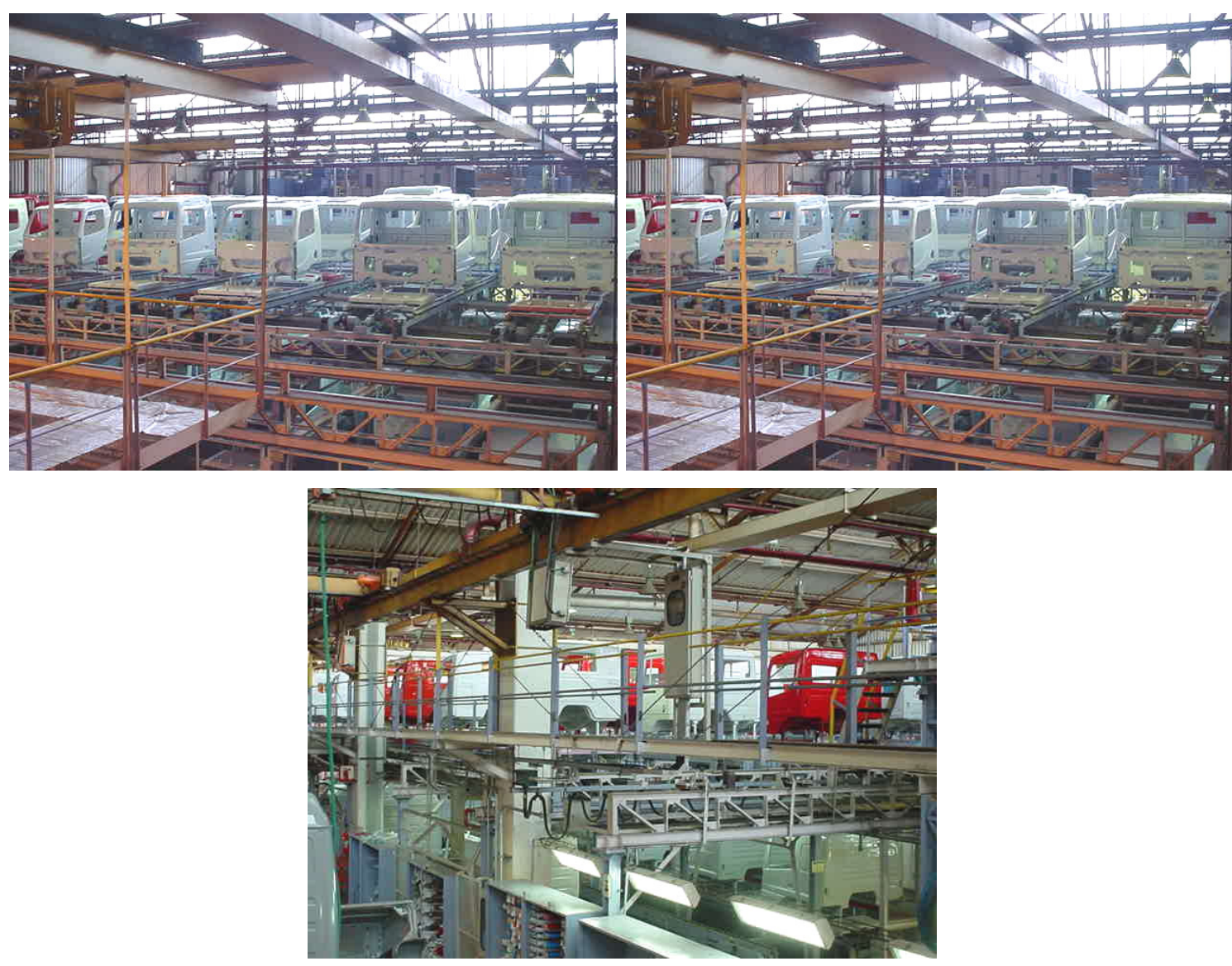

Figura 3.24: Vistas da disposição das cabinas no Puffer 
Para conseguir reordenar as cabinas, o estoque conta com um sistema de controle da posição das cabinas armazenadas e de comparação entre a seqüência prevista de saída do estoque e a seqüência de chegada das cabinas da pintura. De acordo com os resultados dessa comparação, as cabinas são movimentadas e retiradas do estoque. Caso não exista a cabina requerida, o sistema produz um alerta para que o usuário verifique onde está a cabina na pintura e, dependendo dos resultados, o usuário poderá alterar a seqüência de saída do Puffer. Essa comparação das seqüências é feita na entrada e na saída, para que a produção da etapa seguinte não pare por falta de cabina. Muitas vezes ocorre a saída de cabinas desse estoque sem estarem na seqüência correta. A Figura 3.25 mostra a tela do software de controle do Puffer.

Após saírem do estoque de cabinas pintadas, as cabinas vão para a montagem acabamento de cabinas.

\section{Características gerais do Puffer.}

- Capacidade máxima para 102 cabinas.

- Cabinas alocadas em estações móveis, dando total flexibilidade ao estoque.

- São alocadas, no máximo, 83 cabinas, para manutenção da flexibilidade.

- Existência de um controle de número de posições em que uma cabina chega atrasada ao estoque, sendo que o máximo permitido, para não alteração da seqüência de saída, é de 15 posições perdidas na entrada do estoque.

- No mínimo 40 cabinas devem estar no estoque, para garantir a correção da seqüência de saída.

- As cabinas são retiradas de acordo com a necessidade da linha na seqüência.

- Não se consegue corrigir toda a defasagem da seqüência. 


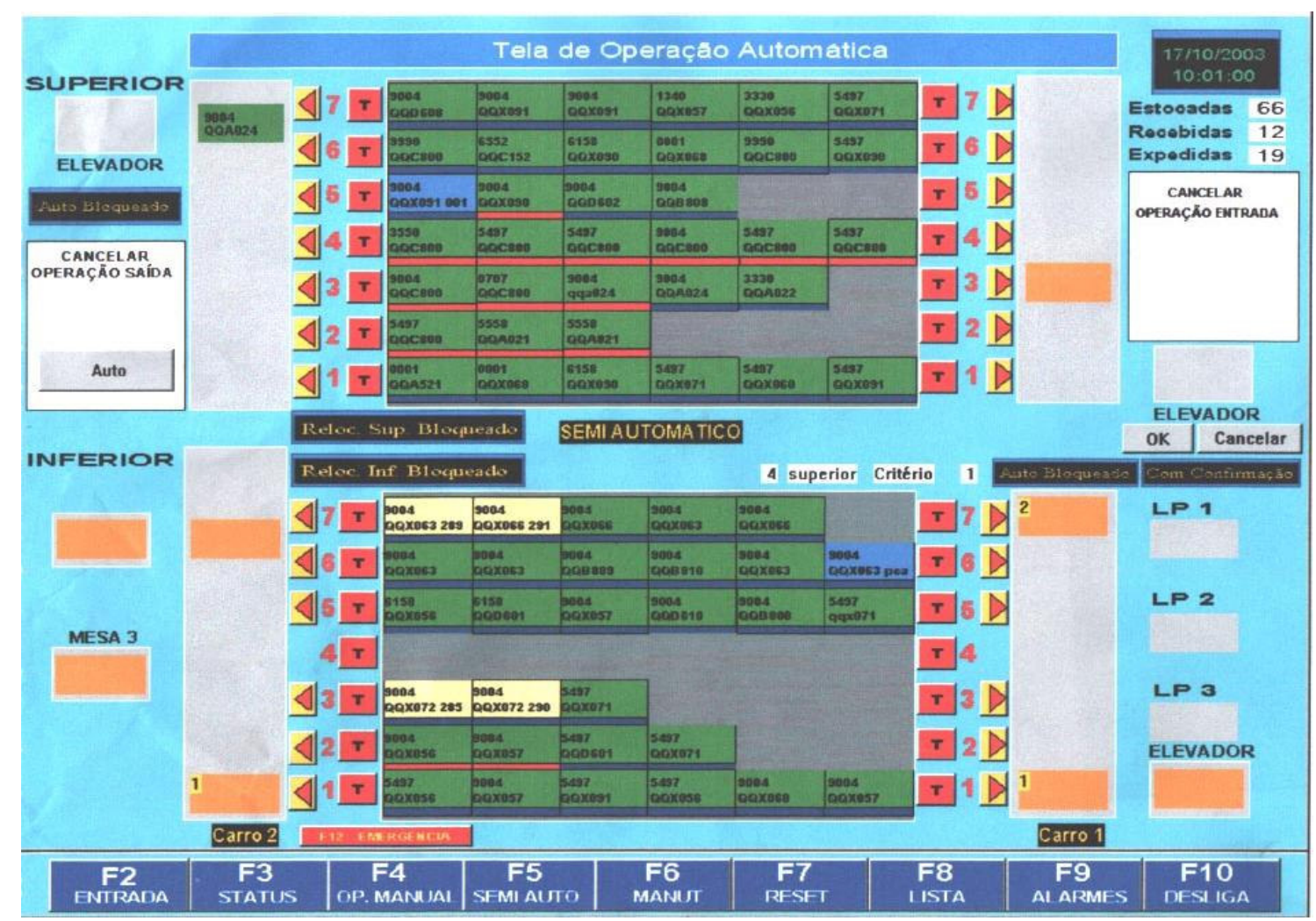

Figura 3.25: Disposição das cabinas no Puffer

Outra consideração importante é que, até essa etapa, as cabinas estavam diferenciadas somente em variantes brutas, na montagem bruta, e pela cor, na pintura. As cabinas são retiradas de acordo com as necessidades da montagem final de caminhões, podendo, às vezes, não estar na seqüência. Na seqüência da montagem final de caminhões, as cabinas estão diferenciadas em variantes exatas, que são as características do acabamento da cabina. Portanto, na hora em que as cabinas são retiradas do Puffer, elas recebem essa variante exata, que indicará o nível de acabamento na próxima etapa, de acordo com a seqüência da montagem final de caminhões.

\subsubsection{Montagem de acabamento das cabinas (E figura 3.1)}

Nessa etapa, as cabinas são novamente separadas. As cabinas dos caminhões leves, médios e semipesados são acabadas em três linhas (1, 3 e 9), e as cabinas dos caminhões pesados e extrapesados são acabadas na linha 5 . 
O processo de acabamento consiste em montar bancos, revestimento interno, painel de instrumentos, vidros, espelhos e outros itens opcionais aos detalhes do acabamento da cabina.

Todos os processos são realizados em linhas com transportadores de correntes do tipo esteiras com Skids, os chamados Conveyors. Não há espaços para acumulação de cabinas e nem áreas de retrabalho. A movimentação entre as linhas é feita por 3 carros transportadores, que movimentam os Skids com as cabinas. Esses carros transportadores são o gargalo do sistema. A figura 3.26 mostra o layout dessas linhas.

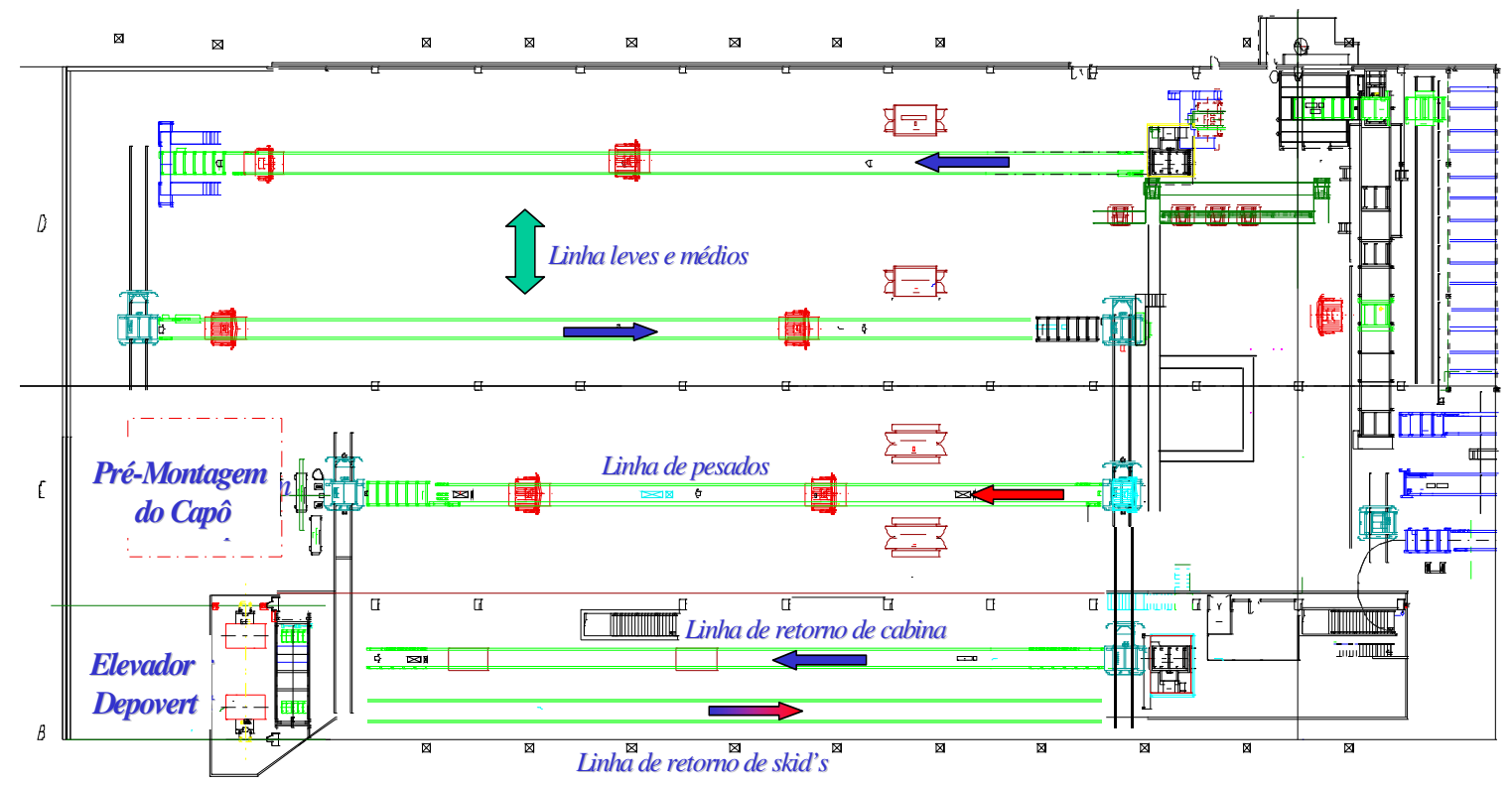

Figura 3.26: Diagrama dos processos do acabamento das cabinas

As linhas 1, 3 e 5 têm 30 postos de trabalho no total e montam os veículos de maior demanda: LN, FPN, HPN, LTC e L98.

Já a linha 9, responsável pelos veículos de menor demanda, HSK e FSK, tem 9 postos de trabalho. O takt time e a velocidade dos transportadores são determinados pela quantidade diária a ser produzida, e são independentes, entre as linhas 9 e 1 , e 3 e 5 .

As fotos da Figura 3.27 mostram a montagem acabamento das cabinas.

Após as cabinas estarem montadas, elas passam para o próximo estoque de cabinas, o estoque de cabinas acabadas. 

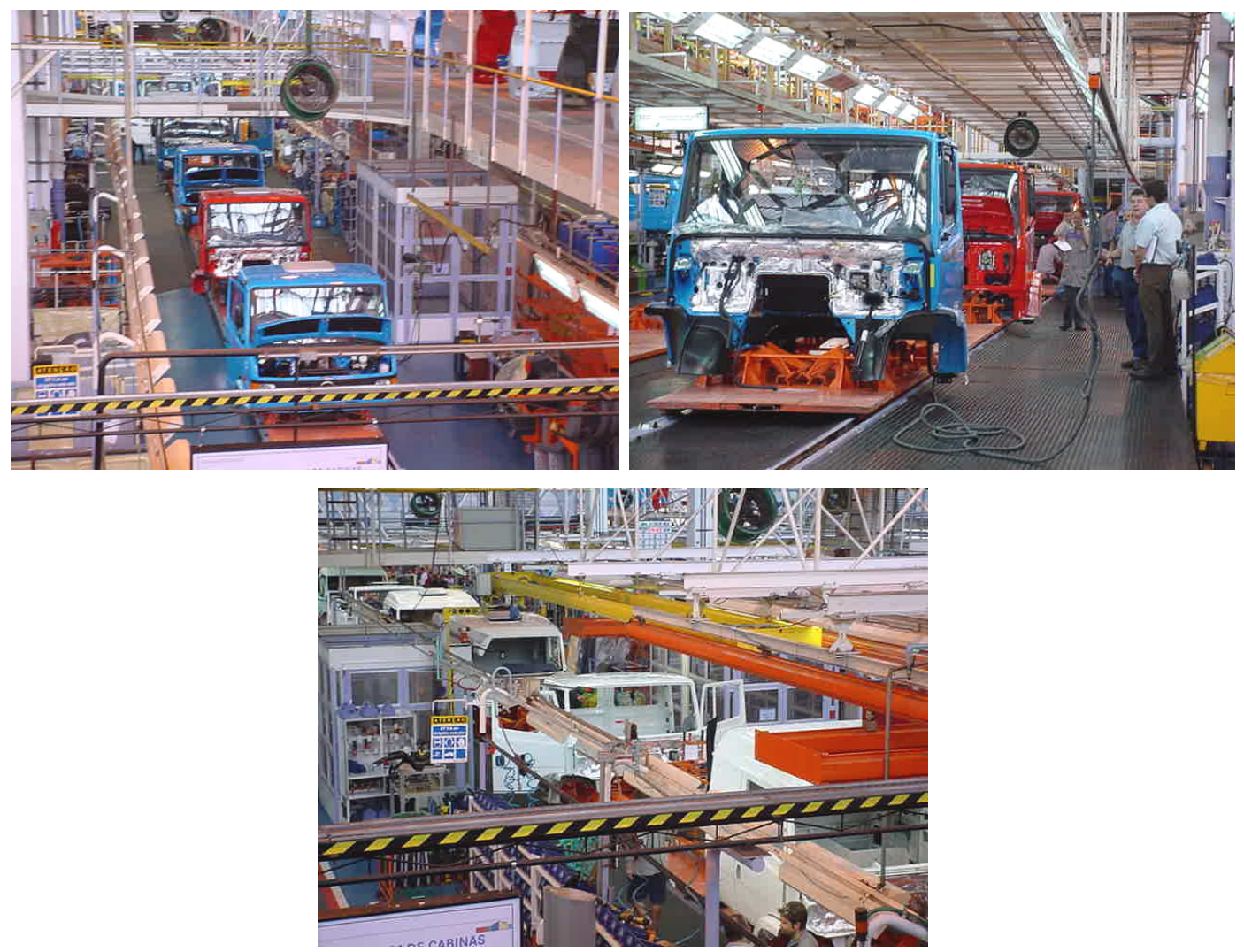

Figura 3.27: Vistas da montagem acabamento de cabinas

3.7.7 Estoque de cabinas acabadas - Depósito Vertical de Cabinas DEPOVERT (S2 Figura 3.1)

Após as cabinas estarem prontas, elas são novamente guardadas em um estoque que tem a mesma flexibilidade de reordenação do Puffer. Nesse caso, porém, existem algumas diferenças.

O DEPOVERT é um sistema complexo de armazenagem, em que as cabinas são armazenadas em uma estrutura vertical que dispõe de 6 andares com 10 colunas de cada lado do estoque. Cada um dos andares tem 6 vagas para armazenagem. Algumas cabinas podem ser alocadas em áreas especiais, totalizando 123 cabinas armazenadas;

Ao centro dessas colunas existe um trans-elevador, que coloca ou retira as cabinas em direção à saída ou à entrada.

Da mesma forma que no Puffer, existe um sistema de controle que memoriza a posição das cabinas armazenadas e compara as seqüências de entrada e saída. 
As cabinas são retiradas do DEPOVERT de acordo com a seqüência da montagem final de caminhões e no momento da montagem. As cabinas não podem sair do DEPOVERT de forma alguma em uma ordem diferente da que vai ser utilizada pela montagem final de caminhões, para que não ocorra perda de produção.
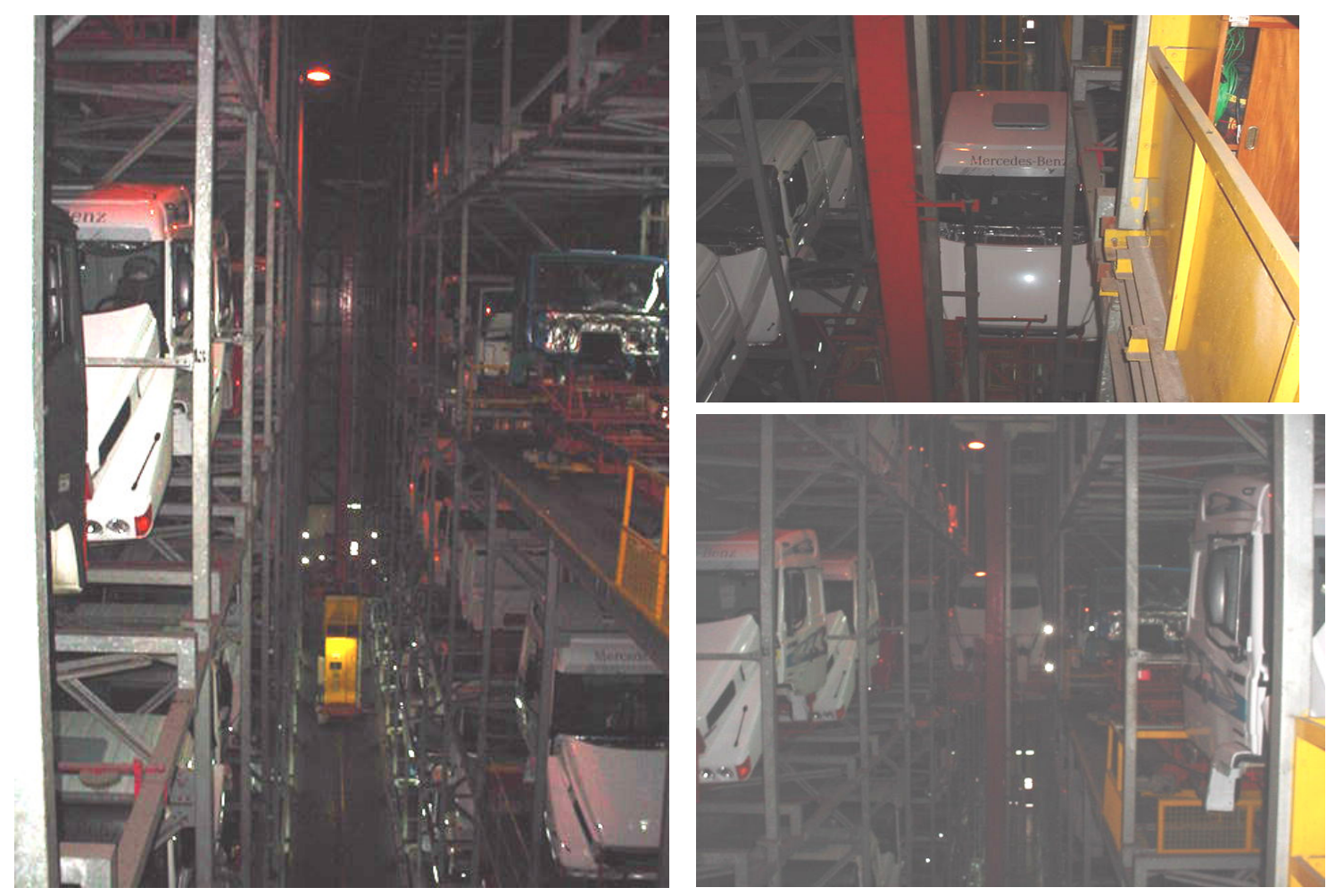

Figura 3.28: Fotos do interior do DEPOVERT

A função do DEPOVERT não é unicamente corrigir a seqüência, já que ela deveria ser corrigida integralmente pelo Puffer. Ele também tem outras funções:

- Pulmão entre as etapas de montagem acabamento da cabina e montagem final de caminhões, quando previne a parada de produção.

- Estoque de cabinas a serem vendidas como reposição ou CKD.

- Durante a montagem acabamento pode faltar algum outro agregado do caminhão, como eixo, motor, ou alguma outra peça que faça com que, na última hora, a seqüência final mude e a cabina tenha que ficar armazenada pronta, à espera de ser utilizada novamente. A cabina é dita bloqueada por falta de agregado.

- O armazenamento de cabinas acabadas apresenta problemas, como o alto nível de diferenciação e, portanto, de difícil reposição. O sistema 
também apresenta uma grande dependência de manutenção preventiva, pois qualquer falha pode significar a parada de produção.

Por armazenar cabinas acabadas e ter problemas de manutenção, o custo de armazenagem desse estoque é muito alto. $O$ fato de ele ser maior que o Puffer também traz dúvidas sobre a correta utilização dos dois estoques. A questão de a cabina ficar armazenada por bloqueio também poderia ser resolvida de outras formas; no entanto, como diversas variáveis influem na utilização desse estoque, uma análise minuciosa deve ser feita no sistema, para que atitudes possam ser tomadas.

3.7.8 Montagem final de caminhões leves e médios e montagem final de caminhões pesados ( $\mathrm{F}$ da Figura 4.1)

Essa é a etapa final no processo produtivo de caminhões da empresa. Todas as partes compradas ou produzidas são recebidas nessa etapa e montadas para compor o caminhão.

Os processos de montagem estão dispostos em linhas, e os caminhões são montados em dois grupos diferentes. Os pesados e extrapesados são montados na linha F2 (Figura 4.1) e os leves, médios, semipesados e pesados são montados na linha F1 (Figura 4.1), além dos chassis de ônibus com motor frontal (OF), que também são montados nesse mesmo prédio.

Esses ônibus não precisam de cabina e, no processo de montagem da cabina na longarina, representam uma folga no fornecimento de cabinas.

\section{Características gerais:}

- As longarinas entram no início do processo, para serem montadas e, no decorrer dos processos, recebem as outras partes, como chicotes elétricos, eixos, motor, cabinas, rodas etc. Ao final das linhas, os veículos saem em funcionamento.

- As linhas utilizam transportadores que levam as longarinas ao longo dos processos. Os transportadores têm a velocidade programada de acordo com a produção diária.

- A linha F1 (Figura 4.1) de montagem dos veículos leves e médios tem 24 postos e produz a maioria dos veículos. 
- A linha F2 (Figura 4.1) de montagem dos veículos pesados tem 9 postos e, dependendo da quantidade a ser produzida, trabalha em um único turno.

- A montagem final está sujeita à falta de qualquer um desses agregados. No caso da falta ser informada com antecedência, o programa é modificado e é montado um outro caminhão que tenha todas as peças disponíveis. Os agregados não faltantes são armazenados em estoques, como é o caso do DEPOVERT para as cabinas. No caso de falta não programada, a linha pára o seu funcionamento.
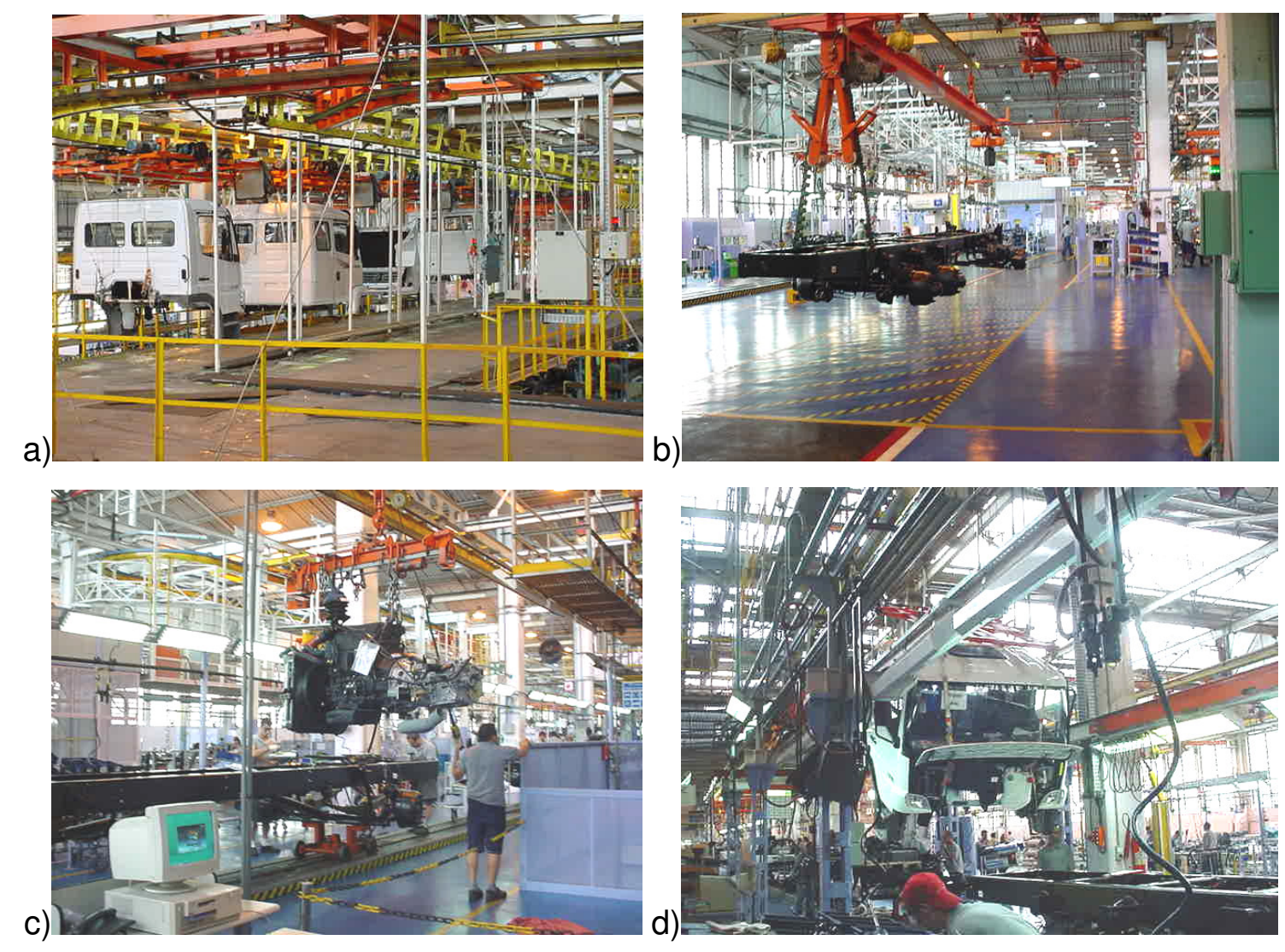

Figura 3.29: Montagem Final dos Caminhões, linha leves e médios: a) foto da chegada das cabinas para montagem; b) mostra o transporte da longarina com os eixos; c) foto da montagem do motor; d) foto da montagem da cabina na longarina. 
a)
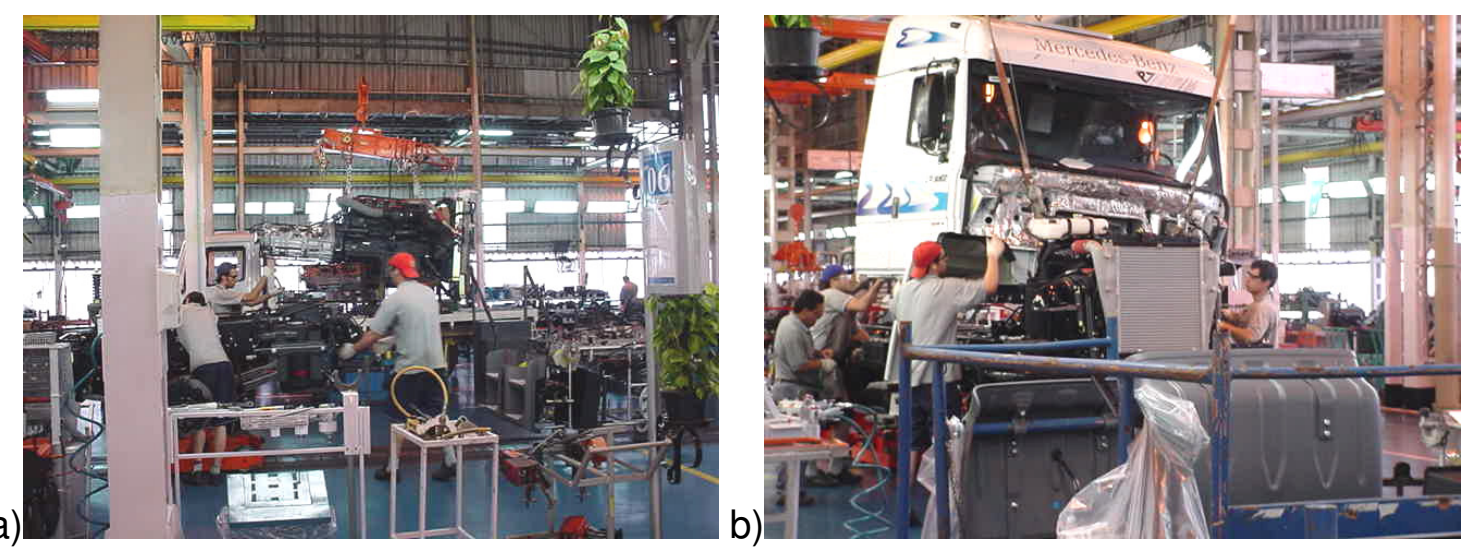

Figura 3.30: Montagem final de Caminhões, linha extrapesados: a) Montagem do Motor; b) Montagem da cabina.

\subsection{Programação das cabinas e seqüência dos processos}

Depois de detalhar todas as etapas, é preciso comentar como essas etapas se interagem e como é programada a produção de todos os veículos. A figura 4.30 mostra um resumo de todas as etapas e da ligação entre elas, de acordo com o que foi exposto até agora.

ROHBAU - FLUXOGRAMA DAS CABINAS

CIRCUITO COMPLETO

DAIMLERCHRYSLER DCA - DIVISÃO PRODUÇÃO DE VEÍCULOS COMERCIAIS SBC / LVC - LOGISSTICA DE VEÍCULOS COMERCIAIS

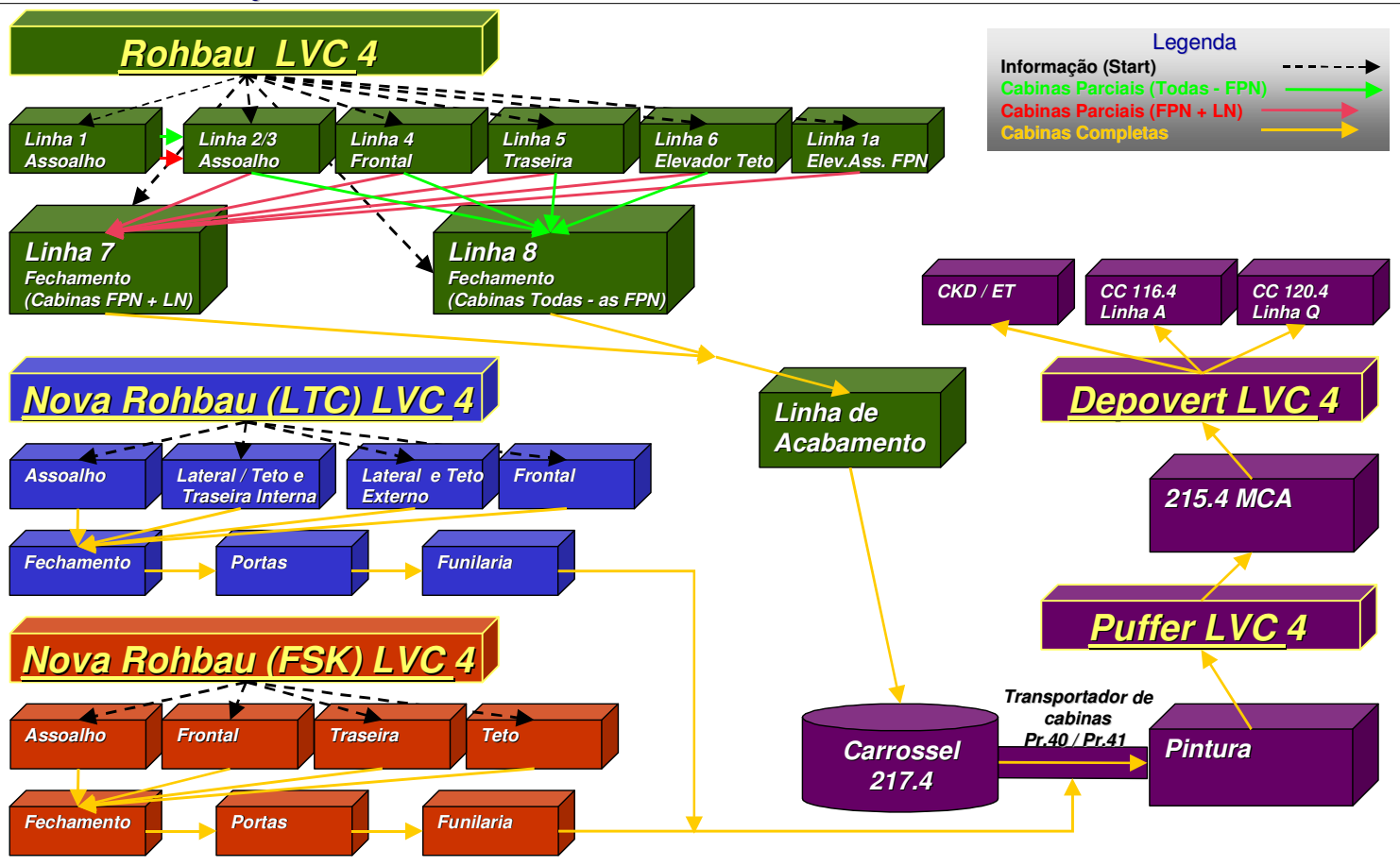

Figura 3.31: Diagrama das etapas produtivas e suas ligações

Fonte: DaimlerChrysler do Brasil 
Após ser revisto o diagrama de processos, é necessário descrever como é feita a programação de todo esse sistema.

O departamento de vendas avalia, de acordo com os pedidos já feitos e com o histórico de vendas, quais caminhões serão produzidos no mês. Essa proporção gera um planejamento mensal da época em que os veículos serão produzidos. O planejamento é discutido por diversas áreas que, em algumas reuniões, estudam a disponibilidade de peças, a previsão de entrega e a capacidade de produção, para programarem a seqüência de veículos a serem produzidos na semana seguinte. Essa é, portanto, a seqüência final que será utilizada para a montagem de todos os componentes dos caminhões.

Depois de aprovada, a seqüência é distribuída para todas as áreas responsáveis pela produção ou compra das peças que compõem os veículos. Cada área tem um tempo diferente para a entrega dos produtos. A cabina é o produto crítico, pois tem o maior tempo de produção: demora em torno de 3 dias e meio para ser entregue na saída do Depósito Vertical. É a seqüência final que rege a montagem final dos caminhões e puxa todos os outros componentes dos caminhões. Portanto, essa seqüência programada deve ser respeitada por todas as etapas de produção, para que não ocorram erros na montagem final. Como existem duas linhas de montagem final de caminhões, são formadas duas seqüências de produção.

Na montagem das cabinas, essa programação é recebida e dividida em duas seqüências independentes, as quais intercalam veículos das duas linhas de montagem final. A seqüência referente à montagem bruta da Rohbau (A da figura 4.1) recebe, tanto veículos pesados, quanto leves e médios, que são intercalados e depois divididos entre os que serão montados pela linha 8 e os que serão montados pela linha 7. A Rohbau apresenta diversas restrições quanto à seqüência dos veículos, como impossibilidade de 3 veículos pesados em seguida e o balanceamento dos veículos FPN da linha 7, devido à produção das linhas 4, 5 e 6, comuns a todos os veículos. Já a seqüência referente à montagem bruta da Nova Rohbau (B da figura 4.1) também contém veículos pesados (FSK) e leves (LTC), mas essa seqüência se mantém diferenciada, no início da produção.

Dessa forma, temos as duas seqüências iniciais da montagem final dos caminhões misturadas e redivididas no início da produção da cabina. Após a distribuição da seqüência de produção de cabinas, cada linha de produção bruta só 
pára a produção quando o sistema estiver bloqueado, ou seja, quando não for possível alojar nas etapas seguintes as cabinas brutas produzidas. Assim, as cabinas não são puxadas, e sim empurradas, devido a índices de avaliação da produção, de acordo com a produtividade. No caso de parada de alguma das linhas, as outras que não estão bloqueadas continuarão a funcionar normalmente. Como cabinas são itens de grande porte, não existem estoques intermediários ou áreas de acumulação. Existe a condição do bloqueio das linhas anteriores, no caso de parada das etapas posteriores (RONCONI, 2003). Nessa etapa, as cabinas estão diferenciadas por modelo e por variante bruta.

As cabinas são novamente intercaladas após algumas etapas de produção, como exemplo, após a montagem das portas na nova Rohbau, ou na entrada do Transportador Aéreo. Nessas intercalações, não são feitas correções de seqüência, ou seja, as cabinas saem das Rohbau fora da seqüência original.

$\mathrm{Na}$ pintura, as cabinas passam por todos os processos quase na mesma ordem. Depois da pintura esmalte, existe um controle que avalia a qualidade da pintura das cabinas. Após a avaliação, caso seja necessário, cada cabina passa por um dos três postos paralelos de reparo das cabinas. Cada cabina tem o seu tempo de reparo, e cabinas sem necessidade de reparo passam por essa etapa sem parar. Algumas vezes, principalmente as cores especiais e pintadas à mão têm maior índice de problema na pintura e precisam ser repintadas e passar por muitos processos novamente. Isso faz com que saiam muito da seqüência predeterminada.

Após a pintura, as cabinas entram no Puffer. Na entrada é comparada a cabina à seqüência principal da montagem final e, no caso de uma cabina estar muito atrasada da posição em que deveria estar (mais de 15 posições), mesmo antes de ela chegar ao Puffer pode ser modificada a seqüência de montagem final dos caminhões, para que o caminhão que iria receber essa cabina espere uma outra igual, ou a chegada da mesma. A retirada das cabinas deve ser feita de acordo com a seqüência a ser utilizada na Montagem Final. Como as cabinas ainda estão diferenciadas somente nos modelos brutos, existe certa flexibilidade para retirar uma cabina bruta igual, sem ser para o caminhão da mesma posição da seqüência a que ela estava determinada. Nesse caso, pode-se corrigir ou postergar eventuais falhas ou mudanças na seqüência. No caso da não existência de alguma cabina similar, para que a produção não cesse é retirada a cabina seguinte, na seqüência, ou a 
mais próxima possível. Isso faz com que algumas cabinas saiam do Puffer fora da seqüência prevista.

$\mathrm{Na}$ Montagem de Acabamento, as cabinas são novamente separadas em duas linhas independentes, mas de acordo com a montagem final. Nessa etapa não ocorrem mais intercalações, e as cabinas são diferenciadas em acabadas (variantes exatas).

Após a Montagem de Acabamento, as cabinas vão para o DEPOVERT e ficam aguardando solicitação de montagem no caminhão, na Montagem Final de Caminhões, ou a solicitação de vendas para retirar a cabina para reposição ou CKD. Como são acumuladas várias cabinas e o DEPOVERT também é flexível, esse estoque tem a função de fazer correções na seqüência, para que não exista qualquer possibilidade de falta de cabina na Montagem Final de Caminhões.

Como o caminhão é formado de vários agregados, da mesma forma que faltam cabinas podem faltar os agregados. Como as cabinas são produzidas com certa antecipação, muitas vezes a falta do agregado é percebida quando a cabina já está pronta, ou em acabamento. Nesse caso, as cabinas ficam bloqueadas no DEPOVERT, esperando serem montadas, e ocupam o espaço destinado para eventuais correções da seqüência. Como estão em um grau de diferenciação muito alto, fica difícil a cabina servir em outro modelo e, algumas vezes, ficam armazenadas durante muito tempo. Caso a falta do agregado seja percebida antes da Montagem de Acabamento da Cabina, muitas vezes pode-se utilizar essa cabina em outro modelo e fazer com que não seja produzida uma outra cabina da mesma variante bruta, mas isso não é o comum. Dessa forma, o DEPOVERT também é utilizado para corrigir outros problemas que não da produção de cabinas, o que mostra que esse estoque pode estar sendo mal utilizado.

A ordem de retirada da cabina do DEPOVERT é dada logo antes da montagem da cabina no caminhão, o que ocorre bem depois do início da montagem da longarina. Pode ocorrer a falta de algum agregado no posto de montagem, o que pára toda a linha, mas, normalmente, quando a longarina começa a ser montada, todos os agregados já foram verificados. Mas como a cabina fica algum tempo armazenada no DEPOVERT, mesmo com esse tempo de verificação da existência do agregado a informação de falta só é recebida quando a cabina já está em fase de acabamento e bastante diferenciada. Caso não existisse o DEPOVERT, não existiria 
o tempo de estocagem e a cabina seria bloqueada pela falta de um agregado quando ainda estivesse no Puffer, o que facilitaria a intercalação.

\section{$3.9 \underline{\text { O problema e os objetivos do estudo }}$}

O estoque de cabinas acabadas (DEPOVERT) tem um alto custo de operação, além de não ser a melhor solução para o problema de correção da seqüência e armazenamento das cabinas bloqueadas pela falta de agregado.

O sistema de movimentação do DEPOVERT é muito complexo, e qualquer falha representa parada de produção, pois não é possível retirar as cabinas manualmente. Para evitar essas falhas, a manutenção preventiva do sistema é cara.

Estocar produtos acabados também não é o ideal, de acordo com a teoria revisada, pois envolve um custo imobilizado muito alto, e os produtos têm pouca flexibilidade, pois não podem ser montados em qualquer produto.

A organização dos estoques na montadora também é duvidosa, pois o estoque de cabinas brutas, ou seja, com pouca diferenciação, é menor que o estoque de cabinas acabadas, ou seja, com grande diferenciação.

A existência de estoques, de acordo com a teoria, também representa um custo para a produção, esconde muitas falhas e erros de produção, sendo como uma folga para que essas falhas não atrapalhem todo o processo. A análise nos estoques força o combate a diversos problemas na produção.

A necessidade da existência de estoques seletivos nesse sistema de produção é clara, pois diversos produtos diferentes são intercalados e fabricados no mesmo sistema produtivo. A seqüência de fabricação desses produtos é alterada nas diversas etapas produtivas, mas seria mais lógico utilizar apenas um estoque de cabinas pintadas, já que o estoque de cabinas acabadas envolve muitos custos e alta variabilidade dos produtos. Seria melhor, pelo menos, que o estoque de cabinas pintadas fosse o principal e o de cabinas acabadas fosse apenas um pequeno pulmão, na ocorrência de eventuais problemas.

A utilização de um sistema de administração da produção também seria útil para melhor controle da seqüência programada ao longo de todos os processos e para que as alterações da seqüência pudessem ser informadas com antecedência.

A redução dos estoques também é desejada para enxugar a produção e controlar de melhor forma os problemas produtivos, de acordo com a teoria JIT. 
No entanto, nenhuma alteração em um sistema desse porte poderia ser feita sem que fossem projetadas ou conhecidas as relações entre cada ação tomada e os resultados obtidos. Num sistema tão grande como esse ficaria complicado observar quais são as causas das necessidades dos estoques. Não se pode simplesmente fazer experimentos no sistema real e observar as reações, já que é um sistema de grande complexidade e que os resultados poderiam prejudicar toda a produção.

Dessa forma, a simulação torna-se a ferramenta mais adequada para estudar o comportamento do sistema diante de vários cenários, ações e situações. Este trabalho mostra, daqui em diante, a modelagem e o estudo do sistema com utilização de simulação para avaliar a necessidade e a possibilidade de redução desses estoques.

\subsection{O cálculo dos custos de operação dos estoques seletivos}

Depois de identificado o problema e o objetivo alvo do estudo, foi feita uma análise detalhada dos custos que envolvem a utilização dos dois estoques seletivos. Esses custos ajudam e reforçam a justificativa de todo este estudo. Os custos foram calculados segundo o método utilizado pela empresa em questão, e diversos analistas de custos da empresa orientaram todo o cálculo, além de fornecerem informações a respeito dos custos envolvidos.

Para o cálculo foram utilizadas as informações que seguem:

- Custo de diferentes modelos de cabinas brutas pintadas e de cabinas acabadas.

- Custo da utilização da área do imóvel e da edificação utilizada.

- Valor de compra dos equipamentos utilizados nos estoques para movimentação e armazenagem das cabinas. Com esses valores foram calculadas a amortização e a depreciação dos equipamentos, que são os valores que incidem nos custos de operação de equipamentos.

- Consumo energético dos equipamentos de movimentação e armazenagem.

- Gastos com manutenção dos equipamentos.

- Custo financeiro do material estocado. Para isso, foram utilizados os preços das cabinas, a proporção de cabinas estocadas, o tempo que elas 
ficam no estoque e o prejuízo financeiro de não manter a moeda parada em estoque em qualquer outra aplicação no mercado financeiro.

As tabelas abaixo mostram os custos de operação do DEPOVERT e do Puffer.

\begin{tabular}{|c|c|c|c|}
\hline \multicolumn{4}{|c|}{ Calculo de custos - operação do Puffer } \\
\hline & Dados & Custo & \\
\hline \multicolumn{4}{|l|}{ Custo edificação } \\
\hline Área ocupada $\left(\mathrm{m}^{2}\right)$ & 751,54 & & \\
\hline Aluguel da área $\left(\mathrm{R} \$ / \mathrm{m}^{2}\right)$ & 140 & $\mathrm{R} \$ 105.215,60$ & $/ \mathrm{m}^{2}$ \\
\hline Equipamentos & Dados & Custo & \\
\hline Mesas Transportadoras (4x) & $\mathrm{R} \$ 280.000,00$ & & \\
\hline Elevadores $(2 \mathrm{X})$ & $R \$ 400.000,00$ & & \\
\hline Transportadores (larg cab x nun x 2000) & $\mathrm{R} \$ 705.600,00$ & & \\
\hline Estrutura (area x 12R $\$ / \mathrm{kg} \times 50 \mathrm{~kg} / \mathrm{m} 2)$ & $\mathrm{R} \$ 450.924,00$ & & \\
\hline Amortização (8 anos) (não computado) & $12 \%$ & $R \$ 369.697,50$ & /ano \\
\hline Depreciação (8 anos) ( Desconto do IR) & $40 \%$ & $(\mathrm{R} \$ 91.826,20)$ & /ano \\
\hline Consumo de energia $(0,12 \mathrm{R} \$ / \mathrm{kWh})$ & 20mWh/ano & $R \$ 2.400,00$ & \\
\hline Manutenção & $3 \%$ & $R \$ 55.095,72$ & /ano \\
\hline Custo total do imobilizado & & $\mathrm{R} \$ 162.711$ & /ano \\
\hline $\begin{array}{l}\text { Veículos Produzidos por ano } \\
\text { Material Estocado (cabinas) }\end{array}$ & $\begin{array}{r}47150 \\
75\end{array}$ & Proporção & $\begin{array}{c}\text { Númeo de } \\
\text { cabinas no } \\
\text { estoque por tipo }\end{array}$ \\
\hline Cabinas tipo pesado & $\mathrm{R} \$ 2.600,00$ & $22,45 \%$ & 17 \\
\hline Cabinas tipo médio & $\mathrm{R} \$ 2.600,00$ & $52,06 \%$ & 39 \\
\hline Cabinas tipo leve & $R \$ 2.600,00$ & $25,49 \%$ & 19 \\
\hline Perído Médio de estoque (min) & 400 & & \\
\hline Taxa SELIC anual & $16,25 \%$ & & \\
\hline & & & Custo \\
\hline Custo médio da cabina no estoque & & & $\mathrm{R} \$ 2.600,00$ \\
\hline Tempo que a cabina fica no estoque no ano & & & 0,00133547 \\
\hline Custo financeiro do imobilizado no estoque & & & $\mathrm{R} \$ 26.603,73$ \\
\hline Custo total operação Puffer / ano & & & $R \$ 189.315,05$ \\
\hline
\end{tabular}

Tabela 3.3: Cálculo dos custos operacionais do Puffer. 


\begin{tabular}{|c|c|c|c|}
\hline \multicolumn{4}{|c|}{ Calculo de custos - operação do Depovert } \\
\hline & Dados & Custo & \\
\hline \multicolumn{4}{|l|}{ Custo edificação } \\
\hline Área ocupada $\left(\mathrm{m}^{2}\right)$ & 1110 & & \\
\hline Aluguel da área $\left(\mathrm{R} \$ / \mathrm{m}^{2}\right)$ & 140 & $R \$ 155.400,00$ & $/ \mathrm{m}^{2}$ \\
\hline Equipamentos & Dados & Custo & \\
\hline Transelevador $(\mathrm{R} \$)$ & $R \$ 1.560 .000,00$ & & \\
\hline Mesas de transfrência entrada e saída & $R \$ 715.000,00$ & & \\
\hline Docas $(\mathrm{R} \$)$ & $\mathrm{R} \$ 1.000 .000,00$ & & \\
\hline Amortização (8 anos) (não computado) & $12 \%$ & $R \$ 659.266,81$ & lano \\
\hline Depreciação (8 anos) ( Desconto do IR) & $40 \%$ & $(\mathrm{R} \$ 163.750,00)$ & lano \\
\hline Consumo de energia $(0,12 \mathrm{R} \$ / \mathrm{kWh})$ & $60 \mathrm{mWh} / \mathrm{ano}$ & $\mathrm{R} \$ 7.200,00$ & \\
\hline Manutenção & $5 \%$ & $R \$ 163.750,00$ & /ano \\
\hline \multirow[t]{2}{*}{ Custo total do imobilizado } & & $R \$ 326.350,00$ & lano \\
\hline & Dados & Proporção & \multirow{3}{*}{$\begin{array}{c}\text { Númeo de } \\
\text { cabinas no } \\
\text { estoque por tipo }\end{array}$} \\
\hline Veículos Produzidos por ano & 47150 & & \\
\hline Material Estocado (cabinas) & 120 & & \\
\hline Cabinas tipo pesado & $\mathrm{R} \$ 17.000,00$ & $22,45 \%$ & 27 \\
\hline Cabinas tipo médio & $\mathrm{R} \$ 8.100,00$ & $52,06 \%$ & 62 \\
\hline Cabinas tipo leve & $\mathrm{R} \$ 6.500,00$ & $25,49 \%$ & 31 \\
\hline Perído Médio de estoque (min) & 600 & & \\
\hline Taxa SELIC anual & $16,25 \%$ & & \\
\hline & & & Custo \\
\hline Custo médio da cabina no estoque & & & $R \$ 9.690,21$ \\
\hline Tempo que a cabina fica no estoque no ano & & & 0,002003205 \\
\hline Custo financeiro do imobilizado no estoque & & & $R \$ 148.728,32$ \\
\hline Custo total operação do Depovert / ano & & & $R \$ 475.078,32$ \\
\hline
\end{tabular}

Tabela 3.4: Cálculo dos custos operacionais do DEPOVERT.

Valores como custo da energia, taxa SELIC, condições de Amortização e Depreciação foram fornecidos pela empresa. Para o cálculo do custo financeiro imobilizado pelo estoque, foi utilizado o preço médio de uma cabina estocada e o tempo que cada cabina fica estocada. Esses valores consideram o preço de cada cabina e o tamanho do estoque (por meio do tempo de estoque). Com esses valores, foi possível calcular, pela Taxa SELIC anual, o quanto deixaria de render uma aplicação financeira com esse valor imobilizado no estoque.

Pode-se notar que estocar cabinas acabadas tem um custo maior, devido ao valor agregado que já foi adicionado ao produto. A diferença do custo anual financeiro, imobilizado entre $R \$ 148.000,00$ para cabinas acabadas e $R \$ 26.600,00$ para cabinas brutas, é de $R \$ 475.000,00$ e $R \$ 190.000,00$, respectivamente. Para custo total de operação dos estoques, isso mostra mais um ponto do mau planejamento na utilização de estoques seletivos. Fica evidente que seria muito melhor trabalhar com maior capacidade para o Puffer e otimizar o DEPOVERT, reduzindo-o ou, até, eliminando-o. 
Após todas essas análises, é possível, agora, definir os principais objetivos do estudo e o planejamento para atingi-los.

\section{Modelagem e simulação}

\subsection{Coleta de dados e Restrições}

De acordo com Banks (1998) e Willians \& Çelik (1998), é necessária uma clara definição dos objetivos, no início do projeto, para que ele tenha sucesso e se consiga a solução dos problemas propostos. Neste estudo, o objetivo principal foi definido pela empresa em conjunto com toda a análise do sistema:

- Avaliar a necessidade e o tamanho dos dois estoques seletivos em processo do sistema.

Para atingir o objetivo, foi necessário entender todo o processo de produção das cabinas e dos caminhões no sistema e avaliar as características do sistema que causam impacto na geração dos estoques:

- A programação e o comportamento da seqüência de produtos a serem produzidos ao longo das etapas da produção.

- Influência da variação do fluxo de cabinas entre as diversas etapas da produção, ou seja, como ocorrem as paradas e variações dos diferentes processos.

Após a definição dos objetivos, parte-se para a definição do modelo conceitual, definindo-se quais características serão modeladas do sistema. Não é possível modelar todos os detalhes e dados do sistema, pois o modelo pode se tornar demasiadamente grande e não ser útil para obtenção dos objetivos, tornando todo o estudo sem utilidade. Foram feitas, então, algumas restrições ou simplificações na análise:

- Dois turnos de produção (somente um turno para a Nova Rohbau);

- Maior parte dos tempos de processos baseados no takt time das linhas de produção. Foram encontradas poucas tabelas históricas de tempos;

- Transportadores entre as etapas de produção consideradas apenas como tempos de processo, de acordo com o tempo de movimentação;

- Os recursos humanos foram considerados balanceados e sempre disponíveis; 
- As falhas de processo foram analisadas apenas pelo tempo de parada e freqüência, sem consideração dos motivos;

- Devido ao tamanho e à complexidade do sistema analisado, o nível de detalhes do modelo foi o maior necessário somente para que o problema pudesse ser analisado, o que não inclui muitos detalhes de cada subprocesso.

Depois de definidas as restrições do estudo, foi iniciada a coleta dos dados. Essa é uma das fases mais trabalhosas, pois conseguir os dados necessários, com qualidade, quantidade e com alguma variabilidade, é tarefa difícil. É comum que os dados do sistema estejam indisponíveis, ou que não estejam no formato desejado para o desenvolvimento do estudo e necessitem de tratamento. Assim, alguns procedimentos são importantes para a coleta dos dados, dentre eles, visitas à planta, entrevistas, acessos a bancos de dados, coleta manual dos dados e, no caso de as informações não existirem, algumas considerações são necessárias (VINCENT, 1998). Para este estudo, os seguintes dados foram coletados:

- Layout das etapas de produção nos três prédios de processos da Figura 4.1 ;

- Histórico de mais de um ano de produção de todas as cabinas e veículos discriminados por variante bruta, exata e cor de cabina;

- Takt time e tempos de processo de todas as etapas da produção;

- Restrições e capacidades máximas dos sistemas e linhas de produção;

- Fluxo e rota dos diversos tipos de cabinas no sistema;

- Detalhes dos sistemas transportadores;

- Lead time para os sistemas e linhas de produção;

- Seqüência de cabinas definida pela programação da produção em cada etapa;

- Informações estatísticas da freqüência e duração das falhas e paradas de processo;

- Lógicas de decisão e bloqueio de veículos e cabinas;

- Situações especiais (situações específicas, produtos específicos etc.).

Para a coleta desses dados, foram necessárias diversas atividades na planta da DaimlerChrysler do Brasil de São Bernardo do Campo. Além de obter documentos e informações concretas do sistema, muitas outras informações só 
foram obtidas com visitas, entrevistas e períodos de observação. De acordo com o capítulo 4, o sistema é de grandes proporções, e diversas áreas da empresa atuam sobre ele. A coordenação desse projeto foi apenas de uma dessas áreas, e o tema em questão envolve várias opiniões internas da montadora. Com isso, muitas vezes a coleta de informações foi difícil, pois muitos dos funcionários tinham receio de passar algumas informações, ou simplesmente não queriam participar do assunto. Dessa forma, além das dificuldades normais de coletar dados, o trabalho ainda precisou de muito esforço político.

Outra questão é a disponibilidade dos dados e a qualidade das informações. Muitas vezes os dados estavam incompletos ou num formato de difícil compreensão, e precisaram ser tratados. Muitas considerações precisaram ser feitas. Outras vezes, os dados não existiam e precisaram ser obtidos pela observação do sistema durante várias horas, além da coleta manual de informações, como a contagem de tempos de processo, e das entrevistas de muitas pessoas diretamente ligadas à produção, como Mestres e Operadores.

O processo de modelagem e simulação é iterativo, e a coleta dos dados é uma atividade constante que ocorreu durante quase toda a análise do sistema.

Os primeiros dados obtidos foram os layouts dos processos e alguns dos tempos. Assim, de acordo com o detalhamento do modelo, novas informações do sistema foram obtidas. Desde o início já ocorreu a implementação dos modelos no software Arena®. O tópico que segue descreve a escolha do software Arena®.

\subsection{A escolha do Software Arena $\AA^{8} 5.0$}

O software de simulação Arena®, da Rockwell Software, é bastante tradicional em projetos de Simulação de Eventos Discretos. Baseado na linguagem SIMAN, muito utilizada em análises mais antigas, esse software apresenta diversas vantagens:

- Interface conhecida (Microsoft $(\mathrm{B})$;

- Modelagem por meio de fluxogramas e estruturas hierárquicas;

- Utilização de módulos e Templates;

- Utilização de dados estatísticos;

- Separação da programação e animação;

- Emissão de relatórios automáticos das estatísticas coletadas; 
- Recursos de programação em VBA e Active X;

- Integração com Microsoft Office®, Visio®, Oracle® e AutoCAD®;

- Módulos de análise de dados Input Analyser, Output Analyser, OptQuest e Scenario Manager.

- Pacotes de Templates: Standard Edition, Professinal Edition, Arena Call Center, Arena Packaging.

A programação na versão utilizada é feita por meio de objetos, e existem diversos blocos e templates pré-programados que facilitam a modelagem e a simulação. Também é possível, no caso de necessidade, a programação diretamente na linguagem SIMAN, por meio de blocos e comandos lógicos.

Outra vantagem é a possibilidade de modelagem em submodelos que são integrados ao modelo principal, o que facilita a visualização e a modelagem dos sistemas.

Apesar dessas vantagens, a utilização do Arena® apresenta algumas desvantagens com relação a outros softwares de simulação utilizados pelo laboratório de Simulação e Controle da EESC-USP, como Automod® e Promodel $\AA^{\circledR}$ : falta de recursos de animação, o que dificulta a apresentação para executivos de empresas; dificuldade de modelagem de situações especiais, devido às restrições da linguagem de programação; e, algumas dificuldades na modelagem de sistemas de movimentação, uma das principais vantagens do Automod®.

O que motivou a escolha do Arena® foi o fato de a montadora em questão também possuir licenças desse software e já o ter utilizado para realizar alguns estudos de simulação de eventos discretos. Isso facilitou o intercâmbio de informações e a apresentação dos resultados. Além disso, o Arena ${ }^{\circledR}$ foi aconselhado pelo orientador deste estudo como um software de fácil aprendizado e utilização, o que beneficiou o desenvolvimento do trabalho.

\subsection{Modelagem}

A modelagem de todo o sistema foi um processo lento e iterativo. Até o modelo estar de acordo, para que os cenários pudessem ser analisados e os objetivos atingidos, muitos modelos diferentes foram desenvolvidos e depois modificados, ao longo de todo o período de estudo. Para facilitar o estudo de um sistema tão grande, a modelagem foi dividida de acordo com as diferentes etapas do processo, o que transformou o modelo em módulos que, depois, foram interligados. 
McLean \& Leong (2002) mostram alguns passos para a modelagem e simulação modular de sistemas. Cada etapa do sistema foi modelada separadamente e, quando atingia a representatividade do sistema real necessária, era unida ao modelo das outras etapas do sistema. Depois de formado o modelo completo, muitas alterações ainda foram feitas, pois foi preciso acertar questões da interdependência das etapas.

Assim, o modelo foi dividido em 10 etapas:

- Seqüenciamento e programação das ordens de produção;

- Linhas e processos de produção Rohbau e Nova Rohbau;

- Saída das Rohbau e Transportador Aéreo;

- Processos de Pintura;

- Puffer,

- Montagem acabamento das cabinas;

- DEPOVERT;

- Linhas de Montagem Final;

- Lógicas para controle, análise e modificação da seqüência programada ao longo de todo o processo.

Todo o modelo foi implementado diretamente no Arena®. Foram utilizadas equações matemáticas e distribuições estatísticas para descrever algumas das situações reais e os dados obtidos. Foi utilizado também, além de tabelas Excel $\circledast$, o software Input Analyser do Arena® para analisar os dados obtidos e obter distribuições estatísticas representativas do sistema real.

Todo o modelo foi desenvolvido utilizando variáveis que pudessem ser alteradas no futuro, para que novos cenários pudessem ser modelados e simulados. A preocupação em utilizar um raciocínio lógico e bem estruturado também era constante em todo o trabalho, para que outras pessoas pudessem entender o modelo e utilizá-lo em estudos futuros.

Os tópicos que seguem descrevem a modelagem e a implementação no Arena $\AA^{\circledR}$, oferecendo detalhes dos raciocínios e lógicas utilizadas, para que sirvam também como a documentação de todo o modelo. Para melhor compreensão dos comandos do Arena $\AA^{\circledR}$ aqui descritos, pode ser consultada a referência Paragon (2002). 
4.3.1 Criação das entidades, Seqüenciamento e programação das ordens de produção

Para o estudo, logo se viu que era necessária uma representação realista da seqüência das cabinas ao longo de todos os processos, pois seria essa a principal causa da existência dos estoques seletivos. Assim, as entidades cabinas foram criadas e diferenciadas de acordo com uma representação da seqüência real de produção e que comanda todo o modelo ao longo de todos os processos e etapas da produção.

A área de logística de produção da montadora forneceu um histórico de um ano e 4 meses da seqüência de montagem dos veículos produzidos. Essa informação veio através de tabela Excel® e estava diferenciada pelo veículo produzido, variante de cabina bruta, variante de cabina exata, ano de produção, mês de produção e quantidade produzida no mês. Com essa tabela foi possível saber quais e quantos veículos foram produzidos em cada mês do ano. A tabela 5.1 é uma parte da tabela recebida que continha aproximadamente 2000 linhas.

\begin{tabular}{|r|r|l|l|l|r|}
\hline Ano & Mes & Tipo Cabina & VarBruta2 & VarExata & Total \\
\hline 2003 & 1 & & QQA610 & & 6 \\
\hline 2003 & 1 & & QQA623 & & 90 \\
\hline 2003 & 1 & & QQA628 & & 1 \\
\hline 2003 & 1 & & X0160032 & & 17 \\
\hline 2003 & 1 & & X0160032 & X0160032 & 1 \\
\hline 2003 & 1 & & X0160036 & & 46 \\
\hline 2003 & 1 & CANAVIEIRO & QQX054 & QQM784 & 33 \\
\hline 2003 & 1 & CANAVIEIRO & QQX054 & QQM785 & 10 \\
\hline 2003 & 1 & CANAVIEIRO & QQX054 & QQM786 & 1 \\
\hline 2003 & 1 & CANAVIEIRO & QQX054 & QQM788 & 15 \\
\hline 2003 & 1 & CANAVIEIRO & QQX054 & QQM791 & 7 \\
\hline 2003 & 1 & FPN & QQD601 & & 1 \\
\hline 2003 & 1 & FPN & QQD601 & QQN657 & 4 \\
\hline 2003 & 1 FPN & QQD601 & QQN659 & 14 \\
\hline 2003 & 1 FPN & QQD601 & QQN662 & 54 \\
\hline 2003 & 1 FPN & QQD601 & QQN665 & 5 \\
\hline 2003 & 1 FPN & QQD602 & & 1 \\
\hline 2003 & 1 FPN & QQD602 & QQN612 & 15 \\
\hline 2003 & 1 FPN & QQD602 & QQN667 & 6 \\
\hline 2003 & 1 FPN & QQD610 & QQD610 & 64 \\
\hline 2003 & 1 FPN & QQX056 & QQN431 & 37 \\
\hline 2003 & 1 FPN & QQX056 & QQN432 & 77 \\
\hline 2003 & 1 FPN & QQX056 & QQN434 & 1 \\
\hline 2003 & 1 FPN & QQX056 & QQN436 & 8 \\
\hline & & & & \\
\hline
\end{tabular}

Tabela 4.1: Parte da tabela fornecida pela montadora sobre os veículos produzidos em um ano 
Para que fosse possível gerar proporções estatísticas dos modelos de veículo produzidos, foi necessário fazer todo um procedimento de análise das informações obtidas. Primeiramente foi necessário saber quantos veículos eram produzidos em cada mês e com essa informação gerar distribuições estatísticas representativas da produção desses veículos. Com a utilização de filtros, gerou-se a seguinte tabela de proporção dos veículos produzidos:

\begin{tabular}{|c|c|c|c|c|c|c|c|c|c|c|c|c|c|}
\hline \multirow{2}{*}{$\begin{array}{c}\text { Porcentagens } \\
\text { mensais }\end{array}$} & \multicolumn{12}{|l|}{2003} & \multirow[t]{2}{*}{2003 Total } \\
\hline & 1 & 2 & 3 & 4 & 5 & 6 & 7 & 8 & 9 & 10 & 11 & 12 & \\
\hline CKD/Vendas & $3,49 \%$ & $2,50 \%$ & $4,21 \%$ & $1,66 \%$ & $3,55 \%$ & $3,76 \%$ & $3,49 \%$ & $0,84 \%$ & $1,84 \%$ & $2,08 \%$ & $2,31 \%$ & $3,21 \%$ & 889 \\
\hline FPN & $17,40 \%$ & $17,61 \%$ & $20,82 \%$ & $18,22 \%$ & $16,85 \%$ & $12,22 \%$ & $10,64 \%$ & $12,15 \%$ & $12,41 \%$ & $10,28 \%$ & $15,18 \%$ & $12,51 \%$ & 4795 \\
\hline FSK & $4,13 \%$ & $3,07 \%$ & $1,53 \%$ & $3,96 \%$ & $4,10 \%$ & $5,27 \%$ & $5,27 \%$ & $4,47 \%$ & $5,73 \%$ & $4,77 \%$ & $5,46 \%$ & $10,02 \%$ & 1572 \\
\hline HPN & $21,03 \%$ & $23,64 \%$ & $25,24 \%$ & $23,68 \%$ & $23,38 \%$ & $20,95 \%$ & $20,29 \%$ & $21,26 \%$ & $23,89 \%$ & $21,41 \%$ & $19,66 \%$ & $31,63 \%$ & 7480 \\
\hline HSK & $7,30 \%$ & $8,12 \%$ & $6,53 \%$ & $6,89 \%$ & $8,38 \%$ & $11,36 \%$ & $12,56 \%$ & $12,57 \%$ & $11,45 \%$ & $10,74 \%$ & $11,92 \%$ & $8,56 \%$ & 3252 \\
\hline LN & $16,14 \%$ & $19,62 \%$ & $18,38 \%$ & $16,28 \%$ & $17,85 \%$ & $15,57 \%$ & $14,16 \%$ & $15,57 \%$ & $9,67 \%$ & $11,32 \%$ & $10,91 \%$ & $14,36 \%$ & 4864 \\
\hline LTC & $3,09 \%$ & $0,76 \%$ & $2,35 \%$ & $0,75 \%$ & $1,47 \%$ & $3,87 \%$ & $5,54 \%$ & $4,47 \%$ & $4,64 \%$ & $5,22 \%$ & $4,92 \%$ & $3,89 \%$ & 1161 \\
\hline Onibus & $27,43 \%$ & $24,67 \%$ & $20,94 \%$ & $28,55 \%$ & $24,42 \%$ & $27,00 \%$ & $28,05 \%$ & $28,67 \%$ & $30,37 \%$ & $34,19 \%$ & $29,63 \%$ & $15,82 \%$ & 8933 \\
\hline Total geral & $100,00 \%$ & $100,00 \%$ & $100,00 \%$ & $100,00 \%$ & $100,00 \%$ & $100,00 \%$ & $100,00 \%$ & $100,00 \%$ & $100,00 \%$ & $100,00 \%$ & $100,00 \%$ & $100,00 \%$ & 32946 \\
\hline
\end{tabular}

Tabela 4.2: Proporções dos tipos de veículos produzidos no ano de 2003

O Arena® trabalha com proporções acumulativas onde as proporções são somadas, o que gerou a seguinte tabela:

\begin{tabular}{|c|c|c|c|c|c|c|c|c|c|c|c|c|c|}
\hline \multirow{2}{*}{$\begin{array}{c}\text { Porcentagens } \\
\text { acumuladas }\end{array}$} & \multicolumn{12}{|l|}{2003} & \multirow[t]{2}{*}{2003 Total } \\
\hline & 1 & 2 & 3 & 4 & 5 & 6 & 7 & 8 & 9 & 10 & 11 & 12 & \\
\hline CKD/Vendas & 0,03 & 0,03 & 0,04 & 0,02 & 0,04 & 0,04 & 0,03 & 0,01 & 0,02 & 0,02 & 0,02 & 0,03 & 889 \\
\hline FPN & 0,21 & 0,20 & 0,25 & 0,20 & 0,20 & 0,16 & 0,14 & 0,13 & 0,14 & 0,12 & 0,17 & 0,16 & 4795 \\
\hline FSK & 0,25 & 0,23 & 0,27 & 0,24 & 0,24 & 0,21 & 0,19 & 0,17 & 0,20 & 0,17 & 0,23 & 0,26 & 1572 \\
\hline HPN & 0,46 & 0,47 & 0,52 & 0,48 & 0,48 & 0,42 & 0,40 & 0,39 & 0,44 & 0,39 & 0,43 & 0,57 & 7480 \\
\hline HSK & 0,53 & 0,55 & 0,58 & 0,54 & 0,56 & 0,54 & 0,52 & 0,51 & 0,55 & 0,49 & 0,55 & 0,66 & 3252 \\
\hline LN & 0,69 & 0,75 & 0,77 & 0,71 & 0,74 & 0,69 & 0,66 & 0,67 & 0,65 & 0,61 & 0,65 & 0,80 & 4864 \\
\hline LTC & 0,73 & 0,75 & 0,79 & 0,71 & 0,76 & 0,73 & 0,72 & 0,71 & 0,70 & 0,66 & 0,70 & 0,84 & 1161 \\
\hline Onibus & 1,00 & 1,00 & 1,00 & 1,00 & 1,00 & 1,00 & 1,00 & 1,00 & 1,00 & 1,00 & 1,00 & 1,00 & 8933 \\
\hline Total geral & 2,00 & 2,00 & 2,00 & 2,00 & 2,00 & 2,00 & 2,00 & 2,00 & 2,00 & 2,00 & 2,00 & 2,00 & 32946 \\
\hline
\end{tabular}

Tabela 4.3: Proporções acumuladas dos tipos de veículos produzidos no ano de 2003

O mesmo procedimento de análise foi feito para a análise de variantes brutas e exatas e com isso foi possível obter as proporções acumuladas para cada tipo de variante, de acordo com a tabela 5.4 para as variantes brutas. Para as variantes exatas existe uma tabela similar. 


\begin{tabular}{|c|c|c|c|c|}
\hline & & Porcentagem & $\begin{array}{c}\text { Porcentagem } \\
\text { Acumulada }\end{array}$ & $\begin{array}{l}\text { Código } \\
\text { Modelo }\end{array}$ \\
\hline \multirow[t]{15}{*}{ CKD/Vendas } & QQA025 & $11,72 \%$ & 0,117 & 211 \\
\hline & QQA519 & $1,26 \%$ & 0,130 & 222 \\
\hline & QQA610 & $20,31 \%$ & 0,333 & 211 \\
\hline & QQA623 & $33,08 \%$ & 0,664 & 211 \\
\hline & QQA628 & $6,56 \%$ & 0,729 & 211 \\
\hline & QQA651 & $3,35 \%$ & 0,763 & 211 \\
\hline & QQC807 & $0,28 \%$ & 0,766 & 12 \\
\hline & QQC836 & $0,84 \%$ & 0,774 & 11 \\
\hline & QQC841 & $10,05 \%$ & 0,874 & 12 \\
\hline & QQC885 & $0,28 \%$ & 0,877 & 11 \\
\hline & QQD602 & $0,56 \%$ & 0,883 & 42 \\
\hline & QQD662 & $6,28 \%$ & 0,946 & 42 \\
\hline & QQD665 & $0,98 \%$ & 0,955 & 42 \\
\hline & QQD685 & $4,47 \%$ & 1,000 & 42 \\
\hline & Total & $100,00 \%$ & 2,000 & \\
\hline \multirow[t]{5}{*}{ FPN } & QQD601 & $19,05 \%$ & 0,191 & 601 \\
\hline & QQD602 & $9,99 \%$ & 0,290 & 602 \\
\hline & QQD605 & $1,43 \%$ & 0,305 & 605 \\
\hline & QQD608 & $1,60 \%$ & 0,321 & 608 \\
\hline & QQD610 & $19,22 \%$ & 0,513 & 610 \\
\hline FPN + L98 & QQX052 & $8,94 \%$ & 0,602 & 52 \\
\hline \multirow{2}{*}{ FPN + L98 } & QQX056 & $36,16 \%$ & 0,964 & 56 \\
\hline & QQX057 & $0,02 \%$ & 0,964 & 57 \\
\hline \multirow[t]{3}{*}{ FPN (L98) } & QQX068 & $3,31 \%$ & 0,997 & 65 \\
\hline & 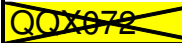 & $>2,2 \%$ & $>1000$ & $>42$ \\
\hline & Total & $100,00 \%$ & 2,000 & \\
\hline \multirow[t]{3}{*}{ FSK } & QQX063 & $62,64 \%$ & 0,626 & 63 \\
\hline & QQX066 & $37,36 \%$ & 1,000 & 66 \\
\hline & Total & $100,00 \%$ & 2,000 & \\
\hline
\end{tabular}

Tabela 4.4: Proporções das Variantes Brutas

Com essas proporções foi possível começar a modelar o surgimento das entidades do modelo e a sua diferenciação de acordo com a seqüência de produção.

As entidades são criadas no modelo através de único bloco Create que cria um único tipo de entidade. Essa entidade representa todos os veículos a serem produzidos e o tempo entre a criação de cada entidade ficou definido como intervalo de tempo conseguido pela divisão entre o tempo total de produção em um dia e o número de veículos a serem produzidos nesse dia, ou seja, o takt time virtual para a produção de todos os veículos.

Depois de criada as entidades, foi decidido que o tipo de veículo diferencia as entidades do modelo, ou seja, um veículo FSK se torna uma entidade correspondente no modelo e da mesma forma para os outros veículos e outras entidades. 
Já as variantes brutas modificam a entidade através dos atributos, ou seja, uma entidade do tipo FSK com a variante bruta QQX063 (Tabela 5.4) se torna uma entidade correspondente que teria um atributo equivalente ao QQX063. É necessário recordar que um atributo no Arenaß modifica a entidade e a acompanha até o fim da simulação.

Como a observação da tabela, existem diferentes nomenclaturas e códigos para os diferentes tipos de veículo e variantes de cabina. Não é possível com o Arena®, definir tantos códigos e nomes. Isso tornaria o trabalho confuso e sujeito a diversos erros. Dessa forma foi crida uma tabela de correlação de códigos para que fosse possível modelar as diferentes variantes. A tabela 5.5 mostra algumas dessas correlações. 


\begin{tabular}{|c|c|c|c|c|}
\hline Tipo Veículo & Entity.Type & Variante & Entity.type2 & Descrição \\
\hline \multirow[t]{7}{*}{ HPN } & 1 & QQC152 & 152 & Cabina HPN \\
\hline & & QQC 800 & 800 & Cab. HPN M96 L1620 c Facelift D \\
\hline & & QQC 802 & 802 & Cab. HPN M96 LK1620 c Facelift \\
\hline & & QQB 808 & 808 & Cab. 1623 SKL+PSE M96 Leito / Larga \\
\hline & & QQX 057 & 157 & Mesma variante FPN (desconsiderado) \\
\hline & & QQX 060 & 60 & Cab. 1418EL/51 M1999 \\
\hline & & QQX 091 & 191 & Mesma variante LTC (desconsiderada) \\
\hline \multirow[t]{5}{*}{$\overline{\mathrm{LN}}$} & 2 & QQA 021 & 21 & Cab. LN1 (710) EURO II D6888 \\
\hline & & QQA 022 & 22 & Cab. LN EURO II \\
\hline & & QQA 023 & 23 & Cab. LN 710 EURO II - Rev. Lavável \\
\hline & & QQA 024 & 24 & Cab. LN 710 EURO II - Rev. Lavável \\
\hline & & QQA 650 & 650 & Cab. LN ônibus \\
\hline \multirow[t]{8}{*}{ HSK } & 3 & QQB 809 & 809 & Cab. SKL \\
\hline & & QQB 810 & 810 & Cab. SKL \\
\hline & & QQB 812 & 812 & Cab. HPN SKL Leito / Larga \\
\hline & & QQB 813 & 813 & Cab. SKL M96 LS 1632 D694811 Capo c 5 furos \\
\hline & & QQX 054 & 54 & Cab. Canavieiro LS 2638 \\
\hline & & QQX 057 & 357 & Mesma variante FPN (desconsiderado) \\
\hline & & QQX 072 & 72 & Cab. HSK teto alto \\
\hline & & QQX 073 & 73 & Cab. HSK teto baixo \\
\hline \multirow[t]{10}{*}{ FPN } & 4 & QQD 601 & 601 & Cab. FPN (M96) - D693810 - 1 \\
\hline & & QQD 602 & 602 & Cab. FPN M96 1720 - D69381 \\
\hline & & QQD 605 & 605 & Cab. FPN M96 1720K - D6938 \\
\hline & & QQD 608 & 608 & Cab. FPN M96 - D693.880 - 1 \\
\hline & & QQD 610 & 610 & Cab. FPN M96 1720/48 6x2 D69381 \\
\hline & & QQX 052 & 52 & Cab. FPN \\
\hline & & QQX 056 & 56 & Cab. 1318 M2000 / Cab. 1215C M2000 \\
\hline & & QQX 057 & 57 & Cab. 2428 / 2423 / 1728 / 1718 M17 curta estreita (desc \\
\hline & & QQX 068 & 68 & Meia Cabina L98 \\
\hline & & QQX 072 & 472 & Cab. FPN (Mesma variante HSK) - desconsiderado \\
\hline FSK & 5 & $\begin{array}{l}\text { QQX } 063 \\
\text { QQX } 066\end{array}$ & $\begin{array}{l}63 \\
66\end{array}$ & $\begin{array}{l}\text { Cabina FSK teto alto / tunel alto } \\
\text { Cabina FSK teto baixo / tunel alto }\end{array}$ \\
\hline \multirow[t]{4}{*}{ LTC } & 6 & QQX 070 & 70 & Cab. LTC 715 C/ Espelho p RAM \\
\hline & & QQX 071 & 71 & Cab. LTC 715 S/ Espelho p RAM \\
\hline & & QQX 090 & 90 & Cab. LTC 915 C/ Espelho p RAM \\
\hline & & QQX 091 & 91 & Cab. LTC 915 S/ Espelho p RAM \\
\hline ônibus & 7 & & & \\
\hline \multirow[t]{12}{*}{ Vendas/CKD } & 8 & QQA 066 & 222 & Cab. LN Pintada \\
\hline & & QQC 850 & 11 & Cab. HPN M96 Bruta ET. A69456000 \\
\hline & & QQC 851 & 13 & Cab. HPN M96 ET Completa A69460 \\
\hline & & QQC 861 & 12 & Cab. ET HPN M96 Pintada \\
\hline & & QQC 862 & 12 & Cab. ET HPN M96 Pintada \\
\hline & & QQC 863 & 12 & Cab. ET HPN M96 Pintada \\
\hline & & QQC 864 & 12 & Cab. ET HPN M96 Pintada \\
\hline & & QQC 865 & 12 & Cab. ET HPN M96 Pintada \\
\hline & & QQD 260 & 41 & Cab. FPN ET+PSE Bruta \\
\hline & & QQD 650 & 42 & Cab. FPN M96 Repos. A6936000 \\
\hline & & QQ 66 & 51 & Cab. FSK Bruta \\
\hline & & QQN 901 & 633 & Cab. LTC Acabada \\
\hline
\end{tabular}

Tabela 4.5: Correlações entre tipos de veículo e variantes brutas com o tipo de entidade e o atributo de variante exata

$\mathrm{Na}$ tabela 5.5 já aparecem alguns dos termos utilizados no Arena®. Entity.Type é o tipo de entidade e representa o tipo de veículo. Já o comando Entity. Type2 foi o atributo escolhido para representar a variante bruta. 
O restante das variantes e outras características como cor da cabina geraram atributos da mesma forma, mas seria muito extenso expor todos eles.

A modelagem no Arena® de todo o processo de geração da seqüência ficou como mostra a figura 5.1.

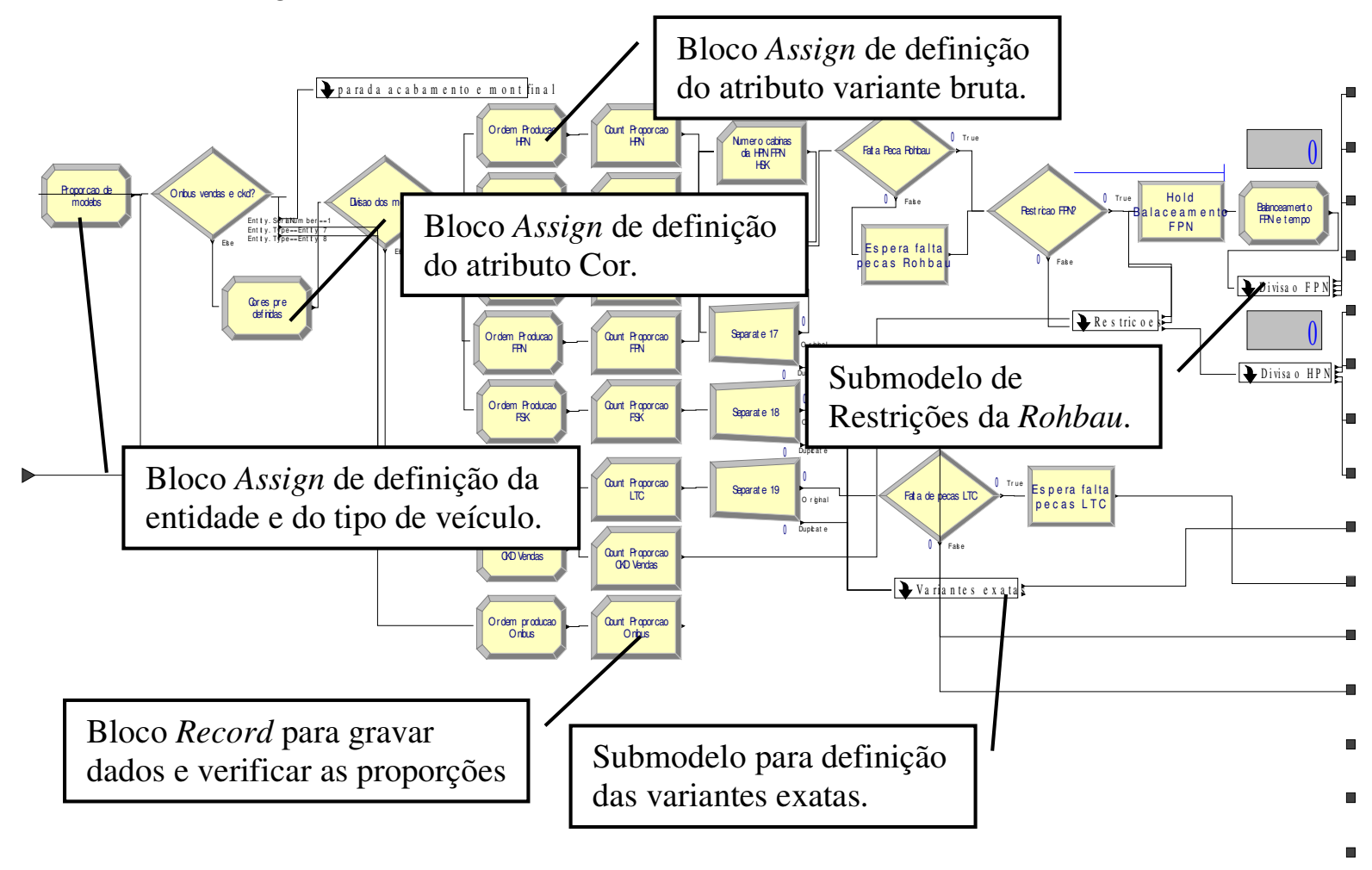

Figura 4.1: Modelo da programação da seqüência de produção dos veículos

Vinte e cinco por cento dos veículos tem as cores das cabinas definidas antes pelo departamento de vendas, principalmente as com cores especiais. O restante é definido na pintura pela proporção já colocada: (branca - 60\%, azul - 20\% e vermelha - 20\%). Para essas cabinas com cor pré-definida, esse atributo já é definido na construção da seqüência.

A definição do tipo das entidades e das variantes brutas e exatas é feita através dos blocos Assign do Arena®, ilustrado na figura 5.2. 


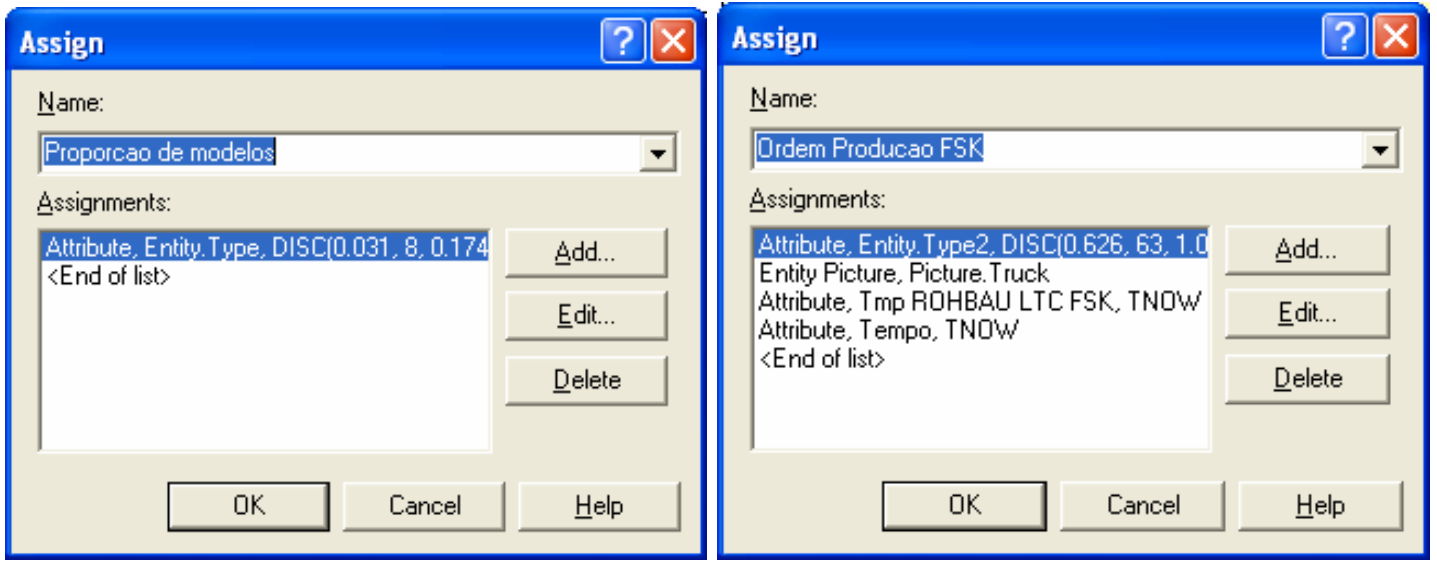

Figura 4.2: Dois dos blocos Assign de definição dos atributos das entidades

Além das variantes brutas e exatas também são definidos vários atributos e variáveis que serão utilizados no controle da seqüência ao longo dos processos e atributos para controle do tempo dos processos. O controle da seqüência é feito ao final de cada etapa do modelo para verificar o quanto cada etapa foi responsável pela variação ou defasagem da seqüência. Dentre esses atributos pode-se citar: "Entity.SequenceMBruta" que indica a posição da cabina na seqüência criada originalmente e "Tmp ROHBAU LTC FSK" que serve para marcar o tempo de produção do início da Nova Rohbau. Essa informação será subtraída do tempo final da Nova Rohbau para informação do tempo necessário de produção.

Através dos blocos Record foi possível gravar as informações específicas contidas em cada entidade, como tempos de processo, atributos, quantidade de entidades. Essas informações foram úteis para a verificação e validação do modelo através de relatórios fornecidos pelo Arena® e através da observação da simulação. No capítulo 4.5 será descrita a validação e verificação.

Nesse momento a seqüência de entidades é criada para duas etapas, para a Rohbau e Nova Rohbau e para a montagem final. A seqüência das Rohbau ainda não está diferenciada por variante exata e é modificada logo a pós a criação de acordo com as restrições. As restrições da Rohbau são a impossibilidade de montagem de 3 cabinas pesadas na seqüência e uma nova divisão das cabinas do modelo FPN para balanceamento. A figura 5.3 mostra o modelo de restrição das cabinas pesadas, esse modelo conta as cabinas pesadas em seqüência e caso existam mais de 2 em seqüência, ele atrasa a cabina pesada para separá-la. 


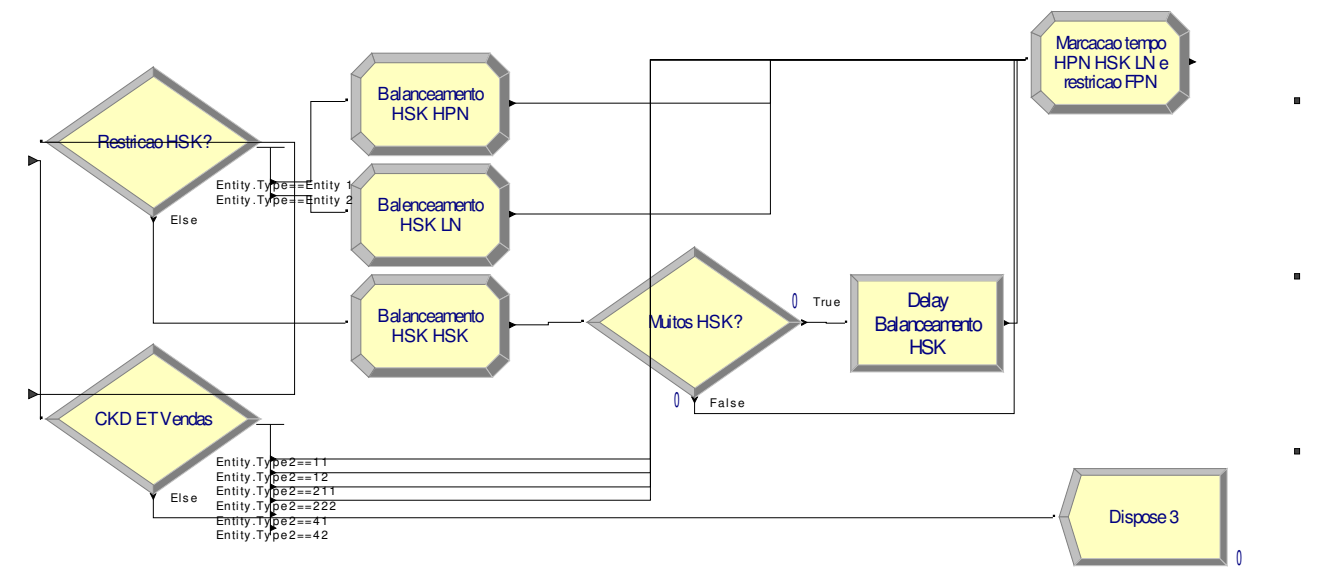

Figura 4.3: Modelo para modificar a seqüência devido à restrição de cabinas pesadas

Já a seqüência da montagem final está diferenciada pelas variantes exatas e não apresenta modificações. Depois de criadas as entidades, elas vão para os outros processos que também foram modelados de acordo com o sistema real. No caso da Rohbau e Nova Rohbau, a seqüência é dividida de acordo com os tipos de veículo e as respectivas linhas de produção.

\subsubsection{Linhas e processos de produção Rohbau}

Nessa etapa foram modeladas as linhas 1, 1A, 2/3, 4, 5, 6, 7 e 8, a linha Grill e a linha Funilaria.

As linhas de montagem do assoalho $1,2 / 3$ e $1 \mathrm{~A}$ foram modeladas anteriormente as linhas 7 e 8 respectivamente. Já as linhas 4,5 e 6 foram modeladas separadamente e um bloco Decide foi utilizado para direcionar as peças. Após a saída das linhas 7 e 8 foram modeladas a linha Grill e a linha Funilaria, até a entrega no elevador do Transportador Aéreo.

Todas as linhas foram modeladas baseadas na configuração de postos de trabalho, elevadores e postos pulmão ou de trabalhos extra. O tempo de processo utilizado para cada posto de trabalho depende do takt time de cada linha, ou seja, o tempo disponível dividido pelo número de cabinas a serem produzidas em cada linha. Para que seja mais fácil modificar os tempos de processo foram criadas variáveis para definição do usuário de quantas cabinas de cada tipo seriam produzidas. A tabela abaixo mostra o cálculo do takt time de todas as etapas do sistema, de acordo com o que é produzido em cada sistema. 


\begin{tabular}{|c|c|c|c|c|c|c|c|c|c|c|c|}
\hline Produção & HPN & LN & HSK & FPN & FSK & LTC & Turno & Ônibus & & & \\
\hline Setembro & 30 & 15 & 17 & 25 & 8 & 7 & 440 & 43 & & & \\
\hline Calcular com & 46 & 30 & 22 & 30 & 12 & 7 & & 57 & & & \\
\hline Takt & Rohbau HPN & Rohbau FPN & $\mathrm{HPN}+\mathrm{FPN}$ & FSK+LTC & FSK & LTC & FSK+HSK & Prédio 41 & $\mathrm{HPN}+\mathrm{FPN}+\mathrm{LTC}$ & Todos & Pintura \\
\hline & 8,979591837 & 29,33333333 & 6,875 & 23,15789474 & 36,7 & 62,85714286 & 25,882353 & 5,176471 & 7,787610619 & 4,313725 & 5,986395 \\
\hline
\end{tabular}

Tabela 4.6: Cálculo do takt time de cada etapa do sistema

O modelo de todas as linhas segue a mesma idéia, foi definido um recurso com a capacidade total da linha através do bloco Seize e depois foram utilizados blocos Process para os postos de trabalho, com um recurso de capacidade unitária que representa o posto, e Delay para os postos pulmão e elevadores. Os blocos Process têm o tempo definido através do takt time da linha e os Delay como um ou dois minutos de acordo com o tempo de movimentação.

Antes de cada bloco Release para liberação do recurso da capacidade da linha, foi utilizado um bloco Seize da etapa seguinte. Como não existem estoques intermediários entre as etapas e o sistema pode ficar bloqueado quando a etapa seguinte estiver parada, é necessário que se solicite o recurso da etapa seguinte antes de liberar o da etapa atual.

A figura abaixo ilustra a modelagem da linha $2 / 3$.

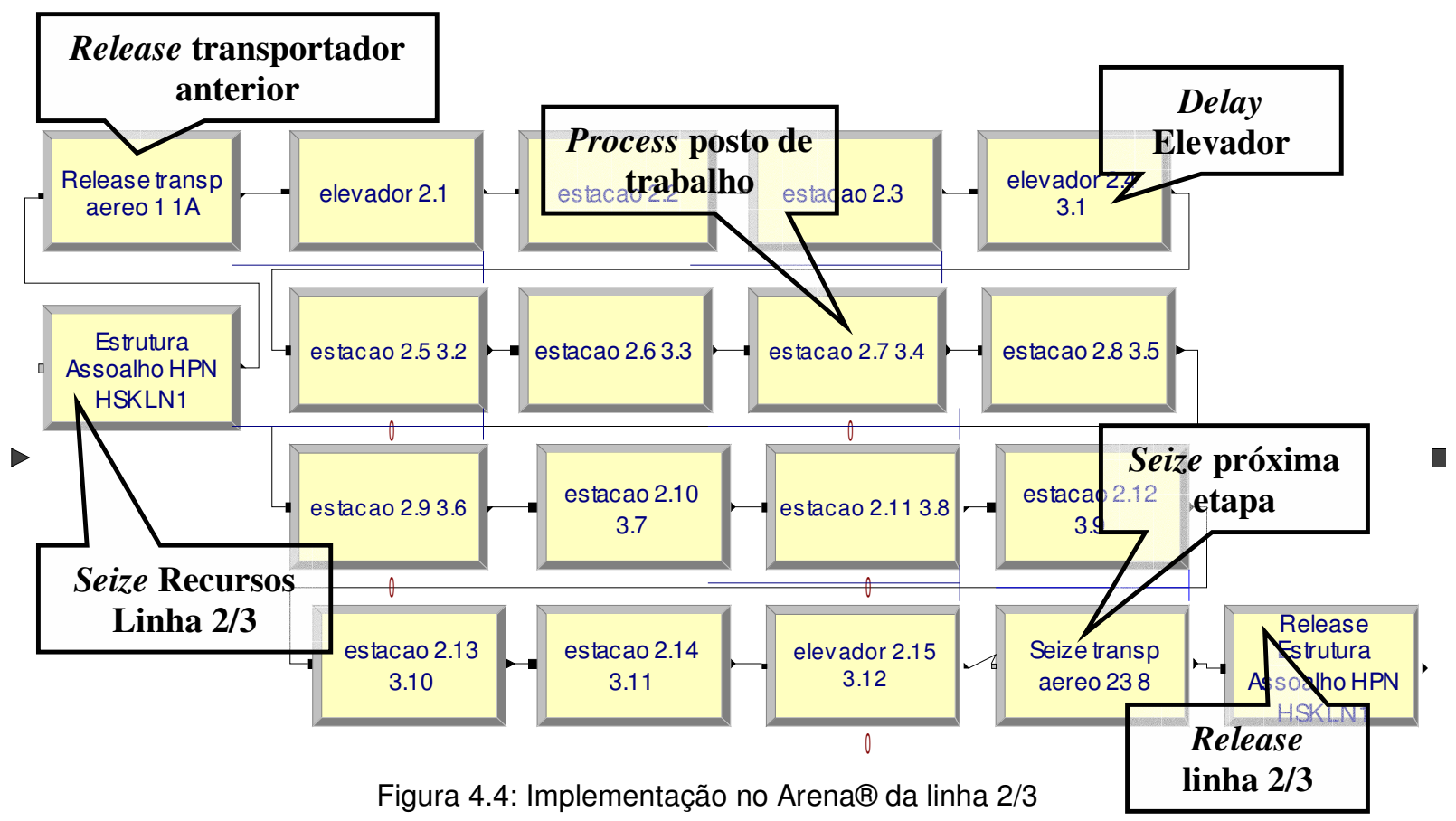

A modelagem de todas as outras linhas seguiu esse princípio, mas cada uma de acordo com o seu produto específico, capacidade e características especiais. 
As linhas 7 e 8 são especiais, pois recebem produtos de outras linhas. Para modelar essa montagem, as entidades foram quadruplicadas na entrada da Rohbau. Quando uma entidade é duplicada, a cópia mantém todas as características da original. Assim foram utilizadas cópias das entidades para simular a montagem do teto, da parede traseira e da parede frontal. Após a montagem dessas peças, elas são encaminhas às linhas 7 ou 8 através de blocos Decide que avaliam de qual tipo básico de cabina é a peça. Após o decide as peças são unidas às entidades principais em blocos Match e Batch, no modelo das linhas 7 e 8 . Os blocos Match comparam as variantes brutas das entidades e só permitem a passagem pelo bloco das entidades de variantes brutas iguais. Isso ocorre, pois muitas vezes podem ocorrer falhas na montagem de algum dos itens e só podem ser montados itens iguais. Depois dos blocos Match, as entidades são reunificadas através de um bloco Batch. A figura 5.5 mostra o modelo da linha 8, o qual é similar ao modelo da linha 7.

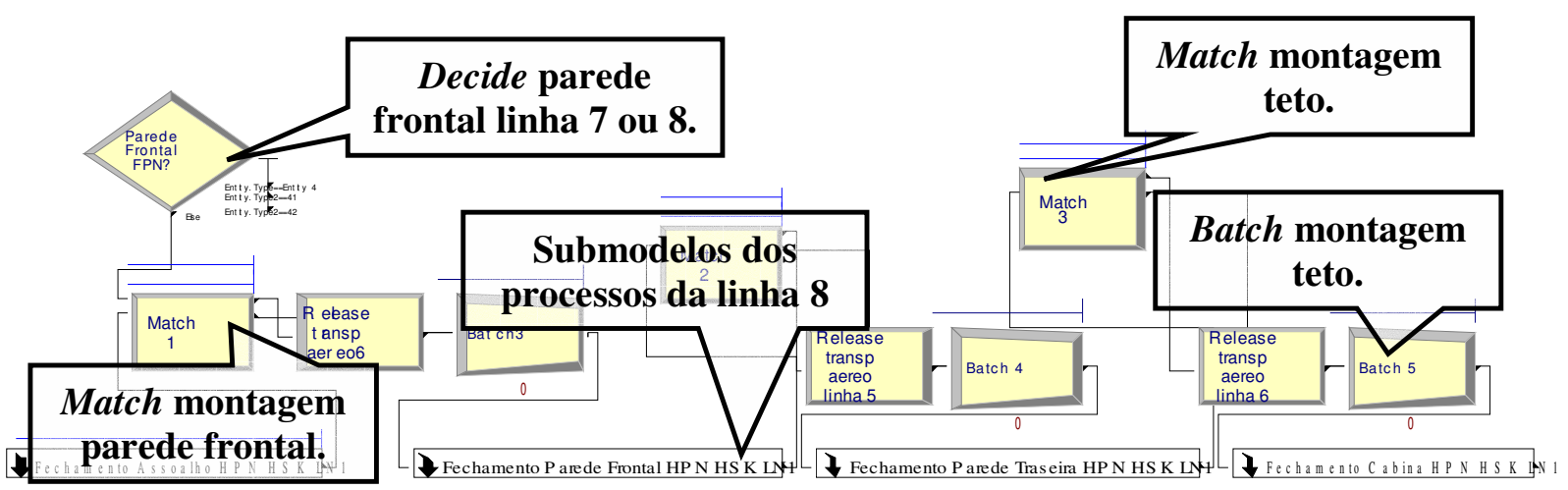

Figura 4.5: Montagem das partes das cabinas na linha 8

Depois de unificadas, as entidades vão para a linha Grill e depois para a linha Funilaria para serem encaminhadas ao transportador aéreo.

$\mathrm{Na}$ linha Grill foi considerado um único recurso de capacidade 6 para a alocação de, no máximo, 6 cabinas na linha. Os processos foram modelados como blocos Delay de acordo com as informações dos tempos de processo. Também foi criada a possibilidade de um retrabalho onde, estatisticamente, no máximo 2 cabinas podem estar sendo retrabalhadas, o que é um processo real no sistema, já que um dos processos da linha Grill é o controle visual. Após a linha Grill, as cabinas passam por um transportador aéreo em direção à linha de montagem de portas e funilaria, onde passará por mais cinco estações, e será retirada para o elevador que leva as cabinas para a pintura. 
A linha de montagem de portas e funilaria também foi modelada de acordo com as tabelas de tempos de processos, e utiliza um recurso de capacidade 5 de acordo com a capacidade da linha. Mas essa linha foi considerada apenas como um bloco Process com o tempo somado de todos os processos para simplificação.

Após a montagem das portas, as cabinas são escolhidas segundo a regra de 15 de cada tipo por mês para medição. O processo de medição de uma cabina dura em torno de 2 horas. Existe uma única sala de medição amostral para todas as cabinas de todos os modelos.

Os Skids, que são solidários às cabinas por quase todo o processo, foram modelados como um recurso de capacidade finita (número de Skids disponíveis). Caso ocorresse algum problema de ocupação dos Skids, a falta bloqueia o sistema que não pode mais movimentar as cabinas.

Outra característica, também foi modelada, foram as falhas de processo. Através do tratamento dos dados obtidos pelo sistema da cadastramento de falhas da montadora, foi possível analisar quais falhas ocorriam, em quais etapas e o tempo de duração durante o período de um ano. As falhas de processo e paradas de linha são ocorrências complicadas e o seu cadastramento é muitas vezes não é fiel, pois nem todos querem relatar as falhas cometidas. A maior parte do relatório de falhas contém informações que um outro setor não responsável pela falha. Dessa forma, foi necessário, além de trabalhar os dados, muita pesquisa para que fosse possível modelar as falhas o mais próximo possível da realidade. A tabela abaixo mostra a estatística de falhas de processo modelada.

\begin{tabular}{|c|c|c|c|c|c|c|c|c|c|c|c|c|}
\cline { 2 - 12 } \multicolumn{1}{c|}{ Rohbau } & \multicolumn{10}{c|}{ Área } \\
\cline { 2 - 13 } \multicolumn{1}{c|}{} & Linha 1 & Linha 1A & Linha 2/3 & Linha 4 & Linha 5 & Linha 6 & Linha 7 & Linha 8 & Grill & Funilaria & Elevador \\
\hline Tempo médio & $02: 15$ & $02: 00$ & $01: 13$ & $02: 48$ & $01: 41$ & $01: 15$ & & $02: 09$ & $02: 06$ & $02: 51$ & $01: 00$ \\
\hline DesvPad & $02: 11$ & & $01: 02$ & $01: 27$ & $00: 42$ & & & $01: 37$ & $02: 16$ & $02: 42$ & \\
\hline Paradas/mês & 3,75 & 0,25 & 1,5 & 1 & 1,75 & 0,25 & 0 & 1,5 & 2,5 & 7 & 0,25 \\
\hline DesvPad & 1,4392 & 0,26726 & 0,851631 & 0,82542 & 0,8549 & 0,2673 & 0 & 0,9376 & 0,994 & 2,11224 & 0,26726 \\
\hline
\end{tabular}

Tabela 4.7: Estatística de falhas de processo - Rohbau

Essas estatísticas foram implementadas no módulo Failure do Arenaß. As falhas foram programadas no respectivo recurso como Preempt, ou seja, ela interrompe o trabalho do recurso imediatamente, como se fosse uma parada de linha. A Figura 5.6 mostra a programação de uma falha no Arenaß. 


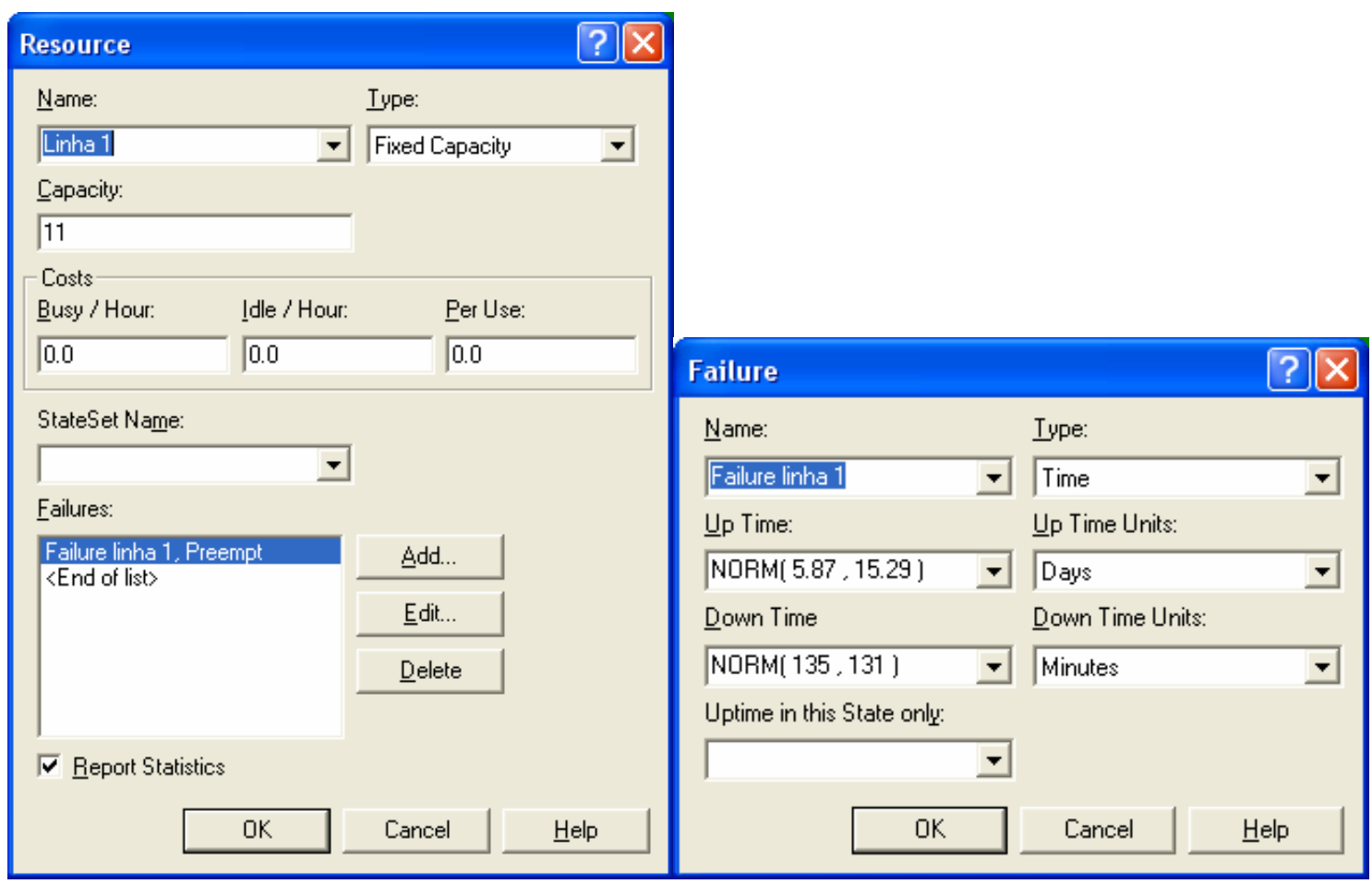

Figura 4.6: Resource Linha 1 e a sua respectiva estatística de falha

Várias informações das entidades são gravadas com blocos Record e baseados nos atributos determinados previamente, como o tempo do processo total, takt time das cabinas e o número de cabinas que passou pelo modelo. Também foram utilizados recursos de animação, para que seja possível ver o que ocorre com o modelo em tempo real. O modelo final de toda a Rohbau no Arena tem a seguinte forma:

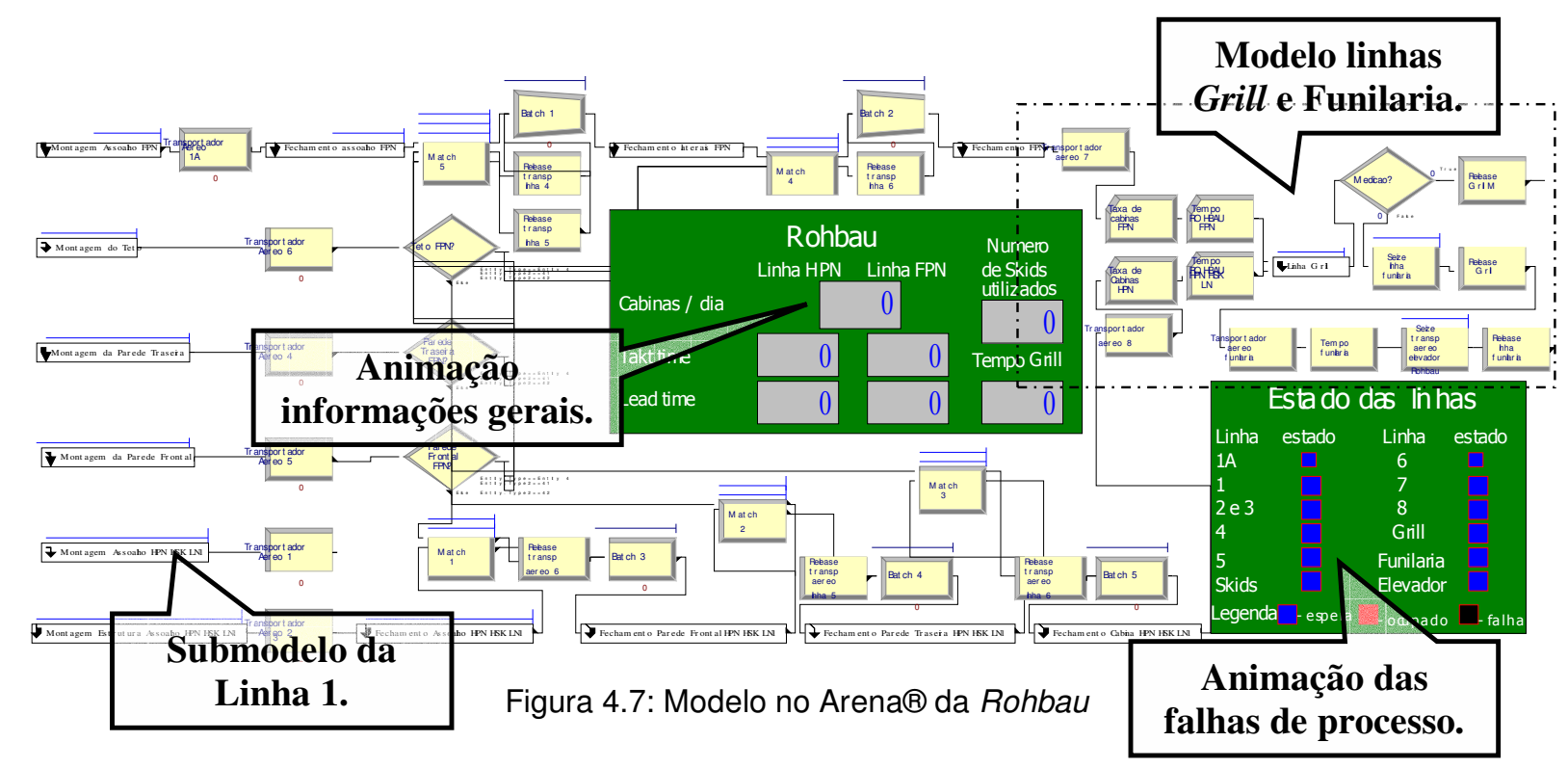


Em nenhum momento, durante a modelagem, foram consideradas características como mão-de-obra, ou balanceamento da mão-de-obra. Os recursos foram modelados apenas para especificar as capacidades das linhas e características acima foram desconsideradas por não serem relevantes para o problema da geração dos estoques, ou seja, a modelagem foi feita direcionada aos objetivos a serem atingidos.

\subsubsection{Linha e processo de produção nova Rohbau}

Nesta linha, o volume de dados disponíveis é muito pequeno. As duas linhas foram construídas recentemente para serem responsáveis por toda a produção no futuro, junto ao lançamento de novos veículos. Mas isso ainda não ocorreu devido à indefinição dos modelos a serem produzidos pela empresa. E ainda existem muitos testes sendo feitos nas linhas, o que faz com que os regimes de trabalho sejam muito inconstantes. A linha ainda trabalha apenas em 1 turno, enquanto toda o restante da fábrica trabalha em 2, devido aos baixos índices de produção.

Da mesma forma que na Rohbau, as entidades seqüenciadas chegam à Nova Rohbau já divididas. Foram modeladas duas linhas de produção da Nova Rohbau, a referente ao LTC e a outra referente ao FSK. Os tempos de processo também foram modelados de acordo com o takt time, ou seja, pelo tempo disponível dividido pelo número de veículos produzidos. Logicamente que o tempo disponível é menor nesse caso e as linhas ficam paradas durante um turno diário.

Para as duas linhas foram utilizados blocos Process para modelar cada um dos processos macro, ou seja, montagem do assoalho, das paredes e teto. $\mathrm{Da}$ mesma forma celular que é o sistema real.

Os AGV também foram configurados como recursos ocupados pelas cabinas, pois ficam solidários às cabinas ao longo de todo o processo. Eles são selecionados no início do processo e liberados na quando entram no Transportador Aéreo. Os AGV que determinam o bloqueio da linha em caso de parada das etapas posteriores ou anteriores.

Cada etapa do processo, modelada por um bloco Process, utiliza um recurso correspondente que tem a capacidade do número de cabinas que podem ser trabalhadas simultaneamente. Uma característica especial é a utilização de um módulo Schedule que configura a operabilidade do recurso durante um único turno. A Figura 5.8 mostra a configuração dos blocos Process, Resource e Schedule para a 
Área 11 que é a montagem do assoalho do LTC. Essa área tem capacidade para 5 cabinas em processo, por isso o Schedule tem capacidade 5 durante 440 minutos e 0 durante os outros 440 minutos. Assim está configurado o trabalho em 1 único turno.

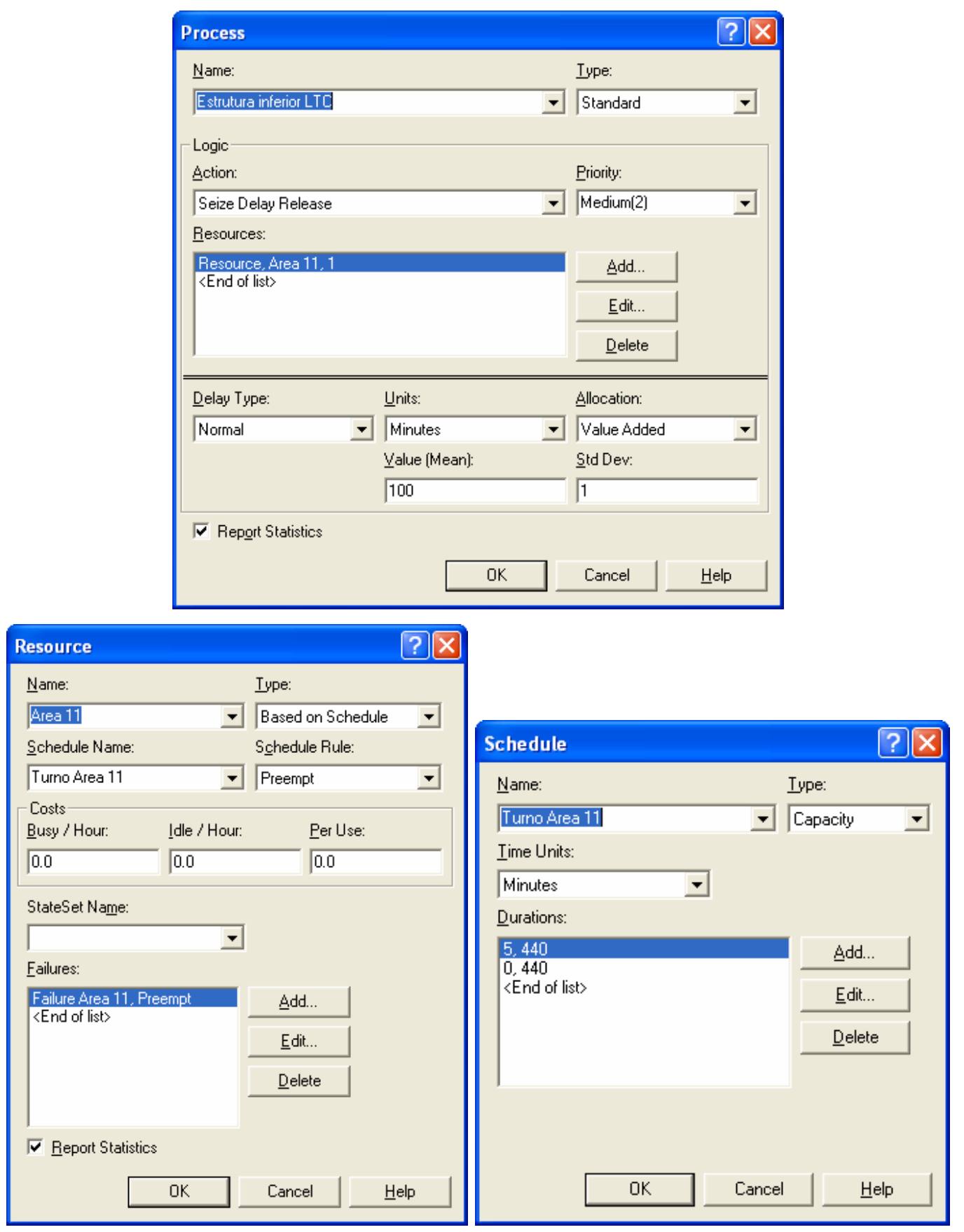

Figura 4.8: Exemplo da configuração do processo da área 11, através dos blocos Process, Resource e Schedule para 1 único turno 
Assim como na Rohbau, também foram definidas as falhas de processo para a nova Rohbau com base nos mesmos relatórios de falhas de processos obtidos para essa área. As dificuldades nos relatórios foram ainda maiores, devido à falta de informação confiável. A tabela 5.8 mostra as estatísticas obtidas.

\begin{tabular}{|c|c|c|c|c|c|c|c|c|}
\hline $\begin{array}{c}\text { Nova } \\
\text { Rohbau }\end{array}$ & \multicolumn{9}{|c|}{ Áreas } \\
\cline { 2 - 9 } & Área 1 & Áreas 2/3 & Área 4 & Área 5 & Áreas 7/8 & Área 9 & Área 11 & Áreas 12/13 \\
\hline $\begin{array}{c}\text { Tempo } \\
\text { médio }\end{array}$ & $02: 08$ & $01: 30$ & $02: 16$ & $01: 22$ & $01: 29$ & $05: 03$ & $01: 50$ & $01: 52$ \\
\hline DesvPad & $02: 16$ & $01: 50$ & $02: 07$ & $00: 54$ & $01: 18$ & $03: 31$ & $01: 26$ & $01: 15$ \\
\hline Paradas/mês & 3,00 & 1,93 & 1,67 & 2,33 & 5,53 & 0,33 & 0,93 & 2,20 \\
\hline DesvPad & 3,51 & 2,99 & 2,69 & 2,85 & 9,32 & 0,72 & 1,49 & 2,88 \\
\hline
\end{tabular}

Tabela 4.8: Estatística de falhas de processo Nova Rohbau

Depois das características definidas, foi modelada toda a Nova Rohbau, que ficou como mostra a Figura 5.9

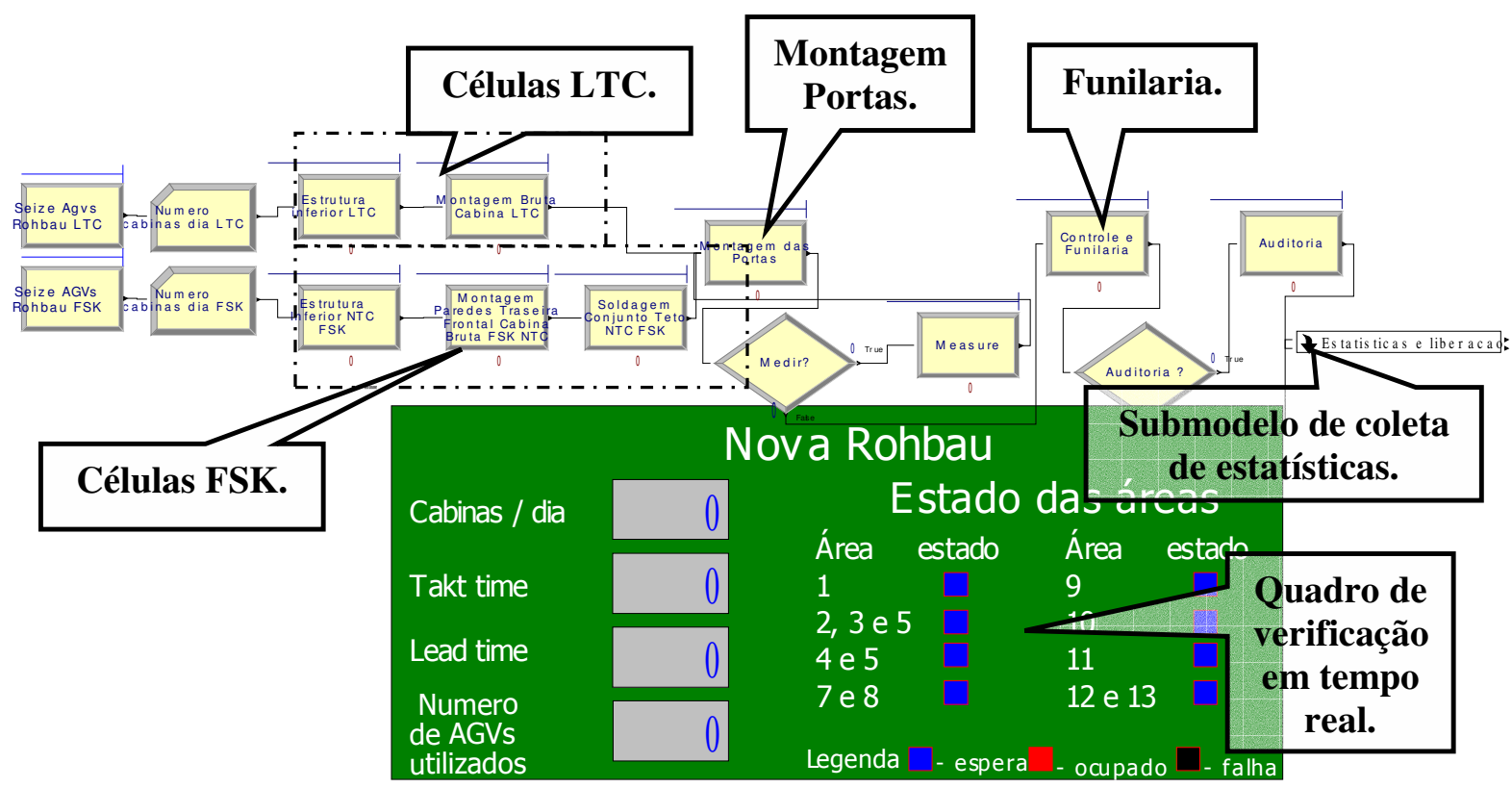

Figura 4.9: Implementação no Arena® do modelo da Nova Rohbau

Portanto as entidades são montadas nas suas respectivas linhas e depois passam para uma única linha de montagem de portas. Após a montagem das portas são selecionadas, da mesma forma, 15 cabinas de cada tipo ao mês para serem medidas na sala de medição da Rohbau. A modelagem dessa medição foi feita 
através de um bloco Process que compartilha o recurso da sala de medição da Rohbau. Assim, ficou mais fácil a modelagem, sendo como se a sala de medição viesse até a Nova Rohbau.

Depois da montagem das portas, as cabinas vão para a funilaria, constituída por dois postos paralelos. A funilaria era o gargalo dessa etapa de produção, devido ao alto número de defeitos nas cabinas, pois a Nova Rohbau é uma linha muito nova. Dessa forma foi feito um estudo de tempos e métodos na funilaria para tornar o trabalho mais eficiente. Todos os tempos obtidos foram incluídos no modelo.

Depois da funilaria as entidades são lidas por um submodelo de coleta de informações baseado em blocos Record que armazena os dados e propicia a verificação, tanto em tempo real como através de relatórios.

\subsubsection{Saída das Rohbau e o Transportador Aéreo.}

As cabinas provenientes da Rohbau e Nova Rohbau devem seguir para a pintura através do Transportador Aéreo. A lógica de alimentação do Transportador Aéreo é a de ordem de chegadas, ou FIFO (First In, First Out - Primeiro que chega, primeiro que sai). Não é feita qualquer tentativa de correção na entrada. Muitas vezes a seqüência ainda é prejudicada pela falha do operador em alimentar o Transportador. Outra característica é que a falta de espaço faz com que o sistema seja bloqueado caso a pintura não possa receber mais cabinas.

Dessa forma é necessário ocupar o recurso Elevador do Transportador Aéreo através de um bloco Seize antes de liberar os recursos das Rohbau, para que o modelo represente o sistema real.

O transportador aéreo foi modelado como um Conveyor acumulativo. Este poderia ter sido modelado apenas como um bloco Delay, devido à baixa significância deste transportador, mas com foco na utilização futura do modelo e na disposição dos dados na forma de velocidades, comprimentos e capacidade de acumulação no transportador, preferiu-se a utilização de um Conveyor acumulativo baseado na velocidade $(2,5 \mathrm{~m} / \mathrm{min})$, na distância $(200 \mathrm{~m})$, no tamanho de cada célula $(4 \mathrm{~m})$ e na capacidade de acumulação (30 células), de acordo como o sistema real. A Figura 5.10 apresenta o modelo do Transportador Aéreo. 


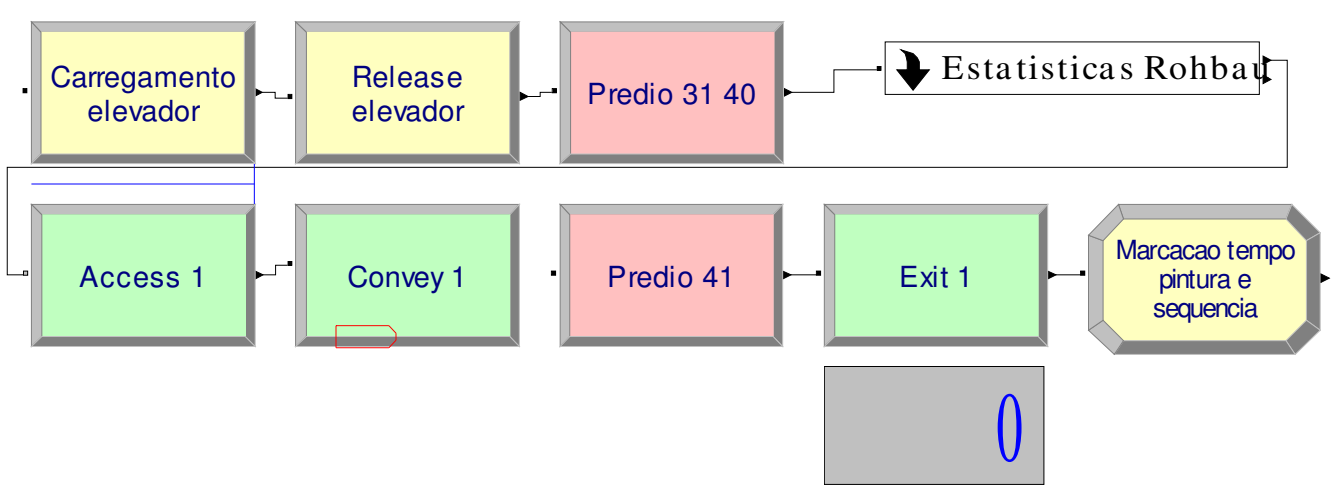

Figura 4.10: Modelo do Transportador Aéreo

O submodelo "estatísticas Rohbau" é o primeiro registro da seqüência das cabinas que saem da produção. Primeiramente é feita a contagem de quantas cabinas saem pelo transportador aéreo através de um bloco Record. Com a utilização dos atributos: "Numero de posições perdidas"; "Numero Serial"; "Entity.SequenceMBruta"; e da variável "sequencia 2 mont bruta", é feita a comparação entre a seqüência das cabinas que entraram na Rohbau e a seqüência que elas saem. São contadas quantas cabinas estão fora da seqüência e em quantas posições as cabinas estão defasadas. Com a utilização de um bloco Read/Write, gera-se o arquivo Seqüência2.xls com dados sobre as entidades cabinas que estão fora da seqüência. Os dados gravados são: o Serial Number que é um número criado pelo Arena® que não pode ser modificado; Os atributos Entity.Type, Entity.Type2 e Entity.Type3; e dados sobre o número de posições defasadas e quantas cabinas já estão fora da seqüência. Esse arquivo será comparado a arquivos posteriores para verificação da variabilidade da seqüência e rastreamento dos problemas no decorrer do sistema. A figura 5.11 mostra o modelo de verificação da seqüência.

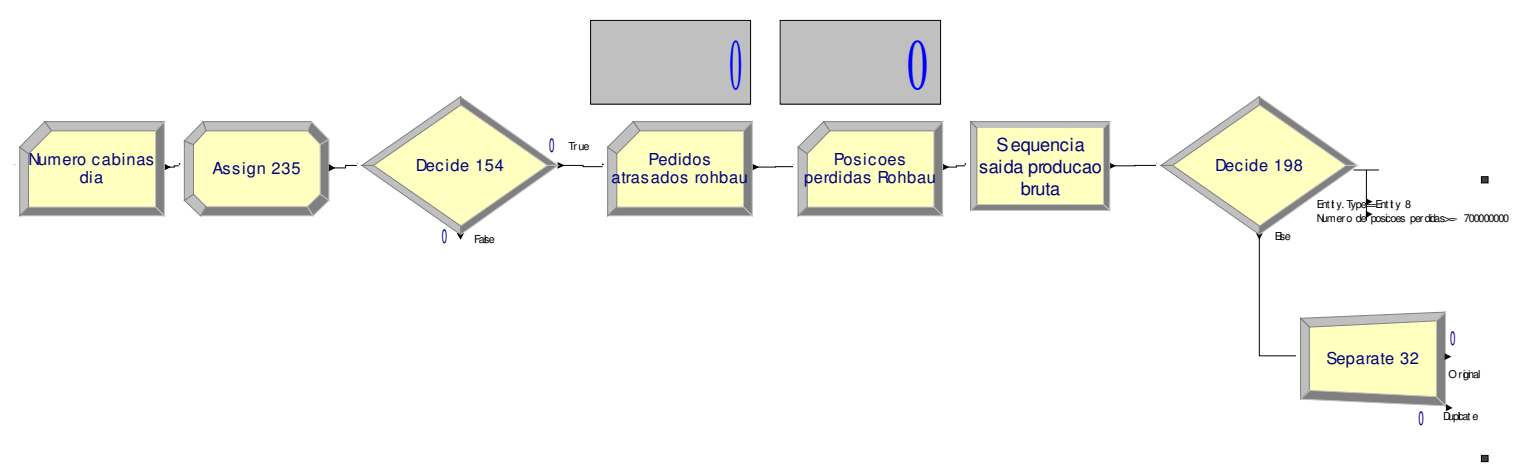

Figura 4.11: Verificação da seqüência na saída da Rohbau 


\subsubsection{Processos de Pintura}

A modelagem dos processos de pintura envolveu uma extensa quantidade de blocos. Esse processo também poderia ser modelado como um bloco Delay, mas uma quantidade grande de informações seria ignorada. No processo de pintura existem alguns retrabalhos e retornos, onde a cabina pode retornar vários processos para serem refeitos. Isso significa que existe, nesse processo, diferença entre seqüência que entra na pintura e a seqüência que sai para o Puffer. Dependendo de algumas condições o índice de retrabalho pode ser alto e cada retrabalho representa uma grande defasagem da cabina na seqüência, já que uma cabina retrabalhada pode ter que voltar muitos processos.

Assim, os processos de pintura foram modelados de acordo com cada etapa, e com os tempos obtidos para os processos. Uma restrição do sistema é que somente em algumas áreas podem ocorrer filas dentro do processo. Desta forma cada recurso só pode ser liberado quando o próximo já tiver sido requisitado. Isto foi feito através do trabalho com os blocos Seize e Release dos recursos. A figura mostra este arranjo.

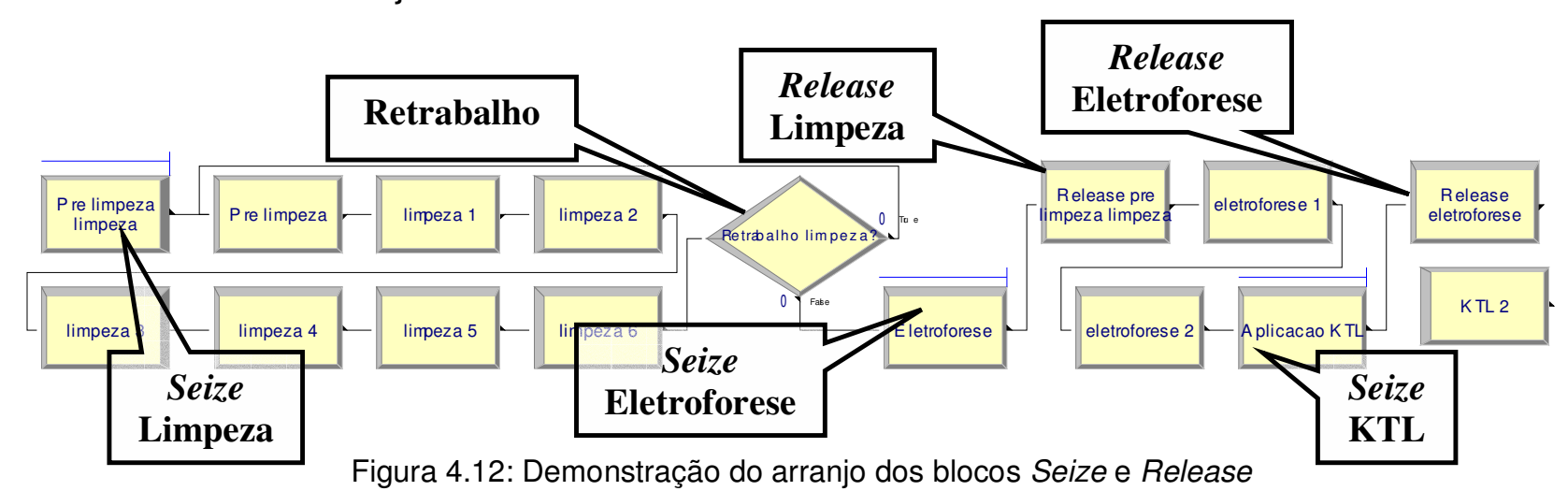

Os tempos de processo desta etapa foram modelados de acordo com as folhas de tempos fornecidas pela fábrica e cada estação de trabalho foi modelada. Todas as estações foram modeladas devido à facilidade dos dados e para facilitar a visualização.

O modelo desta etapa atingiu um tamanho considerável, mas é de fácil entendimento. A figura a seguir mostra esse modelo. 

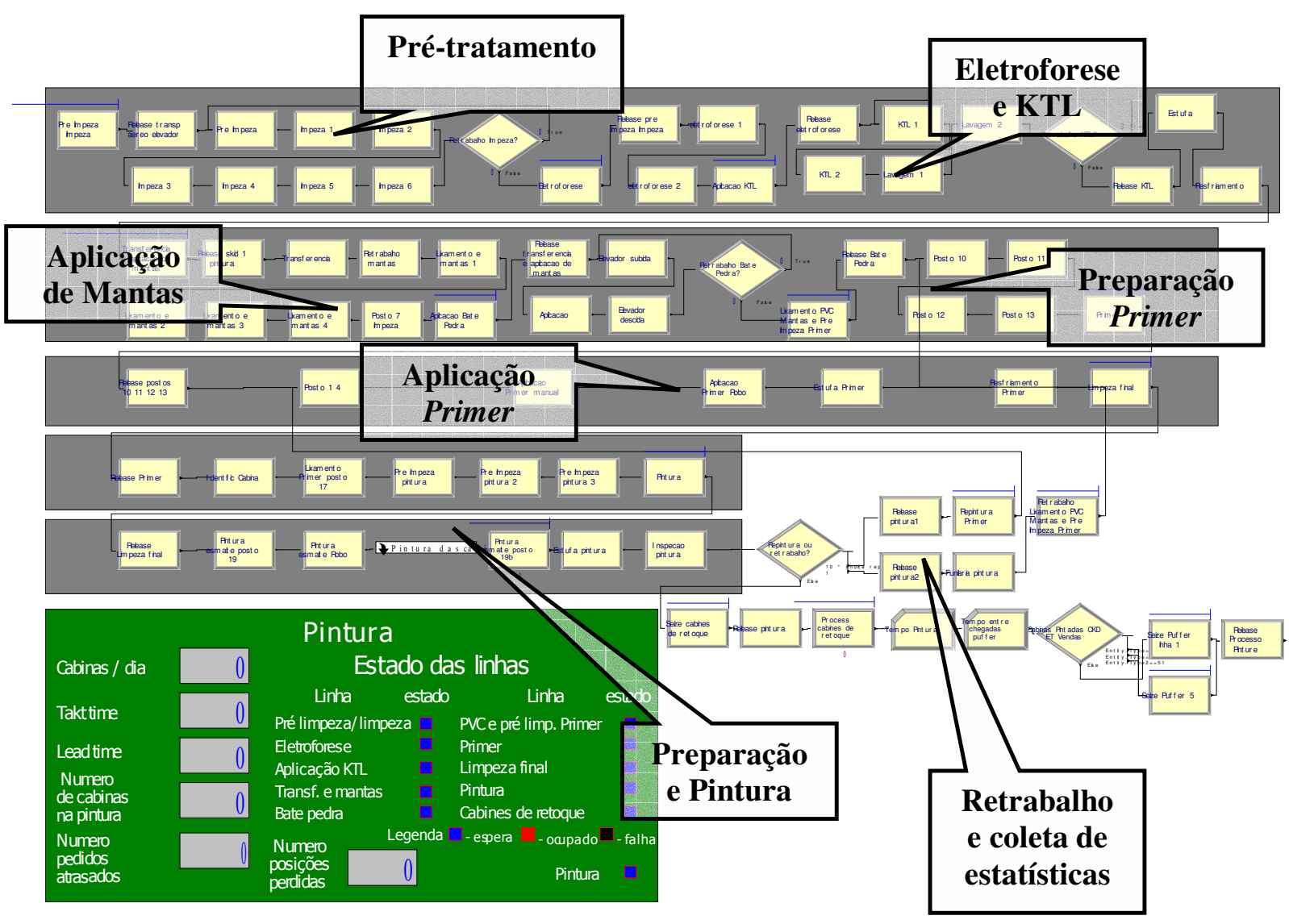

Figura 4.13: Modelo dos processos de pintura

A pintura, hoje, é o gargalo do sistema de produção, com vários processos e tarefas no limite da capacidade. Além de, como já explicado, a pintura de cores especiais, como as cores metálicas e pinturas a mão, apresentarem um alto índice de defeitos e necessitarem muitas vezes serem repintadas ou, até mesmo, passarem por quase todo o processo novamente. Os retrabalhos nas pinturas especiais chegam a 30\%. Já no restante, chegam a 10\%, o que resulta em uma defasagem muito grande nas seqüências.

Foi criado um submodelo na pintura, para determinar as cores, os retrabalhos e devido à animação. Ficou mais didático quando a cor das figuras que representam cada caminhão muda após a pintura. Nesse submodelo, a cor é definida através da proporção: $60 \%$ branca, $20 \%$ azul e $20 \%$ vermelha, a cor da cabina que ainda não tinha sido previamente determinada. Também são utilizados blocos Assign para definir o atributo "Índice Repintura" que é um índice que determina quais cabinas sofrerão mais retrabalho. Para as cabinas de cores especiais, esse índice é maior, e quando essas cabinas chegam no bloco Decide, o qual verifica a probabilidade de retrabalho, as chances são maiores. 


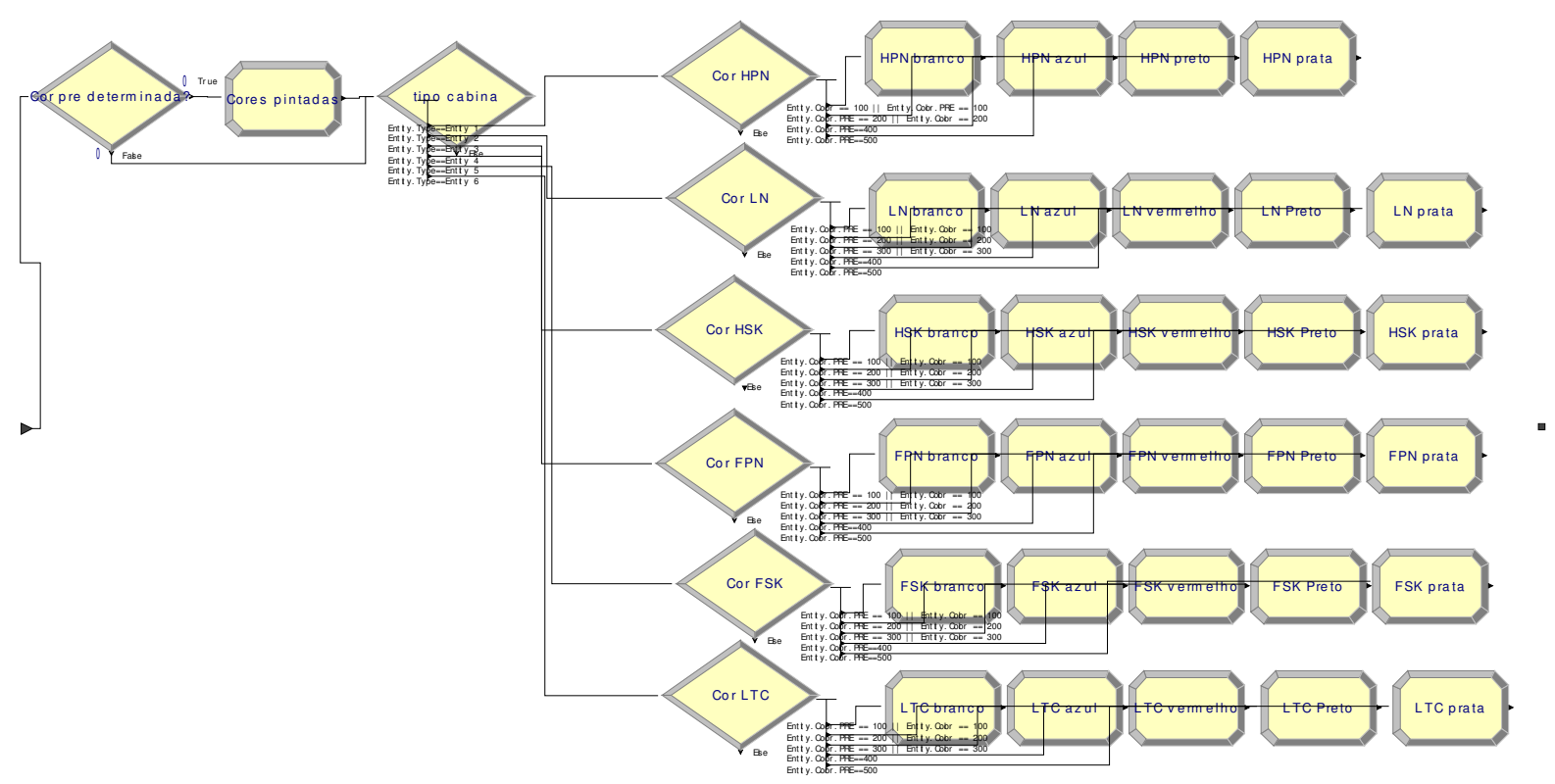

Figura 4.14: Determinação das cores das cabinas

Além dos retrabalhos, as paradas de linha também ocorrem constantemente, o que prejudica todo o sistema. Da mesma forma que na Rohbau e Nova Rohbau, as falhas de processo e paradas de linha foram obtidas através de bancos de dados com os mesmos problemas de confiabilidade. A Tabela 5.9 mostra a análise estatística dessas paradas.

\begin{tabular}{|c|c|c|c|c|c|c|c|c|c|c|c|c|}
\hline \multicolumn{13}{|c|}{ Área } \\
\hline $\begin{array}{l}\text { Linha 1A } \\
\text { Elevador }\end{array}$ & \multicolumn{2}{|c|}{$\begin{array}{c}\text { Pré Limpeza KTL } \\
\text { Posto } 1\end{array}$} & \multicolumn{2}{|c|}{$\begin{array}{c}\text { Pré Tratamento } \\
\text { Posto } 2\end{array}$} & \multicolumn{2}{|c|}{\begin{tabular}{|c|} 
Elevador KTL \\
Posto 3
\end{tabular}} & Estufa KTL & \multicolumn{2}{|c|}{ Elevador estufa } & \multicolumn{2}{|c|}{$\begin{array}{c}\text { Robô batida pedra } \\
\text { Posto } 8\end{array}$} & $\begin{array}{l}\text { Linha } 8 \\
\text { Posto } 8\end{array}$ \\
\hline 01:20 & & $01: 28$ & & 01:02 & & $00: 31$ & $00: 4$ & & $00: 22$ & & 07:27 & $00: 20$ \\
\hline $02: 07$ & & 02:04 & & $01: 30$ & & $00: 17$ & $00: 2$ & & $00: 10$ & & $02: 00$ & 00:07 \\
\hline 1,86 & & 1,14 & & 2,00 & & 2,57 & 2,5 & & 0,29 & & 2,00 & 2,00 \\
\hline 2,04 & & 3,02 & & 2,08 & & 2,82 & 2,9 & & 0,76 & & 3,21 & 3,21 \\
\hline \multicolumn{13}{|c|}{ Área } \\
\hline \multicolumn{2}{|c|}{$\begin{array}{c}\text { Aplicação PVC } \\
\text { Posto } 11\end{array}$} & \multicolumn{2}{|c|}{$\begin{array}{c}\text { Lixamento Primer } \\
\text { Posto } 13\end{array}$} & \multicolumn{2}{|c|}{$\begin{array}{c}\text { Cabine Primer } \\
\text { Posto } 15\end{array}$} & \multicolumn{2}{|c|}{\begin{tabular}{|l|} 
Estufa Primer \\
Estufa Primer
\end{tabular}} & \begin{tabular}{|c|} 
Posto 19 \\
Pintura
\end{tabular} & \multicolumn{2}{|c|}{$\begin{array}{l}\text { Estufa esmalte } \\
\text { Estufa pintura }\end{array}$} & \multicolumn{2}{|c|}{\begin{tabular}{|c|} 
Cabine Retoque \\
Posto 21
\end{tabular}} \\
\hline & $03: 44$ & \multicolumn{2}{|c|}{ \#DIV/0! } & & $00: 22$ & \multicolumn{2}{|c|}{$07: 35$} & $01: 56$ & \multicolumn{2}{|r|}{$01: 24$} & \multicolumn{2}{|c|}{ \#DIV/0! } \\
\hline & $04: 34$ & \multicolumn{2}{|c|}{ \#DIV/0! } & & $00: 09$ & \multicolumn{2}{|c|}{ \#DIV/0! } & 01:07 & \multicolumn{2}{|r|}{$00: 30$} & \multicolumn{2}{|c|}{ \#DIV/0! } \\
\hline & 0,29 & \multicolumn{2}{|r|}{0,00} & \multicolumn{2}{|r|}{0,57} & \multicolumn{2}{|r|}{0,14} & 0,57 & \multicolumn{2}{|r|}{1,43} & \multicolumn{2}{|r|}{0,00} \\
\hline & 0,76 & \multicolumn{2}{|r|}{0,00} & \multicolumn{2}{|r|}{0,98} & & 0,38 & 1,51 & \multicolumn{2}{|r|}{1,90} & \multicolumn{2}{|r|}{0,00} \\
\hline
\end{tabular}

Tabela 4.9: Estatísticas de paradas na Pintura de acordo com o posto de trabalho

As informações dessa tabela foram utilizadas da mesma forma nos blocos Failure para determinar a probabilidade de falha ou parada dos recursos.

Da mesma forma que no Transportador Aéreo, foi criada uma rotina para avaliar as mudanças na seqüência que ocorrem durante a etapa pintura. Dessa vez, 
a seqüência de saída da pintura foi comparada com a seqüência de entrada na pintura e com a seqüência de entrada na Rohbau. Foi utilizado o mesmo procedimento do Transportador Aéreo. As entidades também passam por mais um bloco Read/Write para o registro da seqüência de passagem e de diversos outros atributos no arquivo sequencia3.xls. As informações obtidas também são gravadas em blocos Record para serem analisados nos relatórios e em tempo real.

\subsubsection{Puffer}

A modelagem do Puffer de cabinas pintadas foi a principal etapa do trabalho de modelagem, pois também serviu de base para o modelo do DEPOVERT. Mas também foi a etapa mais trabalhosa, pois o Puffer têm várias lógicas de decisão relativas aos momentos em que falta a cabina e a seqüência da montagem final tem que ser modificada. Além disso, é necessário que a cabina seja retirada do Puffer de acordo com a seqüência final, ou quando faltar alguma cabina o mais próximo da seqüência da montagem final. Essa foi a idéia inicial, cruzar a seqüência da montagem final com as entidades alocadas no Puffer e de alguma forma liberar as entidades acumuladas o mais condizente possível com essa seqüência. Por isso que no modelo de programação da seqüência, ela foi liberada para as duas Rohbau e depois para a montagem final. Essa mesma seqüência foi utilizada para liberar as entidades cabinas do Puffer.

O Puffer real apresenta diversas posições para acomodar até 120 cabinas, onde cada posição, ou estação acomoda somente uma cabina. Quando se necessita de uma cabina no estoque, ele se remaneja automaticamente para a retirada da cabina. A idéia foi utilizar algum bloco do Arena® que retenha as entidades que passam por ele até que alguma informação seja dada e a entidade seja liberada.

Dois blocos lógicos poderiam ser utilizados, o Bloco Hold e o Bloco Match. Para o bloco Hold, seria necessário que um sinal fosse liberado quando a entidade cabina tivesse de ser liberada. Assim, uma entidade vinda da seqüência da montagem final passaria por um bloco Signal e liberaria a entidade cabina do bloco Hold.

O problema desse método é quando uma entidade cabina ainda não estivesse no bloco Hold, a entidade vinda da seqüência passasse pelo bloco Signal e fosse perdida. Um outro problema é o fato de serem necessário tantos blocos Hold 
como o nível de diferenciação das entidades cabinas e a geração de um código de sinal produzido pelo bloco Signal. A Figura 5.15 mostra os blocos Hold e Signal.

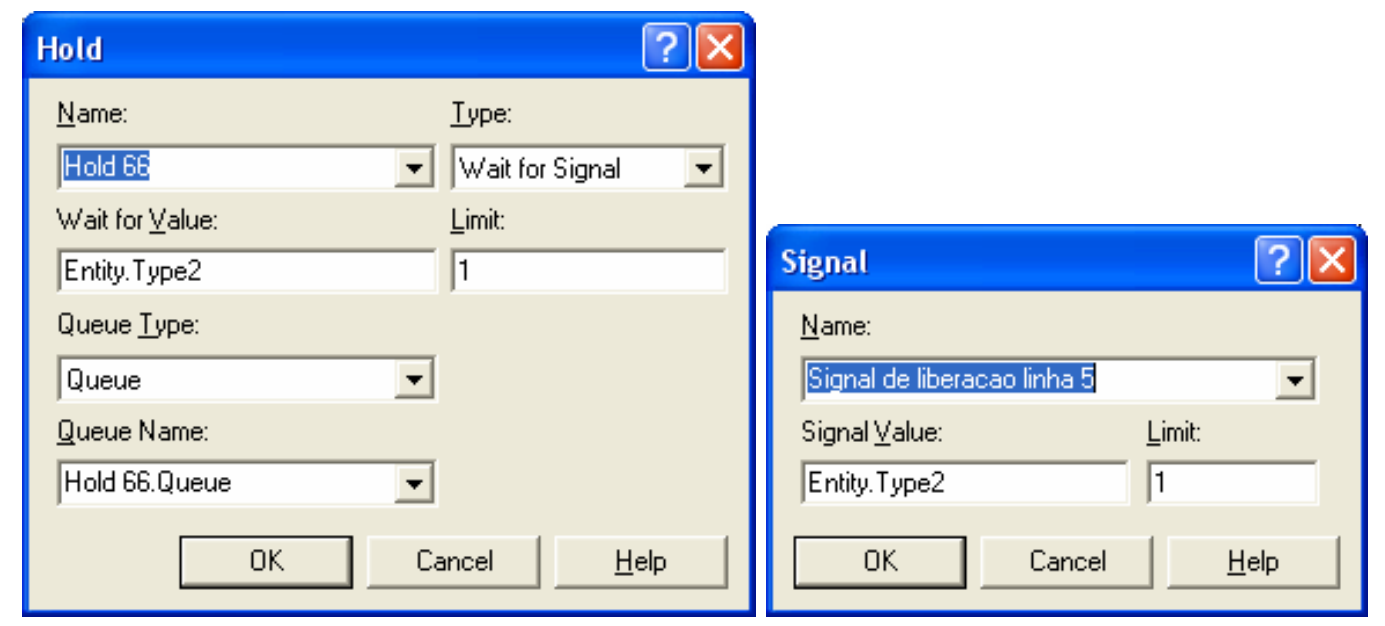

Figura 4.15: Blocos Hold e Signal para modelagem do Puffer

Após alguns testes, notou-se que essa não seria a melhor maneira de modelar o Puffer. Partiu-se para a utilização dos blocos Match e a idéia seria que a entidade cabina ficasse em um bloco Match até que a entidade da seqüência final chegasse e a liberasse, de acordo com algum atributo especial. A vantagem desse procedimento é que no caso da entidade da seqüência chegar antes, ela também espera a entidade cabina chegar para que as duas sejam liberadas em simultaneamente. Outra vantagem é que as entidades que serão comparadas em um bloco Match podem ser comparadas por um atributo específico.

As cabinas são liberadas do Puffer de acordo com a variante bruta e quando tem alguma pintura especial, que já foi pré-determinada na seqüência inicial, a pintura é o segundo quesito para liberação. Dessa forma, os blocos Match necessitariam de um atributo que indicasse as duas características, mas isso traria uma alta possibilidade de erros. Assim, a idéia foi utilizar um bloco Match para cada atributo de variante bruta e as cabinas seriam escolhidas em cada um dos blocos Match pelo atributo da cor pré-determinada.

As entidades cabina chegam da pintura e são direcionadas através de um bloco Decide para o bloco Match do atributo variante bruta correspondente. Lá aguardam a chegada das entidades da seqüência final e que liberam as entidades cabinas de acordo com o atributo de cor, caso a entidade cabina esteja armazenada no modelo do Puffer. A Figura 5.16 mostra o modelo do Puffer com os blocos Match. 


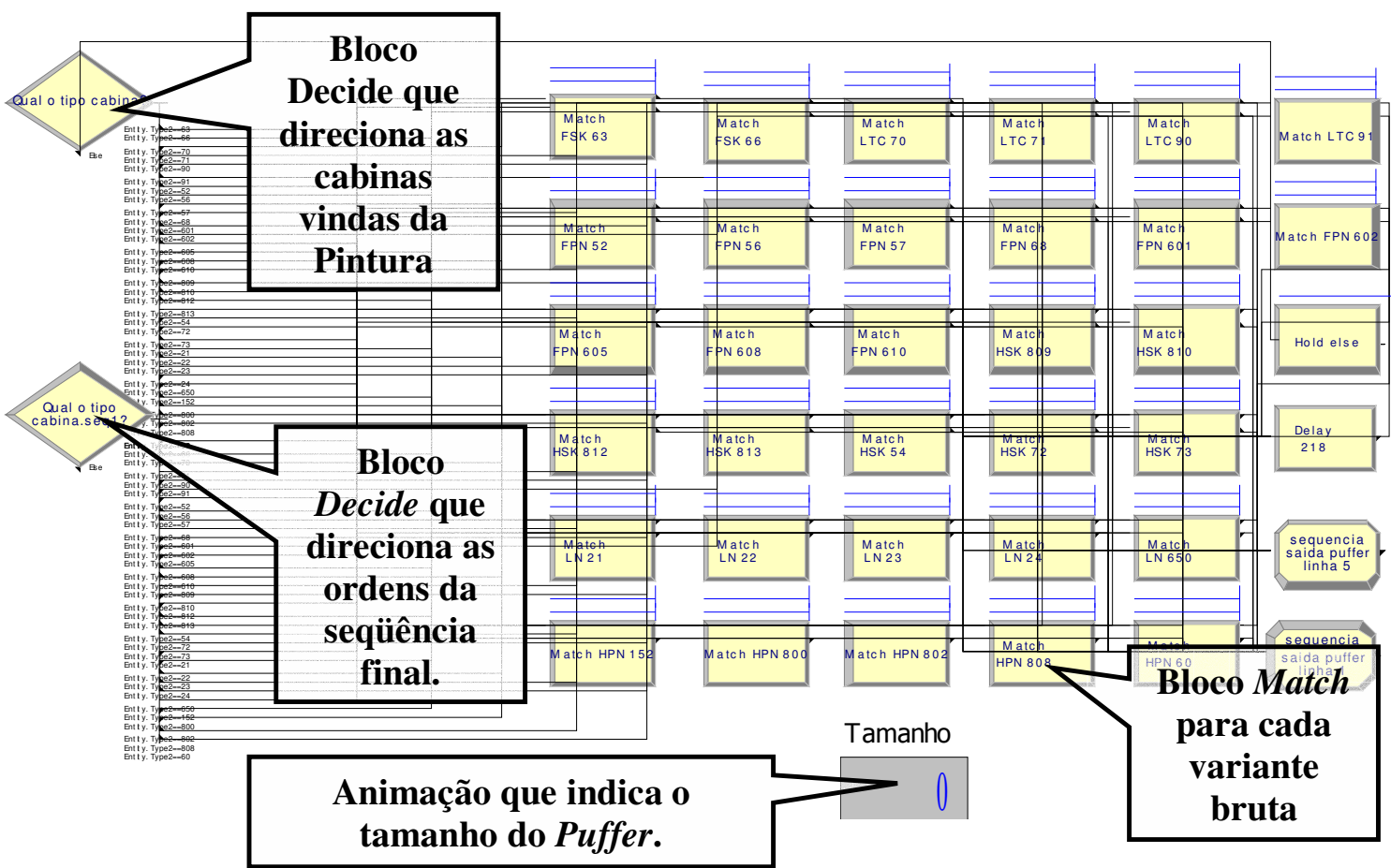

Figura 4.16: Modelo do Puffer com a utilização de blocos Match

A capacidade máxima do Puffer é determinada pela utilização de um recurso de capacidade máxima 120 que determina quando o Puffer está cheio. Esse recurso resulta no bloqueio da etapa anterior, caso o Puffer esteja cheio.

Para determinar a quantidade de cabinas que poderiam ficar no Puffer e para fazer alguns testes de cenário, foi utilizado um bloco Delay para atrasar a chagada das entidades da seqüência final e, portanto, a retirada das cabinas do Puffer. A Figura 5.17 mostra esse bloco Delay.

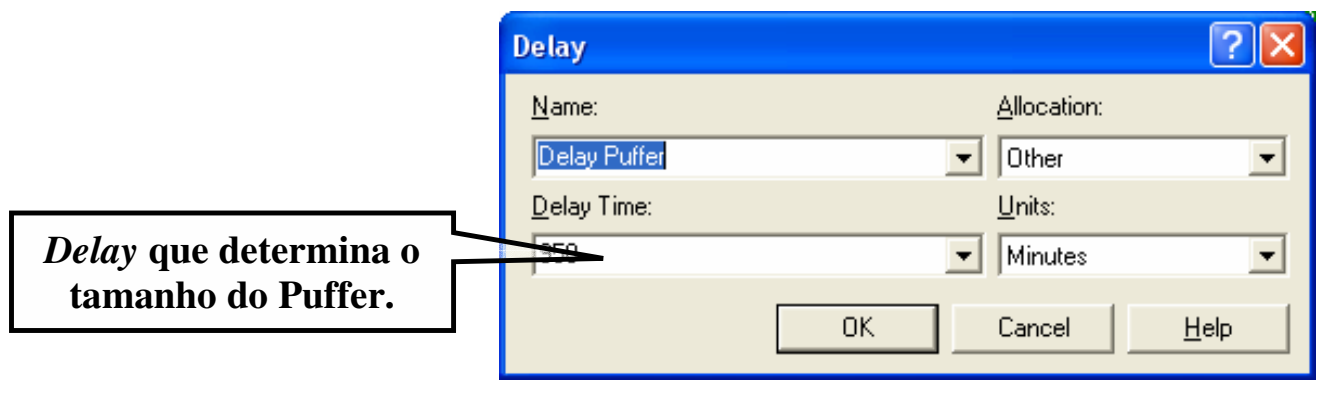

Figura 4.17: Bloco Delay que determina o número de cabinas no Puffer

Esse modelo representou muito bem o Puffer, mas com o decorrer do detalhamento do modelo, ocorreram algumas falhas no funcionamento do modelo. Como já colocado, o sistema não tem muitos espaços para alocação de cabinas nas etapas intermediárias. Isso significa que, quando uma etapa posterior pára, as 
etapas anteriores também param. Dessa forma, as entidades da seqüência final teriam que ser bloqueadas caso não seja possível liberar as entidades cabinas do Puffer. Outra situação seria caso o Puffer esvaziasse pela parada de uma das etapas anteriores. Nesse caso, o Puffer também teria que ser bloqueado, para que possa encher novamente.

A idéia foi usar um conjunto de blocos Hold que seguram as entidades da seqüência final, caso a etapa seguinte ou a anterior ao Puffer estejam paradas. $O$ complicado desse método é que, na inexistência da condição de bloqueio, o bloco Hold libera todas as entidades simultaneamente, o que gera o desequilíbrio do sistema. Dessa forma, foi necessário criar um equivalente a um filtro "passa baixa", que faria com que as entidades bloqueadas no bloco Hold, quando liberadas, saiam na freqüência que é a correta para o funcionamento das etapas seguintes. A figura 5.18 mostra o modelo do bloqueio através do bloco Hold e o sistema de filtro através de um conjunto Seize, Delay, Release.

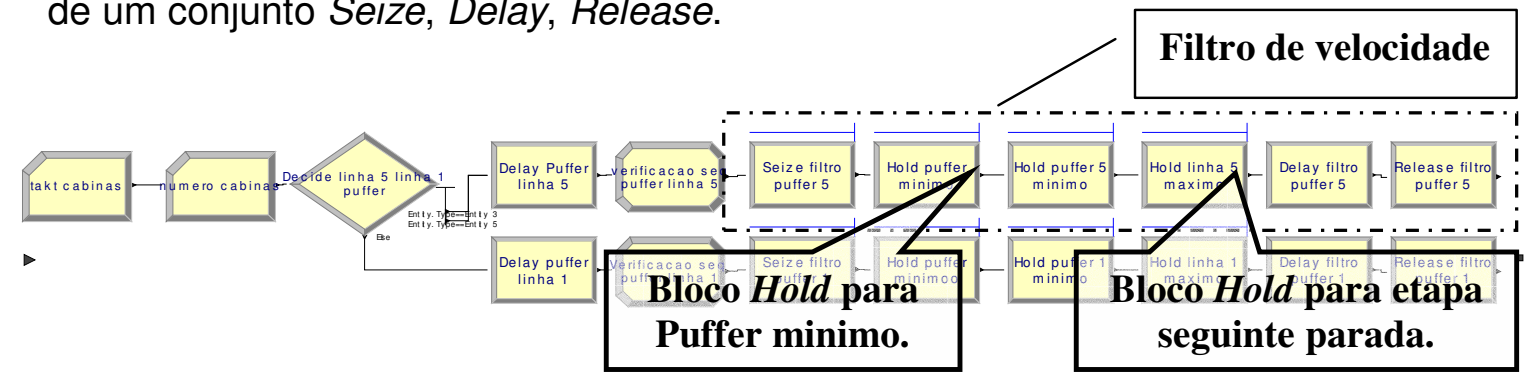

Figura 4.18: Controle das entidades da seqüência final para operação do Puffer

Com esse modelo de controle, foi possível garantir que o modelo do Puffer não teria problemas diante das variações do fluxo das entidades cabina nas etapas anteriores e posteriores.

O modelo garantiu que as entidades cabinas sejam retiradas do Puffer de maneira próxima à seqüência de montagem final. Isso só não ocorre quando não existe a cabina no Puffer, onde a cabina mais próxima na seqüência é retirada. $O$ modelo também garante que o Puffer não saia do equilíbrio diante do esvaziamento ou da lotação na ocorrência de diferenças entre o fluxo das etapas anteriores e posteriores.

Mas o modelo do Puffer tem que ser capaz de modificar a seqüência da montagem final dos caminhões caso a cabina não possa ser entregue no momento certo, de acordo com o sistema real, assim como é o sistema real. 
A regra no sistema real é que a seqüência deve ser conferida na entrada do Puffer também, e não só na saída. Isso é feito para que seja controlado o atraso da cabina antes que se perceba que não haverá a cabina na última hora. Com essa antecipação é possível modificar a seqüência da montagem final e retirar dela o veículo que poderia utilizar essa cabina. Isso é uma segurança para que as linhas de montagem final de veículos não parem por falta de cabina no caminhão. Foi estabelecido que, se uma cabina não chegar até 15 posições na entrada do Puffer, essa cabina é dada como muito atrasada e o veículo que seria montando com essa cabina é bloqueado e a seqüência da montagem final modificada.

A modelagem dessa situação foi de certa complicação. A idéia era verificar as entidades cabinas no momento que elas saem da pintura. Para isso foi criado um Puffer Virtual que armazena uma cópia das entidades cabinas que saem da pintura. E da mesma forma que no Puffer, foi utilizada uma cópia das entidades da seqüência final para verificar a seqüência das entidades do Puffer Virtual. A diferença do atraso temporal das entidades duplicadas da seqüência final é menor do que as que vão para o Puffer, para que o Puffer Virtual possa ser checado antes. O método de verificação também é diferente, já que não é possível esperar uma entidade cabina muito atrasada sair, para que seja dada a ordem de modificação da seqüência. É necessário que, quando a cabina estiver 15 posições atrasadas, já seja dada a ordem de modificação da seqüência final.

Dessa forma foram utilizados blocos Search para verificar se a entidades duplicadas cabinas estavam no Puffer Virtual, que também é formado de blocos Match. A entidade da seqüência final copiada atravessa o bloco Search que procura na fila do bloco Match do Puffer Virtual se existe a entidade duplicada cabina com os mesmos atributos. Caso não exista, a entidade da seqüência é retida em um bloco Hold até que alguma das entidades do Puffer Virtual na seqüência seja liberada. Depois de liberada do bloco Hold a entidade da seqüência faltante passa por um contador de posições perdidas e faz novamente um Loop. Caso essa entidade da seqüência perca mais de 15 posições, é liberada uma ordem de modificação da seqüência final. A entidade fica em Loop até que a entidade cabina cópia correspondente esteja no Puffer Virtual, o que elimina as duas através de um bloco Dispose. 
Todo esse Puffer Virtual não influi no desempenho do sistema e serve somente para avaliar se a seqüência da montagem final deve se modificada. $A$ Figura 5.19 mostra o submodelo Puffer Virtual.

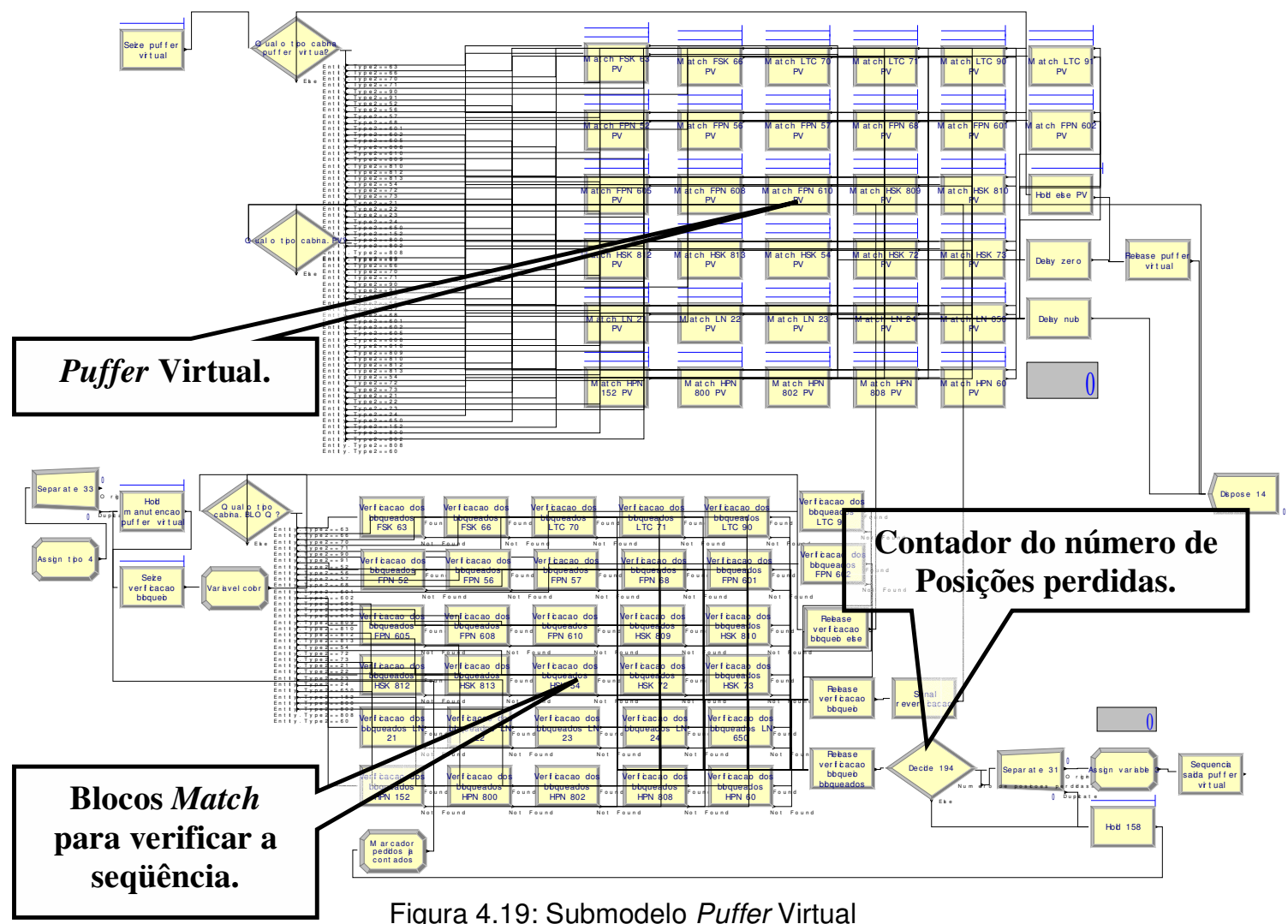

De volta ao Puffer normal, as entidades cabinas que de lá são liberadas, tem que receber a variante exata de acordo com a cabina da seqüência de montagem final que a liberou. Foi feita uma pequena lógica, para atrasar em 3 segundos a entidade cabina enquanto é lida a variante exata da entidade seqüência. Após lido, esse atributo é carregado em uma variável que depois de 3 segundos escreve na entidade cabina a variável exata apropriada.

Depois dessa rotina, as cabinas são liberadas para a montagem acabamento das cabinas. Antes é calculado o atraso das cabinas em relação à seqüência original e o número de posições perdidas e, da mesma forma que nas outras etapas, são gerados os arquivos sequenciap42.xls e sequenciap41.xls. Esses arquivos são diferenciados de acordo com o destino das cabinas, já que a montagem acabamento dividida da mesma forma que a montagem final, em uma linha para leves a semipesados e outra para pesados e extrapesados. 


\subsubsection{Montagem acabamento das cabinas}

As linhas de montagem de acabamento das cabinas foram modeladas de acordo com o sistema real, ou seja, com a utilização de blocos do Template "Advanced Transfer" do Arena ${ }^{\circledR}$. Com os blocos desse Template é possível modelar um transportador do tipo esteira, como é o sistema real. Portando, as linhas foram modeladas como Conveyors.

A escolha da velocidade dos transportadores é determinada através do cálculo da distancia a ser percorrida, dividido pelo takt time multiplicado pelo número de postos. Essa velocidade também varia com a quantidade de cabinas a serem produzidas, ou seja, pelo takt time.

Antes das linhas existem algumas pré-montagens que foram modeladas como blocos Process. Ao longo do sistema não existem possibilidades de acumulo ou retrabalho, caso exista algum problema, todas as linhas do tipo de cabina correspondente param. É importante salientar que desde o início dessa etapa, existem dois fluxos diferentes e independentes, um para cabinas leves, médias e semipesadas e outro para as cabinas pesadas e extrapesadas.

No início do sistema existe um gargalo que é a mesa transportadora. Apesar dos fluxos serem independentes, a mesa é comum no transporte de todas as cabinas, sendo o processo gargalo. Essa mesa foi modelada como dois blocos Process que compartilham um único recurso. O modelo das linhas de montagem de acabamento, depois de implementado no Arena ${ }^{\circledR}$ tem a seguinte forma, de acordo com a Figura 5.20 e a Figura 5.21 mostra a parametrização dos transportadores.

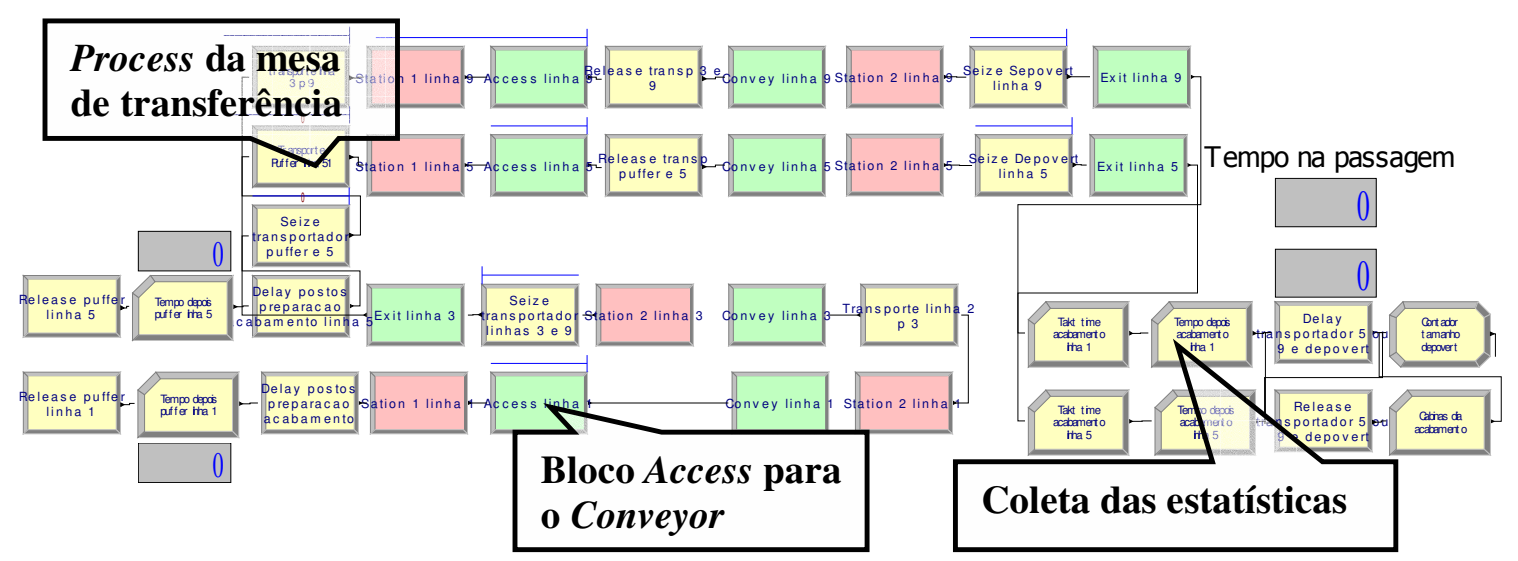

Figura 4.20: Modelo das linhas de montagem acabamento 

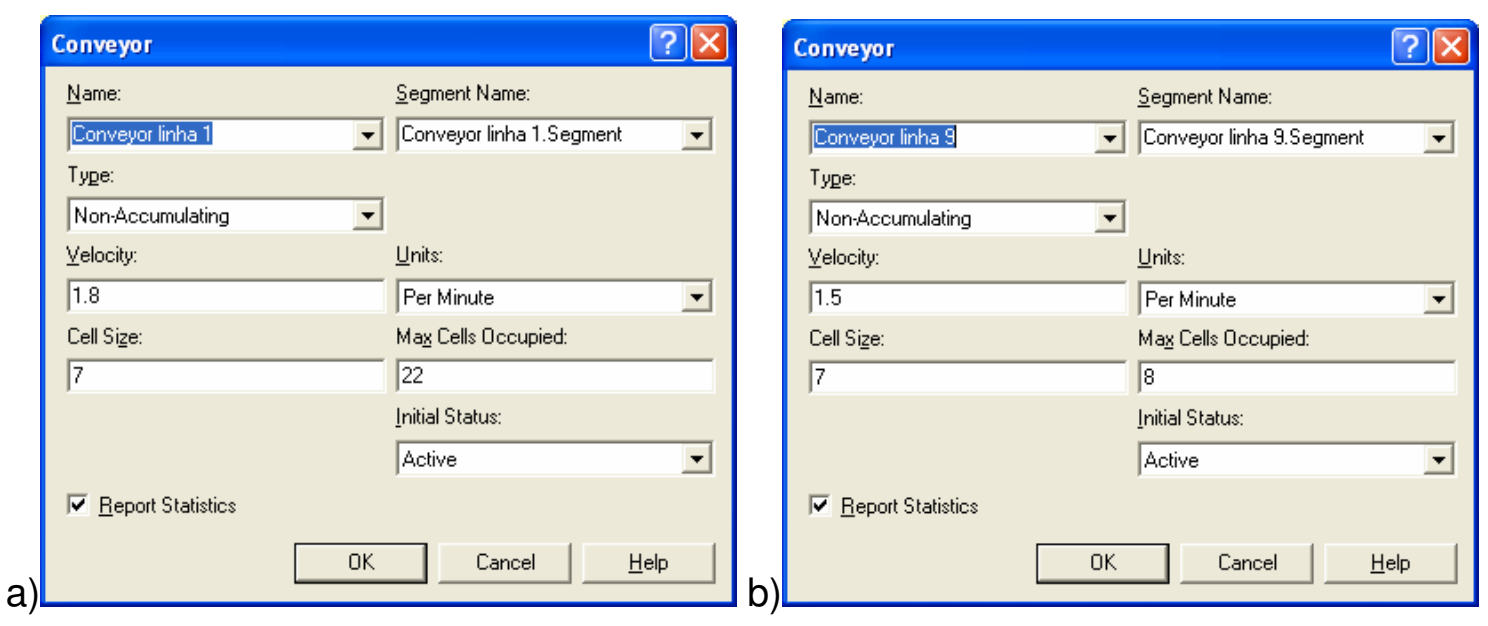

Figura 4.21: Configuração dos transportadores: a) Transportador da linha de leves e médios com 22 postos e velocidade de 1,8 m/ min; b) Transportador da linha de pesados com 8 postos e 1,5 m/ min

Assim como nas outras etapas, a montagem de acabamento das cabinas também apresenta dados sobre as falhas de processo. Nesse caso, o Arena® não possui instruções de falha para sistemas transportadores. Foi necessário criar uma rotina especial para que os sistemas transportadores parassem de funcionar de acordo com as estatísticas de falhas. Nessa rotina foram utilizados os blocos Start e Stop que param e iniciam os sistemas transportadores. Uma entidade do modelo foi isolada e durante a simulação ela percorre os blocos Start e Stop em intervalos de tempos determinados de acordo com a estatística das falhas de processo e param e iniciam os transportadores como se fossem as paradas ou falhas dos processos. A Figura 5.22 ilustra essa lógica que também foi utilizada na montagem final de caminhões.

Na média ocorre uma parada de 2 minutos a cada 15 na linha de médios e leves e uma parada de 5 minutos a cada 30 na linha de pesados. 


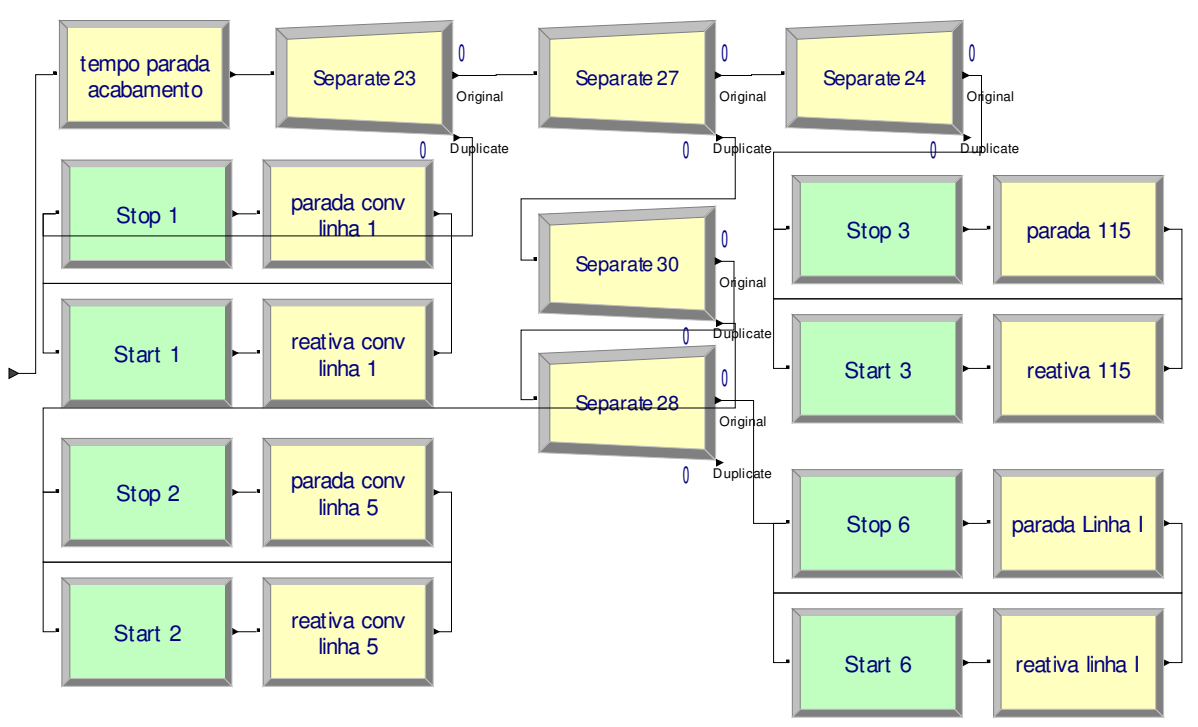

Figura 4.22: Lógica de modelagem das falhas de processos em transportadores.

\subsubsection{Depósito Vertical de Cabinas Acabadas - DEPOVERT.}

A modelagem do DEPOVERT seguiu os mesmos conceitos que a do Puffer, mas com algumas diferenças:

Foi necessário criar um atributo que representasse todos os outros atributos, já que no DEPOVERT as cabinas são retiradas de acordo com a variante brutas, a variante exata e a cor. Esse atributo foi chamado de Entity.Type4 e tinha a seqüente formulação:

\section{Entity.Type $4=($ Entity.Type $\times$ Entity.Type $2 \times$ Entity.Type 3$)+$ Entity.Color.PRE}

Onde Entity.Type é o tipo do veículo, Entity.Type2 é a variante bruta, Entity.Type3 é a variante exata e Entity.Type.PRE é a cor pré-definida da cabina. Os valores obtidos através de Entity.Type4 não foram, em momento algum, iguais e, portanto, podem ser usados nessa diferenciação. Esse atributo poderia ter sido utilizado em outras etapas do modelo, mas só foi desenvolvido nessa etapa.

Dessa forma os blocos Match utilizaram esse atributo para comparar as entidades cabina vindas da montagem final com a seqüência da montagem final. Os blocos Match do modelo foram divididos da mesma forma que o Puffer, para facilitar o estudo e garantir certa segurança.

No tópico anterior foi apresentado que o sistema, a partir da montagem acabamento de cabinas, estava dividido em dois fluxos diferentes e independentes. 
No DEPOVERT não é diferente, pois ele é dividido em postos paras as cabinas leves e médias e outros para as cabinas pesadas. Dessa forma, para limitar a capacidade máxima do DEPOVERT, foram utilizados dois recursos de capacidade máxima e independentes para cada fluxo de cabina.

O DEPOVERT também utiliza um filtro similar ao do Puffer para impedir que a seqüência fique defasada no caso do DEPOVERT ter algum problema que impeça o fluxo normal. A Figura 5.23 mostra o modelo do DEPOVERT e o filtro.
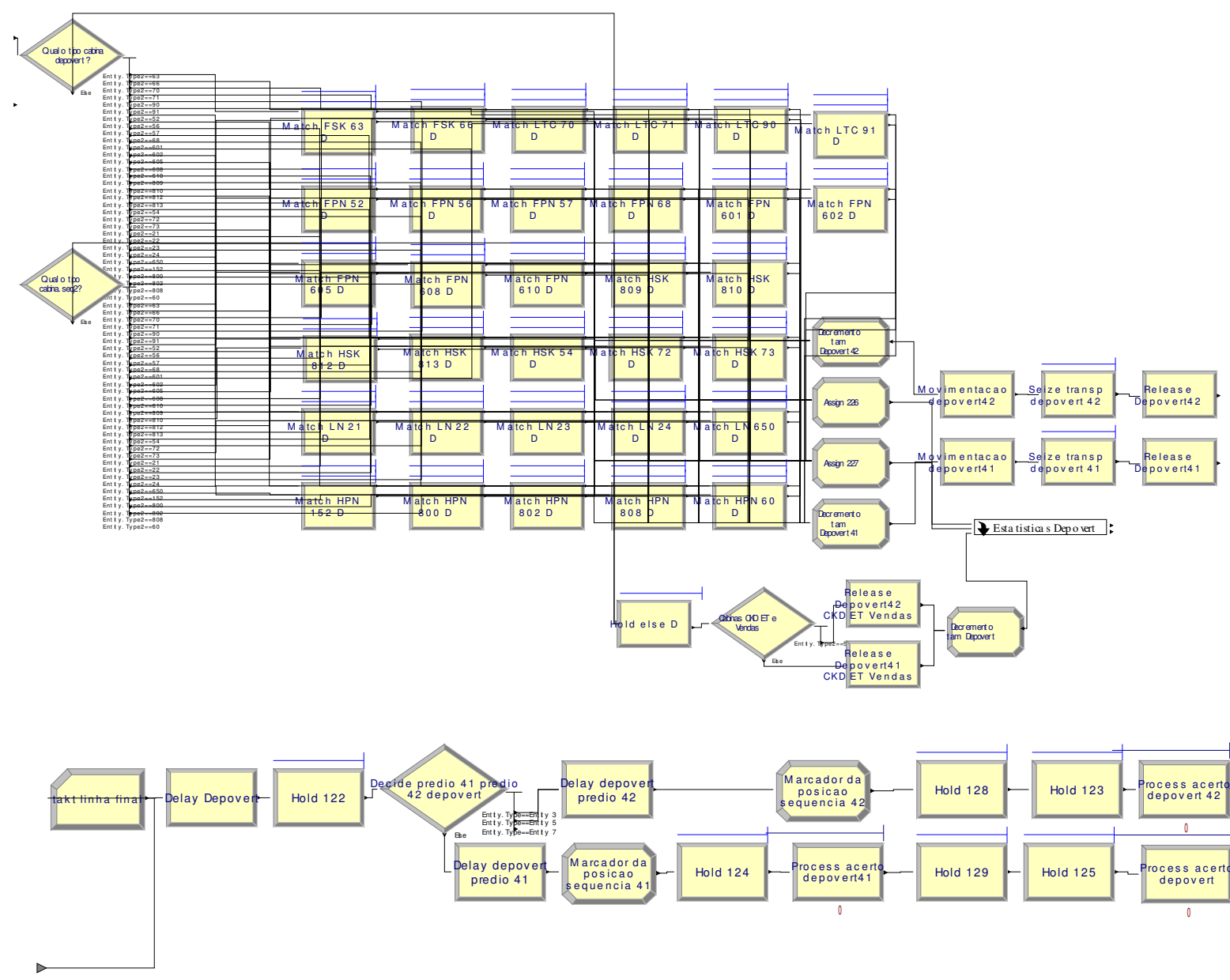

Figura 4.23: modelo do DEPOVERT e do filtro para controle da seqüência

Uma diferença com relação ao Puffer, é que o DEPOVERT tem três saídas diferentes, uma para a linha de montagem final dos leves e médios, outra para a 
linha de montagem final dos pesados e uma terceira para liberação das cabinas para serem vendidas como peça de reposição ou para CKD.

Na saída do DEPOVERT também foram utilizados blocos Read/Write para gravar as seqüências de saída e ainda foram utilizados blocos Record para 0 acompanhamento online e a geração de relatórios.

\subsubsection{Montagem Final dos Caminhões}

A modelagem da montagem final dos caminhões poderia ser bem simples, apenas como um processo sujeito à falhas e que determinasse o ritmo de saída das cabinas do DEPOVERT. Apesar disso ela foi feita em detalhes para que fosse possível utilizar as estatísticas de falha dos processos e para que fosse possível observar algumas questões na análise dos resultados.

Os processos no sistema real são divididos em dois prédios: um para a produção dos caminhões leves, médios, semipesados e chassis de ônibus de motor frontal; outro para a produção dos caminhões pesados e extrapesados. Devido a essa divisão, que os processos são definidos da mesma forma desde a montagem acabamento das cabinas.

Nos dois prédios, a seqüência de processos é bem parecida. No início, as longarinas são montadas em postos de trabalho estáticos. Em seguida são montados os cabos elétricos e eixos com as longarinas de baixo para cima, para facilitar a montagem dos eixos, em um transportador do tipo esteira. Em uma etapa especial, as longarinas são invertidas para que sejam montados os outros agregados como motor e cabina em outro transportador do tipo esteira. Após esses processos é dada a partida nos motores dos caminhões, que saem em movimento das linhas.

A modelagem seguiu a disposição dos processos. No início foram utilizados blocos Process da mesma forma que os postos estáticos de trabalho. Para a modelagem das esteiras transportadoras, foram utilizados os blocos do tipo Conveyors, assim como na montagem acabamento. Nos pontos importantes como, montagem do motor, eixo e cabina, foi colocada uma estação, onde as falhas de processo pudessem ser inseridas e no caso da montagem da cabina, o modelo pudesse interagir com as outras etapas, já que todo o restante do modelo está diretamente ligado com as cabinas. 
Para simular as paradas dos transportadores foi utilizado o mesmo modelo que na montagem acabamento para os transportadores. Já nos blocos Process entraram como estatística de falhas nos recursos através do módulo Failure.

Foram denominados Resources para modelar a capacidade máxima das linhas e a quantidade de cabinas que poderiam entrar na fila para serem montadas nos caminhões.

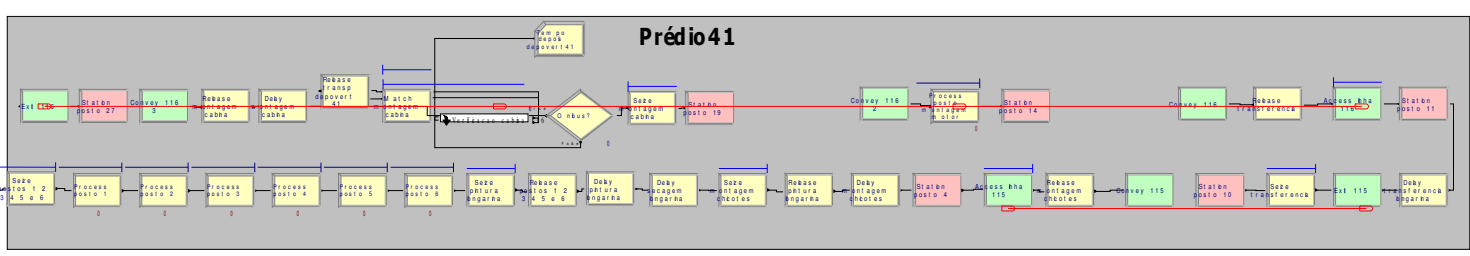

Figura 4.24: Modelo da montagem final Prédio de leves e médios

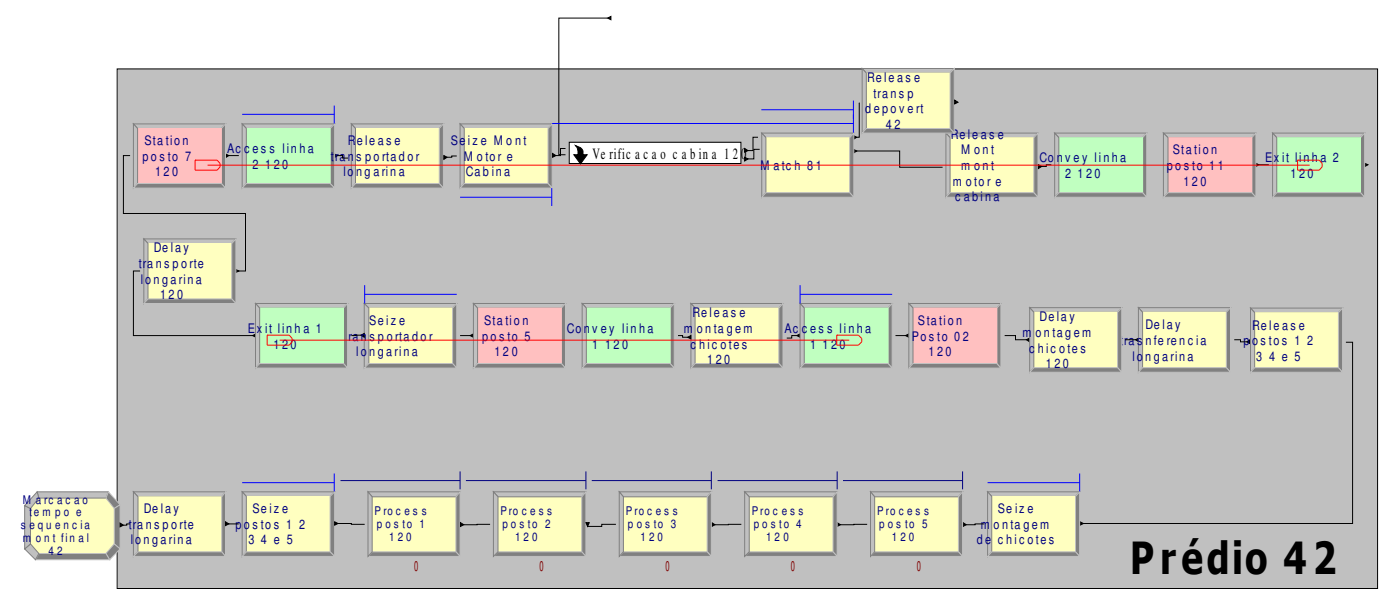

Figura 4.25: Modelo da montagem final do prédio de pesados

Todos os processos produtivos da montadora de interesse foram modelados, de acordo com os objetivos do estudo. Os modelos apresentados são os modelos finais de todo o processo. Uma característica importante é que todas as etapas estão amarradas através da utilização de Resources e a combinação dos blocos Seize e Release, para que não existam acúmulos de entidades cabinas entre as etapas e os bloqueios possam ser simulados.

4.3.10 Lógicas para controle, análise e modificação da seqüência programada ao longo de todo o processo 
Além dos modelos dos processos, muitas lógicas decisórias atuam no sistema durante todo o tempo. Essas decisões são tomadas para que o sistema não desestabilize e para que erros possam ser corrigidos. Assim, para que o modelo pudesse representar o sistema real, de acordo com os objetivos, as decisões que influem no gerenciamento da capacidade dos estoques seletivos devem ser modeladas. Uma decisão de grande influência no comportamento do sistema é a modificação da seqüência de montagem final, pelo atraso das cabinas no Puffer. Quando é percebido o atraso da cabina antes da chegada no Puffer, os planejadores bloqueiam a montagem do veículo que terá essa cabina. Isso já foi descrito durante a descrição do modelo do Puffer e o Puffer Virtual.

Assim, o Puffer Virtual libera uma ordem de bloqueio, quando a entidade cabina sai da pintura até 30 posições atrasadas. Para isso foi necessário fazer com que essa informação cruze com as entidades da seqüência de montagem final, no momento certo, para que a entidade da seqüência final fique bloqueada durante um certo tempo. De volta à descrição do Puffer Virtual, foi colocado que a entidade duplicada que atravessa os blocos Search procurando pela entidade duplicada da cabina no Puffer Virtual e fica em Loop até que essa entidade seja encontrada. Caso a entidade gire mais de 15 voltas no Loop, ela é duplicada novamente e direcionada para o modelo da modificação da seqüência final. A outra entidade em Loop continua o processo de verificação.

A entidade duplicada direcionada para a modificação da seqüência cruza com a seqüência da montagem final em um momento exato para que a seqüência seja modificada e a entidade veículo a ser bloqueada. Para determinar o tempo de bloqueio foi utilizada a entidade da seqüência que sai do Puffer normal, com o número de posições que a entidade cabina está atrasada.

Para isso, foi utilizada uma lógica de grande complexidade, a qual envolve o cálculo do tempo de cruzamento com a seqüência final e a utilização de blocos Match e Search, além da utilização do atributo Entity.Type4, já descrito anteriormente. Basicamente, a entidade advinda do Puffer Virtual, com a instrução de bloqueio, fica em um bloco Match à espera da passagem da entidade da seqüência final. A entidade da seqüência final passa por um bloco Search, que procura na fila do bloco Match, uma entidade com o mesmo atributo Entity. Type4, que indicaria a necessidade do bloqueio. Caso a entidade correspondente exista na fila do bloco Match, a entidade da seqüência final é removida, para o bloco Match. 
Após a comparação das entidades, as duas são liberadas e aguardam o tempo necessário para o bloqueio em um bloco Delay, para, depois, serem liberadas no restante do modelo.

A maior dificuldade desse procedimento é o acerto do tempo, pois a diferença entre o tempo da decisão do bloqueio e o início da montagem final dos veículos é muito curto e isso dificulta a montagem dessa rotina. Apesar desse problema, a rotina funcionou corretamente, mas algumas entidades não foram bloqueadas. Foram necessárias muitas correções e alterações para o correto funcionamento do modelo. A Figura 5.26 mostra o modelo da decisão de bloqueio.

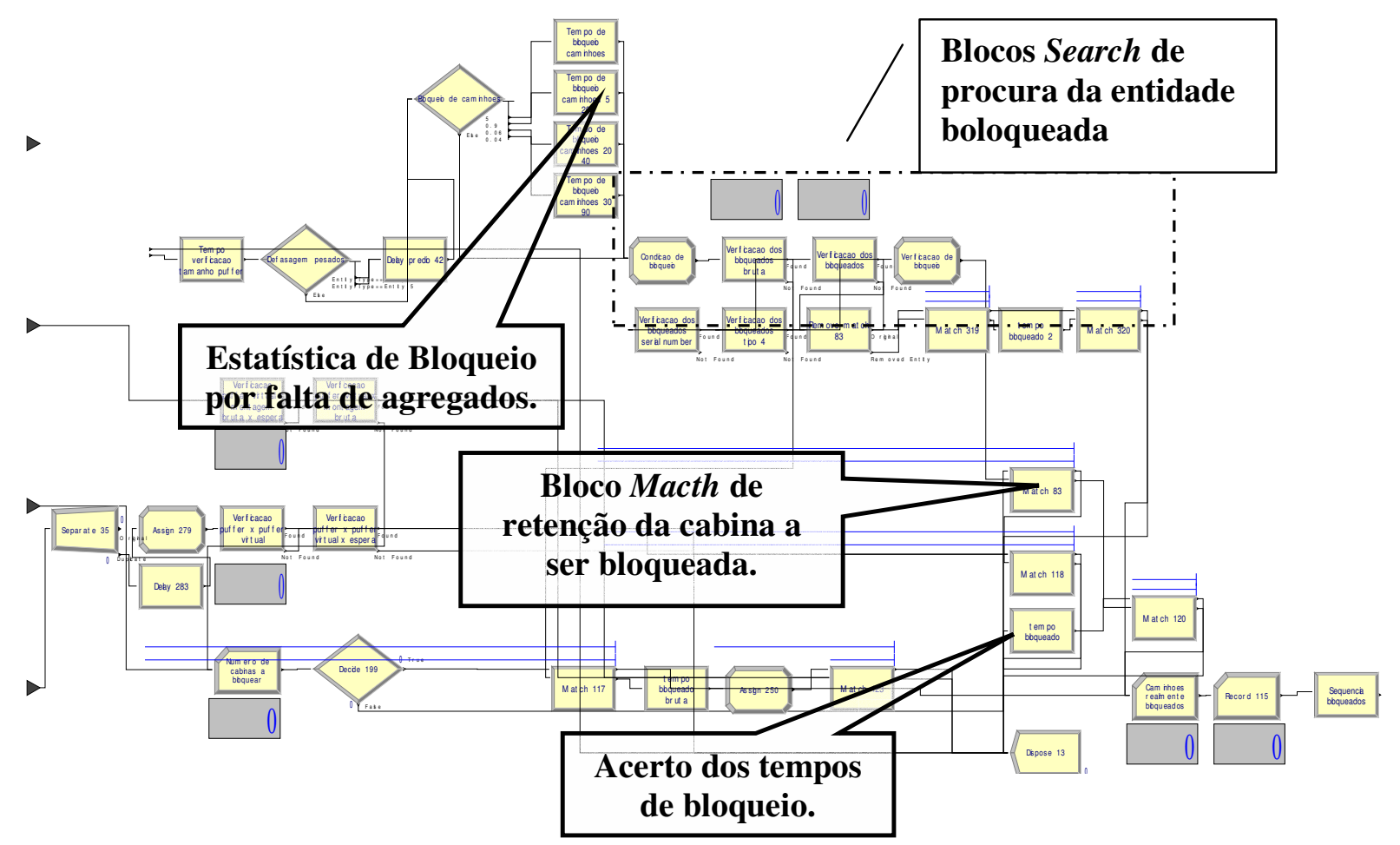

Figura 4.26: Modelo dos bloqueios e mudanças na seqüência final.

Uma outra característica importante, modelada nessa mesma etapa, foi a estatística de mudanças na seqüência final devido à falta de outros agregados como motores, eixos etc. Essas informações foram conseguidas através de dados estatísticos fornecidos pela montadora de ocorrência e tempo de bloqueio e foram modeladas através de blocos Delay. Isso alterou a seqüência final e essa alteração é muito importante para a análise do DEPOVERT, pois muitas vezes são guardadas cabinas prontas no DEPOVERT que não podem ser liberadas porque o caminhão 
não será montado. Com esse modelo pode-se analisar a influencia dessas decisões no comportamento de todo o sistema.

Com esse último modelo, está descrita em detalhes toda a modelagem e a implementação do modelo no Arena® e esse foi o melhor modelo encontrado para análise do sistema e dos problemas propostos. A partir dos próximos capítulos serão descritas a Verificação, Validação e a Simulação propriamente ditas.

\subsection{Simulação}

Antes da simulação, foi feito um planejamento do estudo a ser feito. Foram definidos questões e temas a serem avaliados, além da forma das corridas de simulação e os resultados que deveriam ser analisados. Com esse planejamento, foi possível conseguir melhores resultados e evitar erros.

Para atingir os objetivos propostos, foram identificadas as questões, as características e as informações do sistema que teriam influência direta na necessidade e na utilização dos estoques seletivos. Essas características deveriam então ser avaliadas para dimensionar o impacto que teriam na necessidade dos estoques. Podem-se citar, dentre elas:

- Características físicas e organizacionais do sistema;

- Restrições da seqüência programada em diferentes etapas;

- Incidência de falhas de processo;

- Retrabalhos;

- Número de cabinas bloqueadas no Depovert, por falta de outros agregados;

- Alteração da seqüência programada de produção dos caminhões, por falta de cabina;

- Proporção de cores especiais;

- Quais os tipos de veículos críticos.

Essas características foram avaliadas, durante e após a simulação, por meio dos relatórios de resultados e de análises estatísticas dos arquivos Excel produzidos pelos blocos Read/Write ao longo do modelo. As características foram analisadas em conjunto e individualmente, e os resultados e a influência dessas características na necessidade dos estoques seletivos estão apresentados nos resultados deste trabalho. 
A simulação dos modelos ocorreu de forma a avaliar alguns cenários, e cada um deles considerava ou não alguma dessas características. Diversas corridas foram feitas e, em cada uma delas, foi intensificada ou retirada cada característica, ou um grupo delas, e os resultados foram tabelados. Para facilitar o estudo, foram criados arquivos diferentes do modelo de acordo com as características estudadas.

Dessa forma, foram analisados cenários com ou sem falhas de processo, com ou sem bloqueios de veículos, com ou sem retrabalhos, com retrabalhos e com falhas de processo etc. Foram analisados, ao todo, 11 cenários, para avaliar essas características.

Também foram criados cenários específicos para analisar o comportamento dos estoques seletivos e para definir qual seria o mais adequado para implantação:

- DEPOVERT somente como pulmão de seqüência;

- DEPOVERT para cabinas bloqueadas (sistema atual);

- Possibilidade de eliminação do DEPOVERT:

- Aumentando o tamanho do Puffer para armazenar as cabinas bloqueadas:

- Reduzindo o tempo e o número de cabinas bloqueadas pela falta de agregado.

A análise do sistema de produção da montadora, confrontado com as teorias de estocagem e de produção JIT descritas na revisão bibliográfica, mostra por que foi escolhido o DEPOVERT como foco de melhoria. As cabinas são estocadas acabadas e altamente diferenciadas, com alto custo de armazenagem e numa etapa do sistema que não necessitaria de estoque, pois as cabinas poderiam ser liberadas, diretamente da montagem de acabamento, para a montagem final de caminhões. Uma pré-análise mostra que seria muito melhor estocar as cabinas só no Puffer, onde elas ainda não estão diferenciadas, o custo de estoque é menor e esse é o estoque responsável pela correção da seqüência. Os resultados mostrarão de melhor forma, essa análise.

As corridas de simulação foram planejadas para obtenção dos melhores resultados e das análises estatísticas necessárias para a confiabilidade do estudo. As replicações ocorreram da seguinte forma:

- 1 ano, 47901 veículos, 239 dias;

- 6 replicações; 
- Período diário de produção: 2 turnos.

- Simulação do sistema cheio, ou seja, com excesso de cabinas no processo.

Todas as corridas foram feitas nos computadores do Laboratório de Simulação em Controle, da Escola de Engenharia de São Carlos. Não foram necessários muitos recursos computacionais, pois era possível rodar a simulação em computadores Pentium® III de $650 \mathrm{MHz}$ com $250 \mathrm{MB}$ de memória RAM, com processamento de vídeo integrado na placa mãe e memória RAM compartilhada. Para realização das corridas em um curto espaço de tempo, foi utilizada uma estação baseada em dois processadores Intel Xeon® com 4 GB de memória RAM e aceleração de vídeo com 256 MB de memória RAM.

Antes de começar a gerar resultados com a simulação, é necessário verificar e validar o modelo produzido. Esses procedimentos são essenciais para utilização da análise e dos resultados gerados pela simulação do modelo. Todos os cenários e alternativas de modelagem e simulação também foram verificados e validados.

\subsection{Verificação e Validação do modelo}

Como a modelagem foi iterativa, a verificação do modelo ocorria constantemente. Cada novo passo era verificado, para avaliar se o modelo representava o conceito proposto pelo sistema. Após o término de cada módulo do modelo, ele era verificado e depois validado, para avaliar se a simulação do módulo estava de acordo com a realidade. Após a união de todos os módulos, todo o modelo também foi verificado e validado, até mesmo os cenários. As definições das corridas de simulação também foram submetidas a esses procedimentos.

Os recursos utilizados para verificação e validação foram os de animação, e os dados obtidos pelos relatórios finais do software foram confrontados e comparados com os dados e as lógicas do sistema real. Usaram-se os recursos de animação na observação do comportamento do modelo durante a simulação, e os relatórios basearam-se nas informações coletadas durante a simulação.

Todas as informações e observações obtidas foram apresentadas a diversos planejadores de produção e operadores do sistema modelado que, em extensivas reuniões, confrontaram e discutiram os resultados obtidos, para que o modelo representasse todas as características em questão de acordo com o funcionamento 
real do sistema. Muitas observações e correções foram feitas, com base nessas informações.

Com os recursos de animação foi possível observar, durante a simulação, diversas características do modelo, entre elas o fluxo das entidades, o desbalanceamento entre as etapas do processo, a variação da seqüência programada das cabinas e os momentos em que a necessidade pelos estoques era maior ou menor. Tudo que foi observado pela animação foi comprovado pelos dados dos relatórios finais e estava de acordo com o sistema real.

A animação proporcionou a construção de diagramas, para verificação dos parâmetros durante as corridas de simulação. Foram utilizados diagramas de animação em todos os módulos ou subsistemas do modelo. Os principais parâmetros para validação foram: quantidade de cabinas produzidas por dia; takt time e lead time de cada linha de produção; gargalos de cada etapa da produção; utilização, ociosidade ou parada das linhas; número de cabinas alocadas nos estoques e de cabinas fora da seqüência programada; e outras características especiais, como utilização de recursos, número de cabinas em processo etc. Todos esses parâmetros foram coletados e depois comparados com os reais do sistema. $A$ figura 5.27 mostra um resumo de todos os diagramas animados de cada submodelo, para verificação, e um diagrama final.
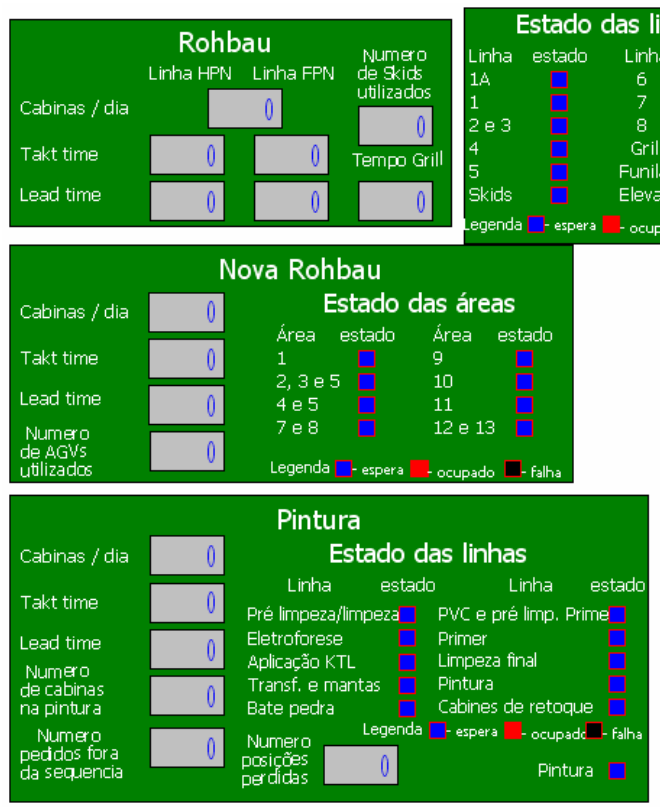

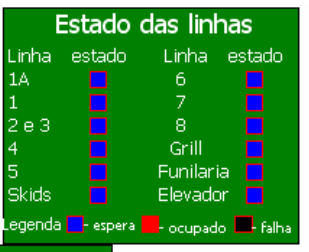

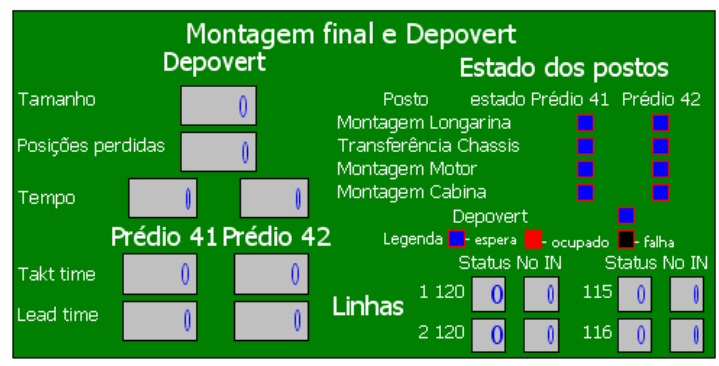

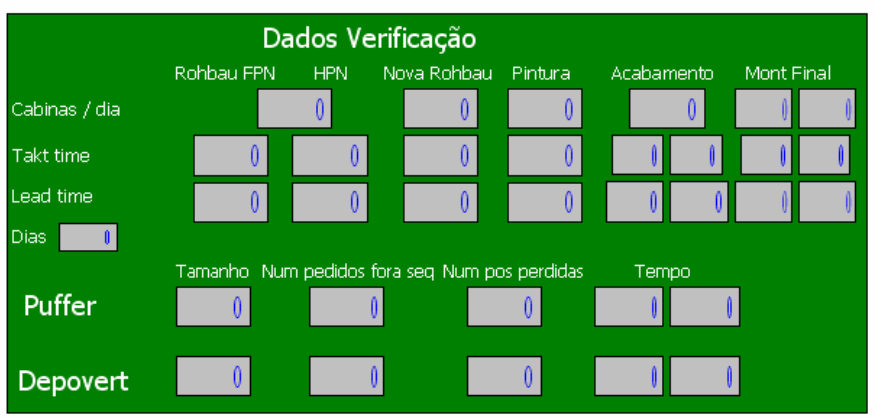

Figura 4.27: Animação para verificação do modelo 
Ao fim de cada corrida de simulação, o Arena® gera relatórios com análises estatísticas de diversos itens, como entidades, recursos, transportadores e outras características determinadas pelo usuário. O relatório "Category Overview" de uma das corridas está no APENDICE I desta dissertação. Com utilização dos dados disponibilizados nos relatórios de resultados da simulação, foram construídas tabelas com os parâmetros a serem verificados, que foram comparados com os parâmetros reais obtidos na montadora, nas reuniões de validação já mencionadas. As tabelas abaixo mostram os parâmetros de validação de todos os submodelos que foram comparados aos sistemas reais da empresa.

\begin{tabular}{|c|l|c|c|}
\cline { 3 - 3 } \multicolumn{2}{c}{ Rohbau } & $\begin{array}{c}\text { Dados médios } \\
\text { calculados de } \\
\text { fábrica (min) }\end{array}$ & $\begin{array}{c}\text { Resultados } \\
\text { médios da } \\
\text { simulação (min) }\end{array}$ \\
\hline Takt time & Linhas 1A e 7 & 29 & 28,78 \\
\hline & Linhas 1, 2/3, 8 & 9 & 8,55 \\
\hline & Linhas 4, 5 e 6 & 7 & 6,09 \\
\hline & Grill e Funilaria & 7 & 6,5 \\
\hline & \multicolumn{2}{c}{} \\
\hline Lead time & Linha 1A até 7 & 270 & 263 \\
\hline & Linha 1 até 8 & 280 & 269 \\
\hline & Grill e Funilaria & 60 & 73 \\
\hline & \multicolumn{2}{c}{} \\
\hline Skids utilizados & 30 & 27 \\
\hline \multicolumn{2}{|c|}{ Produção diária } & 130 & 128 \\
\hline
\end{tabular}

Tabela 4.10: Dados de verificação da Rohbau

\begin{tabular}{|c|c|c|c|}
\hline \multicolumn{2}{|c|}{ Nova Rohbau } & $\begin{array}{l}\text { Dados médios } \\
\text { calculados de } \\
\text { fábrica (min) }\end{array}$ & $\begin{array}{c}\text { Resultados } \\
\text { médios da } \\
\text { simulação (min) }\end{array}$ \\
\hline Takt time & $\begin{array}{l}\text { Linha FSK } \\
\text { Linha LTC }\end{array}$ & 23,15 & $50,65(25,65)$ \\
\hline Lead time & Nova Rohbau & 400 & $680(340)$ \\
\hline \multicolumn{2}{|c|}{ AGVs utilizados } & 9 e 11 (max) & 4 e 6 \\
\hline \multicolumn{2}{|c|}{ Produção diária } & 16 & 15 \\
\hline
\end{tabular}

Tabela 4.11: Dados de verificação da nova Rohbau 


\begin{tabular}{|c|c|c|c|}
\hline \multicolumn{2}{|c|}{ Acabamento } & $\begin{array}{l}\text { Dados médios } \\
\text { calculados de }\end{array}$ & $\begin{array}{l}\text { Resultados } \\
\text { médios da }\end{array}$ \\
\hline \multirow{2}{*}{ Takt time } & Leves e médios & 8 & 7,46 \\
\hline & Pesados & 26 & 26,9 \\
\hline \multirow{3}{*}{ Lead time } & Leves e médios & 270 & 205 \\
\hline & & & \\
\hline & Pesados & 280 & 210 \\
\hline \multirow{3}{*}{$\begin{array}{c}\text { Transp. } \\
\text { Linha } 1 \text { e } 3\end{array}$} & Velocidade & $1,5 \mathrm{~m} / \mathrm{min}$ & $1,8 \mathrm{~m} / \mathrm{min}$ \\
\hline & Número postos & 22 postos & 22 postos \\
\hline & Distância & $154 \mathrm{~m}$ & $154 m$ \\
\hline \multirow{3}{*}{ linha 9} & Velocidade & $1,5 \mathrm{~m} / \mathrm{min}$ & $1,5 \mathrm{~m} / \mathrm{min}$ \\
\hline & Número postos & 8 postos & 8 postos \\
\hline & Distância & $56 m$ & $56 m$ \\
\hline \multirow{3}{*}{ Linha 5} & Velocidade & $0,5 \mathrm{~m} / \mathrm{min}$ & $0,6 \mathrm{~m} / \mathrm{min}$ \\
\hline & Número postos & 9 postos & 9 postos \\
\hline & Distância & $63 m$ & $63 m$ \\
\hline \multicolumn{2}{|c|}{ Tamanho do Posto } & $7 m$ & $7 m$ \\
\hline \multicolumn{2}{|c|}{ Produção diária } & 147 & 149 \\
\hline
\end{tabular}

Tabela 4.12: Dados de verificação da Montagem Acabamento

\begin{tabular}{|c|c|c|c|}
\hline \multicolumn{2}{|c|}{ Montagem final } & \multirow{2}{*}{\begin{tabular}{|c|}
$\begin{array}{l}\text { Dados médios } \\
\text { calculados de } \\
\text { fábrica (min) }\end{array}$ \\
5 \\
\end{tabular}} & \multirow{2}{*}{$\begin{array}{c}\begin{array}{c}\text { Resultados } \\
\text { médios da } \\
\text { simulação (min }\end{array} \\
5,28 \\
\end{array}$} \\
\hline & Prédio 41 & & \\
\hline lakt tıme & Prédio 42 & 26 & 27,05 \\
\hline \multirow{3}{*}{ Lead time } & Prédio 41 & 250 & 245 \\
\hline & & & \\
\hline & Prédio 42 & 550 & 515 \\
\hline \multirow{3}{*}{ Transp. 115} & Velocidade & $4 \mathrm{~m} / \mathrm{min}$ & $4,5 \mathrm{~m} / \mathrm{min}$ \\
\hline & Número postos & 7 postos & 7 postos \\
\hline & Distância & $105 \mathrm{~m}$ & $105 \mathrm{~m}$ \\
\hline \multirow{3}{*}{ Transp. 116} & Velocidade & $4 \mathrm{~m} / \mathrm{min}$ & $4,5 \mathrm{~m} / \mathrm{min}$ \\
\hline & Número postos & 17postos & 17 postos \\
\hline & Distância & $255 m$ & $255 m$ \\
\hline \multirow{3}{*}{ Transp. 120} & Velocidade & $0,5 \mathrm{~m} / \mathrm{min}$ & $0,6 \mathrm{~m} / \mathrm{min}$ \\
\hline & Número postos & 9 postos & 9 postos \\
\hline & Distância & $90 \mathrm{~m}$ & $90 \mathrm{~m}$ \\
\hline \multicolumn{2}{|c|}{ Tamanho do Posto } & 15 e $10 m$ & 15 e $10 m$ \\
\hline \multicolumn{2}{|c|}{ Produção diária } & 204 & 200 \\
\hline
\end{tabular}

Tabela 4.13: Dados de Verificação da Montagem final de Caminhões

Os dados da Tabela 5.11 mostram grande proximidade do modelo com o sistema real. As diferenças dos dados relativos à Linha Nova parecem o dobro. E realmente são, pois a Linha Nova trabalha em 1 único turno, enquanto o restante do sistema trabalha em 2 turnos, assim como o software coleta as estatísticas em 2 turnos. Já os valores restantes se apresentam um pouco maiores, pois os dados de fábrica são referentes a situações normais de fábrica, além do fato de os dados da simulação já levarem em consideração eventuais falhas, filas etc.

As outras tabelas referem-se aos outros submodelos. Todas as tabelas apresentam grande proximidade dos dados reais. 


\begin{tabular}{|c|c|c|c|}
\hline & & $\begin{array}{l}\text { Dados médios } \\
\text { reais de fábrica } \\
\text { (min) }\end{array}$ & $\begin{array}{l}\text { Resultados } \\
\text { médios da } \\
\text { simulação }\end{array}$ \\
\hline \multirow{7}{*}{$\begin{array}{l}\text { Takt } \\
\text { time }\end{array}$} & Rohbau 1A e 7 & 29,33 & 28,78 \\
\hline & Rohbau 1, 2, 3 e 8 & 8,95 & 8,55 \\
\hline & Rohbau 4, 5 e 6 & 6,87 & 6,09 \\
\hline & Nova Rohbau & 23,15 & 50,65 \\
\hline & Pintura & 5,98 & 5,82 \\
\hline & Acabamento & $7,78-26,14$ & $7.46-26.9$ \\
\hline & Montagem final & $5,17-26,14$ & $5.28-27.05$ \\
\hline \multicolumn{2}{|c|}{ Bloqueio de cabinas } & $3,7 \%$ & $5,9 \%$ \\
\hline \multirow{6}{*}{$\begin{array}{c}\text { Lead } \\
\text { time }\end{array}$} & Rohbau 1A até 7 & 350 & $263+73$ \\
\hline & Rohbau 1 até 8 & 350 & $269+73$ \\
\hline & Nova Rohbau & 400 & 680 \\
\hline & Pintura & 350 a 450 & $487^{*}$ \\
\hline & Acabamento & 250 & 200 \\
\hline & Montagem final & $250-550$ & $245-515$ \\
\hline \multicolumn{2}{|c|}{ Produção diária } & $204(147)$ & $200(149)$ \\
\hline
\end{tabular}

Tabela 4.14: Dados gerais de validação do modelo

A Tabela 5.14 apresenta um resumo de todos os dados levantados até agora. Da mesma forma que as outras tabelas, os valores entre o sistema real e os resultados do modelo estão bem próximos.

\subsection{Resultados e conclusões}

Como já foi exposto, foram criados vários cenários para avaliar as características do sistema que mais influíam na necessidade dos estoques. Para facilitar essa análise, o modelo foi copiado de modo que cada cenário gerasse um arquivo diferente. Após a simulação, foram geradas tabelas com os principais resultados, para que fosse possível gerar um gráfico da influência das características. Foi analisada a significância do atraso nas principais etapas: Rohbau e Nova Rohbau, Pintura, e nos estoques seletivos. As análises foram feitas comparando-se a entrada de cada sistema com a saída e com a seqüência original a ser seguida.

Para avaliar a influência de cada característica, foi medida a quantidade e o número de posições em atraso das cabinas em cada etapa do sistema e em cada cenário avaliado. Portanto, cada análise depende de duas informações, que podem não ser relacionadas, pois cada etapa pode apresentar muitas ou poucas cabinas em atraso com muitas ou poucas posições perdidas, dependendo da situação. Outra questão é a existência de maior ou menor produção em etapas diferentes, como na 
Rohbau ou Nova Rohbau. Dessa forma, não foi possível utilizar algum dos tipos de atraso para avaliar as características. Foi necessário criar uma variável que considerasse, ao mesmo tempo, o número de cabinas atrasadas e o número de posições perdidas, além de ser independente do número de cabinas que são produzidas em cada etapa.

Criou-se, então, a variável "atraso absoluto", que é a multiplicação do número de cabinas atrasadas pelo número de posições perdidas dividido pela quantidade de cabinas produzidas em cada etapa. Dessa forma, tem-se uma variável que prioriza a pior condição de atraso e que é independente do número de cabinas produzidas, já que as cabinas atrasadas são proporcionais ao número produzido. Com a divisão pelo número produzido em cada etapa, o atraso absoluto foi normalizado. Como foram feitas 6 replicações, conseguiu-se uma boa tendência dos valores.

Foram geradas tabelas de acordo com os resultados de cada cenário analisado. A Tabela abaixo ilustra um deles.

\begin{tabular}{|c|c|c|c|c|c|c|c|c|c|c|c|c|c|c|c|c|}
\hline \multicolumn{17}{|c|}{ Sistema c bloqueio puffer grd s dpv } \\
\hline & & Rohbau & & & Pintura & & & Pintura $\times \mathrm{Rc}$ & Rohbau & & Puffer & & & Depovert & & \\
\hline Replicacao & Count & Count & Tally & Absoluto & Count & Tally & Absoluto & Count & Tally & Absoluto & Count & Tally & Absoluto & Count & Tally & Absoluto \\
\hline 1 & 36058 & 9457 & 23,92 & 6,273544 & 4445 & 32,48 & 4,003927 & 10048 & 31,14 & 8,67754 & 1305 & 13,47 & 0,487502 & 87 & 3 & 0,007238 \\
\hline 2 & 36010 & 9033 & 25,29 & 6,34392 & 4438 & 31,5 & 3,882172 & 9957 & 31,32 & 8,660184 & 1244 & 13,43 & 0,463952 & 74 & 10,9 & 0,022399 \\
\hline 3 & 36235 & 9359 & 24,89 & 6,428743 & 4493 & 33,93 & 4,207189 & 10159 & 32,08 & 8,994086 & 1380 & 13,28 & 0,505765 & 19 & 6 & 0,003146 \\
\hline 4 & 36093 & 10484 & 22,03 & 6,399095 & 4483 & 32,22 & 4,001947 & 10803 & 29,17 & 8,730876 & 2081 & 15,6 & 0,899443 & 71 & 7 & 0,01377 \\
\hline 5 & 36283 & 9468 & 24,81 & 6,474136 & 4538 & 31,43 & 3,931024 & 10280 & 31,02 & 8,788843 & 1449 & 12,56 & 0,501597 & 93 & 3 & 0,00769 \\
\hline 6 & 36173 & 10143 & 24,61 & 6,900706 & 4484 & 33,11 & 4,104311 & 11100 & 30,3 & 9,297819 & 2087 & 14,06 & 0,811191 & 50 & 7 & 0,009676 \\
\hline média & 36142 & 9657,333 & 24,25833 & $\begin{array}{ll}6,470024 \\
\end{array}$ & 4480,167 & 32,445 & 4,021762 & 10391,17 & 30,83833 & 8,858225 & 1591 & 13,73333 & 0,611575 & 65,66667 & 6,15 & \begin{tabular}{|l|}
0,010653 \\
\end{tabular} \\
\hline
\end{tabular}

Tabela 4.15: Análise do cenário do sistema com bloqueios, Puffer aumentado e sem DEPOVERT

Todas as informações foram unidas em tabelas e gráficos, para que fosse possível analisar continuamente o peso da inclusão das características no sistema e o quanto elas eram responsáveis pelo atraso.

A tabela e o gráfico que seguem mostram a influência dessas características no comportamento do sistema. Partiu-se da hipótese de um sistema sem problemas ou falhas, apenas com as restrições físicas da organização dos processos, ou seja, o fato de as linhas iniciais serem paralelas e depois se tornarem uma e, em seguida, se dividirem novamente. Depois foi feito um modelo com restrições de seqüência, ou seja, com restrições produtivas a certas seqüências especiais. Em seguida, foram analisados os retrabalhos e, por último, as falhas de processo. 


\begin{tabular}{|c|c|c|c|c|c|}
\hline & & $\begin{array}{l}\text { Sistema sem } \\
\text { restrições, falhas } \\
\text { retrabalhos e }\end{array}$ & $\begin{array}{c}\text { Sistema sem } \\
\text { falhas, retrabalhos } \\
\text { e bloqueios }\end{array}$ & $\begin{array}{l}\text { Sistema sem falhas } \\
\text { e bloqueios, com } \\
\text { retrabalhos }\end{array}$ & $\begin{array}{c}\text { Sistema sem bloqueios, } \\
\text { com falhas e } \\
\text { retrabalhos }\end{array}$ \\
\hline \multirow{3}{*}{$\begin{array}{c}\text { Rohbau e } \\
\text { Nova } \\
\text { Rohbau }\end{array}$} & Porcentagem cabinas atrasadas & $30 \%$ & $18 \%$ & $22,0 \%$ & $29,9 \%$ \\
\hline & Posições perdidas & 4,5 & 31,7 & 30,0 & 21,4 \\
\hline & Atraso absoluto & 1,31 & 5,73 & 6,62 & 6,24 \\
\hline \multirow{3}{*}{ Pintura } & Porcentagem cabinas atrasadas & $4 \%$ & $4 \%$ & $11,8 \%$ & $12,12 \%$ \\
\hline & Posições perdidas & 1,0 & 1,0 & 43,5 & 38,2 \\
\hline & Atraso absoluto & 0,04 & 0,04 & 5,12 & 4,63 \\
\hline \multirow{3}{*}{$\begin{array}{c}\text { Pintura } x \\
\text { Rohbau }\end{array}$} & Porcentagem cabinas atrasadas & - & - & - & - \\
\hline & Posições perdidas & - & - & - & - \\
\hline & Atraso absoluto & - & - & - & - \\
\hline \multirow{3}{*}{ Puffer } & Porcentagem cabinas atrasadas & $0,02 \%$ & $1,37 \%$ & $2,18 \%$ & $2,59 \%$ \\
\hline & Posições perdidas & 8,6 & 7,1 & 12,6 & 11,9 \\
\hline & Atraso absoluto & 0,00 & 0,10 & 0,27 & 0,31 \\
\hline \multirow{3}{*}{ Depovert } & Porcentagem cabinas atrasadas & $0,01 \%$ & $0,28 \%$ & $0,81 \%$ & $0,86 \%$ \\
\hline & Posições perdidas & 10,7 & 15,5 & 19,7 & 19,0 \\
\hline & Atraso absoluto & 0,00 & 0,04 & 0,16 & 0,16 \\
\hline
\end{tabular}

Tabela 4.16: Análise da influência das características do sistema no atraso de cabinas

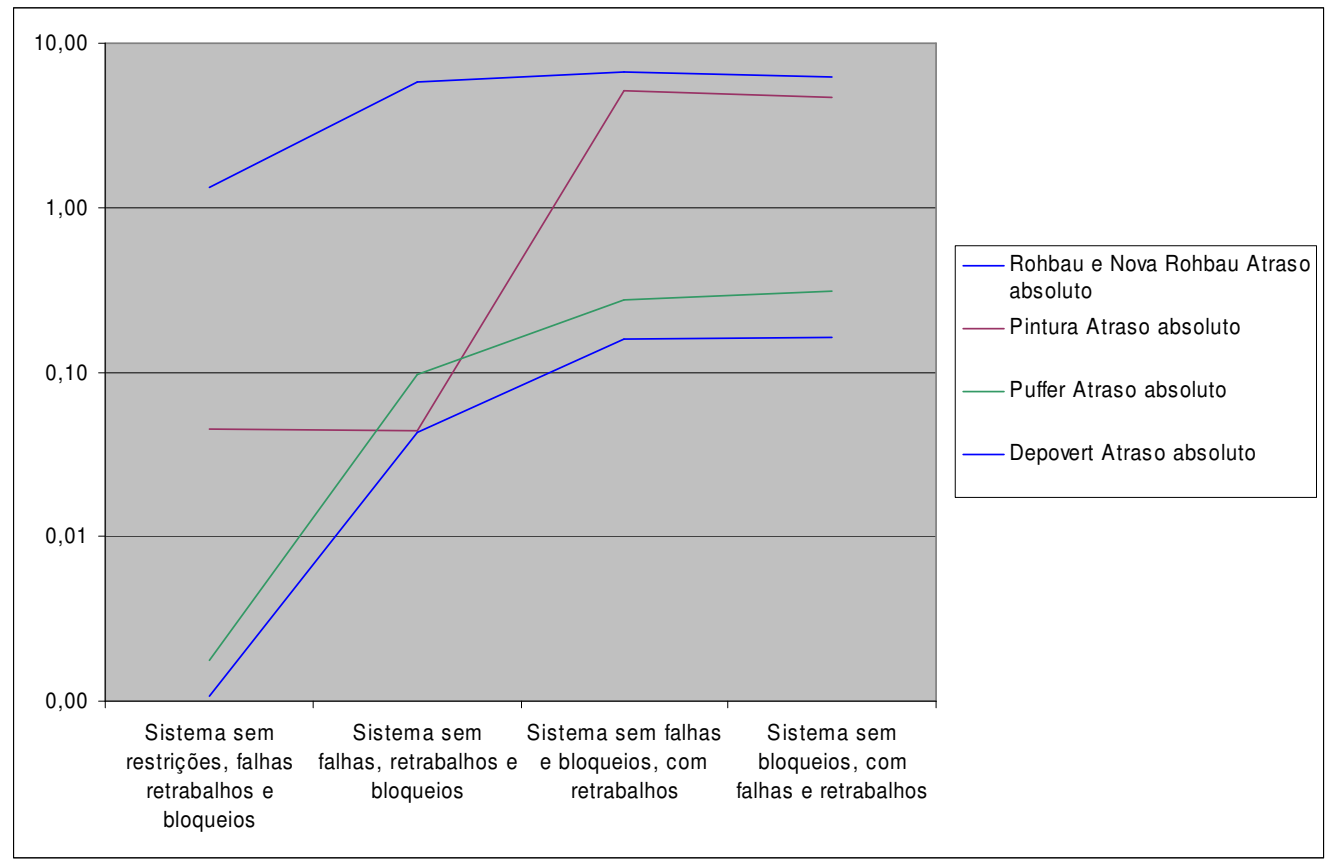

Gráfico 4.1: Influência das características do sistema no atraso das cabinas

A análise do Gráfico 5.1 e da Tabela 5.16, conjuntamente, mostra que, no caso da Rohbau, a configuração de linhas paralelas já traz grande variação na seqüência, mas com poucas posições perdidas. Isso mostra que reorganizar a seqüência após essa etapa seria significativo para redução do atraso, e apenas algumas mudanças seriam necessárias, devido ao baixo número de posições perdidas. Na pintura e nos estoques seletivos, essa condição é pouco significativa.

Já a condição de mudança da seqüência original devido a problemas na capacidade de produção aumentou o atraso na Rohbau, pois aumentou o número de 
posições perdidas. Essa condição também afetou os estoques seletivos, mas não gerou mudanças na pintura.

A condição de retrabalho causou muito atraso na pintura, como já era esperado, pois esse é o principal problema da pintura. Essa condição também aumentou o atraso na Rohbau e, conseqüentemente, nos estoques seletivos.

Finalmente, as paradas de processo, ou falhas, não foram muito significativas.

O modelo ainda não incorporou todas as características especiais do sistema. Após serem inseridos todos os problemas, foi feita uma análise de como as lógicas de decisão e mudanças arbitrárias na seqüência influem no sistema. Dessa forma, foram analisadas as mudanças na seqüência devido aos bloqueios, tanto pela falta de agregados, como pela falta de cabinas. Também foi analisada uma das soluções utilizadas pela montadora, que é a imposição de um limite mínimo para o Puffer. Esse limite garante que existam cabinas suficientes no Puffer, para que ele possa fazer correções na seqüência. A tabela e o gráfico que seguem mostram essa segunda análise.

\begin{tabular}{|c|c|c|c|c|c|}
\hline & & $\begin{array}{c}\text { Sistema sem bloqueios, } \\
\text { com falhas e } \\
\text { retrabalhos }\end{array}$ & $\begin{array}{l}\text { Sistema sem bloqueio (falta } \\
\text { cabinas), c falhas, retrab e } \\
\text { bloqueio (falta agregado) }\end{array}$ & $\begin{array}{c}\text { Sistema com bloqueios (falta } \\
\text { cabina e agragado), falhas e } \\
\text { retrabalhos }\end{array}$ & $\begin{array}{l}\text { Sistema com bloqueios, } \\
\text { falhas e retrabalhos e sem } \\
\text { limite minimo Puffer }\end{array}$ \\
\hline \multirow{3}{*}{$\begin{array}{l}\text { Rohbau e } \\
\text { Nova } \\
\text { Rohbau }\end{array}$} & Porcentagem cabinas atrasadas & $29,9 \%$ & $29 \%$ & $31 \%$ & $27,1 \%$ \\
\hline & Posições perdidas & 21,4 & 22,8 & 21,8 & 24,1 \\
\hline & Atraso absoluto & 6,24 & 6,45 & 6,61 & 6,48 \\
\hline \multirow{3}{*}{ Pintura } & Porcentagem cabinas atrasadas & $12,12 \%$ & $12,2 \%$ & $12 \%$ & $12,2 \%$ \\
\hline & Posições perdidas & 38,2 & 37,7 & 38,2 & 37,8 \\
\hline & Atraso absoluto & 4,63 & 4,62 & 4,75 & 4,62 \\
\hline \multirow{3}{*}{$\begin{array}{l}\text { Pintura x } \\
\text { Rohbau }\end{array}$} & Porcentagem cabinas atrasadas & - & - & $30 \%$ & - \\
\hline & Posições perdidas & - & - & 31,1 & - \\
\hline & Atraso absoluto & - & - & 9,413 & - \\
\hline \multirow{3}{*}{ Puffer } & Porcentagem cabinas atrasadas & $2,59 \%$ & $2,5 \%$ & $2,52 \%$ & $3,8 \%$ \\
\hline & Posições perdidas & 11,9 & 11,6 & 11,6 & 10,8 \\
\hline & Atraso absoluto & 0,31 & 0,29 & 0,30 & 0,40 \\
\hline \multirow{3}{*}{ Depovert } & Porcentagem cabinas atrasadas & $0,86 \%$ & $0,90 \%$ & $0,25 \%$ & $0,2 \%$ \\
\hline & Posições perdidas & 19,0 & 15,2 & 4,8 & 6,5 \\
\hline & Atraso absoluto & 0,16 & 0,14 & 0,02 & 0,01 \\
\hline
\end{tabular}

Tabela 4.17: Influência das mudanças arbitrárias da seqüência no sistema 


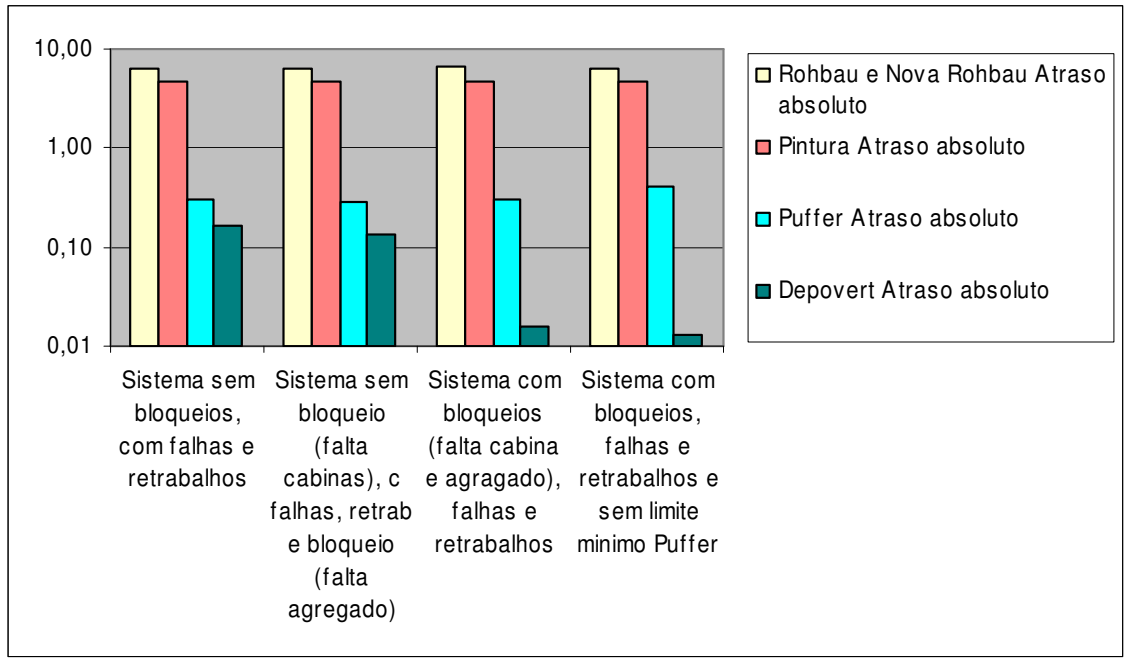

Gráfico 4.2: Influência das mudanças arbitrárias da seqüência no atraso do DEPOVERT

Após a análise conjunta da Tabela 5.17 e do Gráfico 5.2, tem-se que o bloqueio das cabinas por falta de agregado pouco influi no atraso do fim do sistema, ou seja, no DEPOVERT. Já o bloqueio de caminhões por falta de cabina faz com que menos cabinas saiam do DEPOVERT fora da seqüência, já que a seqüência final é modificada de acordo com a falta das cabinas.

A condição de Puffer mínimo também diminui um pouco esse atraso, mas a condição de melhor resultado é a modificação da seqüência final de acordo com o atraso calculado das cabinas.

A análise dos arquivos gerados durante a simulação por meio dos blocos Read/Write possibilitou outros resultados mais detalhados. Esses blocos geraram arquivos que contêm as informações de cada cabina atrasada em cada etapa do sistema, além do número de posições perdidas, tanto relativamente à seqüência original, quanto relativamente à entrada de cada sistema.

Com esses arquivos foi possível analisar o atraso detalhado em cada etapa do processo, diferenciados por modelos e pelo número de posições perdidas, além de outras informações, como cores.

Nessa análise foi feito um histograma da freqüência do atraso de cada tipo de cabina, e também um outro histograma, do número de posições perdidas. No histograma do atraso também foi feita uma normalização, pois os modelos de maior produção também têm, proporcionalmente, maior número de cabinas atrasadas, mas isso não deixaria aparente o tipo de cabina mais problemática. 
Na etapa Rohbau e nova Rohbau, conseguiram-se os seguintes gráficos, após a análise dos dados:
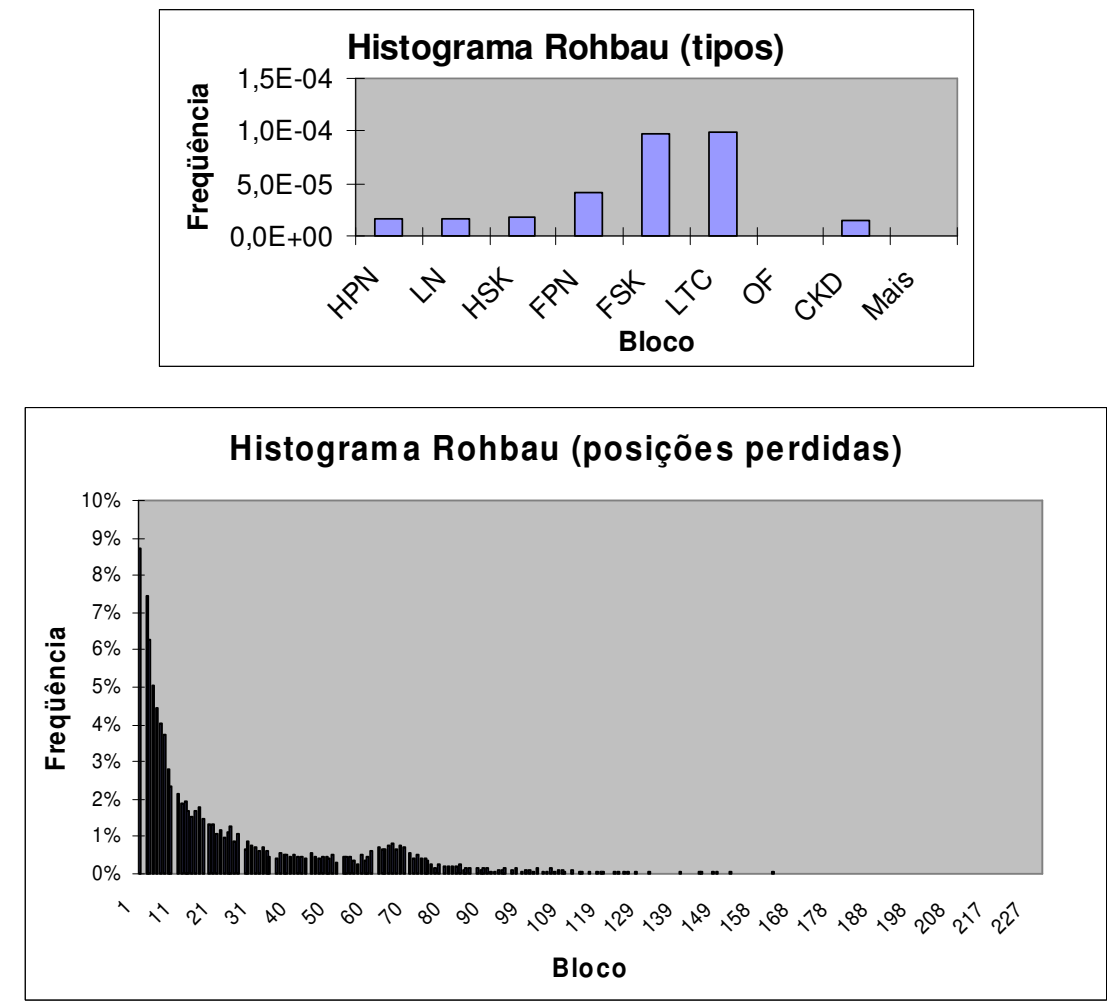

Gráfico 4.3. Gráficos do comportamento das cabinas na saída da Rohbau e nova Rohbau

Analisando-se esses gráficos, é possível concluir que os veículos com maior atraso são o LTC e o FSK, e que os atrasos estão concentrados entre 1 e 15 posições perdidas. Isso se deve aos fatos de que a nova Rohbau que produz os veículos LTC e FSK trabalha em um único turno, enquanto o restante do sistema trabalha em dois turnos.

A própria característica construtiva do sistema, com quatro linhas em paralelo, já gera um atraso pequeno em algumas cabinas, o que explica a alta incidência de cabinas com apenas uma posição perdida, mas o restante se dá uniformemente, devido às falhas de processo, retrabalhos e outras restrições. A análise mostra que, na Rohbau, 30\% das cabinas saem com atraso e com 22 posições perdidas, em média.

$\mathrm{Na}$ etapa de pintura foram analisadas, além dos tipos de veículo e das posições perdidas, as cores dos veículos. Os dados foram analisados entre a entrada e a saída da Pintura e a entrada na Rohbau e a saída na Pintura. 

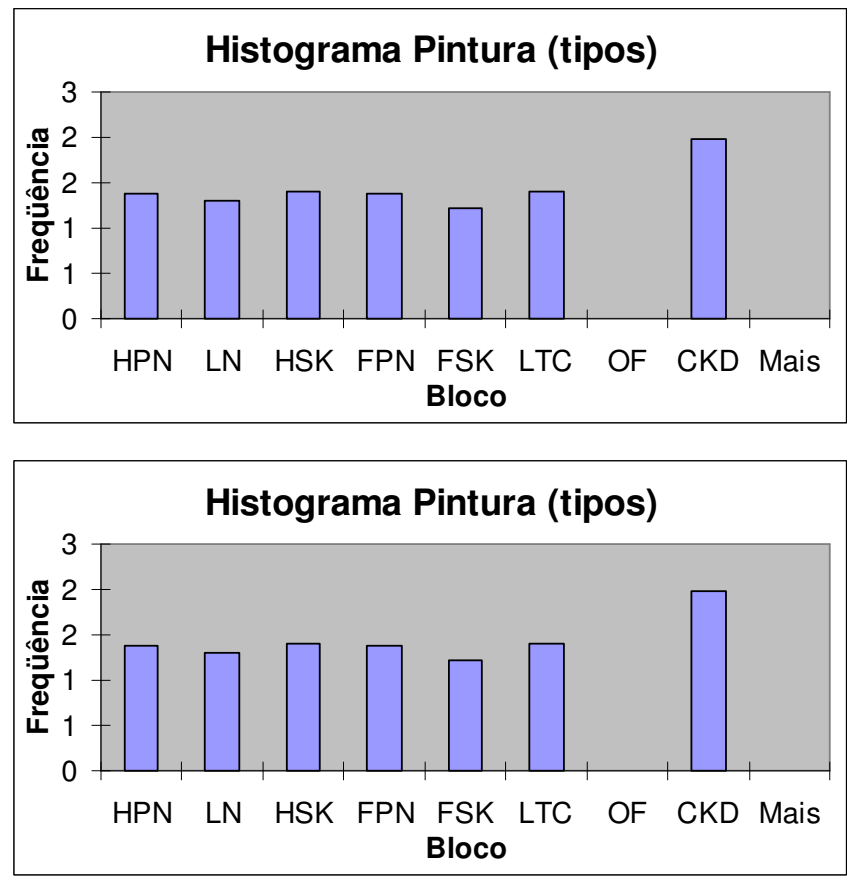

Gráfico 4.4. Gráficos dos veículos e cores atrasados na Pintura
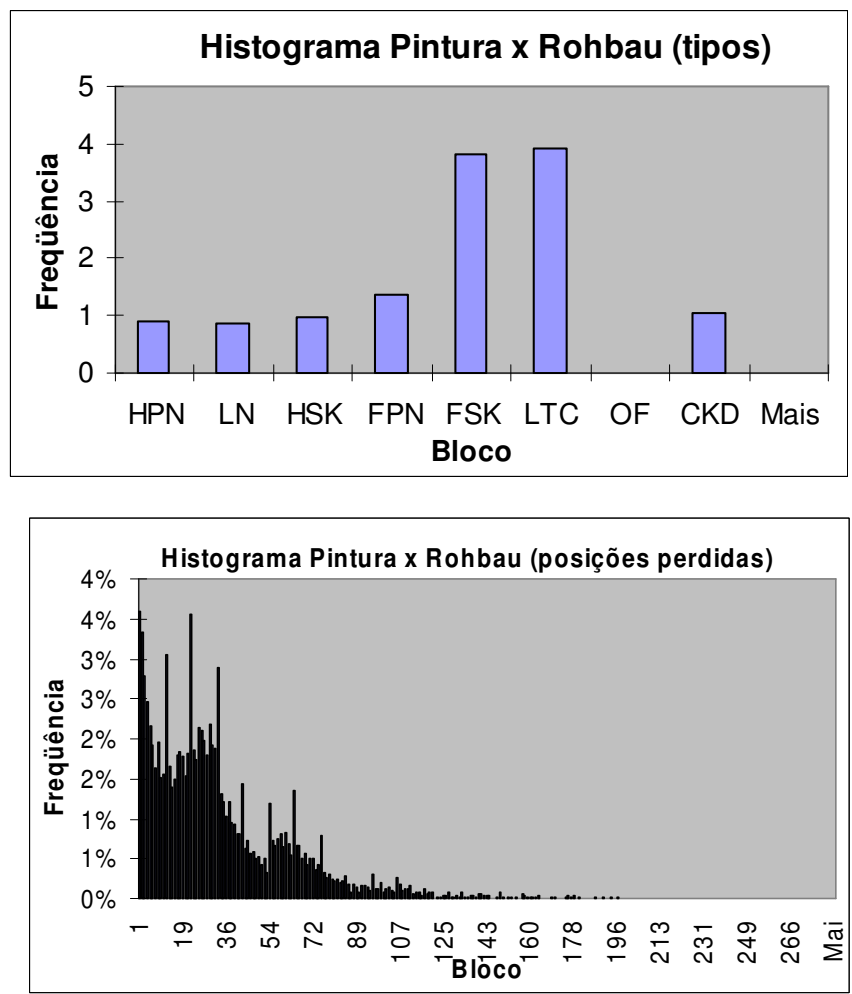

Gráfico 4.5. Gráfico do número de posições perdidas 
Nesses gráficos, pode-se notar que a pintura promove um atraso a todos os veículos de forma igual. A análise anterior mostra que os retrabalhos são a maior causa de atraso na pintura, e eles ocorrem em todos os modelos de forma igual. Já o histograma de cores mostra que as cores mais problemáticas são a prata e a preta, ou seja, as cores especiais, de acordo com o que foi descrito na descrição do sistema.

A comparação do histograma Rohbau x Pintura com o histograma Rohbau, do Gráfico 5.5, mostra que a pintura aumenta o número de cabinas atrasadas de todos os veículos de forma igual. Já a análise da quantidade de posições perdidas mostra que existe um aumento no número de posições perdidas, o que significa que os retrabalhos geram a perda de várias posições.

A pintura libera $12 \%$ de cabinas atrasadas com, em média, 38 posições perdidas, em relação à entrada, e 35\% de cabinas atrasadas com 31 posições perdidas, em média. Quando se compara a seqüência da pintura com a seqüência inicial (Pintura x Rohbau), a média de posições perdidas diminui, pelo fato de ser uma média. Como a maioria das cabinas atrasa nas Rohbau, a média tende para o atraso da Rohbau (30\%, com 22 posições perdidas).

O atraso na saída da pintura faz com que sejam bloqueados $6 \%$ dos veículos produzidos pela provável falta de cabina, pois o controle dos bloqueios é feito na entrada do Puffer.

Foi feita a mesma análise entre a saída do Puffer e a seqüência original, para que fosse possível verificar o quanto o Puffer consegue corrigir a seqüência de cabinas. 

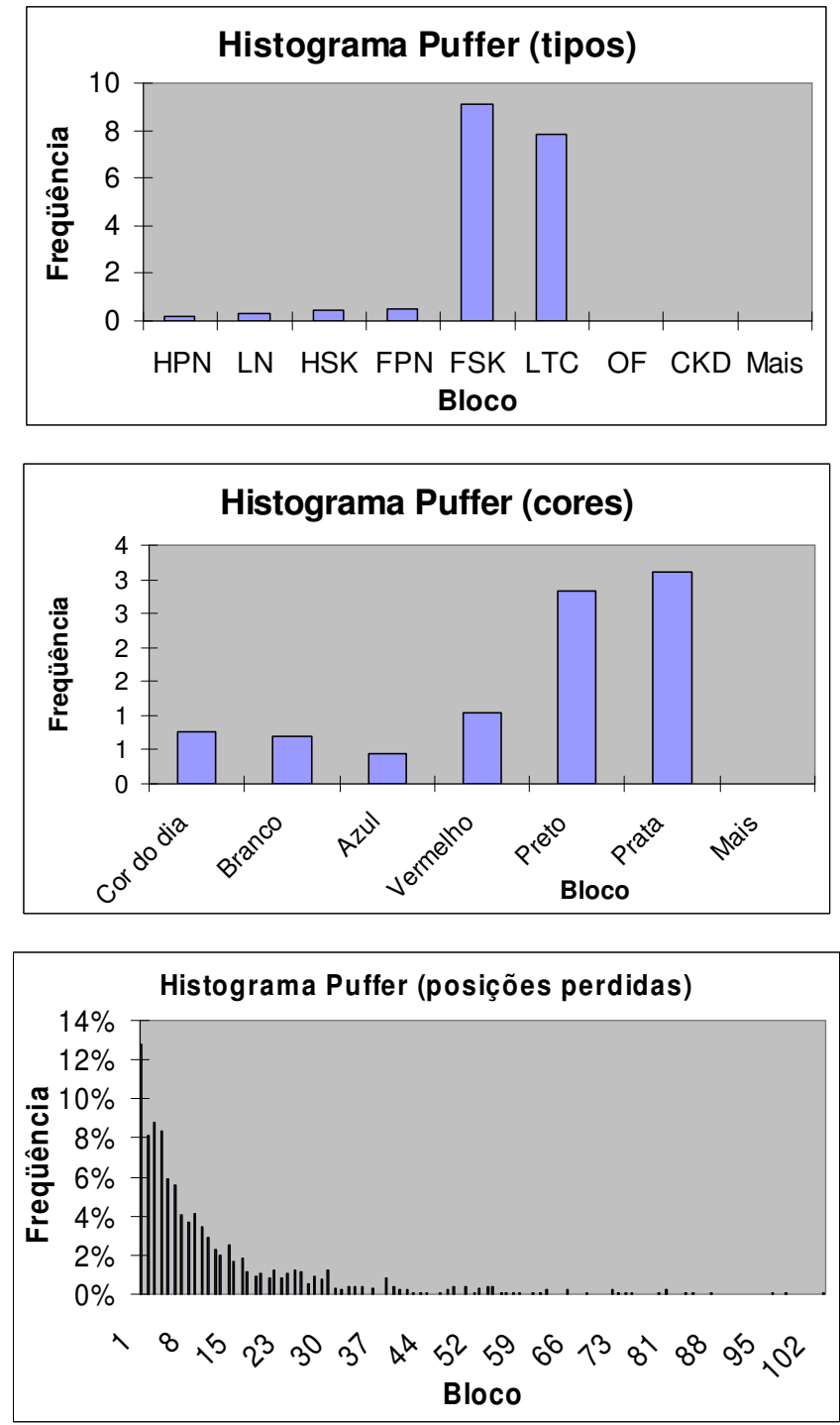

Gráfico 4.6. Comportamento da seqüência na saída do Puffer

No Gráfico 5.6, pode-se notar que as cabinas do FSK e LTC e as cores especiais representam os maiores problemas na saída do Puffer. Essas cabinas atrasadas foram entregues com atraso e, provavelmente, causarão a modificação da seqüência da montagem final de veículos. Esses problemas foram identificados desde o início do sistema, e mostram que atitudes corretivas devem ser tomadas nas outras etapas, para reduzir sua incidência. Outra condição são as cores especiais, que apresentam problemas na pintura e que também causarão alterações na seqüência final. 
A saída do Puffer ainda apresenta um atraso de $2,52 \%$ do total de cabinas, em média, com 12 posições perdidas. Assim como o sistema real, o Puffer não é capaz de corrigir toda a seqüência, mesmo com a redução de $35 \%$ para $2,5 \%$ de cabinas em atraso. Isso mostra, também, que ele está subdimensionado.

A mudança da seqüência original, ou o bloqueio de veículos na montagem final por falta de cabinas, também foi analisada por meio da contagem das cabinas fora do limite de posições perdidas aceitável na entrada do Puffer. Essas cabinas irão modificar a seqüência da montagem final. Os gráficos mostram essa análise.
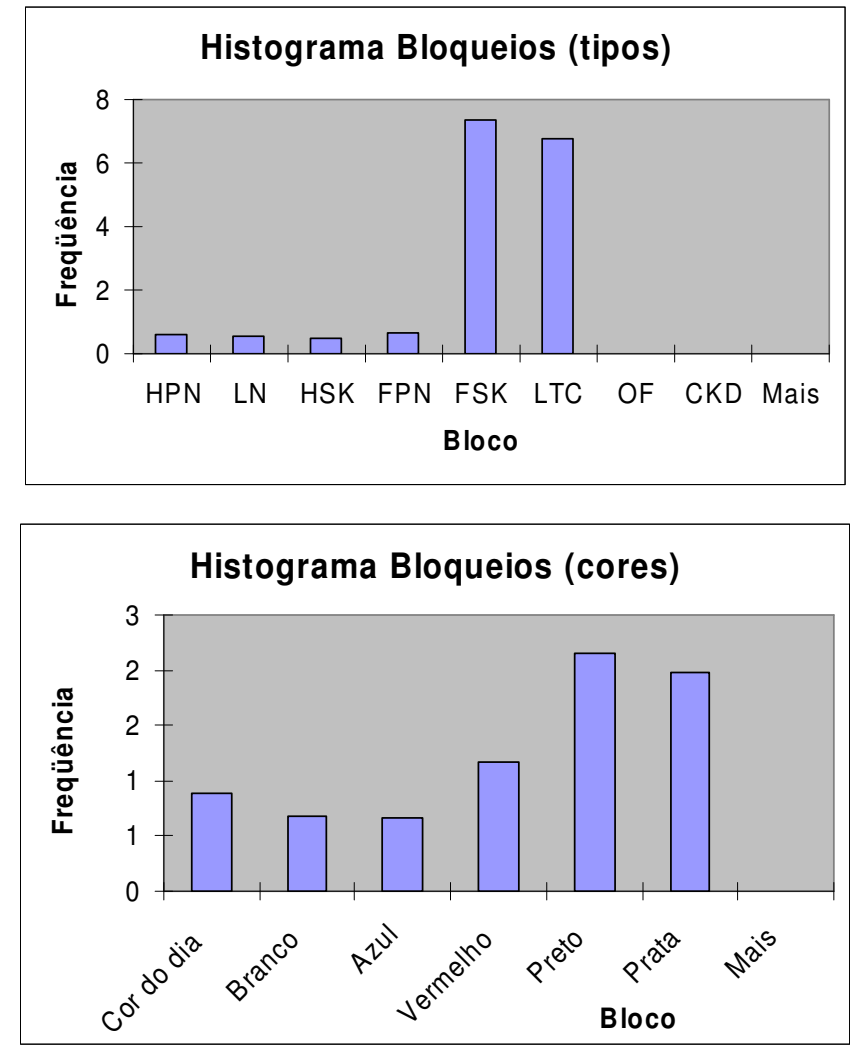

Gráfico 4.7: Histograma das cabinas que irão bloquear veículos na montagem final

Pelos gráficos, comprovamos os problemas com as cabinas LTC e FSK e os problemas com as cores especiais, já demonstrados nas análises anteriores.

A última análise foi feita por meio da comparação da seqüência de saída do DEPOVERT com a seqüência a ser utilizada pela montagem final, com as alterações já feitas, no caso de bloqueios. Os gráficos demonstram total aleatoriedade para os problemas, e isso se deve ao baixo número de cabinas atrasadas: somente $0,25 \%$, ou 85 cabinas, num ano (Gráfico 5.8). Apesar desse atraso não ser permitido, ele ocorre, e algumas vezes as linhas da montagem final param, à espera de uma 
cabina, ou é feito um esquema especial de montagem do caminhão sem cabina. $A$ cabina é montada em outra área e pode representar um problema de qualidade. $\mathrm{O}$ atraso de 85 cabinas em um ano é habitual para a montadora. O número de cabinas que utilizam o DEPOVERT para ficar aguardando um veículo que foi bloqueado é de 7\%, e ocupa de 50 a 80 posições do DEPOVERT.
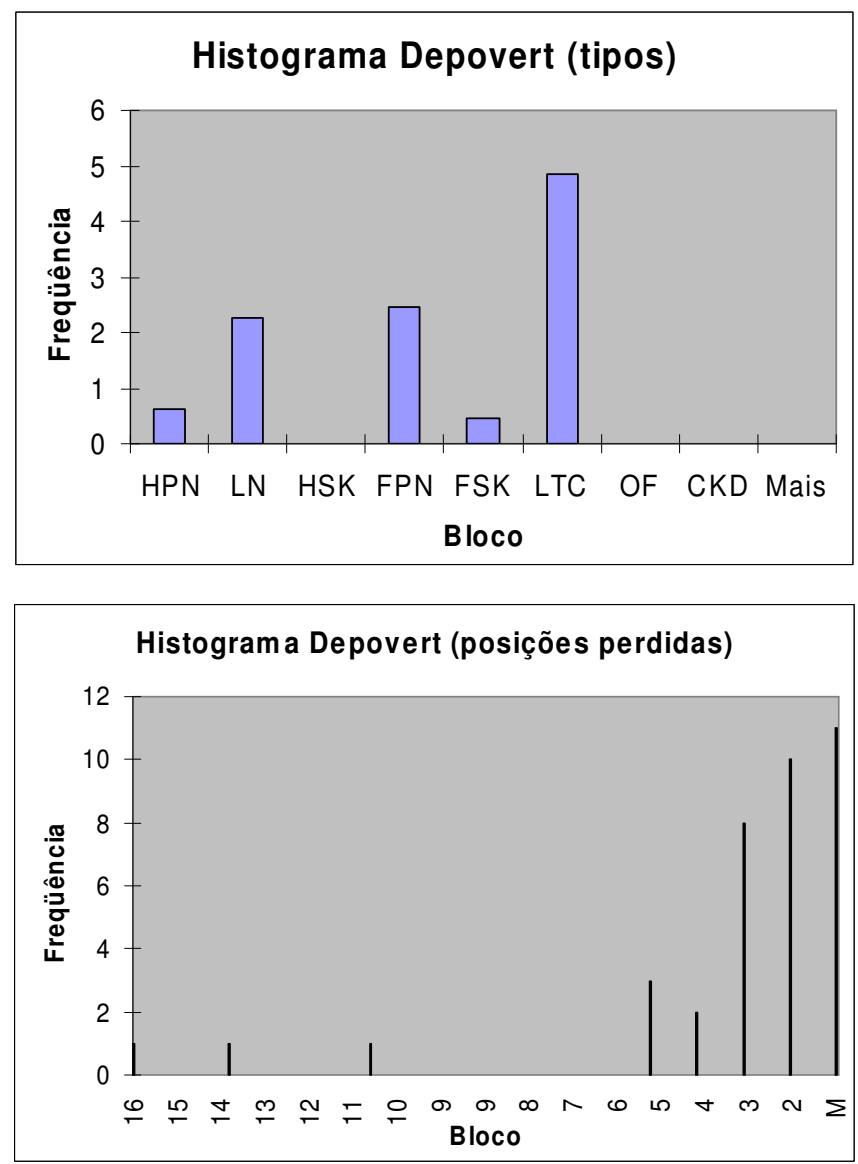

Gráfico 4.8: Atraso de cabinas na saída do DEPOVERT

Todos os resultados apresentados até aqui foram confirmados com os planejadores, gerentes e colaboradores da montadora analisada. Os resultados obtidos também validam o modelo e mostram diversos problemas e questões a serem estudados no sistema.

Após analisar diversas condições do sistema real e verificar onde e por que atrasam as cabinas no sistema, com base nos resultados até aqui demonstrados foi feita a análise dos cenários do redimensionamento dos estoques seletivos e da redução do DEPOVERT. 
Dois cenários diferentes foram simulados: o primeiro foi a eliminação do DEPOVERT, e o segundo foi a eliminação do DEPOVERT com redimensionamento e aumento do Puffer.

Para que o DEPOVERT seja eliminado, algumas mudanças devem ocorrer no modelo do sistema. Como uma das funções do DEPOVERT é guardar as cabinas que foram produzidas, mas por falta de algum outro agregado têm de ser armazenadas para esperar montagem, essas cabinas têm agora que ser armazenadas no Puffer.

Outra questão é o melhor controle das cabinas na entrada do Puffer, para que, caso a cabina esteja muito atrasada, a seqüência da montagem final de caminhões seja logo modificada. Esse melhor controle ocorre porque a existência do DEPOVERT traz uma folga no tempo da tomada de decisão, já que a produção das cabinas está bem adiantada, para compensar o tempo em que elas ficam paradas no DEPOVERT.

Devido ao tempo de acabamento da cabina e o tempo de montagem do caminhão antes de receber a cabina, foi necessário manter um mínimo de cabinas acabadas estocadas, para compensar eventuais falhas da produção e paradas nas linhas.

A simulação do modelo sem o DEPOVERT mostrou-se um sistema muito crítico, mas possível de funcionar. Para que o modelo funcionasse, foi necessário que o DEPOVERT fosse reduzido a um estoque de, no máximo, 25 cabinas e, em média, 17 cabinas.

Já se mencionou que de 50 a 80 posições do DEPOVERT são destinadas às cabinas que foram bloqueadas pela falta de algum agregado. Essas cabinas continuaram a ser bloqueadas nesse modelo e devem ficar, agora, armazenadas no Puffer. A capacidade máxima do Puffer é de 80 cabinas, portanto muito desse espaço ficará comprometido com as cabinas bloqueadas. A vantagem das cabinas serem pouco diferenciadas (brutas e pintadas) não diminuiu muito o número de cabinas paradas.

Somente reduzir o DEPOVERT não se mostrou uma solução para o sistema. Foi testado como o sistema se comportaria caso as cabinas não fossem bloqueadas, ou seja, todas as cabinas seqüenciadas seriam montadas no momento certo. Nesse caso, não seria necessário que o Puffer guardasse cabinas bloqueadas, e a simulação mostrou que o sistema funcionaria, e, caso não ocorresse a falta de 
agregados, seria possível eliminar o DEPOVERT e manter o Puffer da mesma forma que é hoje. A construção e a organização do sistema não garantem que não faltem agregados, portanto essa solução não é viável.

Outra solução seria aumentar a capacidade do Puffer, de modo que ele assimilasse as cabinas que foram bloqueadas e fosse possível reduzir o DEPOVERT.

A simulação desse modelo gerou resultados muito satisfatórios e mostrou que é possível eliminar o DEPOVERT, caso o Puffer seja aumentado. Os principais resultados foram:

- Novo Tamanho do Puffer: 104 cabinas (máximo de 120 cabinas);

- Novo Tamanho do DEPOVERT: máximo de 25 cabinas (pequeno estoque de cabinas para qualquer problema e para suprir o tempo de segurança para bloqueio dos veículos, caso falte alguma cabina).

- Cabinas atrasadas no Puffer: 4,4\% (normal =2,65\%);

- Cabinas atrasadas no DEPOVERT: 0,38\% (normal = 0,25\%);

- Quantidade de Bloqueios: 7,46\% (normal $=6 \%$ ).

Como se pode concluir, a simulação mostra que é possível eliminar o DEPOVERT sem prejuízos para o sistema. Isso traz a redução de custos de armazenagem, menor diferenciação das cabinas estocadas, maior flexibilidade de reposição das cabinas e menor dependência de manutenção, pois o Puffer é bem mais simples e fácil de operar.

O investimento necessário para o projeto é estimado entre $R \$ 700.000,00$ e $R \$ 900.000,00$, dependendo das mudanças estruturais na fábrica.

$O$ custo calculado para o novo Puffer e o novo pequeno estoque que substituiria o DEPOVERT foi calculado em $R \$ 350.000,00$ por ano. Tal quantia corresponde a quase a metade do custo de quase $R \$ 600.000,00$ por ano, no sistema atual.

O departamento de custos da montadora também calculou a atratividade da modificação comparando o investimento e a economia a uma taxa de atratividade de $16,8 \%$, a taxa utilizada na época para avaliar novos projetos. O prazo para retorno do investimento foi de 7 anos. A Tabela abaixo mostra o cálculo: 


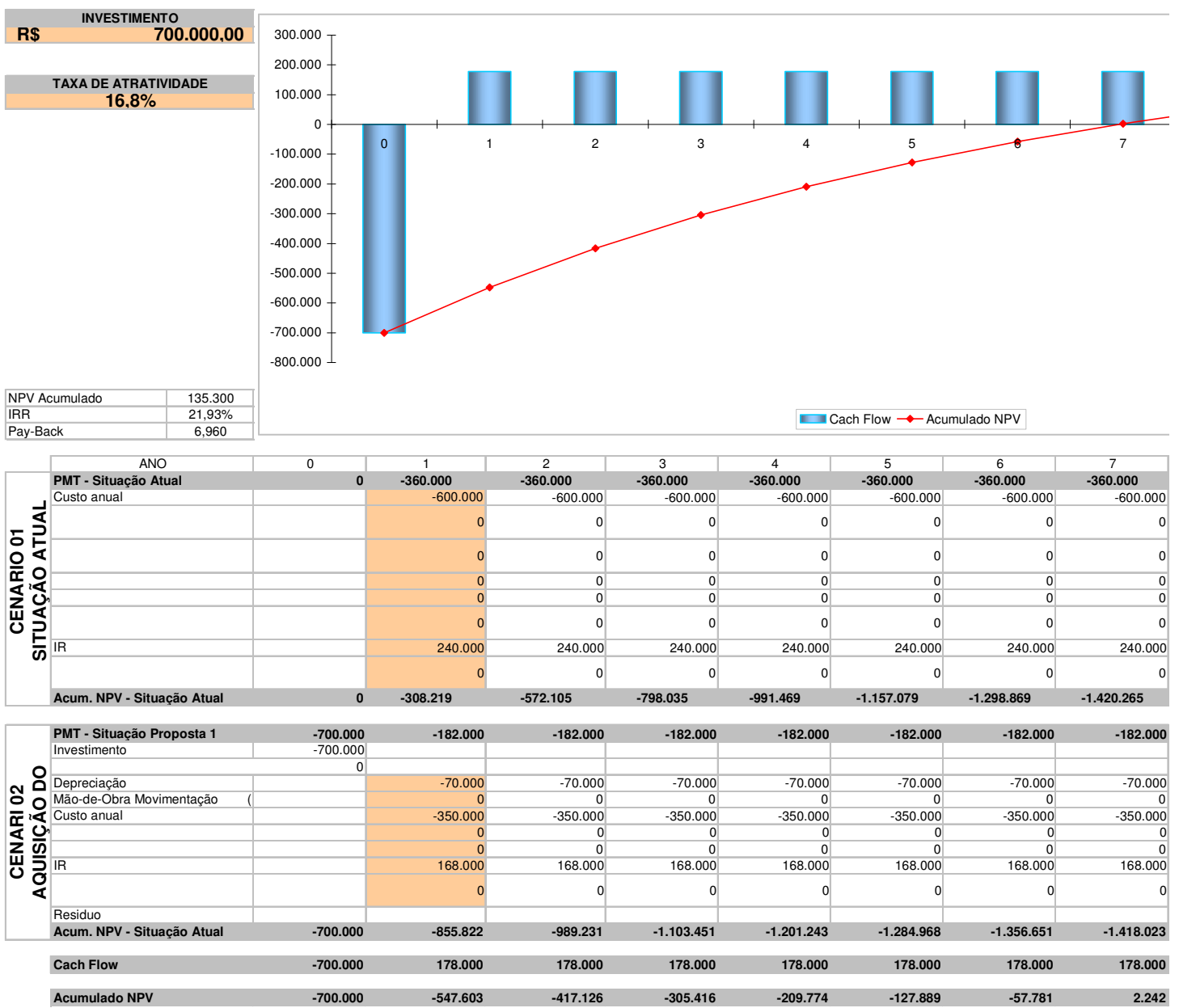

Tabela 4.18: Atratividade da modificação do Puffer e eliminação do DEPOVERT

\section{Conclusões}

O objetivo principal deste trabalho foi analisar a existência e a necessidade dos estoques seletivos de cabinas de uma montadora de veículos comerciais, por meio do uso da técnica da simulação de eventos discretos. O armazenamento de cabinas de caminhões representa um risco para a produção, é de difícil controle e onera a produção.

O desenvolvimento deste trabalho também contribuiu para o conhecimento das dificuldades e benefícios da aplicação da simulação de sistemas discretos em sistemas produtivos de alta complexidade, como são os sistemas de manufatura da indústria automobilística.

Para isso, foi necessário estudar e modelar uma grande parte do sistema de montagem de cabinas e caminhões. A modelagem e o estudo do sistema, descritos 
no capítulo 4 e nos tópicos 5.1, 5.2 e 5.3, mostram um trabalho longo, em que a coleta de dados e as questões específicas do sistema trouxeram dificuldades. $O$ grande número de setores envolvidos dificultava a disponibilidade e o formato dos dados a serem utilizados. Já questões específicas, como lógicas de decisão dos analistas e operadores e relações de dependência entre os diversos setores da produção, foram os pontos de dificuldade da modelagem e, para isso, foi necessário construir vários modelos específicos. Foram necessárias, também, algumas simplificações ou restrições, pois não é possível modelar com todos os detalhes necessários. Essas restrições são previstas e aceitáveis e dependem do raciocínio do modelador. A validação do modelo mostrou que o software e os métodos utilizados foram capazes de representar o sistema de acordo com a realidade, diante dos objetivos pretendidos. Foi possível, portanto, estudar e analisar o sistema plenamente, de acordo com os objetivos.

A simulação do modelo e os resultados obtidos nos tópicos 5.4, 5.5 e 5.6 mostram que as corridas de simulação trouxeram uma análise detalhada do sistema, com a determinação das principais características que influem na necessidade dos estoques seletivos, além de mostrar o quanto cada uma dessas características influi no sistema.

Dessa forma, foi possível prever a redução ou a otimização da utilização dos estoques seletivos por meio de estudos de cenários, em que o melhor cenário foi tido como o principal resultado. É importante salientar que a simulação não produziu o melhor cenário, e que a análise dos resultados das corridas de simulação é que mostrou como deveria ser o melhor cenário.

O estudo mostrou que a técnica da Simulação de Sistemas Discretos é útil e eficaz na solução e análise desse tipo de problema. Além dos resultados, o estudo de Simulação também trouxe à tona diversas questões e problemas que devem ser trabalhados para que se consiga alterar o sistema, diminuir os problemas e otimizar os estoques:

- O estudo de simulação possibilitou analisar o sistema e as características que influem no dimensionamento e na necessidade de existência de estoques em processo;

- Puffer é o principal estoque seletivo e não pode ser eliminado, pois:

- É o estoque que faz a manutenção das principais alterações na seqüência programada ao longo das etapas, e 
- Suporta problemas devido às falhas, retrabalhos, desbalanceamento do fluxo, restrições de capacidade e características especiais presentes no sistema;

- O estudo foi capaz de apresentar a possível redução do DEPOVERT;

- As cabinas armazenadas, por estarem bloqueadas à espera de montagem, ocupam muitas posições no DEPOVERT e impossibilitam somente a eliminação desse estoque, sem outras alterações;

- Se o sistema mantém as mesmas características, é necessário aumentar o Puffer para 120 cabinas, para eliminar o DEPOVERT;

- A eliminação do DEPOVERT resulta na redução de custos operacionais, na não vulnerabilidade às paradas dos equipamentos do DEPOVERT e em projetos de melhoria nas diversas etapas do sistema.

Outra análise que pode ser feita é que um estudo que envolve os estoques exibe diversos problemas na produção. Já é sabido que os estoques servem de fôlego para os problemas da produção, que são amenizados pela existência de estoques. Quando se faz um trabalho com o objetivo de reduzir os estoques, devese trabalhar nos problemas da produção que surgem e que provavelmente causam a existência dos estoques. A Figura 6.1 é típica em estudos de redução de estoques com embasamento na teoria JIT, e ilustra a questão descrita:

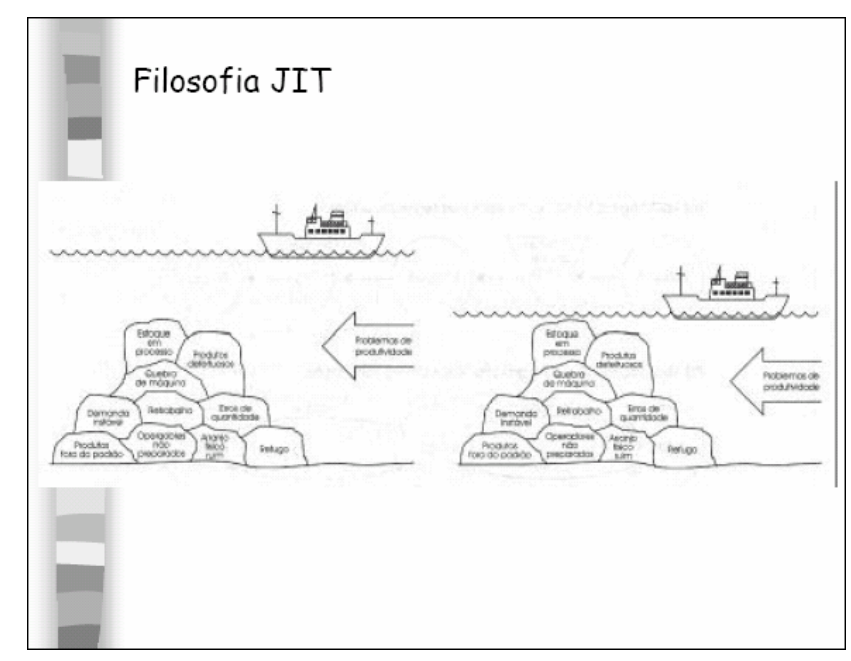

Figura 5.1: Teoria JIT aplicada à redução de estoques.

Os resultados trouxeram uma análise detalhada de quais características influem no sistema e do modo como influem. Características como alterações na 
seqüência devido a restrições de produção, um turno de trabalho na nova Rohbau, não seqüenciamento das cabinas antes da pintura e falhas de processo nas cores especiais da pintura etc. mostraram sua influência na geração dos estoques.

Diversas outras oportunidades de melhorias foram identificadas, como:

- Redução da falta de agregados;

- Ritmo de trabalho constante e redução de falhas;

- Trabalho nos gargalos e restrições;

- Interação entre diversas áreas, diminuindo retrabalhos, perdas de seqüência e variação dos tempos;

- Questão de a produção ser inicialmente empurrada e, após a pintura, ser puxada.

- Melhor controle da seqüência ao longo dos processos.

Como conclusão final, o estudo mostra a capacidade e o poder da ferramenta Simulação de Sistemas Discretos na análise de problemas de grande dificuldade e complexidade dentro da indústria automobilística. Apesar de ser um estudo trabalhoso, os bons resultados comprovam a afirmação.

Este trabalho foi publicado e apresentado nos congressos (ZALLA FILHO \& PORTO, 2004a; ZALLA FILHO et. al, 2004b; ZALLA FILHO \& PORTO, 2005a) e publicado na revista Zalla Filho et. al (2004c).

Como continuidade deste trabalho, sugere-se a construção do modelo do sistema em um outro software com maior liberdade para a programação de lógicas e processos decisórios. Assim, será possível modelar de uma outra forma o processo de decisão dos analistas relativo ao bloqueio das cabinas por futura falta dos outros componentes do caminhão, ou o bloqueio dos caminhões pelo atraso das cabinas. Esse procedimento decisório apresentou grande dificuldade de modelagem no Arena ${ }^{\circledR} 5.0$, devido às restrições de programação fora dos blocos e templates préprogramados. Esse estudo posterior poderia avaliar o modelo e mostrar a fidelidade do estudo feito com relação ao sistema real.

Outra idéia seria a utilização de mais recursos de animação, talvez em uma versão mais nova do Arena $\AA^{\circledR}$, para facilitar a apresentação e a visualização do modelo por analistas não envolvidos diretamente na programação. Os recursos disponíveis na versão 5.0 são limitados e pouco representativos. 
6. Bibliografia.

AIGBEDO, H.; MONDEN, Y. A Parametric Procedure for multi-criteria Sequence Scheduling for Just-In-time Mixed Model Assembly Lines. International Journal of Production Research. Vol. 35, No. 9, 1997. p. 2543-2564.

AXSÄTER, S. Continuous review policies for multi-level inventory systems with stochastic demand. In: Logistics of Production and Inventory. Handbooks in Operation Research and Management Science, Volume 4. Ed. Graves, S.C; Rinnooy Kan, A.H.G; Zipkin, P.H. Netherlands: North-Holland, 1993. p. 175-196.

BAKER, K.R. Requirements Planning. In: Logistics of Production and Inventory. Handbooks in Operation Research and Management Science, Volume 4. Ed. Graves, S.C; Rinnooy Kan, A.H.G; Zipkin, P.H. Netherlands: North-Holland, 1993. p. 571-628.

BALCI, O.: Verification, Validation and Testing. In: Handbook of Simulation. Ed. Jerry Banks. New York: John Wiley \& Sons, Inc., 1998. p. 335-393.

BANKS, J; CARSON, J.S; NELSON, B.L. Discrete-Event System Simulation, 2 ed. New Jersey: Prentice Hall, 1986. 548 p.

BANKS, J. Principles of simulation. In: Handbook of Simulation. New York: John Wiley \& Sons, Inc., 1998. P. 3-30.

BERGE, L. X.: Análise das Potencialidade do Uso da Ferramenta de Simulação Computacional em Operações Logísticas: Estudo de Caso em um Armazém Geral. 2000. Dissertação (Mestrado em Engenharia) - Universidade Federal do Rio Grande do Sul, Porto Alegre, 2000.

CHIN, S. Y. Simulação do Processo de Retirada de Itens em CDP: Um estudo de Caso em Empresa do Ramo Automotivo. 2005. Dissertação (Mestrado em Engenharia), Escola de Engenharia de São Carlos, Universidade de São Paulo, 2005. p. 138.

CHOI, S.D; HOUSHYAR, A. A simulation study of an automotive foundry plant manufacturing engine blocks. In: 2002 Winter Simulation Conference. Proceedings of the... Editors: Yücesan, E.; Chen, C. -H.; Snowdon, J. L.; Charnes, J. M. 2002. p. 1035-1040. 
COLMANETTI, M.S. Modelagem de Sistemas de Manufatura Orientada pelo Custeio das Atividades e Processos. 2001. Dissertação (Mestrado em Engenharia) - Escola de Engenharia de São Carlos, Universidade de São Paulo, São Carlos, 2001.

CORRÊA, H. L.; GIANESI, I. G. N.; CAON, M. Planejamento, Programação e Controle da Produção, 4. ed. São Paulo: Gianesi Corrêa \& Associados, Atlas 2001. $452 \mathrm{p}$.

DING, F.-Y.; SUN, H. Sequence Alteration and Restoration Related to Sequenced Parts Delivery on an Automobile Mixed-Model Assembly Line with Multiple Departments. International Journal of Production Research. Vol. 42, No. 8, April 2004. p. 1525-1543.

FEDERGRUEN, A. Centralized planning models for multi-echelon inventory systems under uncertainty. In: Logistics of Production and Inventory. Handbooks in Operation Research and Management Science, Volume 4. Ed. Graves, S.C; Rinnooy Kan, A.H.G; Zipkin, P.H. Netherlands: North-Holland, 1993. p. 133-174.

FIORONI, M. M.; FANZENE, L. A. G.; BATOCCHIO, A. Aplicação de Templates na Simulação de Transportadores Aéreos em Indústria Automotiva. Artigo da Internet encontrado em http://www.paragon.com.br/brararem.html. 2003

FOGARTY, D. W.; BLACKSTONE Jr, J. H.; HOFFMANN, T. R. Production \& Inventory Management, 2 ed. Ohio, South-Western Publishing Co 1991. 870 p.

FREIMER, M.; SCHRUBEN, L. Colleting Data and Estimating Parameters for Input Distributions. In: 2002 Winter Simulation Conference. Proceedings of the... Editors: Yücesan, E.; Chen, C. -H.; Snowdon, J. L.; Charnes, J. M. 2001. p.392-399.

GONÇALVES FILHO, E.V.; Arranjo Físico da Fábrica: Um Modelo para o Processo de Projeto e um Algoritmo Genérico para a Formação de Células de Fabricação. Tese (Livre Docência) - Escola de Engenharia de São Carlos, Universidade de São Paulo, São Carlos, 2001. p. 133.

GORDON, G. System Simulation. 2nd ed. Englewood Cliffs, New Jersey, Prentice Hall, 1978. p. 423.

GOULART, C.P. Proposta de um Modelo de Referência para Planejamento e Controle da Produção em Empresas Virtuais. 2000. Dissertação (Mestrado em 
Engenharia) - Escola de Engenharia de São Carlos, Universidade de São Paulo, São Carlos, 2000.

GROENEVELT, H. The just-in-time system. In: Logistics of Production and Inventory. Handbooks in Operation Research and Management Science, Volume 4. Ed. Graves, S.C; Rinnooy Kan, A.H.G; Zipkin, P.H. Netherlands: NorthHolland, 1993. p. 629-665.

GUNAL, A; SADAKANE, S; WILLIANS, E.J. Modeling of chain conveyors and their equipment interfaces. In: 1996 Winter Simulation Conference. Proceedings of the... Swain. Picataway: IEEE, 1996. p.1353-1358.

HAN, Y. H.; ZHOU, C.; MCGINNIS, L.; CARMICHAEL, C. NEWCOMB, P. Paint Line Color Change Reduction in Automobile Assembly through Simulation. In: 2003 Winter Simulation Conference. Proceedings of the... ed. Chick, S.; Sânchez, P. J.; Ferrin, D.; Morrice, D. J. 2003. p. 1204-1209.

HARREL, C. R.; BATEMAN, R. E., GOGG, T. J. MOTT, J. R. A.: System Improvement Using Simulation. Orm, Utah, PROMODEL Corporation, 1992.

HARRIS, F. Operations and Cost In: Factory Management Series. Chicago: A.W. Shaw Co, 1915. p. 48-52.

JAYARAMAN, A; GUNAL, A. Applications of discrete event simulation in the design of automotive power train manufacturing systems. In: 1997 Winter Simulation Conference, Proceedings of the... 1997. p. 758-764.

JUNQUEIRA, F. Modelagem de Sistemas Flexíveis de Movimentação de Materiais Através de Redes de PETRI Interpretadas. 2001. Dissertação (Mestrado em Engenharia), Escola Politécnica, Universidade de São Paulo, 2001. p. 128.

LAHMAR, M.; ERGAN, H.; BENJAAFAR, S. Resequencing and Feature Assignment on an Automated Assembly Line. IEEE Transactions on Robotics and Automation. Vol. 19, No. 1, February 2003. p. 89-102.

LAW, A.M; MCCOMAS, M.G. Simulation of manufacturing systems. In: 1999 Winter Simulation Conference. Proceedings of the... 1999. p. 56-59.

LAW, A.M. Introduction to Simulation: A powerful toll for analyzing complex manufacturing systems. Industrial Engineering, 1986. p. 46-63. 
LAW, A.M; HAIDER, S.W. Selecting simulation software for manufacturing applications: Practical guideline and software survey. Industrial Engineering, n. 21, 1989. p. $33-46$

LAW, A. M.; KELTON, W. D.: Simulation and Modeling Analysis. $2^{\text {nd }}$ ed. McGraw Hill, 1991. p. 759.

LAWLER, E.L; LENSTRA, L.K; RINNOOY KAN, A.H.G; SHMOYS, D.B. Sequencing and scheduling: Algorithms and Complexity. In: Logistics of Production and Inventory. Handbooks in Operation Research and Management Science, Volume 4. Ed. Graves, S.C; Rinnooy Kan, A.H.G; Zipkin, P.H. Netherlands: NorthHolland, 1993. p. 445-522.

LEE, H.L; NAHMIAS, S. Single-product, single location models. In: Logistics of Production and Inventory. Handbooks in Operation Research and Management Science, Volume 4. Ed. Graves, S.C; Rinnooy Kan, A.H.G; Zipkin, P.H. Netherlands: North-Holland, 1993. p. 3-59.

LEEMIS, L. Input Modeling Techniques for Discrete Event Simulations. In: 2001 Winter Simulation Conference. Proceedings of the... editors: Peters, B. A.; Smith, J. S.; Medeiros, D. J.; Rohrer, M. W. 2001. p.62-73.

MANE, A.; NAHAVANDI, S.; ZHANG, J. Sequencing Production on an Assembly Line Using Goal Chasing and User Defined Algorithm. In: 2002 Winter Simulation Conference. Proceedings of the... ed. Yücesan, E.; Chen, C. -H.; Snowdon, J. L.; Charnes, J. M. 2002. p. 1269-1273.

MANIVANNAN, M.S. Simulation of logistics and transportation systems. In: Handbook of Simulation, Ed. Jerry Banks. New York: John Wiley \& Sons, Inc., 1998. p. 571-604.

MARIA, A. Introduction to Modeling and Simulation. In: 1997 Winter Simulation Conference, Proceedings of the... 1997. p.7-13.

MCLEAN, C.; LEONG, S. A Framework for Standard Modular Simulation. In: 2002 Winter Simulation Conference. Proceedings of the... Editors: Yücesan, E.; Chen, C. -H.; Snowdon, J. L.; Charnes, J. M. 2002. p.1613-1620.

MONDEN Y.: Toyota Production System. $3^{\text {rd }}$ ed. Norcross: Engineering \& Management Press, 1998. 
MONKS, J. G.: Planejamento e análise de processos (simulação). In: Administração da Produção. McGraw Hill, São Paulo, 1987.

MUCKSTADT, J.A; ROUNDY, R.O. Analysis of multistage production systems In: Logistics of Production and Inventory. Handbooks in Operation Research and Management Science, Volume 4. Ed. Graves, S.C; Rinnooy Kan, A.H.G; Zipkin, P.H. Netherlands: North-Holland, 1993. p. 59-132.

MUSSELMAN, K.J. Guidelines for success. In: Handbook of Simulation. Ed. Jerry Banks. New York: John Wiley \& Sons, Inc., 1998. p. 721-743.

NARAYANASWAMY, R.; JARAYARAMAN, A.; GUNAL, A. K. A sortation system model. Proceedings of the... 1997. p. 866-871.

O'KANE, J. F.; SPENCELEY, J. R.; TAYLOR, R. Simulation as an Essential Tool for Advanced Manufacturing Technology Problems. Journal of Materials Processing Technology. No. 107, 2000. p. 412-424.

PAOLLILO, F.; TAHARA, C. S.; MINUTTI, J.; SALVINI, N. Simulação, e teoria das restrições na VW. In: Innovation'2003 - 3a Conferência Internacional de Produtividade e Simulação. Anais do... 2003 (CD ROM).

PARAGON. Introdução à simulação com ARENA 5.0. Rockwell software, São Paulo, (2002)

PATEL, V; MA, J; ASHBY, J. Discrete event simulation in automotive final process system. In: 2002 Winter Simulation Conference. Proceedings of the... 2002. p. 1030-1034.

PORTO, D. J. V.; RAVELLI, C. A.; PORTO, A. J. V. Estudo da Produtividade dos Tratores de Esteiras: Sistematização e Uso da Simulação. In: XVI Congresso Brasileiro de Engenharia Mecânica. Anais do... 2001 (CD ROM).

PREISS, K.; GOLDMAN, S. L.; NAGEL, R.N. Cooperar para Competir: Construindo Parcerias Eficazes. São Paulo, Futura, 1998.

PRITSKER, A. A. B.: Introduction to Simulation and SLAN-II. $4^{\text {th }}$ ed. New York, John Wiley \& Sons, 1995. 
RIETH, D.; GERLACH, S. Planning and Controlling of Flexible Assembly Systems for Automotive Industry. Proceedings of the 1996 IEEE International Symposium on Computer Aided Control System Design. September, 1996. p. 224-228

ROHRER, M.W. Simulation of manufacturing and material handling systems. In: Handbook of Simulation. Ed. Jerry Banks. New York: John Wiley \& Sons, Inc., 1998. p. 519-545.

ROHRER, M.; STRONG, B. Automotive Applications of Discrete Event Simulation. Automotive Manufacturing \& Production. Vol. 109, no 7, July 1997. p. 38-41.

RONCONI, D. P. A note on Constructive Heuristics for the Flow shop Problem with Blocking. International Journal of Production Economics. Elsevier Science B. V. 2003.

SMITH, J. S. Survey on the Use of Simulation for Manufacturing System Design and Operation. Journal of Manufacturing Systems, vol. 22, no 2, 2003. p.157-171.

SPIECKERMANN, S.; GUTENSCHWAGER, K.; VOSS, S. A sequential Ordering Problem in Automotive Paint Shops. International Journal of Production Research. Taylor \& Francis Ltd, Vol. 42, No. 9, May 2004. p. 1865-1878.

SLY, D.P. Research to application success stories: manufacturing. In: 1997 Winter Simulation Conference. Proceedings of the... 1997. p. 1286-1292.

SURI, R; SANDERS, J.L; KAMATH, M. Performance evaluation of production networks. In: Logistics of Production and Inventory. Handbooks in Operation Research and Management Science, Volume 4. Ed. Graves, S.C; Rinnooy Kan, A.H.G; Zipkin, P.H. Netherlands: North-Holland, 1993. p. 199-286.

TEMPELMEIER, H.; BÜRGER, M. Performance Evaluation of Unbalanced Flow Lines with General Distributed Processing Times, Failures and Imperfect Production. IIE Transactions. No 33, 2001. p.293-302.

ÜLGEN, O; GUNAL, A. Simulation in the automobile industry. In: Handbook of Simulation. Ed. Jerry Banks. New York: John Wiley \& Sons, Inc., 1998. p. 547-570.

ÜLGEN, O; GUNAL, A; GRAJO, E; SHORE, J. The role of simulation in design and operation of body and paint shops in vehicle assembly plants. In: European Simulation Symposium, 1994. Proceedings... 1994. p. 124-128. 
VINCENT, S. Input Data Analysis. In: Handbook of Simulation. Ed. Jerry Banks. New York: John Wiley \& Sons, Inc., 1998. p. 55-91.

WILLIANS, E.J; ÇELIK, H. Analysis of conveyor systems within automotive final assembly. In: 1998 Winter Simulation Conference Proceedings... 1998. p. 915-920.

WILLIANS, E.J; SADAKANE, S. Simulation of a paint shop power and free line. In: 1997 Winter Simulation Conference. Proceedings... 1997. p. 727-732.

YAMADA, M. C.; SOUZA, M. C. F.; PORTO, A. J. V. Simulação de uma Linha de Montagem de Motores: Um Estudo de Caso. In: XXII Encontro de Engenharia de Produção. Anais do... 2001 (CD ROM).

ZALLA FILHO, J. G.; PORTO, A. J. V. Análise dos Estoques em um Processo de um Sistema de Produção de Cabinas Através de Simulação. In: XI Simpósio de Engenharia de Produção - SIMPEP. Anais do... 2004a. (CD ROM).

ZALLA FILHO, J. G.; PORTO, A. J. V.; CACERES, A. S. M. Simulação de um Sistema de Produção de Cabinas de Caminhões. In: XIII Congresso e Exposição Internacionais da Tecnologia da Mobilidade, SAE Brasil, São Paulo Anais do... 2004b. (CD ROM).

ZALLA FILHO, J. G.; PORTO, A. J. V.; GONÇALVES FILHO, E. V. Análise dos Estoques em um Sistema de Produção de Cabinas Através de Simulação. Revista MINERVA. (publicação da FIPAI) Vol 1, No. 1, 2004c.

ZALLA FILHO, J. G.; PORTO, A. J. V. Análise de um Sistema de Produção de Cabinas Através do Uso da Simulação de Eventos Discretos. In: 3ํㅡㄹ Congresso Brasileiro de Engenharia de Fabricação - COBEF. Anais do... 2005a. (CD ROM).

ZERAMDINI, W.; AIGBEDO, H.; MONDEN, Y. Bicriteria Sequencing for Just-In-Time mixed-model assembly lines. International Journal of Production Research. Vol. 38, No. 15 , 2000. p. $3451-3470$. 
APENDICE I - A comparação com o sistema de produção de caminhões da DaimlerChrysler da Alemanha, fábrica de Wörth

Durante 5 meses foi realizado um estágio na fábrica de caminhões de Wörth da DaimlerChrysler da Alemanha. Durante esse estágio foi possível comparar o sistema alemão de produção de caminhões ao sistema estudado no Brasil.

O sistema de produção de cabinas e caminhões em Wörth tem várias similaridades com o da DaimlerChrysler do Brasil. O sistema também é dividido em montagem bruta, pintura, montagem acabamento e montagem de caminhões, mas cada subsistema tem diferenças significativas com relação ao brasileiro. Outra questão é o nível de produção, onde lá são produzidos, em média, 400 veículos por mês em três turnos para a pintura e dois para o restante do sistema. Cada veículo tem um nível bem maior de variações, inclusive diversas variações de cores. Chega a se dizer que são raros mais de 2 veículos iguais em um ano. Cada cabina nasce destinada a um específico veículo desde a montagem bruta e não existem trocas. $\mathrm{A}$ seqüência é montada em até 1,5 mês antes do início de produção e uma semana antes desse início, ela é travada e não são permitidas alterações.

O sistema também possui dois estoques seletivos, um Puffer de cabinas pintadas que tem a função de corrigir as mudanças na seqüência de cabinas devido a problemas na pintura e ao sistema da Rohbau (montagem bruta). Também balanceia o sistema devido à diferença entre a pintura de 3 turnos e a montagem acabamento de 2. Segundo relatos, somente esse estoque é capaz de corrigir todas as diferenças de seqüência. O Puffer de cabinas pintadas tem capacidade máxima para 250 cabinas, mas em média trabalha com 180 cabinas. 


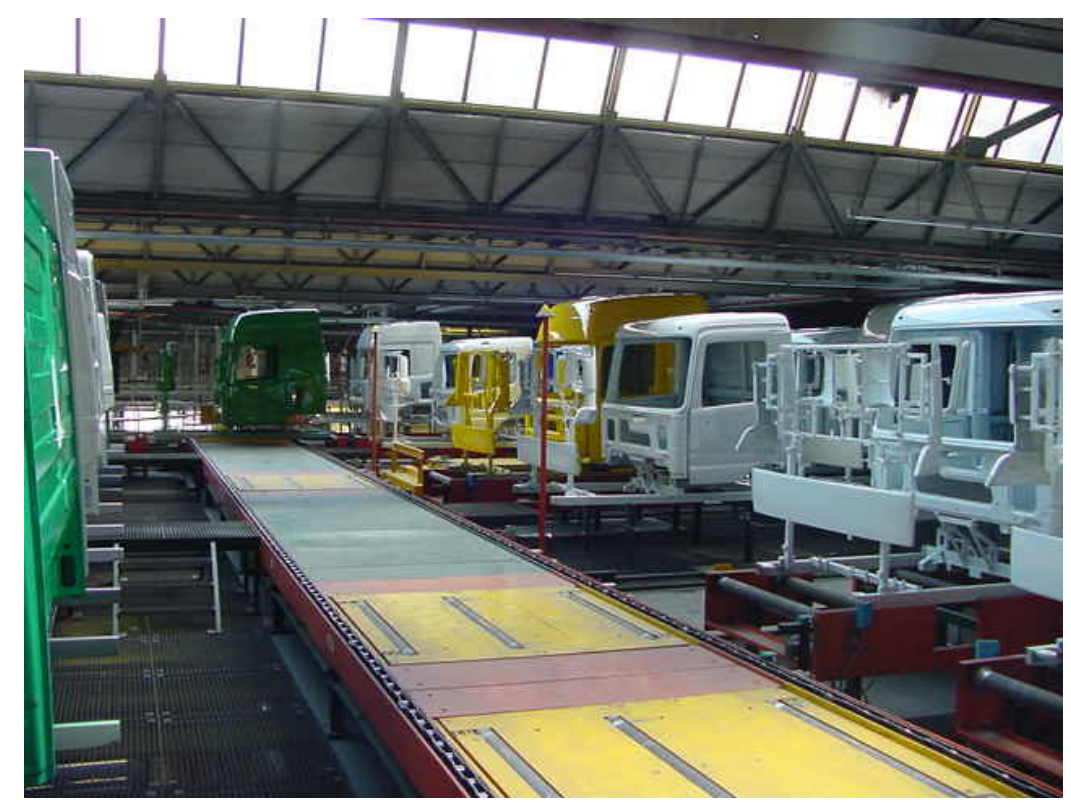

Figura A. Puffer de cabinas pintadas de Wörth

O segundo estoque guarda as cabinas acabadas. Ele tem a função de dividir as cabinas para a montagem final de caminhões, a qual é dividida em três linhas, e serve como um pulmão para eventuais diferenças nas linhas. Também tem uma estação de trabalho para retrabalhos e alguns testes, e também guarda alguma cabina que, por algum outro motivo, não pode ser montada no caminhão, o que acontece muito raramente. É importante observar que depois de divididas as cabinas para as 3 linhas da montagem final, não ocorrem mais trocas na seqüência. É dito que todas as cabinas chegam nesse estoque na seqüência correta de montagem. Esse segundo estoque tem capacidade para em torno de 160 cabinas, mas trabalha normalmente com 90 cabinas. 


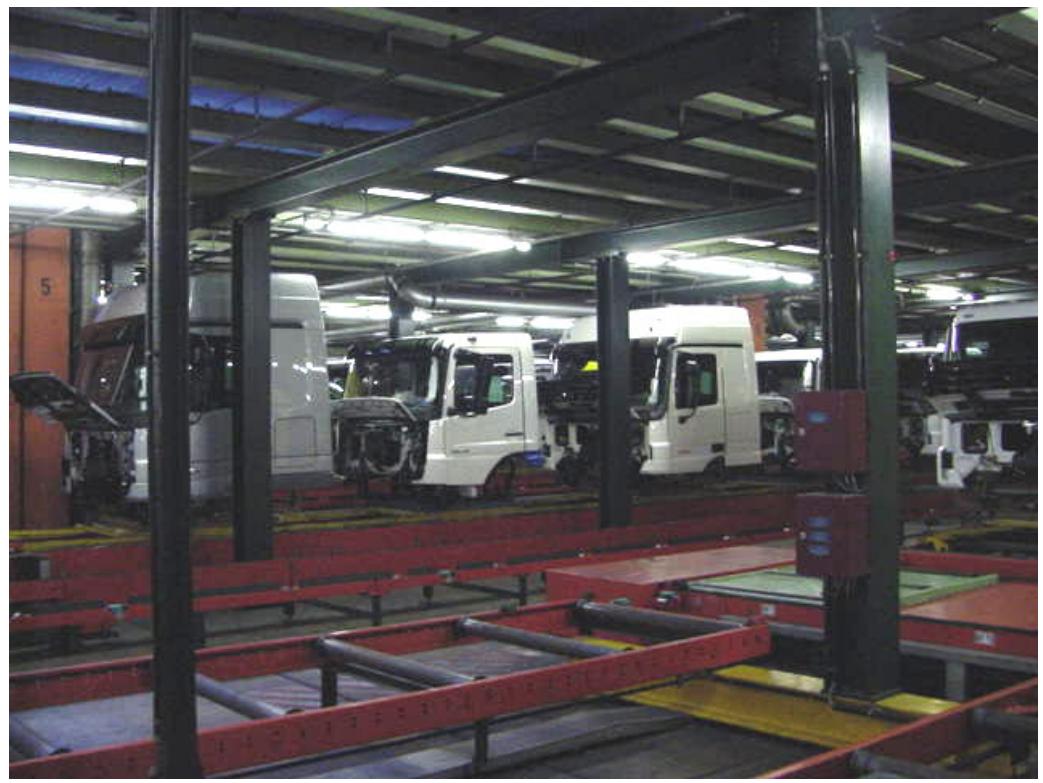

Figura B. Estoque de cabinas Acabadas de Wörth

Outra característica é que, as cabinas CKD e vendas são direcionadas antes do estoque de cabinas acabadas para uma outra área de armazenagem e despacho.

O sistema alemão apresenta diversas dificuldades logísticas como grande número de variáveis e o fato da cabina nascer presa a um veículo único, deixando de ser um produto modular após a montagem bruta, como no Brasil. Ela também é diferenciada em um grande número de cores 0 que impede qualquer remanejamento, onde a pintura é um sistema gargalo que trabalhas em 3 turnos para suprir a demanda. O Puffer de cabinas pintadas também é relativamente maior: 0,62\% da produção diária comparado 0,42\% no Puffer do Brasil.

Mas o sistema Alemão pode ser considerado melhor, pois o Puffer é capaz de corrigir quase toda a seqüência e só atinge a capacidade máxima pela manhã devido aos 3 turnos da pintura.

O estoque de cabinas acabadas tem apenas a função de divisão e correção de eventuais problemas de desbalanceamento do ritmo de produção ou eventuais falhas. A capacidade máxima relativa desse estoque é de $0,37 \%$ comparada com 0,61\% do "DEPOVERT". A cabinas CKD / Vendas são destinadas logo após a produção para uma área específica.

O sistema de Wörth pareceu ser mais evoluído que o de São Bernardo do Campo, pois não estoca muitas cabinas acabadas proporcionalmente e apresenta 
menos problemas no dia-a-dia. As características que levam o sistema alemão a ser melhor sob o ponto de vista de estoques são:

- Verificação prévia da certeza de entrega de todos os itens do caminhão antes da montagem.

- O travamento total da seqüência de produção sete dias antes do início da Rohbau, ou seja, nenhum veículo pode ser alterado ou tirado da seqüência.

- Existência de sistemas e softwares de controle dos estoques e do cumprimento da seqüência.

- A Rohbau pode ser resumida a uma única seqüência de processos com várias células espelho que podem produzir qualquer tipo de cabina, ou seja, é uma única linha em seqüência.

- Diferenças culturais de trabalho durante a produção e no tratamento das falhas com maior comunicação entre as etapas. A responsabilidade de cada operador é maior e o compromisso com o trabalho também.

O sistema de produção do Brasil pode ser melhorado caso algumas atitudes sejam tomadas na direção de melhorias de controle e planejamento, trazendo resultados rápidos e expressivos.

Outra questão importante é: para análises na produção, a utilização da Simulação de Eventos Discretos através do software Witness é expressiva na DaimlerChrysler da Alemanha. Muitos estudos de produção precisam ser analisados e aprovados através da utilização da simulação, como ferramenta de auxílio à tomada de decisão. A simulação faz parte inclusive dos estudos de produção para o SPPP (projeto de veículo a ser lançado em 2010), onde existem áreas específicas para atuação com simulação. Lá os resultados são comprovados e a utilização é de alto valor e de grande importância. 
APENDICE II - Relatório "Category Overview":

O relatório foi exportado diretamente do Arena $\AA^{\circledR}$ através de uma função específica do software e mantém suas características originais.

\section{Projeto Simulacao}

Replications: $1 \quad$ Time Units: Minutes

\section{System Summary}

System

Number Out
Average

$69,164.00$

\section{Conveyor}

\section{Usage}

Blocked

Maximum

Minimum

$$
\text { Average Half Width Value }
$$

Value

Conveyor 1120

Conveyor 115

Conveyor 116

Conveyor 2120

Conveyor linha 1

Conveyor linha 1 e 9

Conveyor linha 5

Conveyor linha 9

Trans aereo

$$
\begin{array}{rr}
0.03512159 & 0,005225592 \\
0.3652 & \text { (Correlated) } \\
0.06617767 & 0,010918570 \\
0.04922805 & 0,006618049 \\
0.1547 & \text { (Correlated) } \\
0.00 & \text { (Insufficient) } \\
0.02298186 & 0,002597885 \\
0.03521838 & 0,003099526
\end{array}
$$

0.00
(Insufficient)
0.00

0.00

0.00

0.00

0.00

0.00

0.00

0.00

0.00
1.0000

1.0000

1.0000

1.0000

1.0000

0.00

1.0000

1.0000

0.00

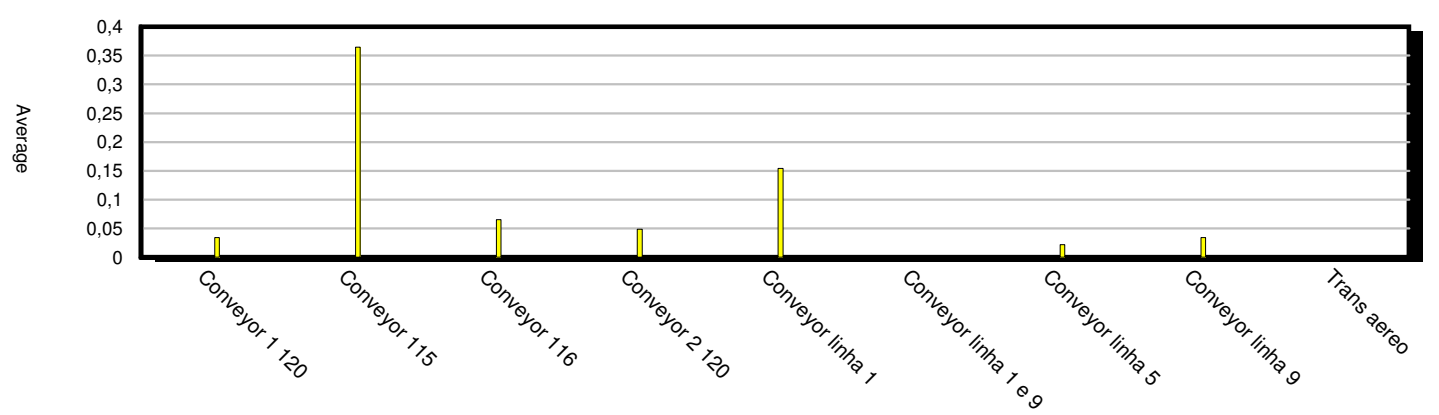


Utilization

Minimum

Maximum

Average Half Width Value

Conveyor 1120

0.3118

(Correlated)

0.4912 (Correlated)

0.3097 (Correlated)

Conveyor 116

0.3101 (Correlated)

Conveyor 2120

$0.3574 \quad$ (Correlated)

Conveyor linha 1 e 9

0.00 (Insufficient)

Conveyor linha 5

0.2363

0.3212

(Correlated)

0.1702

(Correlated)

Trans aereo

0,004138222

0.00

0.6250

0.00

0.5714

0.00

0.5000

0.00

0.6000

0.00

0.5227

0.00

0.00

0.00

0.5556

0.00

0.5625

0.00

0.4375

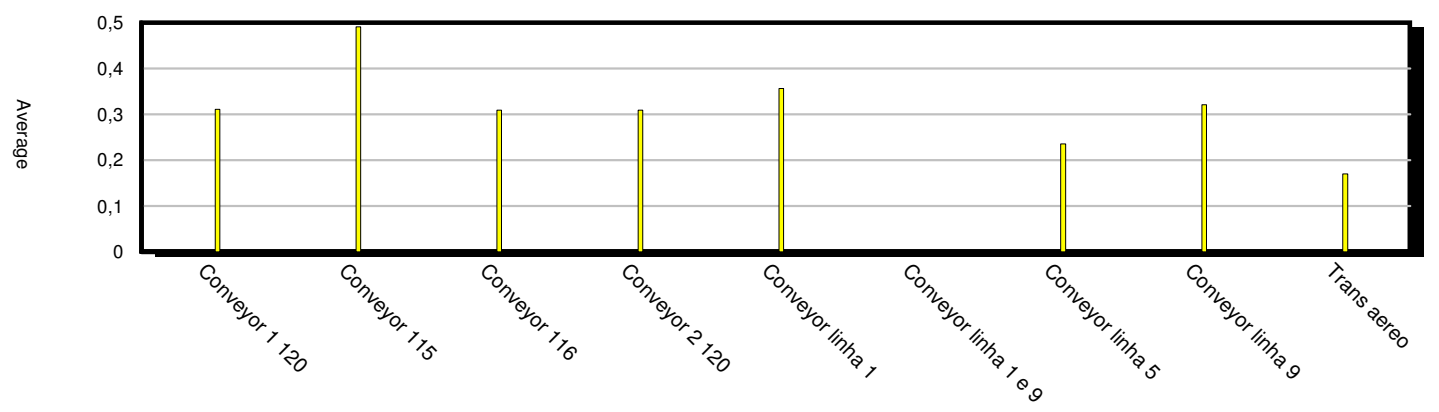

\section{Entity}

\section{Time}

NVA Time

Minimum

Maximum

$\begin{gathered}\text { Average } \\ \text { Value }\end{gathered}$
Half Width $\quad$ Value

Entity 1

Entity 2

0.7879

0,049574382

0.00

59.4366

Entity 3

0.8097

0,079642577

$0.7661 \quad 0,065726451$

0.00

51.0773

$0.7129 \quad$ (Correlated)

0.00

39.9824

Entity 4

Entity 5

Entity 6

Entity 7

Entity 8

$0.00 \quad 0,000000000$

0.00

34.3097

$0.00 \quad 0,000000000$

0.00

0.00

$0.00 \quad 0,000000000$

0.00

0.00

$2.0775 \quad 0,323739304$

0.5000

0.00

32.4661 


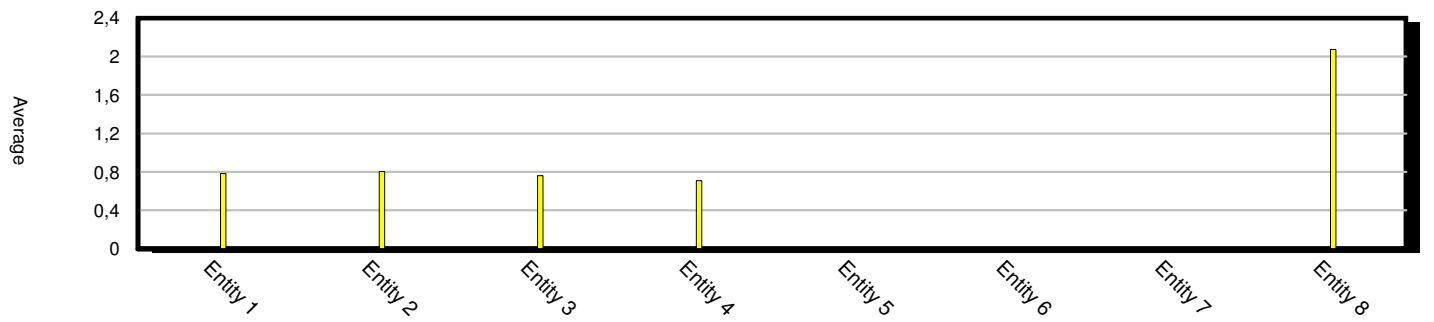

Other Time

Maximum

Entity 2

Entity 3

Entity 4

Entity 5

Entity 6

Entity 7

Entity 8
930.63

930.34

977.09

928.27

920.18

883.50

1896.18

0.00
Half Width

7,13999

6,88288

12,24039

7,93323

18,02584

14,21257

3,74064

0,000000000

Minimum

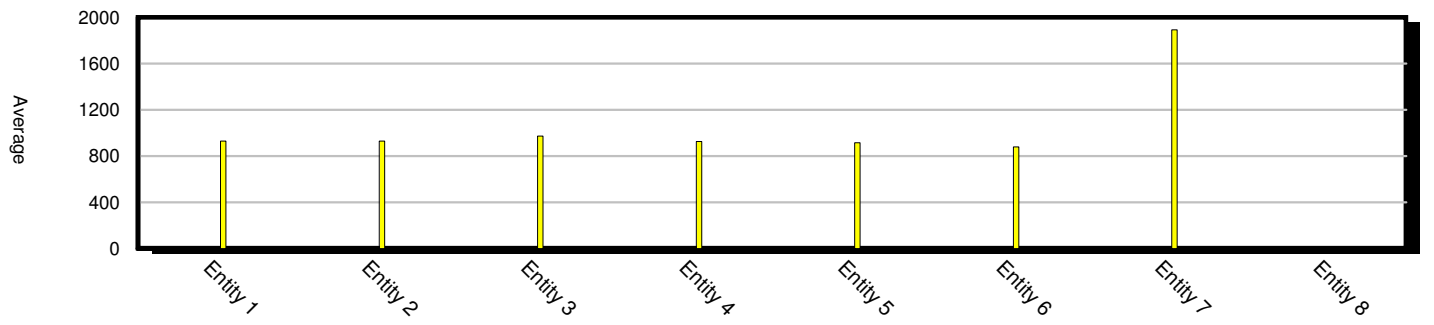

Total Time

Maximum
Minimum

Average

Half Width

Value

Value

810.69

829.58

901.96

832.43

985.99

907.79

1081.05

1254.37
(Correlated)

(Correlated)

15,69241

(Correlated)

32,52521

23,80129

6,51887

46,92076

Value

0.00

2705.30

2705.30

2705.30

2705.30

2705.30

2705.30

2705.30

$\begin{array}{rr}1492.65 & 2705.30 \\ 0.00 & 0.00\end{array}$

Entity 7

Entity 8 


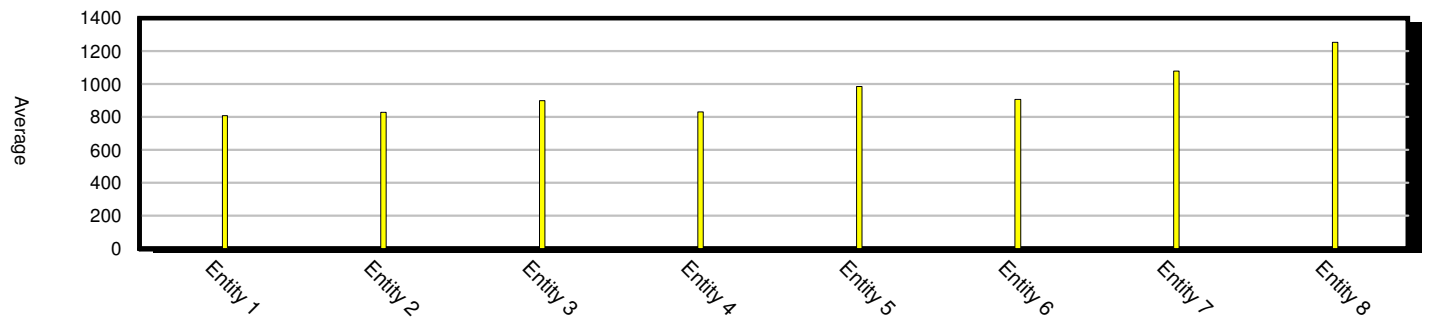

Transfer Time Maximum
Minimum

Average Half Width Value

$\begin{array}{rrrrr}\text { Entity 1 } & 75.6288 & 0,872124413 & 0.00 & 662.16 \\ \text { Entity 2 } & 75.5144 & 0,890358096 & 0.00 & 658.57 \\ \text { Entity 3 } & 80.1797 & 1,99047 & 0.00 & 559.90 \\ \text { Entity 4 } & 73.9291 & 0,904762234 & 0.00 & 657.84 \\ \text { Entity 5 } & 61.3781 & 2,71598 & 0.00 & 579.89 \\ \text { Entity 6 } & 57.5195 & 1,85921 & 0.00 & 519.84 \\ \text { Entity 7 } & 58.7807 & 0,602418923 & 0.00 & 397.09 \\ \text { Entity 8 } & 179.80 & 3,68565 & 64.5000 & 344.37\end{array}$

Entity 1

Entity 2

Entity

Entity 6

Entity 8

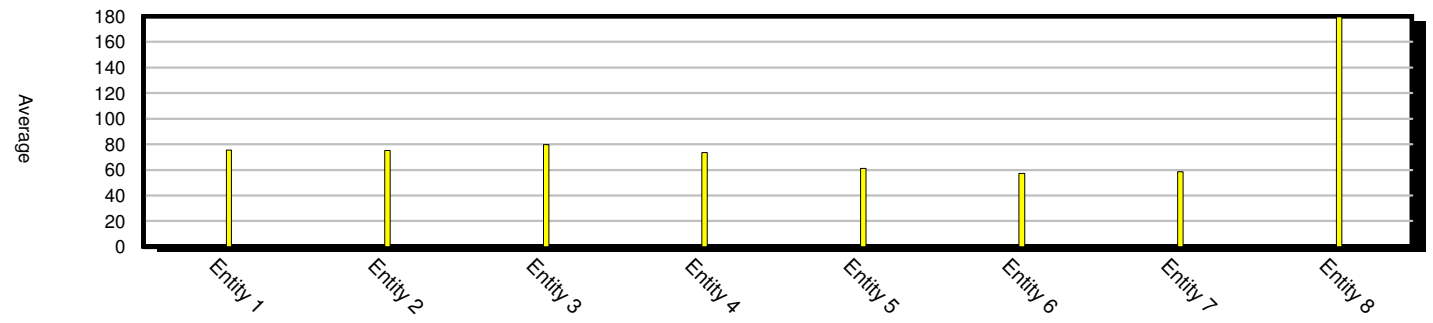

VA Time

Maximum
Entity 1

Entity 2

Entity 3

Entity 4

Entity 5

Entity 6

Entity 7

Entity 8
167.10

167.08

208.19

172.03

186.14

151.84

59.3604

457.06
Minimum

Value

Half Width 


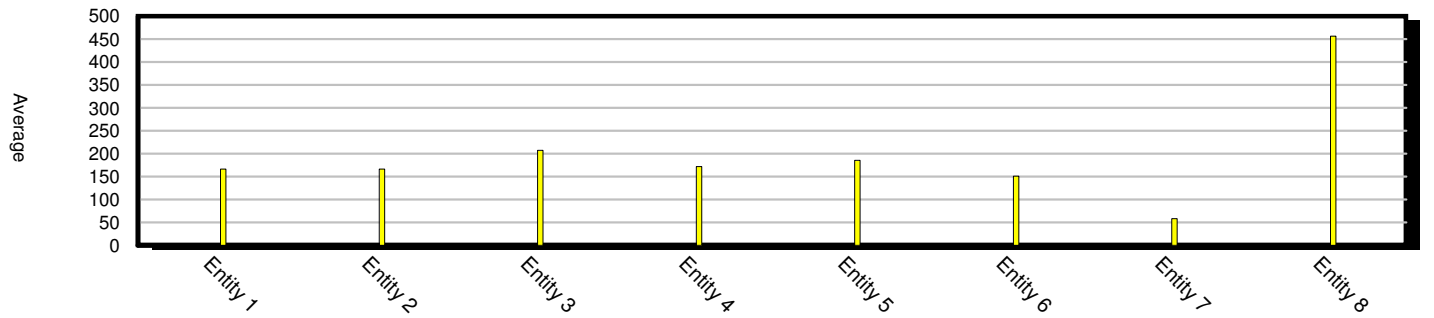

Wait Time

Maximum
Minimum

$$
\text { Average Half Width Value }
$$

Value

\section{Entity 1}

Entity 2

Entity 3

Entity 4

Entity 5

Entity 6

Entity 7

Entity 8
340.80

341.91

372.55

333.35

457.66

392.90

46.6989

1238.35

(Correlated)
(Correlated)
(Correlated)
(Correlated)
(Correlated)
(Correlated)
(Correlated)
57,65524

0.00

0.00

0.00

0.00

0.00

0.00

0.00

167.94
5039.04

4062.97

4624.74

4380.62

3832.32

2824.03

527.62

3442.93

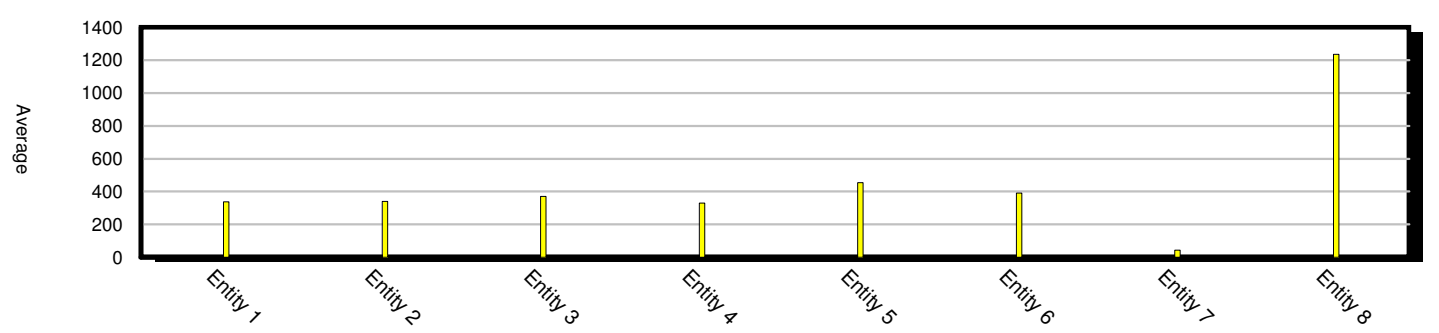

\section{Other}

Number In

Value

Entity 1

46302

Entity 2

30290

Entity 3

21398

Entity 4

Entity 5

Entity 6

27554

6741

Entity 7

4354

Entity 8

9903

OP Rohbau 1

3735

15000 


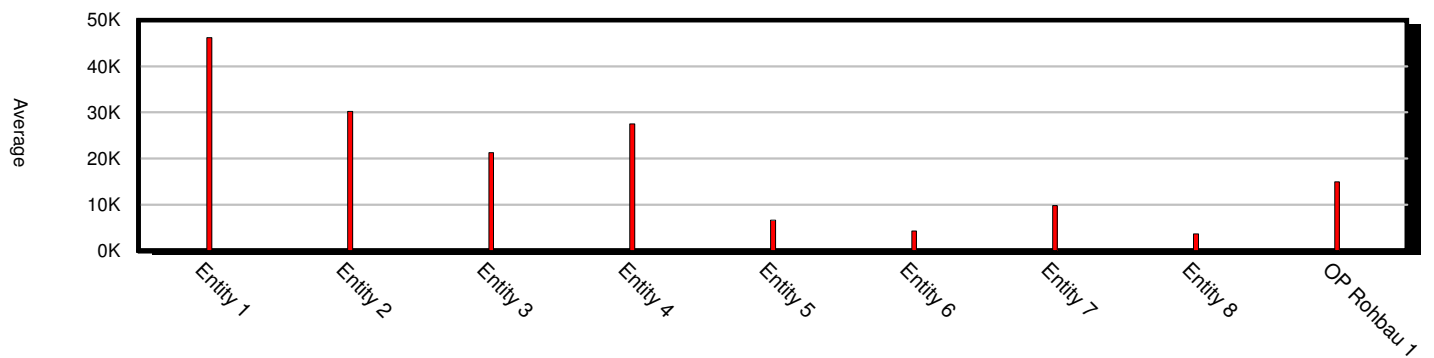

Number Out

Entity 1

45501

Entity 2

29764

Entity 3

21019

Entity 4

26945

Entity 5

6623

Entity 6

4315

Entity 7

9780

Entity 8

3626

OP Rohbau 1

15000

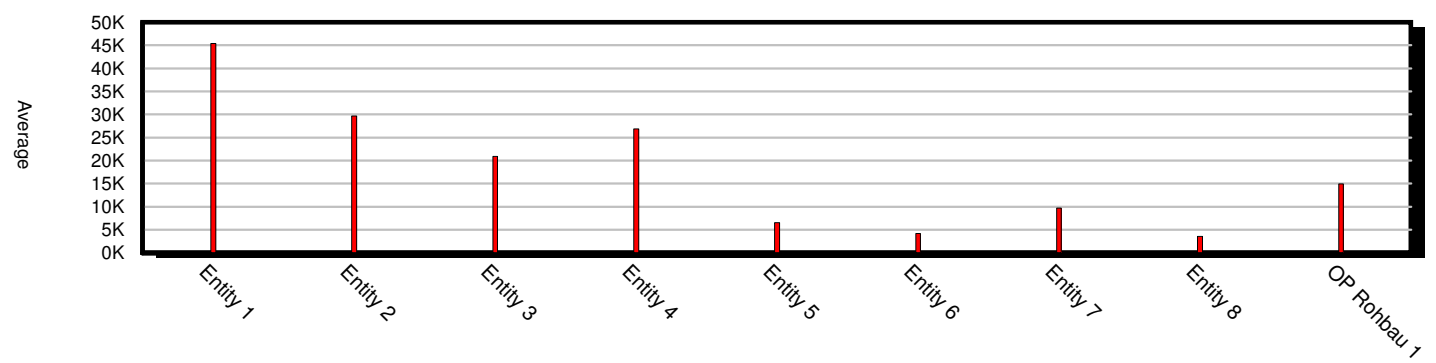

WIP

Maximum
Minimum

Average Half Width Value

Entity 1

Entity 2

Entity 3

Entity 4

Entity 5

Entity 6

Entity 7

Entity 8

OP Rohbau 1
756.22

493.44

402.16

433.02

87.5243

49.3918

107.69

118.06

0.00
(Correlated)

(Correlated)

(Correlated)

(Correlated)

7,19647

(Correlated)

3,41735

(Correlated)

0,000000000
0.00

0.00

978.00

753.00

603.00

$0.00 \quad 618.00$

$0.00 \quad 154.00$

$0.00 \quad 93.0000$

$0.00 \quad 138.00$

$0.00 \quad 186.00$

$0.00 \quad 1.0000$ 


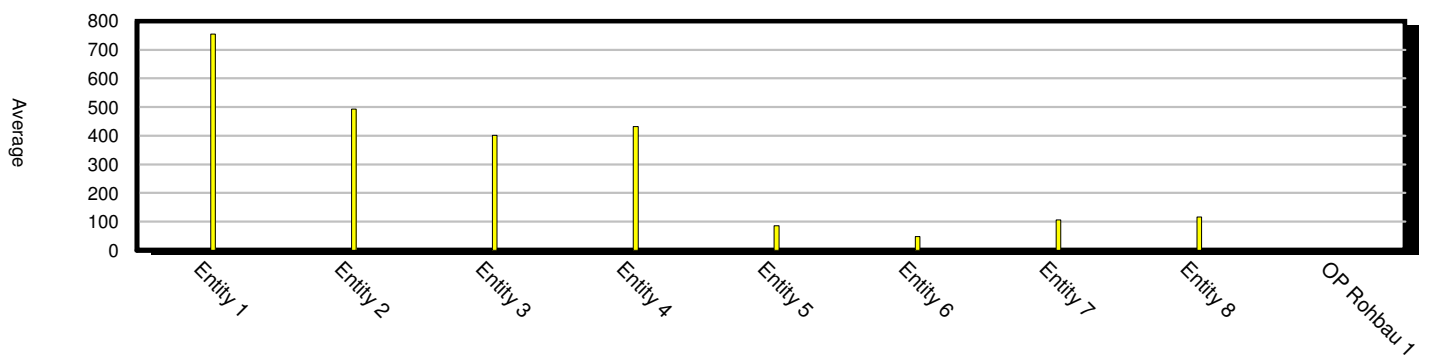

\section{Queue}

\section{Time}

Waiting Time

Maximum
Minimum

Average Half Width Value

Value

Access 1.Queue

Access linha 1 120.Queue

Access linha 1.Queue

Access linha 115.Queue

Access linha 116.Queue

Access linha 2 120.Queue

Access linha 5.Queue

Access linha 9.Queue

Aplicacao Bate Pedra.Queue

Aplicacao KTL.Queue

Assoalho HPN HSK LN1.Queue

Batch montagem cabina

120.Queue

Batch montagem cabina.Queue

Controle e Funilaria.Queue

Eletroforese.Queue

elevador 1.11.Queue

elevador 2.15 3.12.Queue

estacao 1.2.Queue

estacao 1.6.Queue

estacao 2.11 3.8.Queue

estacao 2.5 3.2.Queue

estacao 2.7 3.4.Queue

estacao 2.9 3.6.Queue

estacao 4.10.Queue

estacao 4.2.Queue

estacao 4.4.Queue

estacao 4.6.Queue

estacao 4.8.Queue

estacao 5.10.Queue

estacao 5.12.Queue

estacao 5.2.Queue

estacao 5.4.Queue

estacao 5.6.Queue

$\begin{array}{rrrr}0.9597 & 0,034197948 & 0.00 & 8.1079 \\ 9.9799 & \text { (Correlated) } & 0.00 & 237.70 \\ 8.2599 & \text { (Correlated) } & 0.00 & 52.4535 \\ 7.9454 & 0,594430000 & 0.00 & 118.95 \\ 1.7598 & 0,040483138 & 0.00 & 109.57 \\ 2.1143 & 0,250917099 & 0.00 & 89.6287 \\ 6.1633 & 0,206858038 & 0.00 & 18.8143 \\ 2.0076 & 0,024433883 & 0.00 & 50.9330 \\ 0.8785 & 0,568145508 & 0.00 & 344.90 \\ 0.1454 & 0,038849472 & 0.00 & 76.1858 \\ 7.4629 & 7,24159 & 0.00 & 354.63 \\ 38.8508 & 0,693778136 & 0.00 & 172.76 \\ & & & \\ 11.1126 & 0,146750207 & 0.00 & 196.91 \\ 18.3618 & 3,55521 & 0.00 & 502.82 \\ 3.7108 & 0,578362950 & 0.00 & 170.92 \\ 0.00 & 0,000000000 & 0.00 & 0.00 \\ 0.00 & 0,000000000 & 0.00 & 0.00 \\ 16.1159 & 2,95846 & 0.00 & 74.1999 \\ 0.00 & 0,000000000 & 0.00 & 0.00 \\ 0.00 & 0,000000000 & 0.00 & 0.00 \\ 7.7297 & \text { (Correlated) } & 0.00 & 75.4483 \\ 0.00 & 0,000000000 & 0.00 & 0.00 \\ 0.00 & 0,000000000 & 0.00 & 0.00 \\ 0.00 & 0,000000000 & 0.00 & 0.00 \\ 13.6192 & \text { (Correlated) } & 0.00 & 69.9338 \\ 0.00 & 0,000000000 & 0.00 & 0.00 \\ 0.00 & 0,000000000 & 0.00 & 0.00 \\ 0.00 & 0,000000000 & 0.00 & 0.00 \\ 0.00 & 0,000000000 & 0.00 & 0.00 \\ 11.8272 & (\text { Correlated) } & 0.00 & 0.00000000 \\ 0.00 & 0,000000000 & 0.00 & 69.9338 \\ 0.00 & 0,000000000 & 0.00 & 0.00 \\ & & 0.00 & 0.00\end{array}$




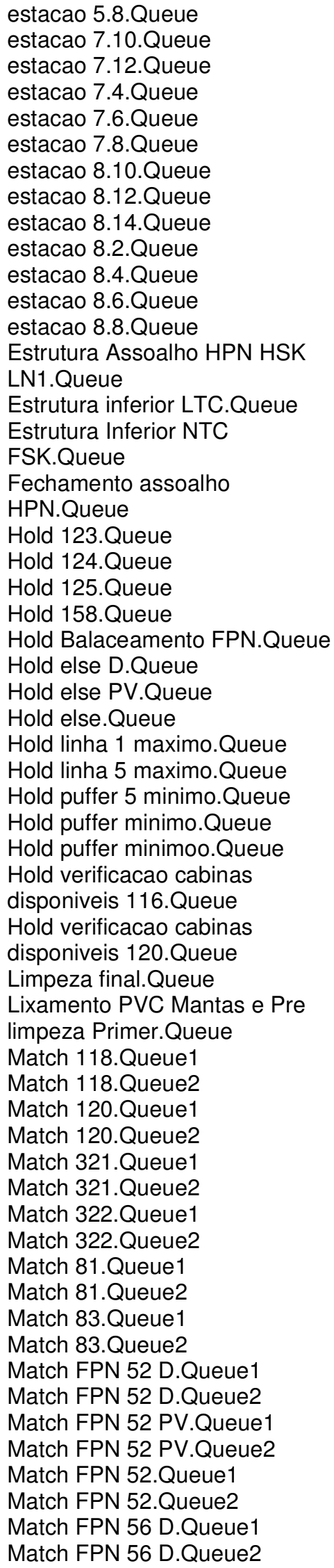

\begin{tabular}{|c|c|c|c|}
\hline 0.00 & 0,000000000 & 0.00 & 0.00 \\
\hline 0.00 & 0,000000000 & 0.00 & 0.00 \\
\hline 0.00 & 0,000000000 & 0.00 & 0.00 \\
\hline 0.7712 & 0,589072158 & 0.00 & 47.6747 \\
\hline 0.00 & 0,000000000 & 0.00 & 0.00 \\
\hline 0.02612778 & 0,042522997 & 0.00 & 6.7988 \\
\hline 0.4712 & (Correlated) & 0.00 & 20.4709 \\
\hline 0.00 & 0,000000000 & 0.00 & 0.00 \\
\hline 0.00 & 0,000000000 & 0.00 & 0.00 \\
\hline 7.2284 & (Correlated) & 0.00 & 90.2069 \\
\hline 1.1689 & 1,79617 & 0.00 & 50.6897 \\
\hline 0.9009 & 1,02615 & 0.00 & 50.6897 \\
\hline 0.00 & 0,000000000 & 0.00 & 0.00 \\
\hline 7.6538 & (Correlated) & 0.00 & 375.74 \\
\hline 120.15 & 12,02424 & 0.00 & 437.45 \\
\hline 103.91 & 12,87869 & 0.00 & 549.78 \\
\hline 6.1513 & 3,14518 & 0.00 & 267.55 \\
\hline 13.5496 & (Insufficient) & 0.2148 & 35.2687 \\
\hline 19.5567 & 3,43900 & 0.00369516 & 132.40 \\
\hline 24.1145 & (Correlated) & 0.00860015 & 232.15 \\
\hline 7.7302 & 0,598278674 & 0.00 & 187.02 \\
\hline 30.3201 & 4,20240 & 0.4058 & 126.80 \\
\hline 665.42 & 59,25745 & 129.87 & 1590.86 \\
\hline 133.89 & 9,72648 & 0.00 & 921.55 \\
\hline 669.09 & 43,20007 & 132.12 & 1630.71 \\
\hline 14.5965 & (Correlated) & 0.00000000 & 87.2593 \\
\hline 9.2960 & (Insufficient) & 0.2466 & 65.6720 \\
\hline 41.6633 & (Insufficient) & 0.03866327 & 256.59 \\
\hline 10.8180 & (Insufficient) & 0.8616 & 26.1311 \\
\hline 25.3574 & (Insufficient) & 0.1916 & 166.13 \\
\hline 2.9545 & 0,459827899 & 0.00851231 & 16.3542 \\
\hline 7.4431 & (Correlated) & 0.00117080 & 23.0040 \\
\hline 21.6420 & 3,34472 & 0.00 & 141.77 \\
\hline 2.0554 & 0,498776338 & 0.00 & 124.61 \\
\hline 0.00 & 0,000000000 & 0.00 & 0.00 \\
\hline 370.19 & 10,86916 & 148.07 & 1209.47 \\
\hline 0.00 & 0,000000000 & 0.00 & 0.00 \\
\hline 392.02 & 16,21443 & 156.90 & 1462.83 \\
\hline 62.2446 & (Correlated) & 4.5519 & 282.25 \\
\hline 0.00 & 0,000000000 & 0.00 & 0.00 \\
\hline 57.0262 & (Correlated) & 11.4967 & 345.55 \\
\hline 0.00 & 0,000000000 & 0.00 & 0.00 \\
\hline 16.5140 & 3,65114 & 0.00 & 227.62 \\
\hline 0.00 & 0,000000000 & 0.00 & 0.00 \\
\hline 255.90 & (Correlated) & 2.0423 & 508.54 \\
\hline 0.00 & 0,000000000 & 0.00 & 0.00 \\
\hline 80.4984 & (Insufficient) & 6.9474 & 386.83 \\
\hline 0.00 & (Insufficient) & 0.00 & 0.00 \\
\hline 85.6724 & (Insufficient) & 0.08282486 & 273.46 \\
\hline 0.00 & (Insufficient) & 0.00 & 0.00 \\
\hline 414.69 & (Insufficient) & 0.00 & 605.59 \\
\hline 0.1787 & (Insufficient) & 0.00 & 29.6635 \\
\hline 78.2192 & (Correlated) & 0.2563 & 480.52 \\
\hline 0.00 & 0,000000000 & 0.00 & 0.00 \\
\hline
\end{tabular}


Match FPN 56 PV.Queue1 Match FPN 56 PV.Queue2 Match FPN 56. Queue1 Match FPN 56.Queue2 Match FPN 601 D.Queue1 Match FPN 601 D.Queue2 Match FPN 601 PV.Queue1 Match FPN 601 PV.Queue2 Match FPN 601.Queue1

Match FPN 601.Queue2 Match FPN 602 D.Queue1 Match FPN 602 D.Queue2 Match FPN 602 PV.Queue1 Match FPN 602 PV.Queue2 Match FPN 602.Queue1 Match FPN 602.Queue2 Match FPN 605 D.Queue1 Match FPN 605 D.Queue2 Match FPN 605 PV.Queue1 Match FPN 605 PV.Queue2 Match FPN 605.Queue1 Match FPN 605.Queue2 Match FPN 608 D.Queue1 Match FPN 608 D.Queue2 Match FPN 608 PV.Queue1 Match FPN 608 PV.Queue2 Match FPN 608.Queue1 Match FPN 608.Queue2 Match FPN 610 D.Queue1 Match FPN 610 D.Queue2 Match FPN 610 PV.Queue1 Match FPN 610 PV.Queue2 Match FPN 610.Queue1 Match FPN 610.Queue2 Match FPN 68 D.Queue1 Match FPN 68 D.Queue2 Match FPN 68 PV.Queue1 Match FPN 68 PV.Queue2 Match FPN 68.Queue1 Match FPN 68.Queue2 Match FSK 63 D.Queue1 Match FSK 63 D.Queue2 Match FSK 63 PV.Queue1 Match FSK 63 PV.Queue2 Match FSK 63.Queue1 Match FSK 63.Queue2 Match FSK 66 D.Queue1 Match FSK 66 D.Queue2 Match FSK 66 PV.Queue1 Match FSK 66 PV.Queue2 Match FSK 66.Queue1 Match FSK 66.Queue2 Match HPN 152 D.Queue1 Match HPN 152 D.Queue2 Match HPN 152 PV.Queue1 Match HPN 152 PV.Queue2 Match HPN 152.Queue1 Match HPN 152.Queue2 Match HPN 60 D.Queue1 Match HPN 60 D.Queue2

\begin{tabular}{|c|c|}
\hline & \\
\hline 0.00 & 0,000000000 \\
\hline 403.38 & \\
\hline 5 & 3880 \\
\hline 0.6091 & \\
\hline 0.00 &, 000000000 \\
\hline 2.5314 & ro \\
\hline 0.00 & 0,00000000 \\
\hline 408.43 & 1495 \\
\hline 1.91 & \\
\hline .5695 & (Insufficient \\
\hline & \\
\hline .0098 & \\
\hline 0.00 & \\
\hline 410.32 & \\
\hline $0.37 c$ & \\
\hline 05 & \\
\hline 0.00 & \\
\hline .5291 & \\
\hline 0. & \\
\hline 416. & \\
\hline & \\
\hline 3961 & \\
\hline 0.00 & \\
\hline 7.4646 & \\
\hline & \\
\hline 422. & \\
\hline 0.00 & \\
\hline .82 & \\
\hline 0.00 & 0,00 \\
\hline 214 & \\
\hline $0 .($ & 0,00 \\
\hline 405.7 & \\
\hline 2.774 & \\
\hline 84.6831 & (Insu \\
\hline 0. & \\
\hline .521 & \\
\hline 0.00 & \\
\hline 420. & \\
\hline & $\operatorname{lnc}$ \\
\hline & \\
\hline $0 .($ & מח \\
\hline .552 & \\
\hline 0.0 & 0000 \\
\hline & \\
\hline 57.05 & \\
\hline & \\
\hline 0.00 & \\
\hline .907 & \\
\hline 08 & \\
\hline 142.27 & \\
\hline & \\
\hline ת & \\
\hline 0.00 & \\
\hline $108 . C$ & \\
\hline & \\
\hline 433 & \\
\hline 0.0 & 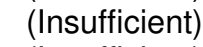 \\
\hline & \\
\hline & \\
\hline
\end{tabular}

288.87

0.00

633.13

128.42

516.80

0.00

242.09

0.00

617.86

385.77

439.22

0.00

272.16

0.00

607.72

63.1534

348.70

0.00

175.75

0.00

549.55

48.2725

339.17

0.00

249.70

0.00

554.22

0.00

658.34

0.00

276.36

0.00

628.57

513.31

708.77

0.00

236.46

0.00

640.91

503.08

862.35

0.00

299.62

0.00

614.22

927.69

812.66

0.00

246.71

0.00

587.25

849.96

464.70

0.00

252.89

0.00

617.05

0.00

517.41

0.00 
Match HPN 60 PV.Queue1 Match HPN 60 PV.Queue2 Match HPN 60.Queue1 Match HPN 60.Queue2 Match HPN 800 D.Queue1 Match HPN 800 D.Queue2 Match HPN 800 PV.Queue1 Match HPN 800 PV.Queue2 Match HPN 800. Queue1 Match HPN 800.Queue2 Match HPN 802 D.Queue1 Match HPN 802 D.Queue2 Match HPN 802 PV.Queue1 Match HPN 802 PV.Queue2 Match HPN 802. Queue1 Match HPN 802.Queue2 Match HPN 808 D.Queue1 Match HPN 808 D.Queue2 Match HPN 808 PV.Queue1 Match HPN 808 PV.Queue2 Match HPN 808. Queue1 Match HPN 808.Queue2 Match HSK 54 D.Queue1 Match HSK 54 D.Queue2 Match HSK 54 PV.Queue1 Match HSK 54 PV.Queue2 Match HSK 54.Queue1 Match HSK 54.Queue2 Match HSK 72 D.Queue1 Match HSK 72 D.Queue2 Match HSK 72 PV.Queue1 Match HSK 72 PV.Queue2 Match HSK 72.Queue1 Match HSK 72.Queue2 Match HSK 73 D.Queue1 Match HSK 73 D.Queue2 Match HSK 73 PV.Queue1 Match HSK 73 PV.Queue2 Match HSK 73.Queue1 Match HSK 73.Queue2 Match HSK 809 D.Queue1 Match HSK 809 D.Queue2 Match HSK 809 PV.Queue1 Match HSK 809 PV.Queue2 Match HSK 809.Queue1 Match HSK 809.Queue2 Match HSK 810 D.Queue1 Match HSK 810 D.Queue2 Match HSK 810 PV.Queue1 Match HSK 810 PV.Queue2 Match HSK 810.Queue1 Match HSK 810.Queue2 Match HSK 812 D.Queue1 Match HSK 812 D.Queue2 Match HSK 812 PV.Queue1 Match HSK 812 PV.Queue2 Match HSK 812.Queue1 Match HSK 812. Queue2 Match HSK 813 D.Queue1 Match HSK 813 D.Queue2

\begin{tabular}{|c|c|c|c|}
\hline 97.9048 & (Insufficient) & 0.01712358 & 294.64 \\
\hline 0.00 & (Insufficient) & 0.00 & 0.00 \\
\hline 433.65 & (Insufficient) & 3.2589 & 654.49 \\
\hline 0.00 & (Insufficient) & 0.00 & 0.00 \\
\hline 75.5306 & 13,23840 & 5.6403 & 568.39 \\
\hline 0.00 & 0,000000000 & 0.00 & 0.00 \\
\hline 94.2418 & (Correlated) & 0.01188475 & 292.66 \\
\hline 0.00 & 0,000000000 & 0.00 & 0.00 \\
\hline 437.11 & 12,96441 & 0.00 & 646.41 \\
\hline 0.4330 & 0,426996750 & 0.00 & 364.37 \\
\hline 71.2916 & (Insufficient) & 11.5576 & 198.84 \\
\hline 0.00 & (Insufficient) & 0.00 & 0.00 \\
\hline 100.54 & (Insufficient) & 0.1564 & 286.40 \\
\hline 0.00 & (Insufficient) & 0.00 & 0.00 \\
\hline 456.61 & (Insufficient) & 134.70 & 659.01 \\
\hline 0.00 & (Insufficient) & 0.00 & 0.00 \\
\hline 84.1983 & (Insufficient) & 18.9039 & 446.87 \\
\hline 0.00 & (Insufficient) & 0.00 & 0.00 \\
\hline 107.31 & (Insufficient) & 0.1010 & 297.93 \\
\hline 0.00 & (Insufficient) & 0.00 & 0.00 \\
\hline 448.60 & (Insufficient) & 0.00 & 654.49 \\
\hline 1.0168 & (Insufficient) & 0.00 & 144.24 \\
\hline 353.06 & (Insufficient) & 308.71 & 689.05 \\
\hline 0.00 & (Insufficient) & 0.00 & 0.00 \\
\hline 106.33 & (Insufficient) & 0.1299 & 268.62 \\
\hline 0.00 & (Insufficient) & 0.00 & 0.00 \\
\hline 422.18 & (Insufficient) & 0.00 & 806.56 \\
\hline 0.9933 & (Insufficient) & 0.00 & 278.94 \\
\hline 358.23 & (Insufficient) & 310.51 & 686.20 \\
\hline 0.00 & (Insufficient) & 0.00 & 0.00 \\
\hline 98.7405 & (Insufficient) & 0.00492740 & 254.89 \\
\hline 0.00 & (Insufficient) & 0.00 & 0.00 \\
\hline 409.28 & (Insufficient) & 0.00 & 605.37 \\
\hline 0.4346 & (Insufficient) & 0.00 & 95.9416 \\
\hline 354.01 & (Insufficient) & 313.75 & 629.15 \\
\hline 0.00 & (Insufficient) & 0.00 & 0.00 \\
\hline 90.1734 & (Insufficient) & 1.4577 & 240.66 \\
\hline 0.00 & (Insufficient) & 0.00 & 0.00 \\
\hline 388.65 & (Insufficient) & 0.00 & 558.60 \\
\hline 0.6513 & (Insufficient) & 0.00 & 33.2151 \\
\hline 389.66 & (Insufficient) & 325.90 & 613.67 \\
\hline 0.00 & (Insufficient) & 0.00 & 0.00 \\
\hline 87.3310 & (Insufficient) & 0.7808 & 228.63 \\
\hline 0.00 & (Insufficient) & 0.00 & 0.00 \\
\hline 414.83 & (Insufficient) & 77.5137 & 706.56 \\
\hline 0.00 & (Insufficient) & 0.00 & 0.00 \\
\hline 356.56 & (Insufficient) & 316.16 & 449.62 \\
\hline 0.00 & (Insufficient) & 0.00 & 0.00 \\
\hline 118.35 & (Insufficient) & 16.7684 & 255.16 \\
\hline 0.00 & (Insufficient) & 0.00 & 0.00 \\
\hline 428.05 & (Insufficient) & 169.18 & 608.94 \\
\hline 0.00 & (Insufficient) & 0.00 & 0.00 \\
\hline 358.39 & (Insufficient) & 319.52 & 666.64 \\
\hline 0.00 & (Insufficient) & 0.00 & 0.00 \\
\hline 83.4457 & (Insufficient) & 1.0602 & 241.11 \\
\hline 0.00 & (Insufficient) & 0.00 & 0.00 \\
\hline 383.25 & (Insufficient) & 0.00 & 555.60 \\
\hline 7.1651 & (Insufficient) & 0.00 & 293.77 \\
\hline 356.53 & 10,57421 & 306.38 & 677.88 \\
\hline 0.00 & 0,000000000 & 0.00 & 0.00 \\
\hline
\end{tabular}


Match HSK 813 PV.Queue1 Match HSK 813 PV.Queue2 Match HSK 813.Queue1 Match HSK 813.Queue2 Match LN 21 D.Queue1 Match LN 21 D.Queue2 Match LN 21 PV.Queue1 Match LN 21 PV.Queue2 Match LN 21.Queue1

Match LN 21.Queue2 Match LN 22 D.Queue1 Match LN 22 D.Queue2 Match LN 22 PV.Queue1 Match LN 22 PV.Queue2 Match LN 22.Queue1 Match LN 22.Queue2 Match LN 23 D.Queue1 Match LN 23 D.Queue2 Match LN 23 PV.Queue1 Match LN 23 PV.Queue2 Match LN 23.Queue1 Match LN 23.Queue2 Match LN 24 D.Queue1 Match LN 24 D.Queue2 Match LN 24 PV.Queue1 Match LN 24 PV.Queue2 Match LN 24.Queue1 Match LN 24.Queue2 Match LN 650 D.Queue1 Match LN 650 D.Queue2 Match LN 650 PV.Queue1 Match LN 650 PV.Queue2 Match LN 650.Queue1 Match LN 650.Queue2 Match LTC 70 D.Queue1 Match LTC 70 D.Queue2 Match LTC 70 PV.Queue1 Match LTC 70 PV.Queue2 Match LTC 70.Queue1 Match LTC 70.Queue2 Match LTC 71 D.Queue1 Match LTC 71 D.Queue2 Match LTC 71 PV.Queue1 Match LTC 71 PV.Queue2 Match LTC 71.Queue1 Match LTC 71.Queue2 Match LTC 90 D.Queue1 Match LTC 90 D.Queue2 Match LTC 90 PV.Queue1 Match LTC 90 PV.Queue2 Match LTC 90.Queue1 Match LTC 90.Queue2 Match LTC 91 D.Queue1 Match LTC 91 D.Queue2 Match LTC 91 PV.Queue1 Match LTC 91 PV.Queue2 Match LTC 91.Queue1 Match LTC 91.Queue2 Match montagem cabina.Queue1

$$
\begin{aligned}
& 95.5911 \\
& 0.00 \\
& 407.92 \\
& 0.7116 \\
& 75.6913 \\
& 0.00
\end{aligned}
$$

0.00191844

0.00

0.00

0.00

5.9206

0.00

0.02544320

0.00

0.00

0.00

6.4490

0.00

0.07010311

0.00

0.00

0.00

50.8712

0.00

9.4811

0.00

255.29

0.00

7.8203

0.00

0.5251

0.00

0.00

0.00

342.72

0.00

11.7386

0.00

2.9909

0.00

10.9204

0.00

6.8441

0.00

186.23

0.00

21.0885

0.00

0.2047

0.00

0.00

0.00

27.5575

0.00

0.08499917

0.00

0.00

0.00

0.00

0.00

0.02050504

0.00

0.00

0.00

0.00

287.71

0.00

798.76

212.50

766.94

0.00

291.19

0.00

655.31

729.59

441.15

0.00

302.20

0.00

620.97

170.87

176.92

0.00

249.12

0.00

553.64

0.00

411.60

0.00

255.48

0.00

589.71

4.3582

342.72

0.00

11.7386

0.00

2.9909

0.00

58.4074

0.00

12.5502

0.00

263.85

0.00

646.74

0.00

301.59

0.00

606.69

488.15

625.72

0.00

316.73

0.00

687.06 


\begin{tabular}{|c|c|c|c|c|}
\hline $\begin{array}{l}\text { Match montagem } \\
\text { cabina.Queue2 }\end{array}$ & 0.00 & 0,000000000 & 0.00 & 0.00 \\
\hline Measure.Queue & 42.6591 & (Insufficient) & 0.00 & 255.90 \\
\hline $\begin{array}{l}\text { Montagem Bruta Cabina } \\
\text { LTC.Queue }\end{array}$ & 17.2102 & 8,05585 & 0.00 & 510.43 \\
\hline Montagem das Portas.Queue & 33.6654 & 8,72635 & 0.00 & 690.96 \\
\hline $\begin{array}{l}\text { Montagem Paredes Traseira } \\
\text { Frontal Cabina Bruta FSK } \\
\text { NTC.Queue }\end{array}$ & 59.6984 & 18,54653 & 0.00 & 707.20 \\
\hline Parede Frontal.Queue & 43.4112 & 20,39602 & 0.00 & 396.03 \\
\hline Parede Traseira.Queue & 53.9830 & 21,20125 & 0.00 & 412.20 \\
\hline $\begin{array}{l}\text { Pintura esmalte posto } \\
\text { 19b.Queue }\end{array}$ & 1.2401 & 0,110005513 & 0.00 & 31.8500 \\
\hline Pintura.Queue & 56.3631 & 4,35997 & 0.00 & 171.99 \\
\hline Pre limpeza limpeza.Queue & 43.7457 & 13,90296 & 0.00 & 274.98 \\
\hline Primer.Queue & 10.9390 & 2,16055 & 0.00 & 141.66 \\
\hline Process 34.Queue & 0.00005161 & 0,000023731 & 0.00 & 0.04854956 \\
\hline Process 35.Queue & 0.00008811 & 0,000059109 & 0.00 & 0.03188289 \\
\hline Process 89.Queue & 0.00000380 & 0,000004599 & 0.00 & 0.01450597 \\
\hline $\begin{array}{l}\text { Process acerto depovert } \\
\text { 42. Queue }\end{array}$ & 12.7787 & 2,51119 & 0.00 & 117.38 \\
\hline Process acerto depovert.Queue & 18.8582 & (Correlated) & 0.00 & 159.59 \\
\hline $\begin{array}{l}\text { Process acerto } \\
\text { depovert41.Queue }\end{array}$ & 0.00 & 0,000000000 & 0.00 & 0.00 \\
\hline $\begin{array}{l}\text { Process cabines de } \\
\text { retoque.Queue }\end{array}$ & 0.7280 & (Correlated) & 0.00 & 11.2792 \\
\hline Process filtro bloqueio.Queue & 0.9059 & (Correlated) & 0.00 & 14.5277 \\
\hline Process posto 1 120.Queue & 6.0318 & 0,598923600 & 0.00 & 57.8775 \\
\hline Process posto 1.Queue & 0.5356 & 0,103671945 & 0.00 & 12.8199 \\
\hline Process posto 2 120.Queue & 1.4255 & 0,199514840 & 0.00 & 18.1522 \\
\hline Process posto 2.Queue & 0.5542 & 0,101745927 & 0.00 & 12.2347 \\
\hline Process posto 3 120.Queue & 1.1507 & 0,163722038 & 0.00 & 17.8926 \\
\hline Process posto 3.Queue & 0.5154 & 0,060232922 & 0.00 & 8.2022 \\
\hline Process posto 4 120.Queue & 5.7599 & 1,19024 & 0.00 & 37.2774 \\
\hline Process posto 4.Queue & 0.5612 & 0,081338360 & 0.00 & 9.3324 \\
\hline Process posto 5 120.Queue & 1.3744 & 0,251842834 & 0.00 & 22.5278 \\
\hline Process posto 5.Queue & 0.5383 & 0,057971501 & 0.00 & 8.5200 \\
\hline Process posto 6.Queue & 0.5290 & 0,062940577 & 0.00 & 11.6480 \\
\hline $\begin{array}{l}\text { Process posto montagem } \\
\text { motor.Queue }\end{array}$ & 0.01740520 & 0,016703368 & 0.00 & 54.5638 \\
\hline Repintura Primer.Queue & 10.9292 & 2,03283 & 0.00 & 137.63 \\
\hline Retrabalho Lixamento PVC & 3.2228 & (Insufficient) & 0.00 & 107.30 \\
\hline \multirow{2}{*}{\multicolumn{5}{|c|}{$\begin{array}{l}\text { Mantas e Pre limpeza } \\
\text { Primer.Queue }\end{array}$}} \\
\hline & & & & \\
\hline Retrabalho.Queue & 0.3303 & 0,161195732 & 0.00 & 24.4339 \\
\hline robo 1.8.Queue & 0.00 & 0,000000000 & 0.00 & 0.00 \\
\hline $\begin{array}{l}\text { Seize AGVs Rohbau } \\
\text { FSK.Queue }\end{array}$ & 38.1289 & 18,95827 & 0.00 & 698.14 \\
\hline \multicolumn{2}{|l|}{ FSK.Queue } & 9,60016 & & 300.16 \\
\hline $\begin{array}{l}\text { Seize cabines de } \\
\text { retoque.Queue }\end{array}$ & 5.3448 & 0,879384072 & 0.00 & 75.1980 \\
\hline Seize Depovert linha 5.Queue & 0.6622 & 0,061635477 & 0.00 & 28.5627 \\
\hline Seize filtro puffer 1.Queue & 53.3770 & (Correlated) & 0.00 & 275.21 \\
\hline Seize filtro puffer 5.Queue & 19.5918 & (Correlated) & 0.00 & 284.49 \\
\hline Seize Grill.Queue & 2.8866 & 1,46006 & 0.00 & 364.63 \\
\hline Seize linha 1A.Queue & 6.5748 & 6,38247 & 0.00 & 270.82 \\
\hline Seize linha 7.Queue & 0.0902 & (Correlated) & 0.00 & 102.84 \\
\hline Seize linha funilaria M.Queue & 5.5618 & (Insufficient) & 0.00 & 255.52 \\
\hline Seize linha funilaria.Queue & 2.6119 & 1,03583 & 0.00 & 254.54 \\
\hline Seize Mont Motor e & 0.0995 & 0,111530963 & 0.00 & 89.4255 \\
\hline
\end{tabular}


Cabina.Queue

Seize montagem cabina.Queue

Seize montagem

chicotes.Queue

Seize montagem de

chicotes.Queue

Seize pintura longarina.Queue

Seize postos $12345 \mathrm{e}$

6. Queue

Seize postos 1234 e 5 .Queue

Seize Puffer 5.Queue

Seize Puffer linha 1.Queue

Seize puffer virtual.Queue

Seize Sepovert linha 9.Queue

Seize Skids Rohbau.Queue

Seize trans aereo grill 7.Queue

Seize transferencia.Queue

Seize transp aereo 11 A.Queue

Seize transp aereo 23 8.Queue

Seize transp aereo elevador

Rohbau nova.Queue

Seize transp aereo elevador

Rohbau.Queue

Seize transp aereo grill 7

8.Queue

Seize transp aereo linha

4.Queue

Seize transp aereo linha

5.Queue

Seize transp aereo linha

6.Queue

Seize transp depovert 41.Queue

Seize transp depovert 42.Queue

Seize transportador linhas $3 \mathrm{e}$

9.Queue

Seize transportador

longarina.Queue

Seize transportador puffer e

5.Queue

Seize verificacao

bloqueio.Queue

Soldagem Conjunto Teto NTC

FSK.Queue

Teto.Queue

Transferencia e aplicacao de mantas.Queue

transporte linha 3 p 9.Queue

Transporte Puffer linha

51.Queue

\section{Other}

Number Waiting

Maximum

\begin{tabular}{|c|c|c|c|}
\hline $\begin{array}{r}0.04417918 \\
9.5951\end{array}$ & $\begin{array}{r}0,036447013 \\
1,73876\end{array}$ & $\begin{array}{l}0.00 \\
0.00\end{array}$ & $\begin{array}{l}110.04 \\
125.97\end{array}$ \\
\hline 0.7725 & 0,627704492 & 0.00 & 123.55 \\
\hline 7.3811 & 2,12681 & 0.00 & 122.97 \\
\hline 28.2816 & 15,12826 & 0.00 & 216.83 \\
\hline 10.7489 & 4,73202 & 0.00 & 164.02 \\
\hline 4.7262 & 0,972648314 & 0.00 & 58.4527 \\
\hline 5.2363 & 0,905910923 & 0.00 & 61.8620 \\
\hline 0.00 & 0,000000000 & 0.00 & 0.00 \\
\hline 0.2675 & 0,022842568 & 0.00 & 48.7924 \\
\hline 5.0112 & 3,07875 & 0.00 & 366.88 \\
\hline 3.8864 & 2,77915 & 0.00 & 479.55 \\
\hline 1.9741 & 0,056618867 & 0.00 & 109.91 \\
\hline 1.0582 & 1,09604 & 0.00 & 308.94 \\
\hline 2.9569 & 1,61786 & 0.00 & 222.17 \\
\hline 7.6880 & 3,81790 & 0.00 & 163.89 \\
\hline 5.4488 & 2,43495 & 0.00 & 287.81 \\
\hline 3.0259 & 2,37932 & 0.00 & 475.46 \\
\hline 16.1455 & 3,48417 & 0.00 & 416.29 \\
\hline 22.8303 & 2,94844 & 0.00 & 431.70 \\
\hline 7.0748 & (Correlated) & 0.00 & 326.79 \\
\hline 2.1181 & (Correlated) & 0.00 & 100.51 \\
\hline 0.00 & 0,000000000 & 0.00 & 0.00 \\
\hline 1.2975 & 0,050944417 & 0.00 & 39.7924 \\
\hline 0.9900 & 0,135165826 & 0.00 & 79.2100 \\
\hline 2.3659 & 0,481927967 & 0.00 & 45.7931 \\
\hline 0.00 & 0,000000000 & 0.00 & 0.00 \\
\hline 16.5361 & 13,34716 & 0.00 & 655.62 \\
\hline 138.40 & 21,78962 & 0.00 & 504.53 \\
\hline 7.2452 & 5,19863 & 0.00 & 366.84 \\
\hline & 0,035174806 & 0.00 & 7.83 \\
\hline 0.7901 & 0,065387573 & 0.00 & \\
\hline
\end{tabular}

Minimum

Average Half Width Value

Value

$\begin{array}{ll}0.1634 & 0,007421484 \\ 0.3547 & 0,044481172\end{array}$

0.00

0.00

Access 1.Queue

Access linha 1 120.Queue 
Access linha 1.Queue

Access linha 115.Queue

Access linha 116.Queue

Access linha 2 120.Queue

Access linha 5.Queue

Access linha 9.Queue

Aplicacao Bate Pedra.Queue

Aplicacao KTL.Queue

Assoalho HPN HSK LN1.Queue

Batch montagem cabina

120.Queue

Batch montagem cabina fora

116. Queue

Batch montagem cabina fora

120.Queue

Batch montagem cabina.Queue

Controle e Funilaria.Queue

Eletroforese.Queue

elevador 1.11.Queue

elevador 2.15 3.12.Queue

estacao 1.2.Queue

estacao 1.6.Queue

estacao 2.11 3.8.Queue

estacao 2.5 3.2.Queue

estacao 2.7 3.4.Queue

estacao 2.9 3.6. Queue

estacao 4.10.Queue

estacao 4.2.Queue

estacao 4.4.Queue

estacao 4.6.Queue

estacao 4.8.Queue

estacao 5.10.Queue

estacao 5.12.Queue

estacao 5.2.Queue

estacao 5.4.Queue

estacao 5.6.Queue

estacao 5.8.Queue

estacao 7.10.Queue

estacao 7.12.Queue

estacao 7.4.Queue

estacao 7.6.Queue

estacao 7.8.Queue

estacao 8.10.Queue

estacao 8.12.Queue

estacao 8.14.Queue

estacao 8.2.Queue

estacao 8.4.Queue

estacao 8.6.Queue

estacao 8.8.Queue

Estrutura Assoalho HPN HSK

LN1.Queue

Estrutura inferior LTC.Queue

Estrutura Inferior NTC

FSK.Queue

Fechamento assoalho

HPN.Queue

Fechamento Laterais.Queue

Fechamento teto.Queue

Hold 122.Queue

Hold 123.Queue

\begin{tabular}{|c|c|c|c|}
\hline 1.0912 & (Correlated) & 0.00 & 8.0000 \\
\hline 1.4710 & (Correlated) & 0.00 & 5.0000 \\
\hline 0.3256 & (Correlated) & 0.00 & 1.0000 \\
\hline 0.07501112 & 0,008834802 & 0.00 & 1.0000 \\
\hline 0.2200 & 0,017726541 & 0.00 & 1.0000 \\
\hline 0.2645 & (Correlated) & 0.00 & 1.0000 \\
\hline 0.1489 & 0,092031538 & 0.00 & 7.0000 \\
\hline 0.02466265 & 0,006913548 & 0.00 & 2.0000 \\
\hline 0.8698 & 1,12621 & 0.00 & 38.0000 \\
\hline 2.7548 & (Correlated) & 0.00 & 7.0000 \\
\hline 0.00 & (Insufficient) & 0.00 & 0.00 \\
\hline 0.00 & (Insufficient) & 0.00 & 0.00 \\
\hline 3.4301 & (Correlated) & 0.00 & 10.0000 \\
\hline 0.3763 & 0,080868597 & 0.00 & 6.0000 \\
\hline 0.6297 & (Correlated) & 0.00 & 8.0000 \\
\hline 0.00 & (Insufficient) & 0.00 & 0.00 \\
\hline 0.00 & (Insufficient) & 0.00 & 0.00 \\
\hline 1.8784 & 0,339521029 & 0.00 & 10.0000 \\
\hline 0.00 & 0,000000000 & 0.00 & 1.0000 \\
\hline 0.00 & 0,000000000 & 0.00 & 1.0000 \\
\hline 0.9001 & (Correlated) & 0.00 & 10.0000 \\
\hline 0.00 & 0,000000000 & 0.00 & 1.0000 \\
\hline 0.00 & 0,000000000 & 0.00 & 1.0000 \\
\hline 0.00 & 0,000000000 & 0.00 & 1.0000 \\
\hline 2.0542 & 0,466756204 & 0.00 & 12.0000 \\
\hline 0.00 & 0,000000000 & 0.00 & 1.0000 \\
\hline 0.00 & 0,000000000 & 0.00 & 1.0000 \\
\hline 0.00 & 0,000000000 & 0.00 & 1.0000 \\
\hline 0.00 & 0,000000000 & 0.00 & 1.0000 \\
\hline 0.00000000 & (Correlated) & 0.00 & 1.0000 \\
\hline 1.7833 & 0,432910587 & 0.00 & 12.0000 \\
\hline 0.00 & 0,000000000 & 0.00 & 1.0000 \\
\hline 0.00 & 0,000000000 & 0.00 & 1.0000 \\
\hline 0.00 & 0,000000000 & 0.00 & 1.0000 \\
\hline 0.00 & (Insufficient) & 0.00 & 1.0000 \\
\hline 0.00 & (Insufficient) & 0.00 & 1.0000 \\
\hline 0.02638495 & 0,019080232 & 0.00 & 4.0000 \\
\hline 0.00 & (Insufficient) & 0.00 & 1.0000 \\
\hline 0.00089307 & (Insufficient) & 0.00 & 1.0000 \\
\hline 0.05477954 & 0,063435379 & 0.00 & 3.0000 \\
\hline 0.00 & 0,000000000 & 0.00 & 1.0000 \\
\hline 0.00 & 0,000000000 & 0.00 & 1.0000 \\
\hline 0.8407 & 0,467013641 & 0.00 & 12.0000 \\
\hline 0.1359 & 0,174138351 & 0.00 & 7.0000 \\
\hline 0.1047 & 0,097210425 & 0.00 & 7.0000 \\
\hline 0.00 & 0,000000000 & 0.00 & 1.0000 \\
\hline 0.8915 & 0,553699608 & 0.00 & 9.0000 \\
\hline 0.9714 & 0,133474778 & 0.00 & 7.0000 \\
\hline 1.3082 & 0,160823784 & 0.00 & 9.0000 \\
\hline 0.7158 & 0,375599538 & 0.00 & 6.0000 \\
\hline 0.00 & (Insufficient) & 0.00 & 0.00 \\
\hline 0.00 & (Insufficient) & 0.00 & 0.00 \\
\hline 0.00 & (Insufficient) & 0.00 & 0.00 \\
\hline 0.00105836 & (Insufficient) & 0.00 & 2.0000 \\
\hline
\end{tabular}


Hold 124.Queue

Hold 125.Queue

Hold 128.Queue

Hold 129.Queue

Hold 158.Queue

Hold 63D.Queue

Hold Balaceamento FPN.Queue

Hold else D.Queue

Hold else PV.Queue

Hold else.Queue

Hold linha 1 maximo.Queue

Hold linha 5 maximo.Queue

Hold manutencao puffer

virtual.Queue

Hold puffer 1 minimo.Queue

Hold puffer 5 minimo.Queue

Hold puffer minimo.Queue

Hold puffer minimoo.Queue

Hold verificacao cabinas

disponiveis 116. Queue

Hold verificacao cabinas

disponiveis 120.Queue

Limpeza final.Queue

Lixamento PVC Mantas e Pre

limpeza Primer.Queue

Match 117.Queue1

Match 117.Queue2

Match 118.Queue1

Match 118.Queue2

Match 120.Queue1

Match 120.Queue2

Match 123.Queue1

Match 123.Queue2

Match 319.Queue1

Match 319.Queue2

Match 320.Queue1

Match 320.Queue2

Match 321.Queue1

Match 321.Queue2

Match 322.Queue1

Match 322.Queue2

Match 81.Queue1

Match 81.Queue2

Match 83.Queue1

Match 83.Queue2

Match cabina fora 116.Queue1

Match cabina fora 116.Queue2

Match cabina fora 116.Queue3

Match cabina fora 120.Queue1

Match cabina fora 120.Queue2

Match cabina fora 120.Queue3

Match FPN 52 D.Queue1

Match FPN 52 D.Queue2

Match FPN 52 PV.Queue1

Match FPN 52 PV.Queue2

Match FPN 52.Queue1

Match FPN 52.Queue2

Match FPN 56 D.Queue1

Match FPN 56 D.Queue2

Match FPN 56 PV.Queue1

\begin{tabular}{|c|c|c|c|}
\hline 0.5124 & (Correlated) & 0.00 & 20.0000 \\
\hline 1.0114 & (Correlated) & 0.00 & 29.0000 \\
\hline 0.00 & (Insufficient) & 0.00 & 0.00 \\
\hline 0.00 & (Insufficient) & 0.00 & 0.00 \\
\hline 8.3322 & (Correlated) & 0.00 & 43.0000 \\
\hline 0.00 & (Insufficient) & 0.00 & 0.00 \\
\hline 0.6134 & 0,139829027 & 0.00 & 9.0000 \\
\hline 4.8192 & (Correlated) & 0.00 & 6.0000 \\
\hline 0.9840 & (Correlated) & 0.00 & 2.0000 \\
\hline 4.9055 & (Correlated) & 0.00 & 6.0000 \\
\hline 0.2308 & (Correlated) & 0.00 & 1.0000 \\
\hline 0.00290444 & (Insufficient) & 0.00 & 1.0000 \\
\hline 0.00 & (Insufficient) & 0.00 & 0.00 \\
\hline 0.00 & (Insufficient) & 0.00 & 0.00 \\
\hline 0.1640 & (Correlated) & 0.00 & 1.0000 \\
\hline 0.00118299 & (Insufficient) & 0.00 & 1.0000 \\
\hline 0.00475359 & (Insufficient) & 0.00 & 1.0000 \\
\hline 0.01693878 & 0,007006267 & 0.00 & 1.0000 \\
\hline 0.04569647 & 0,005480653 & 0.00 & 1.0000 \\
\hline 4.2038 & 0,659515692 & 0.00 & 16.0000 \\
\hline 0.3483 & 0,089091972 & 0.00 & 5.0000 \\
\hline 0.00 & (Insufficient) & 0.00 & 0.00 \\
\hline 0.00 & (Insufficient) & 0.00 & 0.00 \\
\hline 0.00 & 0,000000000 & 0.00 & 1.0000 \\
\hline 4.6281 & (Correlated) & 0.00 & 22.0000 \\
\hline 0.00 & 0,000000000 & 0.00 & 1.0000 \\
\hline 4.8990 & (Correlated) & 0.00 & 22.0000 \\
\hline 0.00 & (Insufficient) & 0.00 & 0.00 \\
\hline 0.00 & (Insufficient) & 0.00 & 0.00 \\
\hline 0.00 & (Insufficient) & 0.00 & 0.00 \\
\hline 0.00 & (Insufficient) & 0.00 & 0.00 \\
\hline 0.00 & (Insufficient) & 0.00 & 0.00 \\
\hline 0.00 & (Insufficient) & 0.00 & 0.00 \\
\hline 7.7784 & (Correlated) & 0.00 & 37.0000 \\
\hline 0.00 & 0,000000000 & 0.00 & 1.0000 \\
\hline 2.0558 & 0,456155912 & 0.00 & 13.0000 \\
\hline 0.00 & 0,000000000 & 0.00 & 1.0000 \\
\hline 0.5859 & 0,160685500 & 0.00 & 6.0000 \\
\hline 0.00 & 0,000000000 & 0.00 & 1.0000 \\
\hline 3.2595 & (Correlated) & 0.00 & 15.0000 \\
\hline 0.00 & 0,000000000 & 0.00 & 1.0000 \\
\hline 0.00 & (Insufficient) & 0.00 & 0.00 \\
\hline 0.00 & (Insufficient) & 0.00 & 0.00 \\
\hline 0.00 & (Insufficient) & 0.00 & 0.00 \\
\hline 0.00 & (Insufficient) & 0.00 & 0.00 \\
\hline 0.00 & (Insufficient) & 0.00 & 0.00 \\
\hline 0.00 & (Insufficient) & 0.00 & 0.00 \\
\hline 0.2099 & 0,047792403 & 0.00 & 3.0000 \\
\hline 0.00 & (Insufficient) & 0.00 & 1.0000 \\
\hline 0.2269 & 0,057111440 & 0.00 & 3.0000 \\
\hline 0.00 & (Insufficient) & 0.00 & 1.0000 \\
\hline 1.0867 & 0,163065839 & 0.00 & 4.0000 \\
\hline 0.00046340 & (Insufficient) & 0.00 & 1.0000 \\
\hline 0.9674 & (Correlated) & 0.00 & 7.0000 \\
\hline 0.00 & 0,000000000 & 0.00 & 1.0000 \\
\hline 0.9351 & (Correlated) & 0.00 & 6.0000 \\
\hline
\end{tabular}

20.0000

0.00

0000

6.0000

6.0000

0000

0.00

.0000

.0000

1.0000

5.0000

0.00

0.00

2.0000

.0000

0.00

0.00

0.00

1.0000

1.0000

1.0000

1.0000

15.0000

0.00

0.00

0.00

0.00

0.00

.0000

3.0000

4.0000

7.0000

6.0000 
Match FPN 56 PV.Queue2 Match FPN 56.Queue1 Match FPN 56. Queue2 Match FPN 57 D.Queue1 Match FPN 57 D.Queue2 Match FPN 57 PV.Queue1 Match FPN 57 PV.Queue2 Match FPN 57.Queue1 Match FPN 57.Queue2 Match FPN 601 D.Queue1 Match FPN 601 D.Queue2 Match FPN 601 PV.Queue1 Match FPN 601 PV.Queue2 Match FPN 601.Queue1 Match FPN 601.Queue2 Match FPN 602 D.Queue1 Match FPN 602 D.Queue2 Match FPN 602 PV.Queue1 Match FPN 602 PV.Queue2 Match FPN 602.Queue1 Match FPN 602.Queue2 Match FPN 605 D.Queue1 Match FPN 605 D.Queue2 Match FPN 605 PV.Queue1 Match FPN 605 PV.Queue2 Match FPN 605.Queue1 Match FPN 605.Queue2 Match FPN 608 D.Queue1 Match FPN 608 D.Queue2 Match FPN 608 PV.Queue1 Match FPN 608 PV.Queue2 Match FPN 608.Queue1 Match FPN 608.Queue2 Match FPN 610 D.Queue1 Match FPN 610 D.Queue2 Match FPN 610 PV.Queue1 Match FPN 610 PV.Queue2 Match FPN 610.Queue1 Match FPN 610.Queue2 Match FPN 68 D.Queue1 Match FPN 68 D.Queue2 Match FPN 68 PV.Queue1 Match FPN 68 PV.Queue2 Match FPN 68.Queue1 Match FPN 68.Queue2 Match FSK 63 D.Queue1 Match FSK 63 D.Queue2 Match FSK 63 PV.Queue1 Match FSK 63 PV.Queue2 Match FSK 63.Queue1 Match FSK 63.Queue2 Match FSK 66 D.Queue1 Match FSK 66 D.Queue2 Match FSK 66 PV.Queue1 Match FSK 66 PV.Queue2 Match FSK 66.Queue1 Match FSK 66.Queue2 Match HPN 152 D.Queue1 Match HPN 152 D.Queue2 Match HPN 152 PV.Queue1

\begin{tabular}{|c|c|c|c|}
\hline 0.00 & 0,000000000 & 0.00 & 1.0000 \\
\hline 5.0399 & 0,372301322 & 0.00 & 13.0000 \\
\hline 0.00440503 & 0,004589805 & 0.00 & 2.0000 \\
\hline 0.00 & (Insufficient) & 0.00 & 0.00 \\
\hline 0.00 & (Insufficient) & 0.00 & 0.00 \\
\hline 0.00 & (Insufficient) & 0.00 & 0.00 \\
\hline 0.00 & (Insufficient) & 0.00 & 0.00 \\
\hline 0.00 & (Insufficient) & 0.00 & 0.00 \\
\hline 0.00 & (Insufficient) & 0.00 & 0.00 \\
\hline 0.4919 & 0,102092478 & 0.00 & 5.0000 \\
\hline 0.00 & 0,000000000 & 0.00 & 1.0000 \\
\hline 0.5111 & (Correlated) & 0.00 & 8.0000 \\
\hline 0.00 & 0,000000000 & 0.00 & 1.0000 \\
\hline 2.5122 & 0,332405168 & 0.00 & 11.0000 \\
\hline 0.01167918 & 0,014294537 & 0.00 & 2.0000 \\
\hline 0.2541 & 0,056205628 & 0.00 & 3.0000 \\
\hline 0.00 & (Insufficient) & 0.00 & 1.0000 \\
\hline 0.2725 & (Correlated) & 0.00 & 3.0000 \\
\hline 0.00 & (Insufficient) & 0.00 & 1.0000 \\
\hline 1.3463 & 0,192770796 & 0.00 & 5.0000 \\
\hline 0.00121417 & (Insufficient) & 0.00 & 1.0000 \\
\hline 0.06249019 & (Insufficient) & 0.00 & 2.0000 \\
\hline 0.00 & (Insufficient) & 0.00 & 1.0000 \\
\hline 0.04305584 & (Insufficient) & 0.00 & 1.0000 \\
\hline 0.00 & (Insufficient) & 0.00 & 1.0000 \\
\hline 0.2475 & (Insufficient) & 0.00 & 3.0000 \\
\hline 0.00075411 & (Insufficient) & 0.00 & 1.0000 \\
\hline 0.02888677 & (Insufficient) & 0.00 & 2.0000 \\
\hline 0.00 & (Insufficient) & 0.00 & 1.0000 \\
\hline 0.03279291 & (Insufficient) & 0.00 & 2.0000 \\
\hline 0.00 & (Insufficient) & 0.00 & 1.0000 \\
\hline 0.1553 & (Insufficient) & 0.00 & 3.0000 \\
\hline 0.00 & (Insufficient) & 0.00 & 1.0000 \\
\hline 0.4852 & 0,102093164 & 0.00 & 4.0000 \\
\hline 0.00 & 0,000000000 & 0.00 & 1.0000 \\
\hline 0.4358 & 0,092805601 & 0.00 & 4.0000 \\
\hline 0.00 & 0,000000000 & 0.00 & 1.0000 \\
\hline 2.4000 & 0,288704863 & 0.00 & 9.0000 \\
\hline 0.01629748 & 0,019072911 & 0.00 & 3.0000 \\
\hline 0.1072 & (Insufficient) & 0.00 & 3.0000 \\
\hline 0.00 & (Insufficient) & 0.00 & 1.0000 \\
\hline 0.1044 & (Insufficient) & 0.00 & 3.0000 \\
\hline 0.00 & (Insufficient) & 0.00 & 1.0000 \\
\hline 0.5316 & (Insufficient) & 0.00 & 4.0000 \\
\hline 0.00785910 & (Insufficient) & 0.00 & 2.0000 \\
\hline 3.8653 & 0,475523499 & 0.00 & 12.0000 \\
\hline 0.00 & 0,000000000 & 0.00 & 1.0000 \\
\hline 0.1769 & 0,059030323 & 0.00 & 5.0000 \\
\hline 0.00 & 0,000000000 & 0.00 & 1.0000 \\
\hline 1.2286 & 0,246210934 & 0.00 & 7.0000 \\
\hline 0.4524 & 0,207528750 & 0.00 & 10.0000 \\
\hline 2.2558 & 0,352182117 & 0.00 & 9.0000 \\
\hline 0.00 & (Insufficient) & 0.00 & 1.0000 \\
\hline 0.07888767 & 0,025745421 & 0.00 & 4.0000 \\
\hline 0.00 & (Insufficient) & 0.00 & 1.0000 \\
\hline 0.6268 & 0,145260417 & 0.00 & 5.0000 \\
\hline 0.2979 & 0,149373625 & 0.00 & 6.0000 \\
\hline 0.08418640 & (Insufficient) & 0.00 & 2.0000 \\
\hline 0.00 & (Insufficient) & 0.00 & 1.0000 \\
\hline 0.0995 & (Insufficient) & 0.00 & 2.0000 \\
\hline
\end{tabular}


Match HPN 152 PV.Queue2

Match HPN 152.Queue1

Match HPN 152.Queue2

Match HPN 60 D.Queue1

Match HPN 60 D.Queue2

Match HPN 60 PV.Queue1

Match HPN 60 PV.Queue2

Match HPN 60.Queue1

Match HPN 60.Queue2

Match HPN 800 D.Queue1

Match HPN 800 D.Queue2

Match HPN 800 PV.Queue1

Match HPN 800 PV.Queue2

Match HPN 800.Queue1

Match HPN 800.Queue2

Match HPN 802 D.Queue1

Match HPN 802 D.Queue2

Match HPN 802 PV.Queue1

Match HPN 802 PV.Queue2

Match HPN 802.Queue1

Match HPN 802. Queue2

Match HPN 808 D.Queue1

Match HPN 808 D.Queue2

Match HPN 808 PV.Queue1

Match HPN 808 PV.Queue2

Match HPN 808.Queue1

Match HPN 808.Queue2

Match HSK 54 D.Queue1

Match HSK 54 D.Queue2

Match HSK 54 PV.Queue1

Match HSK 54 PV.Queue2

Match HSK 54.Queue1

Match HSK 54.Queue2

Match HSK 72 D.Queue1

Match HSK 72 D.Queue2

Match HSK 72 PV.Queue1

Match HSK 72 PV.Queue2

Match HSK 72.Queue1

Match HSK 72.Queue2

Match HSK 73 D.Queue1

Match HSK 73 D.Queue2

Match HSK 73 PV.Queue1

Match HSK 73 PV.Queue2

Match HSK 73.Queue1

Match HSK 73.Queue2

Match HSK 809 D.Queue1

Match HSK 809 D.Queue2

Match HSK 809 PV.Queue1

Match HSK 809 PV.Queue2

Match HSK 809.Queue1

Match HSK 809.Queue2

Match HSK 810 D.Queue1

Match HSK 810 D.Queue2

Match HSK 810 PV.Queue1

Match HSK 810 PV.Queue2

Match HSK 810.Queue1

Match HSK 810.Queue2

Match HSK 812 D.Queue1

Match HSK 812 D.Queue2

Match HSK 812 PV.Queue1

\begin{tabular}{|c|c|c|c|}
\hline 0.00 & (Insufficient) & 0.00 & 1.0000 \\
\hline 0.3999 & (Insufficient) & 0.00 & 3.0000 \\
\hline 0.00 & (Insufficient) & 0.00 & 1.0000 \\
\hline 0.2724 & (Correlated) & 0.00 & 3.0000 \\
\hline 0.00 & (Insufficient) & 0.00 & 1.0000 \\
\hline 0.3579 & 0,077002539 & 0.00 & 3.0000 \\
\hline 0.00 & (Insufficient) & 0.00 & 1.0000 \\
\hline 1.5852 & 0,172960530 & 0.00 & 6.0000 \\
\hline 0.00 & (Insufficient) & 0.00 & 1.0000 \\
\hline 3.2434 & (Correlated) & 0.00 & 14.0000 \\
\hline 0.00 & 0,000000000 & 0.00 & 1.0000 \\
\hline 4.0827 & (Correlated) & 0.00 & 15.0000 \\
\hline 0.00 & 0,000000000 & 0.00 & 1.0000 \\
\hline 18.8762 & 0,878405239 & 0.00 & 34.0000 \\
\hline 0.01862229 & 0,015835634 & 0.00 & 2.0000 \\
\hline 0.03675263 & (Insufficient) & 0.00 & 2.0000 \\
\hline 0.00 & (Insufficient) & 0.00 & 1.0000 \\
\hline 0.05339982 & (Insufficient) & 0.00 & 2.0000 \\
\hline 0.00 & (Insufficient) & 0.00 & 1.0000 \\
\hline 0.2368 & (Insufficient) & 0.00 & 3.0000 \\
\hline 0.00 & (Insufficient) & 0.00 & 1.0000 \\
\hline 0.2368 & (Correlated) & 0.00 & 3.0000 \\
\hline 0.00 & (Insufficient) & 0.00 & 1.0000 \\
\hline 0.3051 & 0,077832812 & 0.00 & 3.0000 \\
\hline 0.00 & (Insufficient) & 0.00 & 1.0000 \\
\hline 1.2657 & 0,211621085 & 0.00 & 7.0000 \\
\hline 0.00285926 & (Insufficient) & 0.00 & 1.0000 \\
\hline 1.6822 & 0,260966616 & 0.00 & 8.0000 \\
\hline 0.00 & (Insufficient) & 0.00 & 1.0000 \\
\hline 0.5097 & (Correlated) & 0.00 & 4.0000 \\
\hline 0.00 & (Insufficient) & 0.00 & 1.0000 \\
\hline 2.0196 & 0,293016183 & 0.00 & 7.0000 \\
\hline 0.00474851 & (Insufficient) & 0.00 & 1.0000 \\
\hline 1.7455 & (Correlated) & 0.00 & 7.0000 \\
\hline 0.00 & (Insufficient) & 0.00 & 1.0000 \\
\hline 0.4874 & (Correlated) & 0.00 & 4.0000 \\
\hline 0.00 & (Insufficient) & 0.00 & 1.0000 \\
\hline 2.0177 & 0,255945129 & 0.00 & 7.0000 \\
\hline 0.00213176 & (Insufficient) & 0.00 & 1.0000 \\
\hline 0.2820 & (Insufficient) & 0.00 & 3.0000 \\
\hline 0.00 & (Insufficient) & 0.00 & 1.0000 \\
\hline 0.07184304 & (Insufficient) & 0.00 & 2.0000 \\
\hline 0.00 & (Insufficient) & 0.00 & 1.0000 \\
\hline 0.3096 & (Insufficient) & 0.00 & 3.0000 \\
\hline 0.00051889 & (Insufficient) & 0.00 & 1.0000 \\
\hline 0.07913469 & (Insufficient) & 0.00 & 1.0000 \\
\hline 0.00 & (Insufficient) & 0.00 & 1.0000 \\
\hline 0.01773568 & (Insufficient) & 0.00 & 1.0000 \\
\hline 0.00 & (Insufficient) & 0.00 & 1.0000 \\
\hline 0.08424620 & (Insufficient) & 0.00 & 1.0000 \\
\hline 0.00 & (Insufficient) & 0.00 & 1.0000 \\
\hline 0.06684205 & (Insufficient) & 0.00 & 2.0000 \\
\hline 0.00 & (Insufficient) & 0.00 & 1.0000 \\
\hline 0.02218596 & (Insufficient) & 0.00 & 1.0000 \\
\hline 0.00 & (Insufficient) & 0.00 & 1.0000 \\
\hline 0.08024342 & (Insufficient) & 0.00 & 2.0000 \\
\hline 0.00 & (Insufficient) & 0.00 & 1.0000 \\
\hline 0.2296 & (Insufficient) & 0.00 & 2.0000 \\
\hline 0.00 & (Insufficient) & 0.00 & 1.0000 \\
\hline 0.05344707 & (Insufficient) & 0.00 & 2.0000 \\
\hline
\end{tabular}


Match HSK 812 PV.Queue2

Match HSK 812.Queue1

Match HSK 812.Queue2

Match HSK 813 D.Queue1

Match HSK 813 D.Queue2

Match HSK 813 PV.Queue1

Match HSK 813 PV.Queue2

Match HSK 813.Queue1

Match HSK 813.Queue2

Match LN 21 D.Queue1

Match LN 21 D.Queue2

Match LN 21 PV.Queue1

Match LN 21 PV.Queue2

Match LN 21. Queue1

Match LN 21.Queue2

Match LN 22 D.Queue1

Match LN 22 D.Queue2

Match LN 22 PV.Queue1

Match LN 22 PV.Queue2

Match LN 22.Queue1

Match LN 22.Queue2

Match LN 23 D.Queue1

Match LN 23 D.Queue2

Match LN 23 PV.Queue1

Match LN 23 PV.Queue2

Match LN 23.Queue1

Match LN 23.Queue2

Match LN 24 D.Queue1

Match LN 24 D.Queue2

Match LN 24 PV.Queue1

Match LN 24 PV.Queue2

Match LN 24.Queue1

Match LN 24.Queue2

Match LN 650 D.Queue1

Match LN 650 D.Queue2

Match LN 650 PV.Queue1

Match LN 650 PV.Queue2

Match LN 650.Queue1

Match LN 650.Queue2

Match LTC 70 D.Queue1

Match LTC 70 D.Queue2

Match LTC 70 PV.Queue1

Match LTC 70 PV.Queue2

Match LTC 70.Queue1

Match LTC 70.Queue2

Match LTC 71 D.Queue1

Match LTC 71 D.Queue2

Match LTC 71 PV.Queue1

Match LTC 71 PV.Queue2

Match LTC 71.Queue1

Match LTC 71.Queue2

Match LTC 90 D.Queue1

Match LTC 90 D.Queue2

Match LTC 90 PV.Queue1

Match LTC 90 PV.Queue2

Match LTC 90.Queue1

Match LTC 90.Queue2

Match LTC 91 D.Queue1

Match LTC 91 D.Queue2

Match LTC 91 PV.Queue1

\begin{tabular}{|c|c|c|c|}
\hline 0.00 & (Insufficient) & 0.00 & 1.0000 \\
\hline 0.2455 & (Insufficient) & 0.00 & 3.0000 \\
\hline 0.00458927 & (Insufficient) & 0.00 & 1.0000 \\
\hline 4.2595 & 0,389954099 & 0.00 & 16.0000 \\
\hline 0.00 & 0,000000000 & 0.00 & 1.0000 \\
\hline 1.1615 & (Correlated) & 0.00 & 8.0000 \\
\hline 0.00 & 0,000000000 & 0.00 & 1.0000 \\
\hline 4.9216 & (Correlated) & 0.00 & 17.0000 \\
\hline 0.00855977 & 0,008418815 & 0.00 & 2.0000 \\
\hline 1.5974 & (Correlated) & 0.00 & 13.0000 \\
\hline 0.00 & 0,000000000 & 0.00 & 1.0000 \\
\hline 2.0505 & (Correlated) & 0.00 & 12.0000 \\
\hline 0.00 & 0,000000000 & 0.00 & 1.0000 \\
\hline 9.3174 & 0,640503353 & 0.00 & 19.0000 \\
\hline 0.03349322 & (Correlated) & 0.00 & 2.0000 \\
\hline 0.7086 & 0,125005720 & 0.00 & 5.0000 \\
\hline 0.00 & 0,000000000 & 0.00 & 1.0000 \\
\hline 0.9658 & (Correlated) & 0.00 & 6.0000 \\
\hline 0.00 & 0,000000000 & 0.00 & 1.0000 \\
\hline 4.3373 & 0,356695398 & 0.00 & 11.0000 \\
\hline 0.00392519 & 0,005724932 & 0.00 & 2.0000 \\
\hline 0.00897261 & (Insufficient) & 0.00 & 1.0000 \\
\hline 0.00 & (Insufficient) & 0.00 & 1.0000 \\
\hline 0.01316865 & (Insufficient) & 0.00 & 1.0000 \\
\hline 0.00 & (Insufficient) & 0.00 & 1.0000 \\
\hline 0.04256180 & (Insufficient) & 0.00 & 1.0000 \\
\hline 0.00 & (Insufficient) & 0.00 & 1.0000 \\
\hline 0.1917 & (Insufficient) & 0.00 & 4.0000 \\
\hline 0.00 & (Insufficient) & 0.00 & 1.0000 \\
\hline 0.2539 & (Insufficient) & 0.00 & 4.0000 \\
\hline 0.00 & (Insufficient) & 0.00 & 1.0000 \\
\hline 1.0275 & (Insufficient) & 0.00 & 6.0000 \\
\hline 0.00006808 & (Insufficient) & 0.00 & 1.0000 \\
\hline 0.00535400 & (Insufficient) & 0.00 & 1.0000 \\
\hline 0.00 & (Insufficient) & 0.00 & 1.0000 \\
\hline 0.00018338 & (Insufficient) & 0.00 & 1.0000 \\
\hline 0.00 & (Insufficient) & 0.00 & 1.0000 \\
\hline 0.00004672 & (Insufficient) & 0.00 & 1.0000 \\
\hline 0.00 & (Insufficient) & 0.00 & 1.0000 \\
\hline 0.00196796 & (Insufficient) & 0.00 & 1.0000 \\
\hline 0.00 & (Insufficient) & 0.00 & 1.0000 \\
\hline 0.00058061 & (Insufficient) & 0.00 & 1.0000 \\
\hline 0.00 & (Insufficient) & 0.00 & 1.0000 \\
\hline 0.01335551 & (Insufficient) & 0.00 & 1.0000 \\
\hline 0.00 & (Insufficient) & 0.00 & 1.0000 \\
\hline 0.6387 & (Correlated) & 0.00 & 4.0000 \\
\hline 0.00 & (Insufficient) & 0.00 & 1.0000 \\
\hline 0.06820592 & 0,027996484 & 0.00 & 2.0000 \\
\hline 0.00 & (Insufficient) & 0.00 & 1.0000 \\
\hline 0.4758 & (Insufficient) & 0.00 & 4.0000 \\
\hline 0.07068455 & (Insufficient) & 0.00 & 2.0000 \\
\hline 0.2905 & (Insufficient) & 0.00 & 4.0000 \\
\hline 0.00 & (Insufficient) & 0.00 & 1.0000 \\
\hline 0.04847874 & (Insufficient) & 0.00 & 2.0000 \\
\hline 0.00 & (Insufficient) & 0.00 & 1.0000 \\
\hline 0.2670 & (Insufficient) & 0.00 & 3.0000 \\
\hline 0.03850299 & (Insufficient) & 0.00 & 2.0000 \\
\hline 0.9195 & 0,172801990 & 0.00 & 5.0000 \\
\hline 0.00007915 & (Insufficient) & 0.00 & 1.0000 \\
\hline 0.0917 & 0,022244020 & 0.00 & 3.0000 \\
\hline
\end{tabular}




\begin{tabular}{|c|c|c|c|c|}
\hline Match LTC 91 PV.Queue2 & 0.00 & (Insufficient) & 0.00 & 1.0000 \\
\hline Match LTC 91.Queue1 & 0.7390 & 0,141465261 & 0.00 & 6.0000 \\
\hline Match LTC 91.Queue2 & 0.0927 & (Insufficient) & 0.00 & 2.0000 \\
\hline $\begin{array}{l}\text { Match montagem } \\
\text { cabina.Queue1 }\end{array}$ & 3.2583 & (Correlated) & 0.00 & 7.0000 \\
\hline $\begin{array}{l}\text { Match montagem } \\
\text { cabina.Queue2 }\end{array}$ & 0.00 & 0,000000000 & 0.00 & 1.0000 \\
\hline Measure.Queue & 0.04531653 & (Insufficient) & 0.00 & 3.0000 \\
\hline $\begin{array}{l}\text { Montagem Bruta Cabina } \\
\text { LTC.Queue }\end{array}$ & 0.1390 & (Insufficient) & 0.00 & 6.0000 \\
\hline Montagem das Portas.Queue & 0.7263 & 0,194875285 & 0.00 & 11.0000 \\
\hline $\begin{array}{l}\text { Montagem Paredes Traseira } \\
\text { Frontal Cabina Bruta FSK } \\
\text { NTC.Queue }\end{array}$ & 0.7502 & 0,236449680 & 0.00 & 9.0000 \\
\hline Parede Frontal.Queue & 6.5470 & 2,94229 & 0.00 & 60.0000 \\
\hline Parede Traseira.Queue & 8.1398 & 3,03414 & 0.00 & 62.0000 \\
\hline $\begin{array}{l}\text { Pintura esmalte posto } \\
\text { 19b.Queue }\end{array}$ & 0.2407 & 0,024438193 & 0.00 & 10.0000 \\
\hline Pintura.Queue & 10.9453 & 0,988975546 & 0.00 & 18.0000 \\
\hline Pre limpeza limpeza.Queue & 7.4899 & (Correlated) & 0.00 & 35.0000 \\
\hline Primer.Queue & 1.8764 & 0,353361680 & 0.00 & 8.0000 \\
\hline Process 34.Queue & 0.00000829 & (Insufficient) & 0.00 & 1.0000 \\
\hline Process 35.Queue & 0.00000315 & (Insufficient) & 0.00 & 1.0000 \\
\hline Process 89.Queue & 0.00000047 & (Insufficient) & 0.00 & 1.0000 \\
\hline $\begin{array}{l}\text { Process acerto depovert } \\
\text { 42. Queue }\end{array}$ & 0.4534 & 0,099644029 & 0.00 & 8.0000 \\
\hline Process acerto depovert.Queue & 2.3383 & (Correlated) & 0.00 & 29.0000 \\
\hline $\begin{array}{l}\text { Process acerto } \\
\text { depovert41.Queue }\end{array}$ & 0.00 & (Insufficient) & 0.00 & 0.00 \\
\hline $\begin{array}{l}\text { Process cabines de } \\
\text { retoque.Queue }\end{array}$ & 0.1231 & (Correlated) & 0.00 & 1.0000 \\
\hline Process filtro bloqueio.Queue & 0.2012 & (Correlated) & 0.00 & 6.0000 \\
\hline Process posto 1 120.Queue & 0.2146 & 0,023477402 & 0.00 & 4.0000 \\
\hline Process posto 1.Queue & 0.0993 & (Correlated) & 0.00 & 3.0000 \\
\hline Process posto 2 120.Queue & 0.05068469 & 0,008695603 & 0.00 & 2.0000 \\
\hline Process posto 2.Queue & 0.1028 & (Correlated) & 0.00 & 3.0000 \\
\hline Process posto 3 120.Queue & 0.04091392 & 0,006477315 & 0.00 & 1.0000 \\
\hline Process posto 3.Queue & 0.0956 & 0,011803012 & 0.00 & 3.0000 \\
\hline Process posto 4 120.Queue & 0.2047 & 0,052023831 & 0.00 & 2.0000 \\
\hline Process posto 4.Queue & 0.1041 & (Correlated) & 0.00 & 3.0000 \\
\hline Process posto 5 120.Queue & 0.04884473 & 0,010548302 & 0.00 & 2.0000 \\
\hline Process posto 5.Queue & 0.0998 & 0,011469016 & 0.00 & 3.0000 \\
\hline Process posto 6.Queue & 0.0981 & (Correlated) & 0.00 & 3.0000 \\
\hline $\begin{array}{l}\text { Process posto montagem } \\
\text { motor.Queue }\end{array}$ & 0.00321934 & (Insufficient) & 0.00 & 1.0000 \\
\hline Repintura Primer.Queue & 0.2486 & 0,048079580 & 0.00 & 4.0000 \\
\hline Retrabalho Lixamento PVC & 0.00679672 & (Insufficient) & 0.00 & 2.0000 \\
\hline $\begin{array}{l}\text { Mantas e Pre limpeza } \\
\text { Primer.Queue }\end{array}$ & & & & \\
\hline Retrabalho.Queue & 0.00490228 & (Insufficient) & 0.00 & 2.0000 \\
\hline robo 1.8.Queue & 0.00 & 0,000000000 & 0.00 & 1.0000 \\
\hline $\begin{array}{l}\text { Seize AGVs Rohbau } \\
\text { FSK.Queue }\end{array}$ & 0.4795 & 0,262893744 & 0.00 & 10.0000 \\
\hline Seize Agvs Rohbau LTC.Queue & 0.0992 & (Insufficient) & 0.00 & 6.0000 \\
\hline $\begin{array}{l}\text { Seize cabines de } \\
\text { retoque.Queue }\end{array}$ & 0.9037 & 0,164988487 & 0.00 & 11.0000 \\
\hline Seize Depovert linha 5.Queue & 0.02360710 & 0,002638802 & 0.00 & 1.0000 \\
\hline Seize filtro puffer 1.Queue & 6.6710 & (Correlated) & 0.00 & 36.0000 \\
\hline Seize filtro puffer 5.Queue & 0.7039 & (Correlated) & 0.00 & 10.0000 \\
\hline Seize Grill.Queue & 0.4339 & 0,177850184 & 0.00 & 6.0000 \\
\hline
\end{tabular}


Seize linha 1A.Queue

Seize linha 7.Queue

Seize linha funilaria M.Queue

Seize linha funilaria. Queue

Seize Mont Motor e

Cabina.Queue

Seize montagem cabina.Queue

Seize montagem

chicotes.Queue

Seize montagem de

chicotes.Queue

Seize pintura longarina.Queue

Seize postos $12345 \mathrm{e}$

6.Queue

Seize postos 1234 e 5.Queue

Seize Puffer 5.Queue

Seize Puffer linha 1.Queue

Seize puffer virtual.Queue

Seize Sepovert linha 9.Queue

Seize Skids Rohbau.Queue

Seize trans aereo grill 7.Queue

Seize transferencia.Queue

Seize transp aereo 1 1A.Queue

Seize transp aereo 23 8.Queue

Seize transp aereo elevador

Rohbau nova.Queue

Seize transp aereo elevador

Rohbau.Queue

Seize transp aereo grill 7

8.Queue

Seize transp aereo linha

4.Queue

Seize transp aereo linha

5.Queue

Seize transp aereo linha

6.Queue

Seize transp depovert 41. Queue

Seize transp depovert 42.Queue

Seize transportador linhas 3 e

9.Queue

Seize transportador

longarina.Queue

Seize transportador puffer e

5.Queue

Seize verificacao

bloqueio.Queue

Soldagem Conjunto Teto NTC

FSK.Queue

Teto.Queue

Transferencia e aplicacao de

mantas.Queue

transporte linha 3 p 9.Queue

Transporte Puffer linha

51. Queue

\section{Resource}

\begin{tabular}{|c|c|c|c|}
\hline 0.2252 & 0,217730075 & 0.00 & 15.0000 \\
\hline 0.00308724 & (Insufficient) & 0.00 & 2.0000 \\
\hline 0.01155590 & (Insufficient) & 0.00 & 1.0000 \\
\hline 0.3864 & 0,149396184 & 0.00 & 6.0000 \\
\hline 0.00353158 & (Insufficient) & 0.00 & 1.0000 \\
\hline 0.00816950 & (Insufficient) & 0.00 & 1.0000 \\
\hline 1.7775 & 0,310261656 & 0.00 & 10.0000 \\
\hline 0.02745369 & 0,020682160 & 0.00 & 3.0000 \\
\hline 1.3686 & (Correlated) & 0.00 & 7.0000 \\
\hline 5.2783 & (Correlated) & 0.00 & 40.0000 \\
\hline 0.3824 & 0,179442236 & 0.00 & 9.0000 \\
\hline 0.1700 & 0,030324474 & 0.00 & 3.0000 \\
\hline 0.6968 & 0,113544186 & 0.00 & 4.0000 \\
\hline 0.00 & (Insufficient) & 0.00 & 0.00 \\
\hline 0.03521838 & 0,003099526 & 0.00 & 1.0000 \\
\hline 0.1714 & 0,102162867 & 0.00 & 5.0000 \\
\hline 0.1362 & (Insufficient) & 0.00 & 8.0000 \\
\hline 0.3653 & (Correlated) & 0.00 & 1.0000 \\
\hline 0.1233 & 0,135610661 & 0.00 & 11.0000 \\
\hline 0.3441 & 0,191711555 & 0.00 & 15.0000 \\
\hline 0.1576 & 0,073865538 & 0.00 & 8.0000 \\
\hline 0.8172 & (Correlated) & 0.00 & 10.0000 \\
\hline 0.3586 & 0,275559177 & 0.00 & 15.0000 \\
\hline 2.4330 & 0,571889731 & 0.00 & 13.0000 \\
\hline 3.4401 & (Correlated) & 0.00 & 13.0000 \\
\hline 1.0654 & (Correlated) & 0.00 & 4.0000 \\
\hline 0.2638 & (Correlated) & 0.00 & 9.0000 \\
\hline 0.00 & (Insufficient) & 0.00 & 0.00 \\
\hline 0.1710 & (Correlated) & 0.00 & 1.0000 \\
\hline 0.03512159 & 0,005225592 & 0.00 & 1.0000 \\
\hline 0.08449127 & 0,016768179 & 0.00 & 4.0000 \\
\hline 0.00 & (Insufficient) & 0.00 & 0.00 \\
\hline 0.2059 & 0,178627890 & 0.00 & 8.0000 \\
\hline 20.8518 & 3,15460 & 0.00 & 74.0000 \\
\hline 1.2279 & 1,05064 & 0.00 & 55.0000 \\
\hline 0.08836630 & 0,006074199 & 0.00 & 1.0000 \\
\hline 0.02821448 & 0,002785176 & 0.00 & 1.0000 \\
\hline
\end{tabular}

Usage 
Number Busy

Maximum
Minimum

Average Half Width Value

Value

acerto bloqueio

acerto depovert

acerto depovert 42

acerto depovert41

acerto puffer

acerto puffer 5

acerto variante puffer

acerto variante puffer2

AGVFSK

AGVLTC

AGVs

Area 1

Area 10

Area 11

Area 13

Area 23

Area 9

Areas 4 e 5

Areas 7 e 8

bloqueador

cabina eletroforese

Cabina Limpeza

cabine de retoque

Depovert

Depovert41

Depovert42

Elevador

est 1.11

est 1.2

est 1.6

est 1.8

est 3.12

est 3.2

est 3.4

est 3.6

est 3.8

est 4.10

est 4.2

est 4.4

est 4.6

est 4.8

est 5.10

est 5.12

est 5.3

est 5.4

est 5.6

est 5.8

est 7.10

est 7.12

est 7.4

est 7.6

est 7.8

est 8.10

$\begin{array}{rrrr}0.5888 & \text { (Correlated) } & 0.00 & 1.0000 \\ 0.6843 & \text { (Correlated) } & 0.00 & 1.0000 \\ 0.5841 & \text { (Correlated) } & 0.00 & 1.0000 \\ 0.00 & 0, \text { (O00000000 } & 0.00 & 1.0000 \\ 0.7997 & \text { (Correlated) } & 0.00 & 1.0000 \\ 0.5799 & \text { (Correlated) } & 0.00 & 1.0000 \\ 0.00803283 & \text { (Correlated) } & 0.00 & 1.0000 \\ 0.00535522 & \text { (Correlated) } & 0.00 & 1.0000 \\ 7.3335 & 0,588818021 & 0.00 & 11.0000 \\ 4.5713 & 0,495319172 & 0.00 & 9.0000 \\ 0.00 & \text { (Insufficient) } & 0.00 & 0.00 \\ 1.5025 & 0,118096653 & 0.00 & 6.0000 \\ 0.07125036 & \text { (Insufficient) } & 0.00 & 1.0000 \\ 0.8075 & 0,089054845 & 0.00 & 5.0000 \\ 0.8104 & 0,094030451 & 0.00 & 6.0000 \\ 0.2486 & 0,019534219 & 0.00 & 1.0000 \\ 0.5200 & 0,036457239 & 0.00 & 2.0000 \\ 0.4987 & 0,042896024 & 0.00 & 2.0000 \\ 0.6471 & 0,048941891 & 0.00 & 3.0000 \\ 0.00 & 0,000000000 & 0.00 & 1.0000 \\ 1.5515 & 0,041333657 & 0.00 & 2.0000 \\ 5.5487 & \text { (Correlated) } & 0.00 & 8.0000 \\ 1.9198 & 0,062565692 & 0.00 & 3.0000 \\ 30.8940 & \text { (Correlated) } & 0.00 & 62.0000 \\ 16.3225 & \text { (Correlated) } & 0.00 & 40.0000 \\ 14.5728 & 1,17711 & 0.00 & 31.0000 \\ 2.0437 & 0,047154690 & 0.00 & 6.0000 \\ 0.2330 & 0,003334796 & 0.00 & 1.0000 \\ 0.8840 & 0,012384159 & 0.00 & 1.0000 \\ 0.8840 & 0,012442541 & 0.00 & 1.0000 \\ 0.8838 & 0,012465001 & 0.00 & 1.0000 \\ 0.2328 & 0,004231898 & 0.00 & 1.0000 \\ 0.8833 & 0,015464768 & 0.00 & 1.0000 \\ 0.8832 & 0,015563471 & 0.00 & 1.0000 \\ 0.8830 & 0,015787473 & 0.00 & 1.0000 \\ 0.8830 & 0,016023482 & 0.00 & 1.0000 \\ 0.8784 & \text { (Correlated) } & 0.00 & 1.0000 \\ 0.8788 & \text { (Correlated) } & 0.00 & 1.0000 \\ 0.8787 & \text { (Correlated) } & 0.00 & 1.0000 \\ 0.8786 & \text { (Correlated) } & 0.00 & 1.0000 \\ 0.8785 & \text { (Correlated) } & 0.00 & 1.0000 \\ 0.8784 & \text { (Correlated) } & 0.00 & 1.0000 \\ 0.8783 & \text { (Correlated) } & 0.00 & 1.0000 \\ 0.8813 & \text { (Correlated) } & 0.00 & 1.0000 \\ 0.8785 & \text { (Correlated) } & 0.00 & 1.0000 \\ 0.8784 & \text { (Correlated) } & 0.00 & 1.0000 \\ 0.8784 & \text { (Correlated) } & 0.00 & 1.0000 \\ 0.5174 & 0,027466309 & 0.00 & 1.0000 \\ 0.5173 & 0,026909649 & 0.00 & 1.0000 \\ 0.5179 & 0,026873502 & 0.00 & 1.0000 \\ 0.5178 & 0,026972797 & 0.00 & 1.0000 \\ 0.5176 & 0,027698865 & 0.00 & 1.0000 \\ 0.8818 & 0,019632461 & 0.00 & 1.0000\end{array}$


est 8.12

est 8.14

est 8.2

est 8.4

est 8.6

est 8.8

Funileiro

Limite pintura

Linha 1

Linha $1 \mathrm{~A}$

Linha 23

Linha 4

Linha 5

Linha 6

linha 7

Linha 7 trecho 1

Linha 7 trecho 2

Linha 7 trecho 3

Linha funilaria

Linha Grill

Linha limpeza final

Linha pintura

Linha Primer

Linha8

Posto 01115

Posto 01120

Posto 1115

Posto 1120

Posto 10115

Posto 14116

Posto 19116

Posto 19b

Posto 2115

Posto 2120

Posto 2 e 3115

Posto 21

Posto 3115

Posto 3120

Posto 4115

Posto 4120

Posto 5115

Posto 5120

Posto 6

Posto 6115

Posto 6120

Posto 8120

Postos 12345 e 6

Postos 1234 e 5

Postos 10111213

Puffer

Puffer 1

Puffer 5

Puffer virtual

Robo bate pedra

sala medicao

skid 1 pintura

skid 2 pintura

skids rohbau

Tanque KTL

transp aereo $11 \mathrm{~A}$

$\begin{array}{rrrr}0.8817 & 0,019641832 & 0.00 & 1.0000 \\ 0.8817 & 0,019677778 & 0.00 & 1.0000 \\ 0.8847 & 0,019879014 & 0.00 & 1.0000 \\ 0.8821 & 0,019585340 & 0.00 & 1.0000 \\ 0.8820 & 0,019456320 & 0.00 & 1.0000 \\ 0.8819 & 0,019423009 & 0.00 & 1.0000 \\ 0.3118 & 0,023666945 & 0.00 & 2.0000 \\ 73.2547 & 3,11353 & 0.00 & 80.0000 \\ 5.8186 & 0,407758814 & 0.00 & 11.0000 \\ 2.7639 & 0,148407356 & 0.00 & 5.0000 \\ 7.0574 & \text { (Correlated) } & 0.00 & 15.0000 \\ 10.3876 & 0,486654512 & 0.00 & 13.0000 \\ 11.8505 & 0,263028385 & 0.00 & 13.0000 \\ 3.9983 & \text { (Correlated) } & 0.00 & 4.0000 \\ 4.8586 & 0,671600950 & 0.00 & 15.0000 \\ 0.00 & \text { (Insufficient) } & 0.00 & 0.00 \\ 0.00 & \text { (Insufficient) } & 0.00 & 0.00 \\ 0.00 & \text { (Insuficient) } & 0.00 & 0.00\end{array}$

$\begin{array}{ll}0.00 & 0.00\end{array}$

$0.00 \quad 10.0000$

$0.00 \quad 6.0000$

$0.00 \quad 18.0000$

$0.00 \quad 11.0000$

$0.00 \quad 16.0000$

$0.00 \quad 15.0000$

$0.00 \quad 10.0000$

$0.00 \quad 7.0000$

$0.00 \quad 1.0000$

$0.00 \quad 1.0000$

$0.00 \quad 1.0000$

$0.00 \quad 1.0000$

$0.00 \quad 1.0000$

$0.00 \quad 1.0000$

$0.00 \quad 1.0000$

$0.00 \quad 1.0000$

$0.00 \quad 5.0000$

$0.00 \quad 4.0000$

$0.00 \quad 1.0000$

$0.00 \quad 1.0000$

$0.00 \quad 1.0000$

$0.00 \quad 2.0000$

$0.00 \quad 1.0000$

$0.00 \quad 2.0000$

$0.00 \quad 7.0000$

$0.00 \quad 1.0000$

$0.00 \quad 1.0000$

$0.00 \quad 1.0000$

$0.00 \quad 7.0000$

$0.00 \quad 8.0000$

$0.00 \quad 8.0000$

$0.00 \quad 75.0000$

$0.00 \quad 68.0000$

$0.00 \quad 24.0000$

$0.00 \quad 38.0000$

$0.00 \quad 5.0000$

$0.00 \quad 1.0000$

$0.00 \quad 70.0000$

$0.00 \quad 71.0000$

$0.00 \quad 42.0000$

$0.00 \quad 4.0000$

$0.00 \quad 9.0000$ 
transp aereo $1 \mathrm{~A} 7$

transp aereo 4

transp aereo elevador

transp aereo grill 78

transp aereo linha 5

transp aereo linha 6

transp depovert 41

transp depovert 42

transp entre linhas 1 e 9

transp entre linhs 1 e 9 e entre

puffer e linha 5

transp entre puffer e linha 5

Transportador 9 ou 5 e depovert

Number Scheduled

Maximum

$\begin{array}{rrrr}0.2426 & 0,011437121 & 0.00 & 3.0000 \\ 1.6467 & 0,373432300 & 0.00 & 6.0000 \\ 7.2360 & 0,576003788 & 0.00 & 8.0000 \\ 23.3237 & \text { (Correlated) } & 0.00 & 35.0000 \\ 1.1369 & 0,174754186 & 0.00 & 6.0000 \\ 5.5215 & 0,348342521 & 0.00 & 6.0000 \\ 3.9590 & 0,008864073 & 0.00 & 4.0000 \\ 4.0018 & \text { (Correlated) } & 0.00 & 7.0000 \\ 0.5859 & 0,160685500 & 0.00 & 6.0000 \\ 0.7495 & \text { (Correlated) } & 0.00 & 1.0000 \\ 0.5773 & \text { (Correlated) } & 0.00 & 1.0000 \\ & & & \\ 0.4290 & \text { (Correlated) } & 0.00 & 1.0000 \\ 0.5024 & \text { (Correlated) } & 0.00 & 1.0000 \\ & & \text { Minimum } & \end{array}$

Average Half Width
Value

acerto bloqueio

acerto depovert

acerto depovert 42

acerto depovert 41

acerto puffer

acerto puffer 5

acerto variante puffer

acerto variante puffer2

AGVFSK

AGVLTC

AGVs

Area 1

Area 10

Area 11

Area 13

Area 23

Area 9

Areas 4 e 5

Areas 7 e 8

bloqueador

cabina eletroforese

Cabina Limpeza

cabine de retoque

Depovert

Depovert41

Depovert42

Elevador

est 1.11

est 1.2

est 1.6

est 1.8

est 3.12

est 3.2

est 3.4

est 3.6

est 3.8

est 4.10

est 4.2

est 4.4

$\begin{array}{rlrr}1.0000 & \text { (Insufficient) } & 1.0000 & 1.0000 \\ 1.0000 & \text { (Insufficient) } & 1.0000 & 1.0000 \\ 1.0000 & \text { (Insufficient) } & 1.0000 & 1.0000 \\ 1.0000 & \text { (Insufficient) } & 1.0000 & 1.0000 \\ 1.0000 & \text { (Insufficient) } & 1.0000 & 1.0000 \\ 1.0000 & \text { (Insufficient) } & 1.0000 & 1.0000 \\ 1.0000 & \text { (Insufficient) } & 1.0000 & 1.0000 \\ 1.0000 & \text { (Insufficient) } & 1.0000 & 1.0000 \\ 11.0000 & \text { (Insufficient) } & 11.0000 & 11.0000 \\ 9.0000 & \text { (Insufficient) } & 9.0000 & 9.0000 \\ 23.0000 & \text { (Insufficient) } & 23.0000 & 23.0000 \\ 3.0107 & \text { (Insufficient) } & 0.00 & 6.0000 \\ 1.0000 & \text { (Insufficient) } & 1.0000 & 1.0000 \\ 2.5089 & \text { (Insufficient) } & 0.00 & 5.0000 \\ 3.0107 & \text { (Insufficient) } & 0.00 & 6.0000 \\ 0.5018 & \text { (Insufficient) } & 0.00 & 1.0000 \\ 1.0036 & \text { (Insufficient) } & 0.00 & 2.0000 \\ 1.0036 & \text { (Insufficient) } & 0.00 & 2.0000 \\ 1.5053 & \text { (Insufficient) } & 0.00 & 3.0000 \\ 1.0000 & \text { (Insufficient) } & 1.0000 & 1.0000 \\ 2.0000 & \text { (Insufficient) } & 2.0000 & 2.0000 \\ 8.0000 & \text { (Insufficient) } & 8.0000 & 8.0000 \\ 3.0000 & \text { (Insufficient) } & 3.0000 & 3.0000 \\ 123.00 & \text { (Insufficient) } & 123.00 & 123.00 \\ 100.00 & \text { (Insufficient) } & 100.00 & 100.00 \\ 100.00 & \text { (Insufficient) } & 100.00 & 100.00 \\ 6.0000 & \text { (Insufficient) } & 6.0000 & 6.0000 \\ 1.0000 & \text { (Insufficient) } & 1.0000 & 1.0000 \\ 1.0000 & \text { (Insufficient) } & 1.0000 & 1.0000 \\ 1.0000 & \text { (Insufficient) } & 1.0000 & 1.0000 \\ 1.0000 & \text { (Insufficient) } & 1.0000 & 1.0000 \\ 1.0000 & \text { (Insufficient) } & 1.0000 & 1.0000 \\ 1.0000 & \text { (Insufficient) } & 1.0000 & 1.0000 \\ 1.0000 & \text { (Insufficient) } & 1.0000 & 1.0000 \\ 1.0000 & \text { (Insufficient) } & 1.0000 & 1.0000 \\ 1.0000 & \text { (Insufficient) } & 1.0000 & 1.0000 \\ 1.0000 & \text { (Insufficient) } & 1.0000 & 1.0000 \\ 1.0000 & \text { (Insufficient) } & 1.0000 & 1.0000 \\ 1.0000 & \text { (Insufficient) } & 1.0000 & 1.0000 \\ & & & \end{array}$


est 4.6

est 4.8

est 5.10

est 5.12

est 5.3

est 5.4

est 5.6

est 5.8

est 7.10

est 7.12

est 7.4

est 7.6

est 7.8

est 8.10

est 8.12

est 8.14

est 8.2

est 8.4

est 8.6

est 8.8

Funileiro

Limite pintura

Linha 1

Linha $1 \mathrm{~A}$

Linha 23

Linha 4

Linha 5

Linha 6

linha 7

Linha 7 trecho 1

Linha 7 trecho 2

Linha 7 trecho 3

Linha funilaria

Linha Grill

Linha limpeza final

Linha pintura

Linha Primer

Linha8

Posto 01115

Posto 01120

Posto 1115

Posto 1120

Posto 10115

Posto 14116

Posto 19116

Posto 19b

Posto 2115

Posto 2120

Posto 2 e 3115

Posto 21

Posto 3115

Posto 3120

Posto 4115

Posto 4120

Posto 5115

Posto 5120

Posto 6

Posto 6115

Posto 6120

Posto 8120

\begin{tabular}{|c|c|c|c|}
\hline 1.0000 & (Insufficient) & 1.0000 & 1.0000 \\
\hline 1.0000 & (Insufficient) & 1.0000 & 1.0000 \\
\hline 1.0000 & (Insufficient) & 1.0000 & 1.0000 \\
\hline 1.0000 & (Insufficient) & 1.0000 & 1.0000 \\
\hline 1.0000 & (Insufficient) & 1.0000 & 1.0000 \\
\hline 1.0000 & (Insufficient) & 1.0000 & 1.0000 \\
\hline 1.0000 & (Insufficient) & 1.0000 & 1.0000 \\
\hline 1.0000 & (Insufficient) & 1.0000 & 1.0000 \\
\hline 1.0000 & (Insufficient) & 1.0000 & 1.0000 \\
\hline 1.0000 & (Insufficient) & 1.0000 & 1.0000 \\
\hline 1.0000 & (Insufficient) & 1.0000 & 1.0000 \\
\hline 1.0000 & (Insufficient) & 1.0000 & 1.0000 \\
\hline 1.0000 & (Insufficient) & 1.0000 & 1.0000 \\
\hline 1.0000 & (Insufficient) & 1.0000 & 1.0000 \\
\hline 1.0000 & (Insufficient) & 1.0000 & 1.0000 \\
\hline 1.0000 & (Insufficient) & 1.0000 & 1.0000 \\
\hline 1.0000 & (Insufficient) & 1.0000 & 1.0000 \\
\hline 1.0000 & (Insufficient) & 1.0000 & 1.0000 \\
\hline 1.0000 & (Insufficient) & 1.0000 & 1.0000 \\
\hline 1.0000 & (Insufficient) & 1.0000 & 1.0000 \\
\hline 2.0000 & (Insufficient) & 2.0000 & 2.0000 \\
\hline 80.0000 & (Insufficient) & 80.0000 & 80.0000 \\
\hline 11.0000 & (Insufficient) & 11.0000 & 11.0000 \\
\hline 5.0000 & (Insufficient) & 5.0000 & 5.0000 \\
\hline 15.0000 & (Insufficient) & 15.0000 & 15.0000 \\
\hline 13.0000 & (Insufficient) & 13.0000 & 13.0000 \\
\hline 13.0000 & (Insufficient) & 13.0000 & 13.0000 \\
\hline 4.0000 & (Insufficient) & 4.0000 & 4.0000 \\
\hline 15.0000 & (Insufficient) & 15.0000 & 15.0000 \\
\hline 3.0000 & (Insufficient) & 3.0000 & 3.0000 \\
\hline 4.0000 & (Insufficient) & 4.0000 & 4.0000 \\
\hline 8.0000 & (Insufficient) & 8.0000 & 8.0000 \\
\hline 10.0000 & (Insufficient) & 10.0000 & 10.0000 \\
\hline 6.0000 & (Insufficient) & 6.0000 & 6.0000 \\
\hline 18.0000 & (Insufficient) & 18.0000 & 18.0000 \\
\hline 11.0000 & (Insufficient) & 11.0000 & 11.0000 \\
\hline 16.0000 & (Insufficient) & 16.0000 & 16.0000 \\
\hline 15.0000 & (Insufficient) & 15.0000 & 15.0000 \\
\hline 10.0000 & (Insufficient) & 10.0000 & 10.0000 \\
\hline 7.0000 & (Insufficient) & 7.0000 & 7.0000 \\
\hline 1.0000 & (Insufficient) & 1.0000 & 1.0000 \\
\hline 1.0000 & (Insufficient) & 1.0000 & 1.0000 \\
\hline 1.0000 & (Insufficient) & 1.0000 & 1.0000 \\
\hline 1.0000 & (Insufficient) & 1.0000 & 1.0000 \\
\hline 5.0000 & (Insufficient) & 5.0000 & 5.0000 \\
\hline 1.0000 & (Insufficient) & 1.0000 & 1.0000 \\
\hline 1.0000 & (Insufficient) & 1.0000 & 1.0000 \\
\hline 1.0000 & (Insufficient) & 1.0000 & 1.0000 \\
\hline 5.0000 & (Insufficient) & 5.0000 & 5.0000 \\
\hline 4.0000 & (Insufficient) & 4.0000 & 4.0000 \\
\hline 1.0000 & (Insufficient) & 1.0000 & 1.0000 \\
\hline 1.0000 & (Insufficient) & 1.0000 & 1.0000 \\
\hline 1.0000 & (Insufficient) & 1.0000 & 1.0000 \\
\hline 2.0000 & (Insufficient) & 2.0000 & 2.0000 \\
\hline 1.0000 & (Insufficient) & 1.0000 & 1.0000 \\
\hline 2.0000 & (Insufficient) & 2.0000 & 2.0000 \\
\hline 7.0000 & (Insufficient) & 7.0000 & 7.0000 \\
\hline 1.0000 & (Insufficient) & 1.0000 & 1.0000 \\
\hline 1.0000 & (Insufficient) & 1.0000 & 1.0000 \\
\hline 5.0000 & (Insufficient) & 5.0000 & 5.0000 \\
\hline
\end{tabular}




\begin{tabular}{|c|c|}
\hline Dostos 12345 e 6 & 7.0000 \\
\hline Postos 1234 e 5 & 8.0000 \\
\hline Postos 10111213 & 8.0000 \\
\hline Puffer & 75.0000 \\
\hline Puffer 1 & 200.00 \\
\hline Puffer 5 & 200.00 \\
\hline Puffer virtual & 200.00 \\
\hline Robo bate pedra & 5.0000 \\
\hline sala medicao & 1.0000 \\
\hline skid 1 pintura & 70.0000 \\
\hline skid 2 pintura & 150.00 \\
\hline skids rohbau & 42.0000 \\
\hline Tanque KTL & 4.0000 \\
\hline transp aereo $11 \mathrm{~A}$ & 9.0000 \\
\hline transp aereo $1 \mathrm{~A} 7$ & 3.0000 \\
\hline transp aereo 238 & 6.0000 \\
\hline transp aereo 4 & 8.0000 \\
\hline transp aereo elevador & 35.0000 \\
\hline transp aereo grill 78 & 6.0000 \\
\hline transp aereo linha 5 & 6.0000 \\
\hline transp aereo linha 6 & 4.0000 \\
\hline transp depovert 41 & 7.000 \\
\hline transp depovert 42 & 7.0000 \\
\hline transp entre linhas 1 e 9 & 1.0000 \\
\hline $\begin{array}{l}\text { transp entre linhs } 1 \text { e } 9 \text { e entre } \\
\text { puffer e linha } 5\end{array}$ & 1.00 \\
\hline transp entre puffer e linha 5 & 1.00 \\
\hline Transportador 9 ou 5 e depovert & 1.00 \\
\hline Number Times Used & \\
\hline & Val \\
\hline acerto bloqueio & 142160 \\
\hline acerto depovert & 7937. \\
\hline acerto depovert 42 & 2271.0 \\
\hline acerto depovert41 & $7939 . C$ \\
\hline acerto puffer & $7994 . C$ \\
\hline acerto puffer 5 & 2300. \\
\hline acerto variante puffer & 10284.00 \\
\hline acerto variante puffer2 & 10284 \\
\hline AGVFSK & 805. \\
\hline AGVLTC & 518.00 \\
\hline$A G V s$ & 0.00 \\
\hline Area 1 & 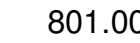 \\
\hline Area 10 & 76.0000 \\
\hline Area 11 & $517 .($ \\
\hline Area 13 & 517.00 \\
\hline Area 23 & 797.00 \\
\hline Area 9 & 1312.00 \\
\hline Areas 4 e 5 & 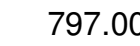 \\
\hline Areas 7 e 8 & 1381. \\
\hline bloqueador & 79347.00 \\
\hline cabina eletroforese & 10861. \\
\hline Cabina Limpeza & 10869 \\
\hline cabine de retoque & 10823. \\
\hline Depovert & 10711.00 \\
\hline Depovert41 & 8429. \\
\hline Depovert42 & 2282.00 \\
\hline Elevador & 10904.00 \\
\hline est 1.11 & 7457. \\
\hline est 1.2 & 7460. \\
\hline
\end{tabular}

$\begin{array}{lrr}\text { (Insufficient) } & 7.0000 & 7.0000 \\ \text { (Insufficient) } & 8.0000 & 8.0000 \\ \text { (Insufficient) } & 8.0000 & 8.0000 \\ \text { (Insufficient) } & 75.0000 & 75.0000 \\ \text { (Insufficient) } & 200.00 & 200.00 \\ \text { (Insufficient) } & 200.00 & 200.00 \\ \text { (Insufficient) } & 200.00 & 200.00 \\ \text { (Insufficient) } & 5.0000 & 5.0000 \\ \text { (Insufficient) } & 1.0000 & 1.0000 \\ \text { (Insufficient) } & 70.0000 & 70.0000 \\ \text { (Insufficient) } & 150.00 & 150.00 \\ \text { (Insufficient) } & 42.0000 & 42.0000 \\ \text { (Insufficient) } & 4.0000 & 4.0000 \\ \text { (Insufficient) } & 9.0000 & 9.0000 \\ \text { (Insufficient) } & 3.0000 & 3.0000 \\ \text { (Insufficient) } & 6.0000 & 6.0000 \\ \text { (Insufficient) } & 8.0000 & 8.0000 \\ \text { (Insufficient) } & 35.0000 & 35.0000 \\ \text { (Insufficient) } & 6.0000 & 6.0000 \\ \text { (Insufficient) } & 6.0000 & 6.0000 \\ \text { (Insufficient) } & 4.0000 & 4.0000 \\ \text { (Insufficient) } & 7.0000 & 7.0000 \\ \text { (Insufficient) } & 7.0000 & 7.0000 \\ \text { (Insufficient) } & 1.0000 & 1.0000 \\ \text { (Insufficient) } & 1.0000 & 1.0000 \\ \text { (Insufficient) } & 1.0000 & \\ \text { (Insufficient) } & 1.0000 & 1.0000 \\ & & 1.0000\end{array}$




\begin{tabular}{|c|c|}
\hline est 1.6 & 7459.00 \\
\hline est 1.8 & 7458.00 \\
\hline est 3.12 & 7450.00 \\
\hline est 3.2 & 7454.00 \\
\hline est 3.4 & 7453.00 \\
\hline est 3.6 & 7452.00 \\
\hline est 3.8 & 7451.00 \\
\hline est 4.10 & 9649.00 \\
\hline est 4.2 & 9653.00 \\
\hline est 4.4 & 9652.00 \\
\hline est 4.6 & 9651.00 \\
\hline est 4.8 & 9650.00 \\
\hline est 5.10 & 9648.00 \\
\hline est 5.12 & 9647.00 \\
\hline est 5.3 & 9651.00 \\
\hline est 5.4 & 9650.00 \\
\hline est 5.6 & 9649.00 \\
\hline est 5.8 & 9648.00 \\
\hline est 7.10 & 2188.00 \\
\hline est 7.12 & 2187.00 \\
\hline est 7.4 & 2190.00 \\
\hline est 7.6 & 2189.00 \\
\hline est 7.8 & 2188.00 \\
\hline est 8.10 & 7441.00 \\
\hline est 8.12 & 7440.00 \\
\hline est 8.14 & 7440.00 \\
\hline est 8.2 & 7445.00 \\
\hline est 8.4 & 7444.00 \\
\hline est 8.6 & 7443.00 \\
\hline est 8.8 & 7442.00 \\
\hline Funileiro & 950.00 \\
\hline Limite pintura & 10869.00 \\
\hline Linha 1 & 7461.00 \\
\hline Linha $1 \mathrm{~A}$ & 2193.00 \\
\hline Linha 23 & 7456.00 \\
\hline Linha 4 & 9654.00 \\
\hline Linha 5 & 9652.00 \\
\hline Linha 6 & 9637.00 \\
\hline linha 7 & 2190.00 \\
\hline Linha 7 trecho 1 & 0.00 \\
\hline Linha 7 trecho 2 & 0.00 \\
\hline Linha 7 trecho 3 & 0.00 \\
\hline Linha funilaria & 9602.00 \\
\hline Linha Grill & 9608.00 \\
\hline Linha limpeza final & 12434.00 \\
\hline Linha pintura & 12425.00 \\
\hline Linha Primer & 12436.00 \\
\hline Linha8 & 7447.00 \\
\hline Posto 01115 & 11866.00 \\
\hline Posto 01120 & 2275.00 \\
\hline Posto 1115 & 11873.00 \\
\hline Posto 1120 & 2277.00 \\
\hline Posto 10115 & 11844.00 \\
\hline Posto 14116 & 11840.00 \\
\hline Posto 19116 & 11837.00 \\
\hline Posto 19b & 12423.00 \\
\hline Posto 2115 & 11872.00 \\
\hline Posto 2120 & 2276.00 \\
\hline Posto 2 e 3115 & 11856.00 \\
\hline Posto 21 & 10823.00 \\
\hline
\end{tabular}


Posto 3115

11872.00

Posto 3120

2276.00

Posto 4115

11871.00

Posto 4120

2275.00

Posto 5115

11870.00

Posto 5120

2275.00

Posto 6

10849.00

Posto 6115

11869.00

Posto 6120

2271.00

Posto 8120

2271.00

11873.00

2277.00

Postos 1234 e 5

10982.00

Postos 10111213

10820.00

Puffer 1

8518.00

Puffer 5

2302.00

Puffer virtual

10820.00

Robo bate pedra

10847.00

sala medicao

201.00

skid 1 pintura

10869.00

10849.00

9646.00

10859.00

7457.00

2190.00

7450.00

9642.00

10904.00

9614.00

9639.00

9633.00

7933.00

2271.00

8436.00

10722.00

transp entre linhs 1 e 9 e entre

puffer e linha 5

transp entre puffer e linha $5 \quad 2286.00$

Transportador 9 ou 5 e depovert $\quad 10711.00$

Scheduled Utilization

acerto bloqueio

Value

acerto depovert

acerto depovert 42

0.5888

0.6843

0.5841

acerto depovert41

0.00

acerto puffer

0.7997

acerto puffer 5

0.5799

acerto variante puffer

acerto variante puffer2

AGVFSK

AGVLTC

AGVs

Area 1

Area 10

Area 11

0.00803283

0.00535522

0.6667

0.5079

0.00

0.4991

Area 13

0.07125036

0.3219

0.2692

Area 23

0.4955

Area 9

0.5182

Areas 4 e 5

0.4969

Areas 7 e 8

0.4299 


\begin{tabular}{|c|c|}
\hline bloqueador & 0.00 \\
\hline cabina eletroforese & 0.7757 \\
\hline Cabina Limpeza & 0.6936 \\
\hline cabine de retoque & 0.6399 \\
\hline Depovert & 0.2512 \\
\hline Depovert41 & 0.1632 \\
\hline Depovert42 & 0.1457 \\
\hline Elevador & 0.3406 \\
\hline est 1.11 & 0.2330 \\
\hline est 1.2 & 0.8840 \\
\hline est 1.6 & 0.8840 \\
\hline est 1.8 & 0.8838 \\
\hline est 3.12 & 0.2328 \\
\hline est 3.2 & 0.8833 \\
\hline est 3.4 & 0.8832 \\
\hline est 3.6 & 0.8830 \\
\hline est 3.8 & 0.8830 \\
\hline est 4.10 & 0.8784 \\
\hline est 4.2 & 0.8788 \\
\hline est 4.4 & 0.8787 \\
\hline est 4.6 & 0.8786 \\
\hline est 4.8 & 0.8785 \\
\hline est 5.10 & 0.8784 \\
\hline est 5.12 & 0.8783 \\
\hline est 5.3 & 0.8813 \\
\hline est 5.4 & 0.8785 \\
\hline est 5.6 & 0.8784 \\
\hline est 5.8 & 0.8784 \\
\hline est 7.10 & 0.5174 \\
\hline est 7.12 & 0.5173 \\
\hline est 7.4 & 0.5179 \\
\hline est 7.6 & 0.5178 \\
\hline est 7.8 & 0.5176 \\
\hline est 8.10 & 0.8818 \\
\hline est 8.12 & 0.8817 \\
\hline est 8.14 & 0.8817 \\
\hline est 8.2 & 0.8847 \\
\hline est 8.4 & 0.8821 \\
\hline est 8.6 & 0.8820 \\
\hline est 8.8 & 0.8819 \\
\hline Funileiro & 0.1559 \\
\hline Limite pintura & 0.9157 \\
\hline Linha 1 & 0.5290 \\
\hline Linha $1 \mathrm{~A}$ & 0.5528 \\
\hline Linha 23 & 0.4705 \\
\hline Linha 4 & 0.7990 \\
\hline Linha 5 & 0.9116 \\
\hline Linha 6 & 0.9996 \\
\hline linha 7 & 0.3239 \\
\hline Linha 7 trecho 1 & 0.00 \\
\hline Linha 7 trecho 2 & 0.00 \\
\hline Linha 7 trecho 3 & 0.00 \\
\hline Linha funilaria & 0.6065 \\
\hline Linha Grill & 0.5173 \\
\hline Linha limpeza final & 0.8606 \\
\hline Linha pintura & 0.9563 \\
\hline Linha Primer & 0.8543 \\
\hline Linha8 & 0.6245 \\
\hline Posto 01115 & 0.8745 \\
\hline Posto 01120 & 0.6537 \\
\hline
\end{tabular}


Posto 1115

Posto 1120

Posto 10115

Posto 14116

Posto 19116

Posto 19b

Posto 2115

Posto 2120

Posto 2 e 3115

Posto 21

Posto 3115

Posto 3120

Posto 4115

Posto 4120

Posto 5115

Posto 5120

Posto 6

Posto 6115

Posto 6120

Posto 8120

Postos 12345 e 6

Postos 1234 e 5

Postos 10111213

Puffer

Puffer 1

Puffer 5

Puffer virtual

Robo bate pedra

sala medicao

skid 1 pintura

skid 2 pintura

skids rohbau

Tanque KTL

transp aereo $11 \mathrm{~A}$

transp aereo $1 \mathrm{~A} 7$

transp aereo 238

transp aereo 4

transp aereo elevador

transp aereo grill 78

transp aereo linha 5

transp aereo linha 6

transp depovert 41

transp depovert 42

transp entre linhas 1 e 9

transp entre linhs 1 e 9 e entre

puffer e linha 5

transp entre puffer e linha 5

Transportador 9 ou 5 e depovert Utilization

Maximum

$$
\begin{array}{r}
0.6272 \\
0.5818 \\
0.9547 \\
0.03655318 \\
0.00338776 \\
0.5454 \\
0.6332 \\
0.5869 \\
0.9090 \\
0.7274 \\
0.6315 \\
0.5835 \\
0.6304 \\
0.6744 \\
0.6324 \\
0.6730 \\
0.8081 \\
0.6323 \\
0.6591 \\
0.00913929 \\
0.8221 \\
0.6293 \\
0.6655 \\
0.9328 \\
0.2903 \\
0.05946762 \\
0.07258209 \\
0.4479 \\
0.3768 \\
0.2446 \\
0.3742 \\
0.6079 \\
0.7717 \\
0.1508 \\
0.08085743 \\
0.2745 \\
0.9045 \\
0.6664 \\
0.1895 \\
0.9203 \\
0.9898 \\
0.5717 \\
0.08369641 \\
0.7495 \\
0.5773 \\
0.4290 \\
0.5024
\end{array}
$$

Minimum

\section{Average}

Value

Half Width

Value acerto bloqueio acerto depovert acerto depovert 42 acerto depovert41 acerto puffer
0.5888

0.6843

0.5841

0.00

0.7997
(Correlated) (Correlated) (Correlated) 0,000000000 (Correlated)
0.00

0.00

0.00

0.00

0.00
1.0000

1.0000

1.0000

1.0000

1.0000 
acerto puffer 5

acerto variante puffer

acerto variante puffer2

AGVFSK

AGVLTC

AGVs

Area 1

Area 10

Area 11

Area 13

Area 23

Area 9

Areas 4 e 5

Areas 7 e 8

bloqueador

cabina eletroforese

Cabina Limpeza

cabine de retoque

Depovert

Depovert41

Depovert42

Elevador

est 1.11

est 1.2

est 1.6

est 1.8

est 3.12

est 3.2

est 3.4

est 3.6

est 3.8

est 4.10

est 4.2

est 4.4

est 4.6

est 4.8

est 5.10

est 5.12

est 5.3

est 5.4

est 5.6

est 5.8

est 7.10

est 7.12

est 7.4

est 7.6

est 7.8

est 8.10

est 8.12

est 8.14

est 8.2

est 8.4

est 8.6

est 8.8

Funileiro

Limite pintura

Linha 1

Linha $1 \mathrm{~A}$

Linha 23

Linha 4

$\begin{array}{rrrr}0.5799 & \text { (Correlated) } & 0.00 & 1.0000 \\ 0.00803283 & \text { (Correlated) } & 0.00 & 1.0000 \\ 0.00535522 & \text { (Correlated) } & 0.00 & 1.0000 \\ 0.6667 & 0,053528911 & 0.00 & 1.0000 \\ 0.5079 & 0,055035464 & 0.00 & 1.0000 \\ 0.00 & \text { (Insufficient) } & 0.00 & 0.00 \\ 0.2701 & 0,021010702 & 0.00 & 1.0000 \\ 0.07125036 & \text { (Insufficient) } & 0.00 & 1.0000 \\ 0.1690 & 0,017897821 & 0.00 & 1.0000 \\ 0.1438 & 0,018450410 & 0.00 & 1.0000 \\ 0.2486 & 0,019534219 & 0.00 & 1.0000 \\ 0.2609 & 0,018207249 & 0.00 & 1.0000 \\ 0.2507 & 0,021687462 & 0.00 & 1.0000 \\ 0.2180 & 0,016784115 & 0.00 & 1.0000 \\ 0.00 & 0,000000000 & 0.00 & 1.0000 \\ 0.7757 & 0,020666828 & 0.00 & 1.0000 \\ 0.6936 & \text { (Correlated) } & 0.00 & 1.0000 \\ 0.6399 & 0,020855231 & 0.00 & 1.0000 \\ 0.2512 & \text { (Correlated) } & 0.00 & 0.5041 \\ 0.1632 & \text { (Correlated) } & 0.00 & 0.4000 \\ 0.1457 & 0,011771089 & 0.00 & 0.3100 \\ 0.3406 & 0,007859115 & 0.00 & 1.0000 \\ 0.2330 & 0,003334796 & 0.00 & 1.0000 \\ 0.8840 & 0,012384159 & 0.00 & 1.0000 \\ 0.8840 & 0,012442541 & 0.00 & 1.0000 \\ 0.8838 & 0,012465001 & 0.00 & 1.0000 \\ 0.2328 & 0,004231898 & 0.00 & 1.0000 \\ 0.8833 & 0,015464768 & 0.00 & 1.0000 \\ 0.8832 & 0,015563471 & 0.00 & 1.0000 \\ 0.8830 & 0,015787473 & 0.00 & 1.0000 \\ 0.8830 & 0,016023482 & 0.00 & 1.0000 \\ 0.8784 & \text { (Correlated) } & 0.00 & 1.0000 \\ 0.8788 & \text { (Correlated) } & 0.00 & 1.0000 \\ 0.8787 & \text { (Correlated) } & 0.00 & 1.0000 \\ 0.8786 & \text { (Correlated) } & 0.00 & 1.0000 \\ 0.8785 & \text { (Correlated) } & 0.00 & 1.0000 \\ 0.8784 & \text { (Correlated) } & 0.00 & 1.0000 \\ 0.8783 & \text { (Correlated) } & 0.00 & 1.0000 \\ 0.8813 & \text { (Correlated) } & 0.00 & 1.0000 \\ 0.8785 & \text { (Correlated) } & 0.00 & 1.0000 \\ 0.8784 & \text { (Correlated) } & 0.00 & 1.0000 \\ 0.8784 & \text { (Correlated) } & 0.00 & 1.0000 \\ 0.5174 & 0,027466309 & 0.00 & 1.0000 \\ 0.5173 & 0,026909649 & 0.00 & 1.0000 \\ 0.5179 & 0,026873502 & 0.00 & 1.0000 \\ 0.5178 & 0,026972797 & 0.00 & 1.0000 \\ 0.5176 & 0,027698865 & 0.00 & 1.0000 \\ 0.8818 & 0,019632461 & 0.00 & 1.0000 \\ 0.8817 & 0,019641832 & 0.00 & 1.0000 \\ 0.8817 & 0,019677778 & 0.00 & 1.0000 \\ 0.8847 & 0,019879014 & 0.00 & 1.0000 \\ 0.8821 & 0,019585340 & 0.00 & 1.0000 \\ 0.8820 & 0,019456320 & 0.00 & 1.0000 \\ 0.8819 & 0,019423009 & 0.00 & 1.0000 \\ 0.1559 & 0,011833473 & 0.00 & 1.0000 \\ 0.9157 & 0,038919098 & 0.00 & 1.0000 \\ 0.5290 & 0,037068983 & 0.00 & 1.0000 \\ 0.5528 & 0,029681471 & 0.00 & 1.0000 \\ 0.4705 & \text { (Correlated) } & 0.00 & 1.0000 \\ 0.7990 & 0,037434962 & 0.00 & 1.0000\end{array}$


Linha 5

linha 7

Linha 7 trecho 1

Linha 7 trecho 2

Linha 7 trecho 3

Linha funilaria

Linha Grill

Linha limpeza final

Linha pintura

Linha Primer

Linha8

Posto 01115

Posto 01120

Posto 1115

Posto 1120

Posto 10115

Posto 14116

Posto 19116

Posto 19b

Posto 2115

Posto 2120

Posto 2 e 3115

Posto 21

Posto 3115

Posto 3120

Posto 4115

Posto 4120

Posto 5115

Posto 5120

Posto 6

Posto 6115

Posto 6120

Posto 8120

Postos 12345 e 6

Postos 1234 e 5

Postos 10111213

Puffer

Puffer 1

Puffer 5

Puffer virtual

Robo bate pedra

sala medicao

skid 1 pintura

skid 2 pintura

skids rohbau

Tanque KTL

transp aereo $11 \mathrm{~A}$

transp aereo $1 \mathrm{~A} 7$

transp aereo 238

transp aereo 4

transp aereo elevador

transp aereo grill 78

transp aereo linha 5

transp aereo linha 6

transp depovert 41

transp depovert 42

transp entre linhas 1 e 9

transp entre linhs 1 e 9 e entre

puffer e linha 5

\begin{tabular}{|c|c|c|c|}
\hline 0.9116 & 0,020232953 & 0.00 & 1.0000 \\
\hline 0.9996 & (Correlated) & 0.00 & 1.0000 \\
\hline 0.3239 & 0,044773397 & 0.00 & 1.0000 \\
\hline 0.00 & (Insufficient) & 0.00 & 0.00 \\
\hline 0.00 & (Insufficient) & 0.00 & 0.00 \\
\hline 0.00 & (Insufficient) & 0.00 & 0.00 \\
\hline 0.6065 & (Correlated) & 0.00 & 1.0000 \\
\hline 0.5173 & 0,027969626 & 0.00 & 1.0000 \\
\hline 0.8606 & 0,059688961 & 0.00 & 1.0000 \\
\hline 0.9563 & 0,030317319 & 0.00 & 1.0000 \\
\hline 0.8543 & 0,050217586 & 0.00 & 1.0000 \\
\hline 0.6245 & 0,054216308 & 0.00 & 1.0000 \\
\hline 0.8745 & (Correlated) & 0.00 & 1.0000 \\
\hline 0.6537 & (Correlated) & 0.00 & 1.0000 \\
\hline 0.6272 & (Correlated) & 0.00 & 1.0000 \\
\hline 0.5818 & (Correlated) & 0.00 & 1.0000 \\
\hline 0.9547 & (Correlated) & 0.00 & 1.0000 \\
\hline 0.03655318 & 0,002302995 & 0.00 & 1.0000 \\
\hline 0.00338776 & 0,001401253 & 0.00 & 0.2000 \\
\hline 0.5454 & 0,020422675 & 0.00 & 1.0000 \\
\hline 0.6332 & (Correlated) & 0.00 & 1.0000 \\
\hline 0.5869 & 0,040288131 & 0.00 & 1.0000 \\
\hline 0.9090 & (Correlated) & 0.00 & 1.0000 \\
\hline 0.7274 & 0,038487319 & 0.00 & 1.0000 \\
\hline 0.6315 & (Correlated) & 0.00 & 1.0000 \\
\hline 0.5835 & 0,039022686 & 0.00 & 1.0000 \\
\hline 0.6304 & (Correlated) & 0.00 & 1.0000 \\
\hline 0.6744 & (Correlated) & 0.00 & 1.0000 \\
\hline 0.6324 & (Correlated) & 0.00 & 1.0000 \\
\hline 0.6730 & (Correlated) & 0.00 & 1.0000 \\
\hline 0.8081 & 0,024995124 & 0.00 & 1.0000 \\
\hline 0.6323 & (Correlated) & 0.00 & 1.0000 \\
\hline 0.6591 & (Correlated) & 0.00 & 1.0000 \\
\hline 0.00913929 & 0,001096131 & 0.00 & 0.2000 \\
\hline 0.8221 & (Correlated) & 0.00 & 1.0000 \\
\hline 0.6293 & 0,046176569 & 0.00 & 1.0000 \\
\hline 0.6655 & 0,049891174 & 0.00 & 1.0000 \\
\hline 0.9328 & (Correlated) & 0.00 & 1.0000 \\
\hline 0.2903 & (Correlated) & 0.00 & 0.3400 \\
\hline 0.05946762 & (Correlated) & 0.00 & 0.1200 \\
\hline 0.07258209 & (Correlated) & 0.00 & 0.1900 \\
\hline 0.4479 & 0,022677694 & 0.00 & 1.0000 \\
\hline 0.3768 & (Correlated) & 0.00 & 1.0000 \\
\hline 0.2446 & 0,015636090 & 0.00 & 1.0000 \\
\hline 0.3742 & 0,019116093 & 0.00 & 0.4733 \\
\hline 0.6079 & (Correlated) & 0.00 & 1.0000 \\
\hline 0.7717 & 0,020052705 & 0.00 & 1.0000 \\
\hline 0.1508 & 0,061553919 & 0.00 & 1.0000 \\
\hline 0.08085743 & 0,003812374 & 0.00 & 1.0000 \\
\hline 0.2745 & 0,062238717 & 0.00 & 1.0000 \\
\hline 0.9045 & 0,072000474 & 0.00 & 1.0000 \\
\hline 0.6664 & (Correlated) & 0.00 & 1.0000 \\
\hline 0.1895 & 0,029125698 & 0.00 & 1.0000 \\
\hline 0.9203 & 0,058057087 & 0.00 & 1.0000 \\
\hline 0.9898 & 0,002216018 & 0.00 & 1.0000 \\
\hline 0.5717 & (Correlated) & 0.00 & 1.0000 \\
\hline 0.08369641 & 0,022955071 & 0.00 & 0.8571 \\
\hline 0.7495 & (Correlated) & 0.00 & 1.0000 \\
\hline 0.5773 & (Correlated) & 0.00 & 1.0000 \\
\hline
\end{tabular}


transp entre puffer e linha 5

Transportador 9 ou 5 e depovert

0.4290

(Correlated)

0.00

1.0000

User Specified

Tally

Between

Maximum

Minimum

Average Half Width Value

Value

takt cabinas

6.0905

0,059791930

4.4184

takt linha final

27.3894

takt linha final 42

5.2808

7.4260

Takt time acabamento linha 1

27.3982

29.1427

Taxa de cabinas FPN

8.5609

Taxa de Cabinas HPN

51.3262

raida NOVA ROHBAU

5.8491

0,041153847

1,27196

0,064322303

0,088045507

1,20250

1,51701

0,197109059

3,51452

Tempo entre chegadas puffer

0,088647591

4.0030
0.00565557
16.3333
3.0502
4.5741
11.4393
0.00
0.00
0.00
0.00139832

42.8326

45.8969

317.04

116.91

141.11

239.33

371.63

337.85

670.91

140.04

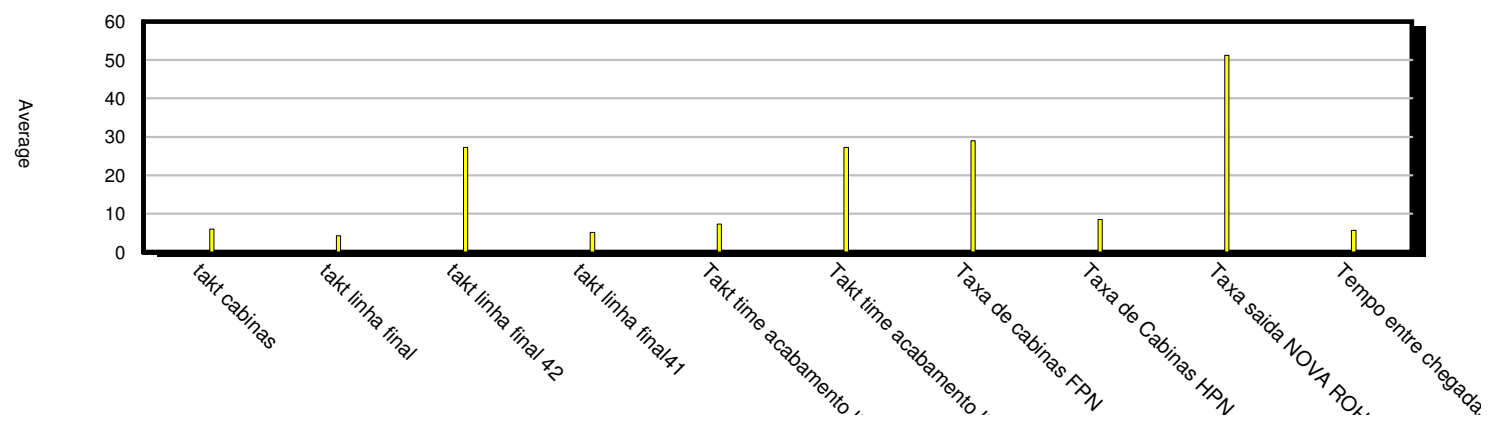

Expression

Minimum

Maximum

$\begin{array}{lll}\begin{array}{c}\text { Average } \\ \text { Value }\end{array} & \text { Half Width } & \text { Value }\end{array}$

Num posicoes perdidas

Num posicoes perdidas mont

final

Num posicoes perdidas pintura

Num posicoes perdidas Rohbau

$\begin{array}{rrrr}12.2114 & \text { (Insufficient) } & 1.0000 & 100.00 \\ 1.0000 & \text { (Insufficient) } & 1.0000 & 1.0000 \\ 39.2946 & 2,38932 & 1.0000 & 230.00 \\ 29.7712 & 3,75840 & 1.0000 & 178.00\end{array}$




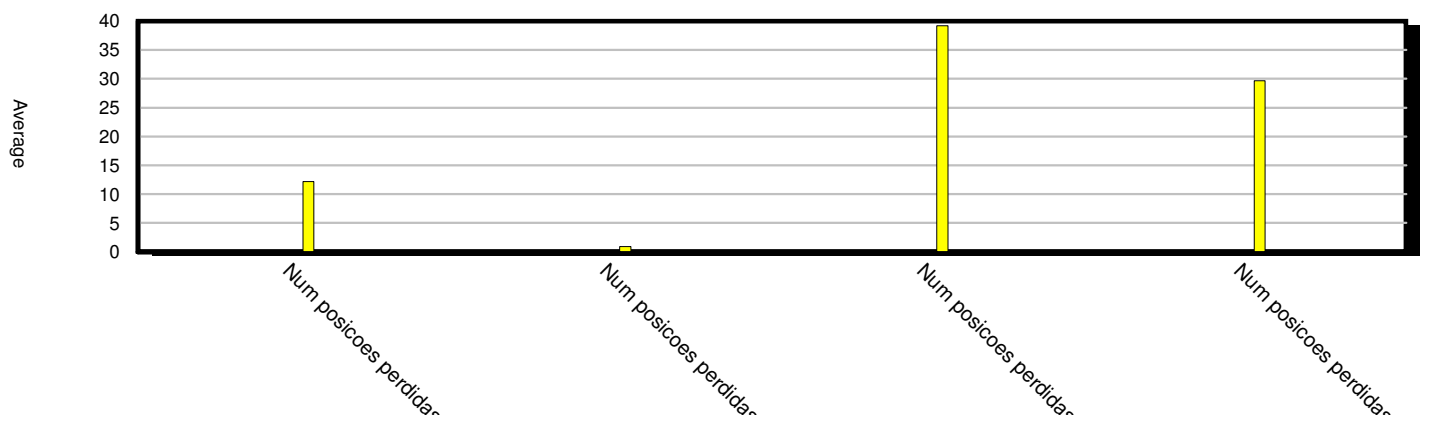

Interval

Maximum
Minimum

$\begin{array}{rrrr}\begin{array}{r}\text { Average } \\ \text { Value }\end{array} & \text { Half Width } & \text { Value } & \\ & & & \\ & & & \\ 392.02 & 16,21443 & 156.90 & 1462.83 \\ 903.67 & \text { (Correlated) } & 633.27 & 2330.56 \\ 1519.90 & \text { (Correlated) } & 931.48 & 3204.03 \\ & & & \\ 1484.47 & 11,59299 & 901.81 & 2521.81 \\ & & & \\ 1605.68 & \text { (Correlated) } & 1080.62 & 2988.42 \\ 1893.05 & 24,65473 & 1320.53 & 3337.47 \\ 237.65 & \text { (Correlated) } & 162.98 & 445.08 \\ & & & \\ 521.88 & 5,60574 & 489.26 & 721.30 \\ & & & \\ 1321.85 & \text { (Correlated) } & 745.59 & 2989.78 \\ 1308.32 & \text { (Correlated) } & 734.74 & 2340.61 \\ 66.2800 & 4,61660 & 51.0000 & 542.08 \\ 470.37 & 23,39382 & 275.66 & 1857.93 \\ 243.71 & 22,64750 & 177.43 & 663.48 \\ 228.57 & \text { (Correlated) } & 161.79 & 637.25 \\ 595.89 & 24,57881 & 205.34 & 1430.34\end{array}$

Record 115

Tempo antes puffer

Tempo depois acabamento

linha 1

Tempo depois acabamento

linha 5

Tempo depois depovert41

Tempo depois depovert42

Tempo depois montagem

final41

Tempo depois montagem

final42

Tempo depois puffer linha 1

Tempo depois puffer linha 5

Tempo grill e funilaria

Tempo Pintura

Tempo ROHBAU FPN

Tempo ROHBAU HPN HSK LN

Tempo ROHBAU LTC FSK

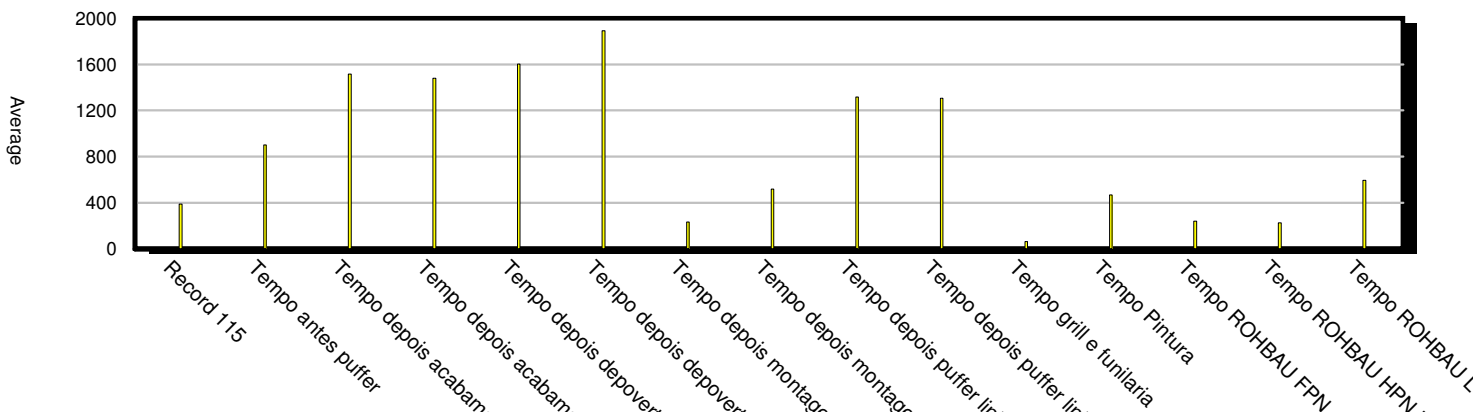

\section{Counter}

Count 


$\begin{array}{lr}\text { Cabinas dia acabamento } & 10711.00 \\ \text { Caminhoes realmente } & 797.00 \\ \text { bloqueados } & \\ \text { Count Proporcao CKD Vendas } & 475.00 \\ \text { Count Proporcao FPN } & 2136.00 \\ \text { Count Proporcao FSK } & 805.00 \\ \text { Count Proporcao HPN } & 3330.00 \\ \text { Count Proporcao HSK } & 1538.00 \\ \text { Count Proporcao LN } & 2176.00 \\ \text { Count Proporcao LTC } & 518.00 \\ \text { Count Proporcao Onibus } & 4021.00 \\ \text { numero cabinas } & 10304.00 \\ \text { Numero cabinas dia } & 10900.00 \\ \text { Numero cabinas dia FSK } & 805.00 \\ \text { Numero cabinas dia HPN FPN } & 9180.00 \\ \text { HSK } & \\ \text { Numero cabinas dia LTC } & 518.00 \\ \text { Numero cabinas pintadas dia } & 10820.00 \\ \text { Numero caminhoes dia 41 } & 11833.00 \\ \text { Numero caminhoes dia 42 } & 2268.00 \\ \text { Numero de cabinas a bloquear } & 816.00 \\ \text { Pedidos atrasados } & 125.00 \\ \text { Pedidos atrasados linha 5 } & 192.00 \\ \text { Pedidos atrasados mont final } 41 & 0.00 \\ \text { Pedidos atrasados mont final 42 } & 10.0000 \\ \text { Pedidos atrasados pintura } & 1324.00 \\ \text { Pedidos atrasados rohbau } & 2500.00 \\ \text { Pedidos atrasados41 } & 0.00 \\ \text { Pedidos atrasados42 } & 0.00 \\ \text { Record FPN 52 } & 173.00 \\ \text { Record FPN 56 } & 812.00 \\ \text { Record FPN 57 } & 0.00 \\ \text { Record FPN 601 } & 483.00 \\ \text { Record FPN 602 } & 1381.00 \\ \text { Record FPN 605 } & 6.0000 \\ \text { Record FPN 608 } & 151.00 \\ \text { Record FPN 610 } & 1.0000 \\ \text { Record FPN 68 } & 4.0000 \\ \text { Record FSK 63 } & 83.0000 \\ \text { Record FSK 66 } & \\ \text { Record HPN 152 } & \end{array}$


Record LTC 91

\section{Time Persistent}

Variable

Maximum

color pre

Color PV

tam depovert

tam puffer

tipo 4

Variable 2

Variable 3

Verificador cabina 116

Verificador cabina 1162

Verificador cabina 120

Verificador cabina 1202
263.00

Minimum

Average Half Width $\quad$ Value
Value

0.00
117.32
30.1291
69.9571
260029.53
7105.07
7203.37
244427.66
248925.95
799012.36
796152.55

$\begin{array}{lr}0.00 & 0.00 \\ 0.00 & 500.00 \\ 0.00 & 62.0000 \\ 0.00 & 75.0000 \\ 0.00 & 2032187 \\ 0.00 & 14581.00 \\ 0.00 & 14710.00 \\ 0.00 & 1659124 \\ 0.00 & 1659124 \\ 0.00 & 2032187 \\ 0.00 & 2032187\end{array}$

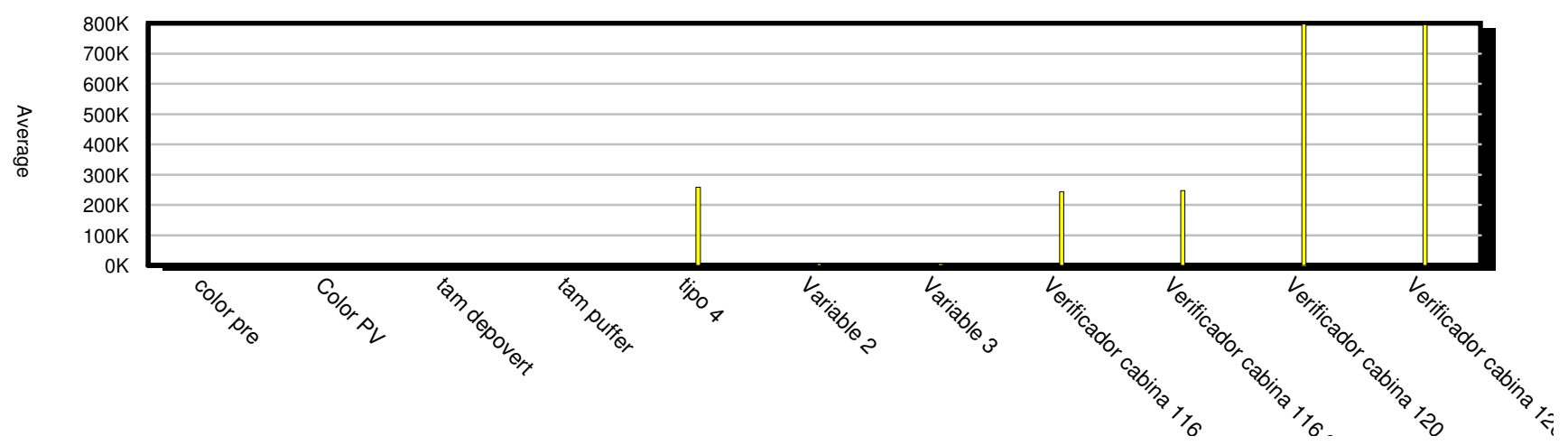

